\title{
Co-evolution of soils and
}

landscapes in the Anthropocene

from natural to intensively managed landscapes
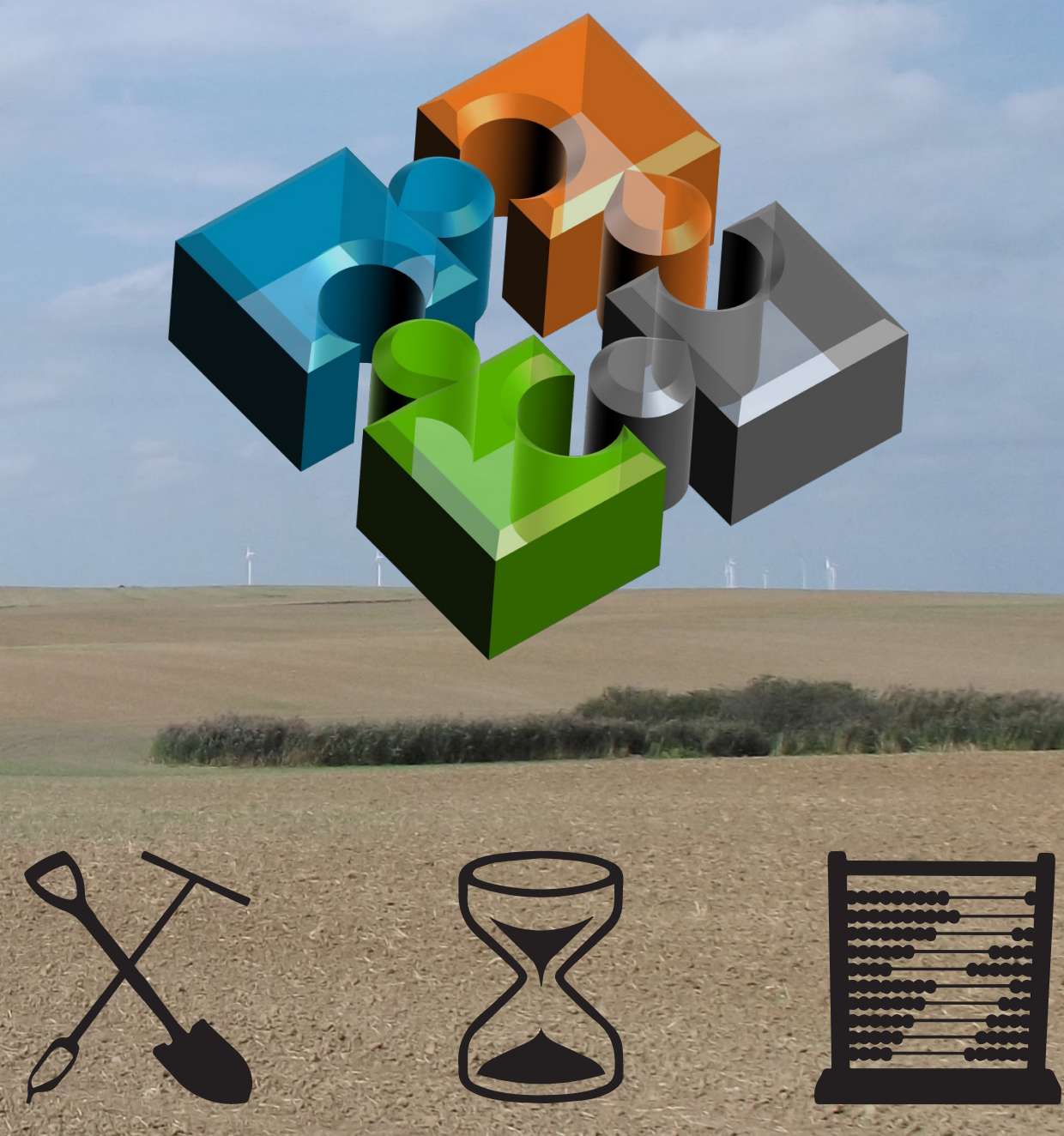

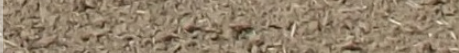
ming

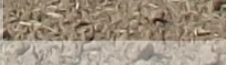

\section{W.M. (Marijn) van der Meij}




\section{Propositions}

1. The diversity of natural landscapes cannot be recovered with nature-based solutions.

(this thesis)

2. Soil evolution should be studied in four dimensions.

(this thesis)

3. Complex problems require simple models.

4. Quick fixes hamper long-term solutions for environmental problems.

5. Governments should take responsibility for scientific publishing.

6. Civil disobedience is a necessary last resort to turn the climatic tide.

Propositions belonging to the thesis entitled:

Co-evolution of soils and landscapes in the Anthropocene - from natural to intensively managed landscapes

W.M. (Marijn) van der Meij

Wageningen, 8 April 2020 

Co-evolution of soils and landscapes in the Anthropocene from natural to intensively managed landscapes

W.M. (Marijn) van der Meij 


\section{Thesis committee}

\section{Promotors}

Prof. Dr J. Wallinga

Professor of Soil Geography and Landscape

Wageningen University and Research

Prof. Dr M. Sommer

Professor of Soil Landscape Research

Leibniz - Zentrum für Agrarlandschaftsforschung (ZALF), Müncheberg, Germany

Universität Potsdam, Germany

\section{Co-promotor}

Dr A.J.A.M. Temme

Associate professor, Department of Geography and Geospatial Science

Kansas State University, Manhattan, Kansas, USA

\section{Other members}

Prof. Dr J.W. van Groenigen, Wageningen University and Research

Prof. Dr K. van Oost, Université catholique de Louvain, Belgium

Dr S. Cornu, CEREGE, INRAE, France

Prof. Dr P. Finke, Ghent University, Belgium

This research was conducted under auspices of the C.T. de Wit Graduate School for

Production Ecology and Resource Conservation (PE\&RC) 


\title{
Co-evolution of soils and landscapes in the Anthropocene - from natural to intensively managed landscapes
}

\author{
W.M. (Marijn) van der Meij
}

\section{Thesis}

submitted in fulfilment of the requirements for the degree of doctor

$$
\text { at Wageningen University }
$$

by the authority of the Rector Magnificus,

$$
\begin{aligned}
& \text { Prof. Dr A.P.J. Mol, } \\
& \text { in the presence of the }
\end{aligned}
$$

Thesis Committee appointed by the Academic Board

to be defended in public

on Wednesday 8 April 2020

at 4 p.m. in the Aula. 
W. M. (Marijn) van der Meij

Co-evolution of soils and landscapes in the Anthropocene - from natural to intensively managed landscapes

298 pages

PhD thesis, Wageningen University, Wageningen, the Netherlands (2020)

With references, with summaries in English and Dutch

ISBN 978-94-6395-312-2

DOI https://doi.org/10.18174/514493 
All thing has a cause. Look into your pass for answer

Fortune cookie quote 


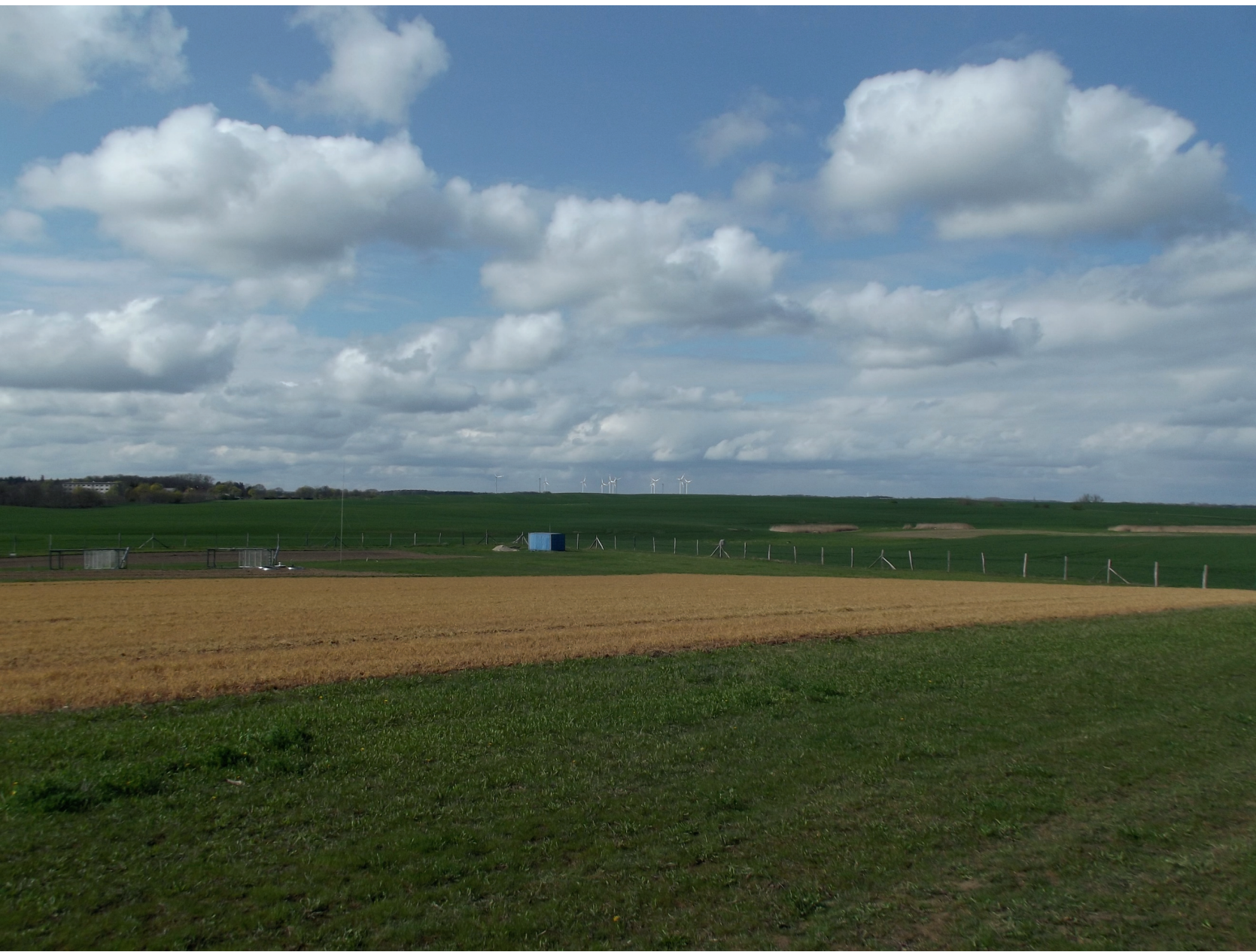




\section{Acknowledgements}

My PhD research was an exploration through space and time. I learned new skills, gained new knowledge, visited new places and met new people. Everywhere I went during my studies and research, I met people who shared my fascination for the complexity and fragility of our environment. From majestic mountain ranges to intricate soil pore systems, every landscape raises similar questions about their origin, development and resilience to future changes. Understanding and protecting our surroundings is essential to keep being amazed, calmed and inspired by it. I am glad I got the opportunity to contribute a small part to our understanding of the formation and functioning of our surroundings.

I am grateful to a lot of people who supported me during my research, both on a professional and on a personal level, ultimately leading to this dissertation. First of all I want to thank my supervisors. Arnaud, thank you for your unlimited enthusiasm about everything earth-related. Your lectures during my study and supervision of my master thesis about soil formation on Spitsbergen sparked my interest in the complex evolution of landscapes across the globe. Your move to the United States did not hinder our collaboration. On the contrary, I have the feeling we had very fruitful discussions over Skype or during meetings at conferences, in Wageningen or in The Little Apple. I hope we will continue working together in the future, despite the spatial and temporal distance. Michael, thank you for giving me the opportunity and means to carry out my research. Your field-oriented focus helped me remember that models do not always do justice to the complexity we can observe in the field. The two 10 $\mathrm{m}^{3}$-pits that you excavated for our first visit to CarboZALF-D, just to observe the soils that can be found in the area, are good examples showing the importance you contribute to extensive field knowledge. My visits to Müncheberg, Dedelow and Melzow kept me with both feet in the ground. Jakob, thank you for your critical view and for asking difficult questions. Your landscape view on my research opened up new approaches and directions, which certainly increased the quality and impact of this dissertation. Due to your guidance I finished this dissertation in a timely manner and evolved into the researcher I am now.

During my PhD I stayed at various institutes, so there are a lot of colleagues to thank. First the colleagues of SGL, where I spent most of my time. Jasper and Selçuk, thanks for the countless cups of coffee, tea, beer and the occasional party/concert. I hope we will keep seeing each other at the office, at conferences, at dinner parties or in the pub (combinations 
of these locations are of course possible and encouraged). Thank you Simona, Marcos, Kasia, Chantal, Maricke, Luc, Cindy, Alex, Tijn and Anatol for the fun $\mathrm{PhD}$ activities and occasional drinks. All other SGL colleagues, thank you for the good times and inspiring working environment. I will miss the SGL barbecue and the Christmas lunch! Liebe Kollegen am ZALF, auch wenn ich nicht oft bei Euch war, bin ich doch sehr dankbar für die gute Zusammenarbeit und die inspirierende Atmosphäre am ZALF. Horst, Wilfried, Sylvia und Norbert möchte ich danken für ihre Hilfe im Feld und bei den Modellierungen. Frau Lange und Frau Jahn gilt mein Dank für ihre logistische und administrative Unterstützung. Henry Lin, Fei Jiang, Li Guo and colleagues, I had a good time during my visit to the hydropedology group at Penn State University, which gave me a lot of new insights between the tight coupling of hydrology and soil science. Thank you for making me feel welcome and showing me around in the Critical Zone Observatory. I was shocked to hear of Henry Lin's passing last year. This is a great loss for his family, friends, colleagues and to the soil science community. Colleagues and friends at Kansas State University, Abbey and Abigail, Michael and Michael, also a thanks to you for the hospitality, discussions, barbecue and midnight walks at the prairie.

Pap en mam, zonder jullie was ik nooit in Wageningen beland en had dit mooie boekje er niet gelegen. Vanaf de eerste open dag voelde ik me thuis in Wageningen, want de andere ouders die daar rond liepen leken erg op jullie. De liefde voor de natuur en buiten zijn hebben jullie mij met de paplepel ingegoten. Dank jullie wel voor jullie steun tijdens mijn studie en $\mathrm{PhD}$. Lotte, zonder jou was het afronden van mijn proefschrift zeker niet gelukt. Je voelde goed aan wanneer ik afleiding nodig had of wanneer je me juist beter met rust kon laten. Ik hoop dat we nog veel mooie landschappen zullen gaan zien samen (en dat ik je niet ga vervelen met mijn verhalen over hun ontstaanswijze). Bedankt voor al je steun en liefde de afgelopen jaren en de jaren die nog komen gaan. 


\section{Table of contents}

\section{Chapter 1. General introduction}

1.1 Introduction 2

1.2 Soils in the Anthropocene 2

1.3 Evolution of soils and landscapes 5

1.3.1 Landscapes and co-evolution 5

$\begin{array}{lll}\text { 1.3.2 Pedogenic pathways } & 7\end{array}$

1.4 Methods for studying soil-landscape evolution 8

1.4.1 Reconstruction methods and the pitfall of polygenesis 8

1.4.2 Simulation methods and their limitations 9

$\begin{array}{lll}1.5 & \text { Research needs } & 11\end{array}$

$\begin{array}{lll}1.6 & \text { Research objectives and questions } & 12\end{array}$

$\begin{array}{lll}1.7 & \text { Study area } & 12\end{array}$

$\begin{array}{lll}1.8 & \text { Thesis outline } & 13\end{array}$

\section{Chapter 2. Topography reconstruction of eroding} landscapes - a case study from a hummocky ground moraine (CarboZALF-D)

Abstract $\quad 18$

2.1 Introduction $\quad 19$

$\begin{array}{lll}2.2 & \text { Study area } & 22\end{array}$

2.3 Methods $\quad 26$

2.3.1 Approaches 26

$\begin{array}{ll}\text { 2.3.2 Data preparation } & 28\end{array}$

2.3.3 Validation 31

2.3.4 Comparison of methods $\quad 32$

$2.4 \quad$ Results 33

2.4.1 Variation and uncertainty in reconstructed topography 33

$\begin{array}{lll}2.4 .2 & \text { Reconstructed topography } & 37\end{array}$

2.5 Discussion $\quad 41$

2.5.1 Evolution of soil thickness and topography 41

2.5.2 Points of attention during topography reconstruction 46

2.6 Conclusions $\quad 50$

2.7 Acknowledgements 51

Supplement 2.1 Descriptions of representative soils from CarboZALF-D 52

Supplement 2.2 Supplementary results $\quad 54$ 


\section{Chapter 3. Reconstructing rates and patterns of colluvial soil redistribution in agrarian (hummocky)}

landscapes

Abstract

3.1 Introduction $\quad 59$

$\begin{array}{lll}3.2 & \text { Methods } & 64\end{array}$

$\begin{array}{lll}3.2 .1 & \text { Study area } & 64\end{array}$

$\begin{array}{ll}\text { 3.2.2 Data collection and preparation } & 67\end{array}$

$\begin{array}{lll}3.2 .3 & \text { Data analysis } & 69\end{array}$

$\begin{array}{lll}3.3 & \text { Results } & 74\end{array}$

$\begin{array}{lll}3.3 .1 & \text { Field and lab results } & 74\end{array}$

$\begin{array}{lll}3.3 .2 & \text { Age results } & 74\end{array}$

$\begin{array}{lll}\text { 3.3.3 Deposition rates } & 78\end{array}$

3.4 Discussion $\quad 81$

3.4.1 The benefit of advanced age and rate modeling in colluvial settings $\quad 81$

3.4.2 Spatial and temporal patterns of deposition 84

3.5 Conclusions 88

Supplement 3.1 Archaeological reconstruction of land-use history in the Uckermark $\begin{array}{ll}\text { region } & 90\end{array}$

Supplement 3.2 Photos and descriptions of the sampled profiles 94

Supplement 3.3 Age-density plots of all samples, for each step in the analysis 95

Supplement 3.4 Lab results and reconstructed ages and rates for each sample in each $\begin{array}{ll}\text { step in the analysis } & 97\end{array}$

\section{Chapter 4. On the role of hydrologic processes in soil and landscape evolution modeling: concepts,} complications and partial solutions

4.2 Review of relations between water flow and soil-landscape properties 109

$\begin{array}{ll}\text { 4.2.1 Landscape development } & 109\end{array}$

$\begin{array}{ll}4.2 .2 \text { Soil development } & 110\end{array}$

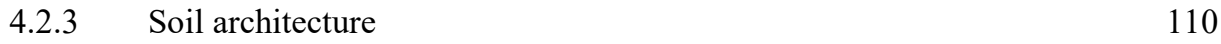

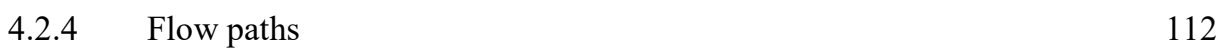

$\begin{array}{lll}\text { 4.2.5 Two examples } & 114\end{array}$

$\begin{array}{lll}4.3 & \text { Challenges for modeling hydrology in SLEMs } & 118\end{array}$

4.3.1 Modeling processes with different timescales $\quad 120$

4.3.2 Missing links between pedogenesis and hydrology 126

$\begin{array}{ll}\text { 4.3.3 Illustration of a hydrological SLEM } & 127\end{array}$ 
4.3.4 Current obstacles with soil hydrological parameters 129

4.3.5 Identification and quantification of flow paths 137

$\begin{array}{lll}4.4 & \text { Recommendations } & 139\end{array}$

4.5 Acknowledgements 141

Supplement 4.1 Adjustments to Lorica for daily water flow 142

$\begin{array}{lll}\text { S4.1.1 Daily processes } & 142\end{array}$

$\begin{array}{lll}\text { S4.1.2 Monthly processes } & 144\end{array}$

S4.1.3 Yearly processes 144

S4.1.4 Boundary conditions and process parameters 146

Supplement 4.2: Soil and hydraulic properties used for the water retention curves 147

\section{Chapter 5. Modeling soil and landscape evolution - the effect of rainfall and land-use change on soil and landscape patterns

Abstract $\quad 152$

$\begin{array}{lll}5.1 & \text { Introduction } & 153\end{array}$

$\begin{array}{lll}5.2 & \text { Methods } & 157\end{array}$

$\begin{array}{lll}5.2 .1 & \text { Model } & 157\end{array}$

$\begin{array}{ll}\text { 5.2.2 Experimental setup } & 164\end{array}$

$\begin{array}{ll}\text { 5.2.3 Analysis and evaluation } & 166\end{array}$

$\begin{array}{lll}5.3 & \text { Results } & 168\end{array}$

5.3.1 Simulated soil and landscape evolution 168

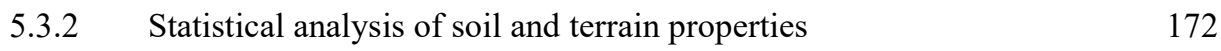

$\begin{array}{lll}5.4 & \text { Discussion } & 176\end{array}$

$\begin{array}{lll}\text { 5.4.1 Soil patterns and properties } & 176\end{array}$

$\begin{array}{ll}\text { 5.4.2 Drivers of soil formation } & 178\end{array}$

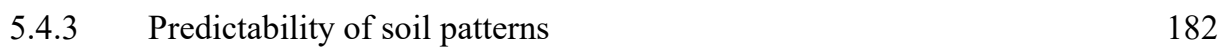

$\begin{array}{lll}5.5 & \text { Conclusions } & 184\end{array}$

5.6 Acknowledgements 185

Supplement 5.1: Model equations and parameters of HydroLorica 186

$\begin{array}{lll}\text { S5.1.1 Hydrologic processes } & 186\end{array}$

$\begin{array}{ll}\text { S5.1.2 Determination of vegetation type } & 186\end{array}$

$\begin{array}{ll}\text { S5.1.3 (Bio-)geomorphic processes } & 187\end{array}$

$\begin{array}{lll}\text { S5.1.4 (Bio-)pedogenic processes } & 188\end{array}$ 
6.1 Methods for quantifying soil-landscape change

6.1.1 Reconstruction of past landscapes and quantification of rates of landscape change

6.1.2 HydroLorica - a water-driven SLEM for studying Holocene and Anthropocene soil-landscape evolution

6.2 Evolution of soils and landscapes in the Anthropocene

6.2.1 Drivers and scales of Anthropocene soil-landscape evolution

6.2.2 Pedogenic pathways

6.3 Implications for soil-landscape co-evolution

6.3.1 Does soil-landscape co-evolution occur in intensively managed landscapes?

6.3.2 Co-evolution of landscapes and their management

\section{References}




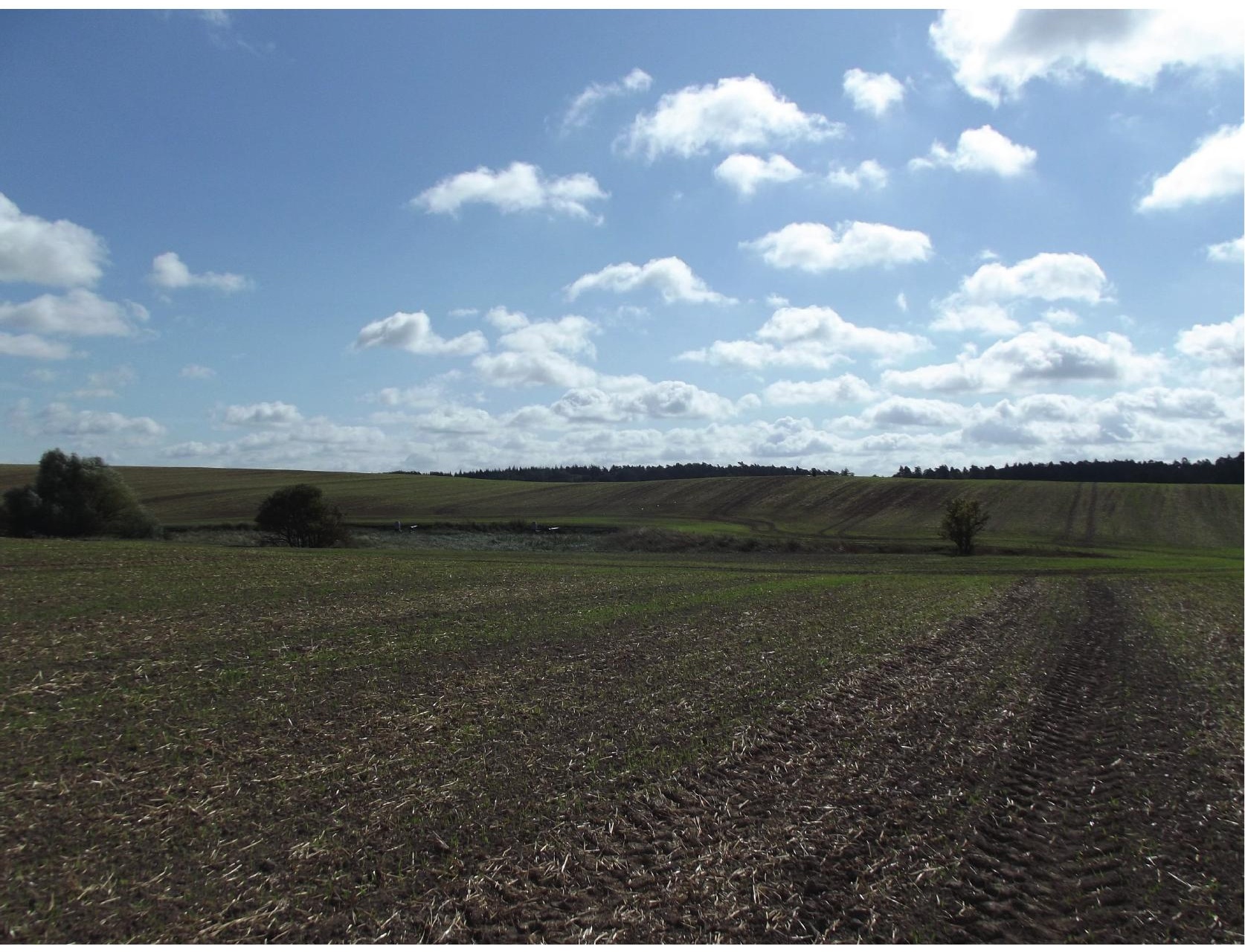


Chapter 1. General introduction 


\subsection{Introduction}

Soil, the basis of life. We rely on it to feed ourselves, to support our structures, to preserve our heritage and to maintain a healthy living environment (Blum, 2005). Yet, soils are degrading worldwide, threatening these soil functions (Montanarella et al., 2016; IPCC, 2019). The changes we make as humans in the landscape far exceed those occurring in natural systems (Wilkinson, 2005; Alewell et al., 2015), making us one of the dominant factors of soil formation (Amundson and Jenny, 1991; Richter et al., 2015). More often than not, we trigger and aggravate erosion processes (Poesen, 2018), we contaminate our soils (Carré et al., 2017), we deplete its resources (Tan et al., 2005) and reduce biodiversity (Van der Wal et al., 2008; IPBES, 2019). Our awareness of this impact gives us the responsibility to develop sustainable land-management practices, for the environment and for future generations.

Landscapes are influenced and degraded by humans along a range of scales; from prehistoric land use to modern intensive agriculture, and from elemental fertilization to global climate change. Luckily, natural soil and landscape processes show potential to mitigate or reverse human impacts, to develop sustainable management for resilient landscapes (i.e. nature-based solutions, European Commission, 2015; Keesstra et al., 2018b; Lafortezza et al., 2018). A clear understanding of the functioning of these natural processes in an anthropogenic world is therefore a fundamental research focus.

\subsection{Soils in the Anthropocene}

The Anthropocene is a proposed geological epoch where humans are the main forcing actors (Crutzen, 2002). Various starting dates for this epoch are proposed, but Lewis and Maslin (2015) mark 1610 and $1964 \mathrm{CE}$ as years that conform most to the geological criteria that mark the start of the Anthropocene as new geological epoch. The onset of agriculture might be a more suitable starting point of the Anthropocene from a soil-science perspective, because agricultural practices substantially change soil properties and patterns with rates much higher than in natural settings and introduce new processes and drivers changing soils and landscapes. This leads to the formation of agricultural landscapes rather than natural landscapes (Smith and Zeder, 2013; Richter et al., 2015). Soils that have substantial anthropogenic additions or alterations even have their own classification in the World 
Reference Base for soil resources: Anthrosols or Technosols (IUSS Working Group WRB, 2015).

World-wide, landscapes have been subject to anthropogenic change for thousands of years (Stephens et al., 2019). The Amazon, historically considered a pristine ecosystem, has in fact been managed for over several millennia, which has led to the creation of calcareous shell soils, charcoal-stained brown soils and black cultural soils (terra preta), and the formation of various anthropogenic earthworks (Roosevelt, 2013). Anthrosols can be found elsewhere in the world too. For example, centuries of fertilization of sandy soils in Western Europe led to the formation of plaggen soils or Plaggic Anthrosols (Blume and Leinweber, 2004) which have a fertile anthropogenic layer of up to $130 \mathrm{~cm}$ on top of the original soil. These fertile anthropogenic soils contain very stable and high carbon stocks, which could provide valuable lessons for carbon sequestration (Kern et al., 2019). Technosols formed in anthropogenic parent materials such as mining waste or building artefacts develop very fast due to their young age, often highly reactive substrate and favorable climate conditions (Leguédois et al., 2016).

More often than not, anthropogenic forcing on soils leads to degradation rather than improvement. For example, the European plaggen soils are enriched in nutrients, but the landscapes from which the plaggen were removed are severely degraded (Koster, 2009; Pierik et al., 2018). Another example occurs in the Arctic, where anthropogenic climate warming leads to the melting of permafrost and triggers complex feedbacks that promote breakdown and emissions of large quantities of stored carbon (Schuur et al., 2015; Parazoo et al., 2018; Schädel et al., 2018). The most well-known and direct effect of anthropogenic forcing on soil degradation is soil erosion (Lal, 2001; Guerra et al., 2017; Poesen, 2018). Deforestation, harvest and intensive land management degrade soils by exposing it to wind, water and gravity gradients. Anthropogenic erosion degrades soils with rates much higher than natural processes can recover the soil (Montgomery, 2007). Soil erosion is not just a problem of recent times; prehistoric land use already triggered erosion and influenced agricultural sustainability (Hughes and Thirgood, 1982; Vanwalleghem et al., 2017; Wang and Van Oost, 2018; Stephens et al., 2019). Soil erosion plays a complex role in the carbon cycling in agricultural landscapes. On the one hand, organic matter release is promoted by breakdown of aggregates, transport and export of soil material and reduced carbon input, while on the other hand carbon uptake and preservation is promoted by increased 
sequestration in newly exposed soil material in eroding positions and stabilization by burial in depositional positions (Doetterl et al., 2016). New findings continuously switch the consensus on whether soil erosion acts as source or sink of carbon (e.g. Hoffmann et al., 2017; Lugato et al., 2018; Lal, 2019; Yan et al., 2019), which raises the question whether an unambiguous answer to this issue can be found.

Intensively managed agricultural landscapes have completely different landscape functions compared to natural landscapes (Kumar et al., 2018). Human pressure on the landscape contributed to and substantially aggravated environmental problems such as global warming, soil erosion and loss of biodiversity (Harte, 2007). Soil science can provide partial solutions to most of these problems (Bouma, 2014). For example, sequestration of carbon in the soil can potentially decrease atmospheric $\mathrm{CO}_{2}$ (Minasny et al., 2017; Rumpel et al., 2019; Schlesinger and Amundson, 2019), and sustainable land management can prevent and reverse land degradation (Kust et al., 2017; Cowie et al., 2018; Keesstra et al., 2018a). To tackle these problems, we need a thorough and fundamental understanding of the drivers and the processes responsible. Also, we must look for their causes, and solutions, over larger spatial and longer time scales. For example, to prevent and reverse soil degradation by anthropogenic erosion, we need to know how erosion processes work and interact with the rest of the landscape, we need to scale measured erosion rates in space and time to assess severity and damage, and we need to know which processes are essential for land recovery (Sietz et al., 2017; Poesen, 2018).

In short, we need to increase the spatial and temporal dimensions of our understanding to tackle current environmental problems, and to develop sustainable land-management practices that mitigate future changes in climate and land-use demands. This requires 1) the development and improvement of methods that can aid in increasing our understanding of long-term soil and landscape change in the Anthropocene, as current methods are not always applicable over these larger spatiotemporal scales, and 2) a clear understanding of how natural soil-landscape formation can aid in combating anthropogenic soil-landscape degradation in intensively managed landscapes through nature-based management. 


\subsection{Evolution of soils and landscapes}

Soils are complex systems that form under a variety of influences. The state factor theory of Jenny (1941) describes the state of a soil $\boldsymbol{S}$ as a function of various environmental factors: $S=f(c l, o, r, p, t, \ldots)$. These factors include climate, organisms (originally including humans), relief, parent material and time. Humans are currently recognized as additional soil forming factor, due to their big impact on soil processes and properties (Amundson and Jenny, 1991; Richter and Yaalon, 2012). Local, regional and global variations in the soil forming factors have formed a huge diversity of soils around the world (e.g. IUSS Working Group WRB, 2015). In recent times, the soil-science community adopted the scorpan approach of McBratney et al. (2003) to map the spread of soils and their properties. Scorpan is based on the clorpt model, but includes additional terms for the spatial location of a soil and information on additional or former soil properties at that location. By considering the spatial location, a link with geostatistics is enabled in order to predict the spatial spread of soil properties based on measured properties and environmental covariates.

Next to the myriad of functions soils provide, they themselves have a myriad of visual appearances. Soil geography is the science that studies the distribution of soils and their properties (Blume et al., 2016). Soils can be studied along a range of spatial scales; from chemical elements, via pores, soil layers (horizons) and profiles (pedons) to whole landscapes. Especially soil landscapes with substantial relief are sensitive to anthropogenic degradation, as erosion processes are driven by gravity gradients.

\subsubsection{Landscapes and co-evolution}

A landscape can be defined in various ways; as a scenic picture, a collection of landforms, a portion of territory that can be viewed at one time from one place or a particular area of activity (Merriam-Webster, 2019). The landscape can fulfill many different functions (Willemen et al., 2008). As a physical geographer, I am interested in the physical aspects of the landscape; the soils, topography, water bodies and vegetation. However, other disciplines experience the term landscape as an ecological, cultural, or philosophical entity. The term landscape thus has various meanings and uses in different disciplines and can cause confusion in multidisciplinary studies. For clarity, I define here the terms I use to describe soils, topography and their spatial patterns. 
I view the landscape as a collection of coupled, spatially varying physical components, such as soils, topography, vegetation and the hydrological system (Figure 1.1). These components are coupled in space and time by fluxes of water, solutes and sediments (e.g. Huggett, 1975; Sommer and Schlichting, 1997). The topography or terrain comprises all properties related to the surface of the landscape (e.g. elevation, slope, relative topographic position). Models that simulate the long-term changes in topography are called Landscape Evolution Models (LEMs, e.g. Temme et al., 2017). The spatial spread of the individual components of the landscape is referred to as patterns (e.g. soil patterns or terrain patterns). With time, the components and patterns of soils and landscape fluctuate and change. Over sub-annual timescales, these changes are often fast and cyclic due to daily or seasonal cycles. Over annual to millennial timescales, the cumulative net changes of the short-term fluctuations lead to the evolution of soils and landscape (Lin, 2011). Soil Evolution Models (SEMs) can be used to simulate this long-term evolution of soils.

Soils form under the influence of their surroundings. Vice versa, soil properties can also control changes in their surroundings: soils can develop erosion-resistant layers, soil quality determines what vegetation can grow, and less permeable soil layers can change the direction of water flow. The intertwined formation of soils and the other aspects of the landscape is called co-evolution (Figure 1.1). The term co-evolution originates from the field of ecology, where it is used to indicate interactive evolution of different species (Ehrlich and Raven, 1964). In soil science, soil-landscape co-evolution is often used to describe and understand simultaneous development of soils and landforms under pedogenic, geomorphic, biotic and hydrologic fluxes and processes (Huggett, 1975; Sommer and Schlichting, 1997; Johnson, 2002; Phillips and Lorz, 2008; Schaetzl and Thompson, 2015; Willgoose, 2018). However, the essential interactions between soils and topography are not always recognized. Soillandscape co-evolution can induce negative feedbacks which lead to self-organization or (temporary) self-preservation of the landscape (e.g. Hedwall et al., 2017). At the same time, positive feedbacks induced by soil-landscape co-evolution can lead to exceedance of thresholds and tipping points, which can change directions of water, solute and matter flow. Models that simulate the (co-)evolution of soils, topography and possibly other aspects of the landscape are called Soil-Landscape Evolution Models (SLEMs). A clear understanding of occurrence of, and spatiotemporal scales and interactions related to soil-landscape coevolution in both natural and agricultural settings is essential for developing nature-based 
land-management strategies, because these feedbacks can have intended or unintended sideeffects of a certain management strategy. SLEMs can help identifying and quantifying possible soil-landscape co-evolution.

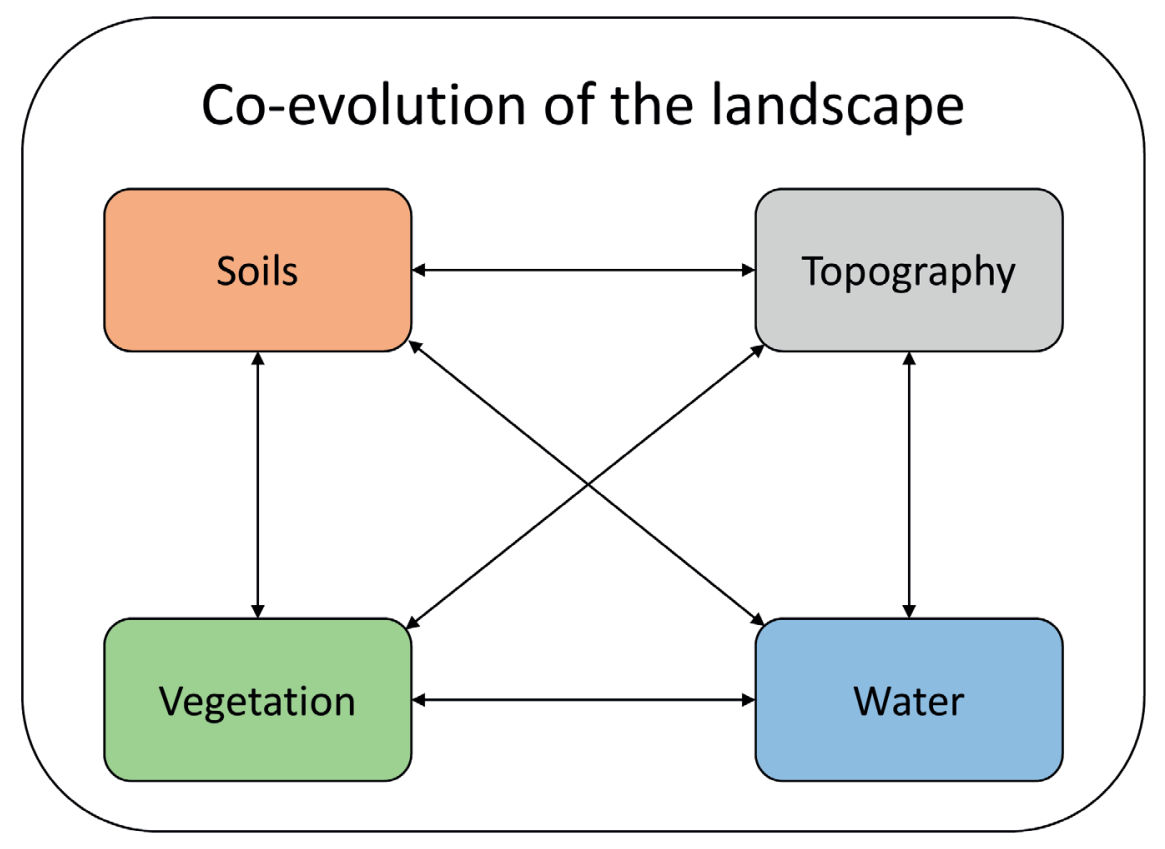

Figure 1.1: Co-evolution of the landscape.

\subsubsection{Pedogenic pathways}

The evolution of soils is often conceptualized in a set of general trajectories in order to grasp and predict what is going on beneath our feet (Phillips, 2019). These evolutionary trajectories are called pedogenic pathways. Classical pedogenic models describe the evolution of soils towards a stable steady state (e.g. Jenny, 1941). The diagnostic soil horizons as described in the WRB system are often considered as more or less stable states (Targulian and Krasilnikov, 2007). This steady state model has been challenged, because it is highly unlikely for soils to reach a steady state in the period that the environment they develop in can be assumed stable. All pedogenic processes, even slow ones, have to be terminated or be in dynamic equilibrium with their environment in order to reach steady state (Targulian and Krasilnikov, 2007). Soil processes take a range of characteristic times to change a soil (Brantley, 2008). Some faster processes, such as carbon cycling are more likely to reach 
steady state, while slow processes such as mineral weathering do decrease in rate but take extremely long to completely weather out a soil profile (Sauer, 2015). Over the characteristic temporal and spatial scales of pedogenesis, the environment cannot be considered as a constant factor. Changes in environmental factors such as climate or land use can trigger multiple pedogenic pathways that affect earlier developed soil properties (Targulian and Bronnikova, 2019). Also, changes in denudation, erosion and deposition can disrupt the reaching of a steady state soil (Phillips, 2010). Therefore, conceptualization, and quantification, of soil evolution under varying initial and boundary conditions, e.g. land-use intensification, requires a model that considers multiple pedogenic pathways (Phillips, 2019). Changes to a soil in one location can induce changes in soils in locations close by or even far away (Schoorl et al., 2002; Ma et al., 2017; Poesen, 2018), because of the lateral connection of soils by fluxes of water, sediments, carbon and solutes (Huggett, 1975; Sommer and Schlichting, 1997). Therefore, evaluation of pedogenic pathways should be done on a landscape scale rather than a pedon scale.

To identify pedogenic pathways and possible soil-landscape co-evolution, we require data and methods that bridge the spatiotemporal scales associated with the evolution of soils and landscapes. Current methods need to be improved and combined in order to conceptualize, quantify and verify pedogenic pathways in anthropogenic landscapes.

\subsection{Methods for studying soil-landscape evolution}

Soil geographers have a range of methods at their disposal to study the evolution of soils and landscapes. For this thesis, I make a distinction between reconstruction methods that reconstruct past states and rates of change of soils and landscapes based on data from observations, measurements and statistical data analysis techniques, and simulation methods that generate data through numerical interpolation, or simulation of soil and landscapeforming processes.

\subsubsection{Reconstruction methods and the pitfall of polygenesis}

Reconstruction methods reconstruct past states of soils and landscapes and corresponding rates of change using current soil and landscape properties. These properties include soil horizonation, texture and structure, organic and mineral composition, geophysical properties and radionuclide contents for sediment dating. Various field and laboratory methods can be 
used to measure these properties and often statistical techniques are required to analyze these measurements (e.g. Bronk Ramsey, 2008; Cunningham and Wallinga, 2012).

Reconstruction methods can face the problems of polygenesis and equifinality: different initial states could have developed via different processes to very similar outcomes (Phillips, 2019). The current soil and landscape properties that are used to reconstruct past states might thus be attributed to multiple sets of processes acting with different rates. Also, reconstruction methods are not always able to derive past soil states, because past states can be overprinted by more recent processes (Targulian and Bronnikova, 2019). The space-for-time approach, or chronosequence, can partly circumvent these problems (Stevens and Walker, 1970; Shepard, 2018). This approach compares soils formed in similar settings but with different ages to distill the age effect on soil formation. Typical settings for chronosequences are river terraces, lava flows or proglacial areas (Birkeland, 1992; Temme et al., 2016; Shepard, 2018). Similarly, to study the effect of topography, climate or human impact on soils one could select sites with gradients in topography, climate or anthropogenic forcing (Sommer and Schlichting, 1997; Purton et al., 2015). The assumption that changes in other soil forming factors are much smaller than changes in the factor under study is not always valid and has to be checked in advance, because this assumption can (unknowingly) distort the sequence and lead to misinterpretations due to polygenesis. For example, non-uniformity in parent material can suggest non-existing trends in e.g. weathering rates (Harden, 1988), variation in landforms can have a larger effect on soil variation than age in chronosequences (Van der Meij et al., 2016), effects of past climate periods can still be present in current soils (Mason et al., 2016), and agricultural drainage can substantially increase pedogenic rates (Montagne et al., 2009). Numerical models that simulate the evolution of soils and landscapes in space and through time offer new options to disentangle the effect of different initial states, boundary conditions, processes and drivers on soil development by simulating and testing several hypotheses of soil and landscape evolution.

\subsubsection{Simulation methods and their limitations}

Simulation methods generate data either by interpolation of observations, or simulation of processes. The numerical interpolation of soil observations with the goal of producing spatially explicit maps of soil types and properties is called Digital Soil Mapping (DSM). DSM uses the concept of scorpan to estimate difficult to obtain soil data from easier to obtain 
environmental data using statistical methods such as regression and machine learning (McBratney et al., 2003; Padarian et al., 2019; Wadoux, 2019; Zeraatpisheh et al., 2019). These methods perform well for interpolating observations in space, but their applicability in time is limited due to limited observations and limited consideration of process knowledge (Grunwald, 2009; Gasch et al., 2015). This process knowledge is essential to constrain, or complement spatial prediction models (Angelini, 2018; Ma et al., 2019a).

Studying the changes in soils and their properties over time can be done by simulating the processes and mechanisms responsible for these changes. Models simulating these processes are called Soil Evolution Models (SEMs). SEMs have been developed for soil processes over a range of scales, from soil pore hydrology to millennial soil-landscape co-evolution (Minasny et al., 2015; Vereecken et al., 2016; Stockmann et al., 2018). The spatial and temporal scales of soil change are correlated. Processes operating on smaller spatial scales often have small characteristic temporal scales too. For example, soil-pore hydrology is controlled by sub-daily changes in hydraulic pressure, while continental plate tectonics occur over millions of years. One can wonder to what extent sub-daily pore water fluctuations contribute to the overall evolution of the landscape. Consequently, one can question whether it is necessary to simulate these small-scale processes for questions about the large-scale landscape. Over these larger scales, the processes changing soils and landscapes get more numerous and available data gets more uncertain. Models simulating over larger spatial and temporal ranges therefore often have less complex and less detailed representations of the pedogenic and geomorphic processes to account for data availability and uncertainty, and to reduce calculation time. These models are called reduced-complexity models (e.g. Brasington and Richards, 2007; Kirkby, 2018).

Reducing the complexity of models facilitates their applicability in a certain setting but can hamper applying the model in settings with different processes and drivers. Especially SLEMs have limited process coverage (Minasny et al., 2015) and often lack essential drivers that enable their deployment in various geographic and climatic settings (Opolot et al., 2015). Substantial improvements have to be made to SLEMs to make them suitable for studying the effect of climatic and anthropogenic forcing on the evolution of soils and landscapes. 


\subsection{Research needs}

Soil erosion is an anthropogenic threat that directly influences soil patterns and degrades soils. Soil erosion occurs in the majority of agricultural landscapes (Pimentel and Kounang, 1998; Chappell et al., 2015; Borrelli et al., 2017), is a direct threat on biodiversity and food security (Pimentel, 2006) and interacts with environmental issues at both smaller and larger scales (Doetterl et al., 2016; Gerke et al., 2016; Lugato et al., 2018). Soil erosion has been a dominant process impacting the landscape over thousands of years, but its rates have been increasing substantially in recent times (e.g. Wilkinson, 2005; Dreibrodt et al., 2010). Besides the well-studied process of water erosion, tillage erosion has been shown to be of similar or even larger importance for land degradation in intensively managed agricultural landscapes (Van Oost et al., 2005b; Van Oost et al., 2009; Kumar et al., 2018). The types and rates of soil erosion processes are a function of land management, topography, vegetation type and cover, climate and soil properties (Cerdan et al., 2010), which are approximately the same factors that control soil formation (Jenny, 1941). These similar factors can cause complex interactions between soil formation and erosion processes, leading to possible soil-landscape co-evolution. A characterization of these erosion processes and possible interactions with other soil and landscape processes is essential for developing sustainable soil management strategies to prevent further soil degradation. Concretely, there is a need to:

- Define the spatial and temporal scales on which soils and landscapes have been affected by anthropogenic soil erosion.

- Quantify how anthropogenic processes impact pedogenic pathways and soil and landscape properties.

- Identify possible soil-landscape co-evolution that can assist or obstruct sustainable land management.

The large spatial and temporal ranges associated with these research needs call for development and improvement of reconstruction and simulation methods for studying soil and landscape change to quantify human impact on soil-landscape properties and functions. Specifically, methods are needed to distinguish the effects of natural and anthropogenic processes on soil and landscape properties, and to provide data over a range of spatial and especially temporal scales. Development of these methods requires well-sampled study areas where different types of data can be used to feed and test the methods. Preferably, these areas 
contain complete geo-archives that facilitate quantification of landscape change using the sedimentological record.

\subsection{Research objectives and questions}

The aim of this thesis is to identify and quantify pedogenic pathways and possible coevolution of soils and landscapes during the transition from natural land cover to intensive land management in the Anthropocene. I defined the following objectives, with respective research questions that I will answer to reach the objectives.

1. Develop methods for studying soil and landscape change that cover spatial and temporal dimensions of soil-landscape evolution in the Anthropocene.

a. How can pre-agricultural landscapes be reconstructed and long-term dynamics of agricultural landscape change be quantified?

b. What improvements are required to equip SLEMs to simulate soillandscape evolution in natural and intensively managed settings?

2. Gather insights in pedogenic pathways in intensively managed landscapes in the Anthropocene.

a. What are the dominant drivers of soil-landscape evolution in preagricultural and agricultural settings and at what spatial and temporal scales do they affect the system?

b. How does soil-landscape evolution change due to the transition from natural land cover to agricultural land use?

3. Evaluate implications of possible soil-landscape co-evolution on sustainable land management.

a. Does soil-landscape co-evolution occur in intensively managed landscapes?

b. How can possible soil-landscape co-evolution influence management of intensively managed landscapes?

\subsection{Study area}

Soil erosion by water and tillage requires terrain gradients. These gradients drive the transport of water and sediments downslope (Liu et al., 2001; De Alba et al., 2004; Wysocka- 
Czubaszek and Czubaszek, 2014). Also, soil erosion by tillage especially occurs in agricultural areas which are accessible to machinery (slopes $<20 \%$, Bibby and Mackney, 1969). These conditions constrain the research area for this thesis to gently to moderately sloped agricultural landscapes which are intensively managed. These undulating landscapes are numerous around the globe, but occur most often in glacial till- or loess-based settings, due to the high fertility of the parent material (Catt, 2001; Bedard-Haughn and Pennock, 2002; Zhang et al., 2004; Vitharana et al., 2008; Kumar et al., 2018; Wilson et al., 2018). These landscapes can also be influenced partly by wind erosion (Blanco-Canqui and Lal, 2008). However, I will not consider the effects of wind erosion, because the spatial scale of wind erosion far exceeds the typical hillslope scale on which soil formation and anthropogenic erosion can interact. The study of wind-soil interactions therefore requires different methods that are beyond the scope of this thesis.

Field work for this thesis was conducted in the hummocky ground moraine landscape of north-eastern Germany. This landscape was formed after the retreat of the Weichselian ice cap (Lüthgens et al., 2011). This young morainic landscape is characterized by numerous closed catchments (kettle holes) formed by the melting of dead ice (Andersson, 1998). The heterogeneous glacial till as the parent material, undulating small-scale topography and pedogenic processes have formed a complex hydrological system that affects the current-day soil and landscape functions (Gerke et al., 2010; Gerke et al., 2016). Currently, soils are heavily eroded by intensive land management (Frielinghaus and Vahrson, 1998; Li et al., 2002; Sommer et al., 2008). My specific study site is called CarboZALF-D, located $100 \mathrm{~km}$ north of Berlin (Sommer et al., 2016). This landscape laboratory was designed for research on interactions between erosion, carbon dynamics and other soil functions (e.g. Rieckh et al., 2014; Aldana Jague et al., 2016; Hoffmann et al., 2018). The resulting extensive dataset, together with the complete geo-archive in the closed catchment, complex landscape genesis and intensive land management make this site suitable for studying the long-term effects of humans on soil patterns and functions.

\subsection{Thesis outline}

This thesis has four research chapters that each cover multiple research objectives and one chapter in which I synthesize the findings from this thesis to answer the research questions (Figure 1.2). The research chapters have either been published as peer-reviewed articles 
(Chapters 2-4) or as discussion article (Chapter 5) in international peer-reviewed journals. Chapters 2 and 3 describe the influence of humans on erosion rates and landscape patterns using reconstruction methods. Chapters 4 and 5 describe the dominant drivers of soil and landscape evolution in natural and agricultural settings and quantify their impact on soil and terrain patterns using simulation methods.

In this introductory Chapter 1 I outlined the research aim and objectives and I provided their scientific background and societal relevance.

In Chapter 2 we reconstruct the pre-agricultural paleosurface of the CarboZALF-D study site using an extensive dataset of soil descriptions. We present the reconstructed surface and mention several complications and points of attention for similar future research.

In Chapter 3 we develop a method for determining deposition rates in agricultural settings using optically stimulated luminescence (OSL) dating. The luminescence signal, which is a proxy for sediment age, constantly gets reset through tillage reworking after deposition. Our methodology corrects for this resetting. We describe the method, show the age and rate results for study site CarboZALF-D and discuss implications for landscape evolution of hummocky landscapes such as CarboZALF-D.

In Chapter 4 we review the role of water as dominant driver of natural soil-landscape evolution. Water flow plays a pivotal role in pedogenesis, but this role cannot be modeled accurately due several practical and methodological challenges. We describe partial solutions for these challenges, which are necessary to develop SLEMs that can simulate natural soillandscape evolution under changing climatic forcing.

In Chapter 5 we utilize the partial solutions from Chapter 4 to develop a water flow-driven SLEM, named HydroLorica. This model can simulate the development of soils and landscapes in both natural and agricultural settings. We use HydroLorica to simulate soillandscape evolution in the Anthropocene under changing climatic and anthropogenic forcing for undulating loamy landscapes. We quantify the role of climate and land use on soil and landscape patterns.

In Chapter 6 I answer the research questions of this thesis by synthesizing the findings from the research chapters. I provide an overview of the lessons learned and I suggest directions for future research on soil-landscape evolution in the Anthropocene. 


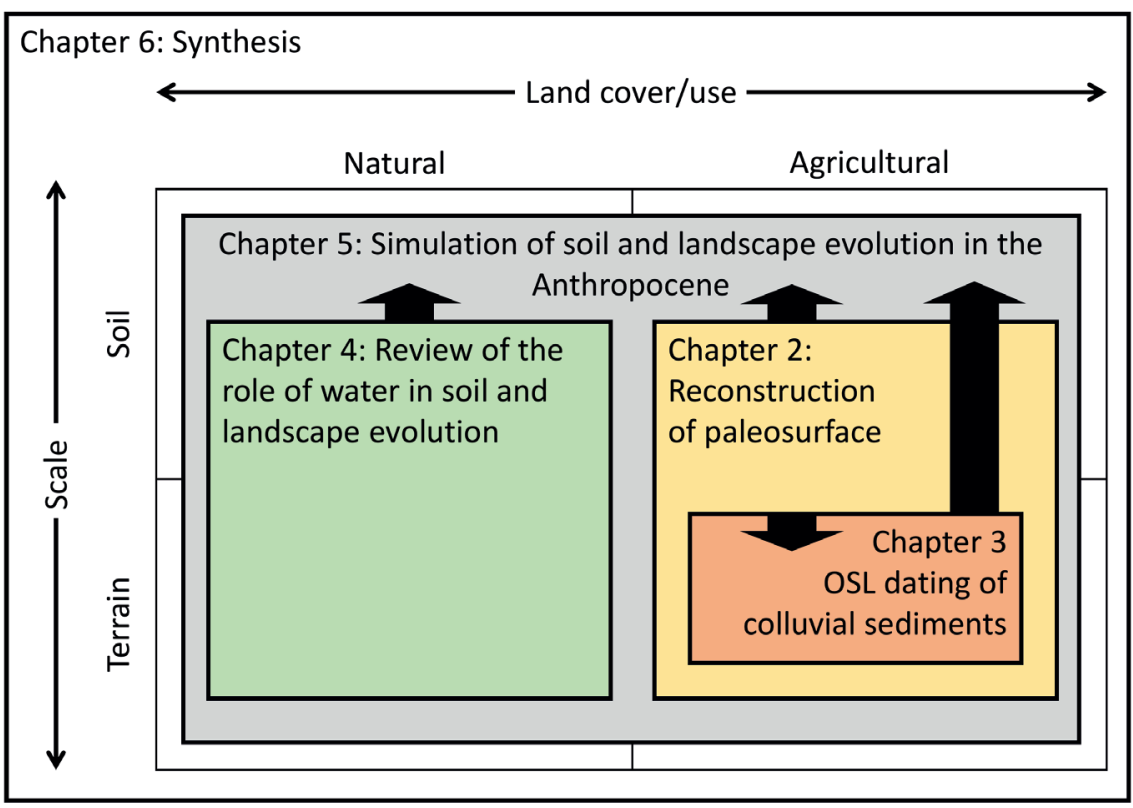

Figure 1.2: Quadrant of spatial scales and land cover/use domains that are covered by the different chapters of this thesis. The arrows indicate how findings from the research chapters feed into each other. 


\section{Chapter 2. Topography reconstruction of eroding}

landscapes - a case study from a hummocky ground moraine (CarboZALF-D)

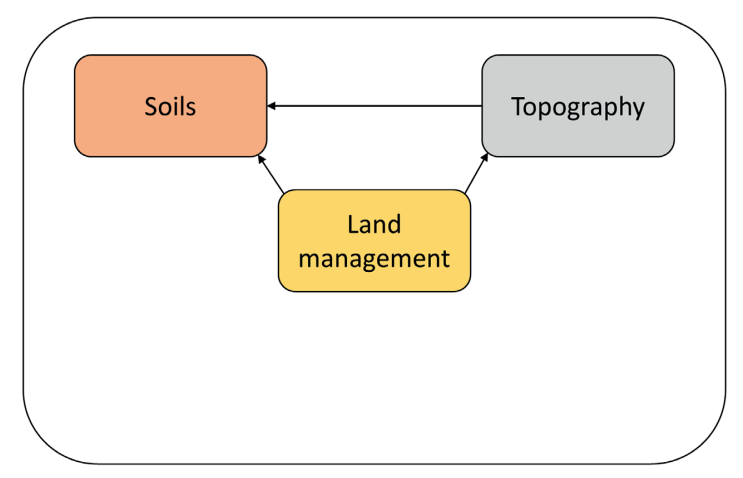




\begin{abstract}
Erosion processes, aggravated by human activity, have a large impact on the spatial variation of soil and topographic properties. Knowledge of the topography prior to human-induced erosion (paleotopography) in naturally stable landscapes is valuable for identifying vulnerable landscape positions and is required as starting point for erosion modeling exercises. However, developing accurate reconstructions of paleotopography provide a major challenge for geomorphologists. Here, we present a set of paleotopographies for a closed kettle hole catchment in north-east Germany (4 ha), obtained through different reconstruction approaches. Current soil and colluvium thickness, estimated from a dataset of 264 soil descriptions using Ordinary Kriging, were used as input for a mass balance, or were compared with a set of undisturbed soil thicknesses to estimate the amount of erosion. The performance of the different approaches was assessed with cross-validation and the count of mispredicted eroded, depositional or stable landscape positions.
\end{abstract}

The paleotopographic reconstruction approach based on the average thickness of undisturbed soils in the study area showed the best performance. This thickness $(1.00 \mathrm{~m})$ is comparable to the average undisturbed soil thickness in the region and in line with global correlations of soil thickness as a function of rainfall and initial $\mathrm{CaCO}_{3}$ content. The performance of the different approaches depended more on mispredictions of landscape position due to the assumption of a spatially constant initial soil depth than on small variations in this depth. To conclude, we mention several methodological and practical points of attention for future topography reconstruction studies, concerning data quality and availability, spatial configuration of data and other processes affecting topography.

Published as: Van der Meij, W.M., Temme, A.J.A.M., Wallinga, J., Hierold, W., Sommer, M., 2017. Topography reconstruction of eroding landscapes - A case study from a hummocky ground moraine (CarboZALF-D). Geomorphology, 295, 758-772. https://doi.org/10.1016/j.geomorph.2017.08.015 


\subsection{Introduction}

Human disturbances, such as deforestation and intensified land use, have added to the natural rate of topography change. Removal of permanent vegetation increased vulnerability of soils to both wind and water-induced erosion. In addition, tillage erosion moved soil material downslope. These various forms of soil erosion form a hazard to different soil functions, such as food production, water management, carbon storage and biodiversity (e.g. Pimentel et al., 1995; Van Oost et al., 2007; Pimentel and Burgess, 2013; Amundson et al., 2015; Montanarella et al., 2016).

In Central Europe, the first significant land cover change due to increased population density dates back to the Young Neolithic ( 4350 - 3650 BCE, Lechterbeck et al., 2014). This coincides with an increased amount of slope deposits in Germany ( 4350 BCE, Dreibrodt et al., 2010). Also other maxima in the phases of deposition coincide with periods of increased population pressure, such as the late Bronze Age and pre-roman Iron Age $(\sim 1600 \mathrm{BCE}-1$ $\mathrm{CE})$, high and late Medieval Times $(\sim 1000-1350 \mathrm{CE})$ and the Modern Times $(1500 \mathrm{CE}-$ now, Dreibrodt et al., 2010). Erosion rates once more increased significantly with the mechanization of agriculture and collectivization of land after the Second World War (e.g. Frielinghaus and Vahrson, 1998; Sommer et al., 2008). This intensification increased the relative role of tillage erosion compared to water and wind erosion (Govers et al., 1996; Kietzer, 2007; Van Oost et al., 2009).

Clearly, the impact of human use on topography can be substantial (Goudie, 2013) and depends on both natural factors (e.g. landform stability (Hancock et al., 2015) and soil erodibility (Song et al., 2005)), and anthropogenic factors (e.g. land use (Montgomery, 2007), management strategy (Keesstra et al., 2016) or mechanization of agriculture (Fig. 3 in Sommer et al., 2008)). Reconstruction of sediment erosion and transport pathways provides quantitative insight with respect to the sensitivity of a landscape to erosion and thereby helps identify vulnerable landscape positions and damaging management. However, such reconstructions require detailed information on the topography of a landscape before a phase of erosion (paleotopography), which is usually not available. Furthermore, the changes of landforms over time by e.g. the filling of a lake or peaty area by sediments can illustrate the development or destruction of natural habitats accompanying a certain landscape type (cf. Kalettka and Rudat, 2006). In addition to topography, erosion also influences soil properties, 
leading to changes in soil productivity and land use (Bakker et al., 2005) and redistribution of carbon (Aldana Jague et al., 2016) with currently unknown consequences for the global carbon cycle (Doetterl et al., 2016). Improved understanding of the relations between erosion and soil and topographical properties can help the development of new conservation and management strategies for protecting soils and landscape functions in agricultural landscapes prone to erosion (Tscharntke et al., 2005).

Landscape evolution models (LEMs) are often used to simulate scenarios of different types and intensities of erosion and land management over long timescales (e.g. Schoorl and Veldkamp, 2001; Van Oost et al., 2005b; Hancock et al., 2010; Baartman et al., 2012; Zhang et al., 2016). When appropriately parametrized with field data, these studies can give an indication of the genesis of a landscape and relative contributions of different erosion processes. However, one major shortcoming of landscape evolution modeling is that the initial shape of the topography is often unknown and this uncertainty propagates through the model simulations (Temme and Veldkamp, 2009; Perron and Fagherazzi, 2012; Minasny et al., 2015). In some modeling approaches, the present topography is used as starting point, the model is calibrated using present-day soil and sediment properties and simulations are done forward in time (e.g. Hancock et al., 2014). However, when topography has changed substantially over time (e.g. Phillips, 2003), that approach will not provide insight in erosion history and formation of the present topography. Hence, different attempts have been made to estimate initial topographies (cf. Table 1 in Dotterweich, 2008). In locations experiencing deposition, colluvium thickness obtained through soil descriptions and proximal sensing has been interpreted as an indicator of deposition (e.g. Saey et al., 2008; Vermeer et al., 2014). In locations experiencing erosion, depths to certain soil horizons have been used to estimate eroded volume, with an assumed initial soil depth (e.g. Rommens et al., 2005; Świtoniak, 2014). Usually a spatially constant (average) initial soil depth is assumed, as correlations between soil or horizon depths and topographic predictors in undisturbed landscapes are weak at best (Pennock, 2003; Vanwalleghem et al., 2010). Previous studies have suggested that the observed variation in natural soil thickness might depend more on random controls such as tree fall (Phillips and Lorz, 2008) and variations in parent material (Armson and Fessenden, 1973; Vanwalleghem et al., 2010) than on topographic controls.

Geochronological methods can provide erosion rates for recent (e.g. Cesium-137, Ritchie and McHenry, 1990) and long-term topographic change (e.g. Beryllium-10, Gosse and Phillips, 
2001; Egli et al., 2010). The usefulness of these different approaches depends on data availability, knowledge of spatially distributed soil properties, interpolation techniques and knowledge on spatial variation in erosion (Rommens et al., 2005). Another method for estimating initial topography is reverse erosion modeling to simulate initial topography by reversing an erosion model, leading to virtual uptake of material in depositional locations and redistribution of this material on the original sediment sources (e.g. Temme et al., 2011b). However, reverse erosion modeling encounters two major problems, namely polygenesis and equifinality: a certain final topography can be reached from different initial topographies, through different combinations of processes (Peeters et al., 2006; Temme et al., 2011b). It is most useful when the change in landforms has been minimal over the timescale of interest. Although each method has the potential to be used as an indicator of erosion history, integration of the different methods over different spatial and temporal scales gives a better understanding of complete erosion history (Dotterweich, 2008).

To summarize, information on paleotopography is essential for understanding erosion processes, sediment redistribution and current soil diversity (Dotterweich, 2008), but there is no widely applicable method to reconstruct the topography of paleolandscapes. To our knowledge, there have been no in-depth studies concerning the uncertainty that comes with detailed reconstruction of soils, topography and their accompanying properties in eroding landscapes. Moreover, the effect of assumptions that have to be made for these methods, such as e.g. a uniform initial soil depth, has not yet been quantified.

In this contribution we identify and quantify the uncertainty of different approaches for initial topography reconstruction, based on soil descriptions, to guide future topography reconstruction efforts. The spatial setting is a closed agricultural kettle hole catchment located in the ground moraine landscape of NE Germany. Sommer et al. (2008) used this naturally stable landscape to formulate their time-split approach to characterize the shift from undisturbed, progressive pedogenesis (throughout the Holocene) to regressive erosion processes by abrupt human disturbances in the landscape (e.g. deforestation or mechanization of agriculture). Humans populated this region already in the Neolithic and Bronze Age (Schatz, 2000). However, their impact on the landscape was very local, with an unknown intensity. Therefore, the exact temporal extent of human influence in our specific study area is unknown. We define the initial topography as the shape of the landscape before abrupt changes in land use occurred and the landscape started to change substantially by erosion. 
Kettle hole catchments have been the focus of multiple geomorphic and pedo-environmental studies before (e.g. Pennock et al., 1987; Frielinghaus and Vahrson, 1998; Landi et al., 2004; Karasiewicz et al., 2014; Mendyk et al., 2016). They provide a suitable setting for topography reconstruction, because all detached soil material is redeposited inside the same closed catchment. This geo-archive provides the possibility of formulating a mass balance to test the validity of the reconstructed topography.

\subsection{Study area}

This study was performed in agricultural landscape laboratory CarboZALF-D (Sommer et al., 2016), located near the village of Dedelow, $100 \mathrm{~km}$ north of Berlin. The hummocky ground moraine landscape formed after retreat of the glaciers in the Pomeranian phase of the Weichselien. Since then, the young $(\sim 13 \mathrm{ka})$ landscape has not yet formed a connected drainage pattern (Sommer et al., 2008). The topography still mainly consists of closed catchments, which were formed by melting of dead ice (Andersson, 1998). These kettle holes, or potholes, are defined as the central depressional wetland which receives water from the surrounding closed kettle hole catchment (Kalettka and Rudat, 2006). Muddy lake sediments were deposited in the center of such kettle holes, on top of the permanently reduced till. Periglacial processes reworked and translocated till material along the slopes. During the Holocene, high groundwater levels resulted in peat growth inside the kettle hole (Histosols). On the slopes away from the depressions, Luvisols formed in the glacial till under natural conditions. These have a general horizon sequence of Ah-E-Bt-Ck (Figure 2.2), with the suffix $k$ for pedogenic carbonates in the parent material. The depth to the $\mathrm{Ck}$ horizon was used as definition of soil thickness in this study.

This previously undisturbed landscape started eroding, due to changes in land use and agricultural practices. First, water erosion was the dominant erosion process in the deforested landscape. Later, with the increased mechanization of agriculture, tillage erosion became more dominant. Consequently, most of the pedons, primarily developed as Luvisols, are now eroded. When erosion takes place, material from the top layer (Ap horizon) is removed and transported downslope. However, due to continuous ploughing activity, the thickness of the Ap horizon will remain constant, and the effect of erosion is that the horizon below the Ap will become thinner and eventually disappears. The soil descriptions were grouped in different erosion intensities and soil types (IUSS Working Group WRB, 2015), based on the 
absence of the $\mathrm{E}$ or Bt horizon of the standard Luvisol profile. Non- or slightly eroded soils still show the Ap-E-Bt-Ck horizon (Albic Luvisols (Cutanic)). In strongly eroded soils, the E horizon is absent (Ap-Bt-Ck, Calcic Luvisols (Cutanic)). Extremely eroded soils also miss the complete Bt horizon (Ap-Ck, Calcaric Regosols (Densic)). These (eroded) Luvisols occur on the plateaus and hillslopes (Figure 2.1). They show different degrees of redoximorphism, depending on $\mathrm{Bt}$ and $\mathrm{Ck}$ horizon density and topographic position. The kettle hole and surrounding soils are covered by a thick layer of sandy colluvium, consisting of the eroded soil material from the slopes. Soils in this colluvium can be classified as Endogleyic Colluvic Regosols (Arenic). The gleyic properties of these soils, and of some soils close to the depression (Figure 2.1), are caused by high groundwater levels in these lower areas. Detailed soil descriptions of four soil profiles representative for the different landscape positions can be found in Supplement 2.1.

The kettle hole catchment of CarboZALF-D originally consisted of two smaller catchments with a low saddle position between the two depressions (Figure 2.1). The layer of colluvium currently overlaps both depressions, creating one bigger system. A thin layer of colluvium is found on the northern border of the watershed divide, suggesting minor loss of colluvium to the next (lower) kettle hole catchment. The CarboZALF-D catchment is split by a railroad constructed in the year 1900 (Mauruszat, 2016). The area on the far southwest side of the railroad is relatively flat and most soil profiles are still intact (Albic Luvisols). Also, where limited erosion has occurred in this area, the associated deposits were found very close to the erosional sites. Hence, we assumed that soil redistribution in this part of the original catchment is limited and local and did not contribute substantially to the overall soil translocation in the remainder of the CarboZALF-D catchment. Therefore, we only considered the larger north-eastern part of the catchment (Figure 2.1).

CarboZALF-D has been subject of studies concerning carbon dynamics in an eroding landscape (e.g. Hoffmann et al., 2015; Aldana Jague et al., 2016; Gerke et al., 2016; Miller et al., 2016). This has led to an extensive dataset, with, amongst others, more than 260 soil profile descriptions. The density of descriptions in the study area is 49 locations ha- ${ }^{-1}$. The 30 year average annual rainfall $(1981-2010)$ equals $500 \mathrm{~mm}$, with a standard deviation of 98 $\mathrm{mm}$. Minimum and maximum annual precipitation were respectively 349 and $761 \mathrm{~mm}$. The average potential evapotranspiration during the same period was $550 \mathrm{~mm}$, resulting in a negative climatic water balance of $50 \mathrm{~mm}$ (details on recent soil water fluxes at CarboZALF- 
$\mathrm{D}$ can be found in Rieckh et al., 2014). The average annual air temperature at $2 \mathrm{~m}$ height is $8.6{ }^{\circ} \mathrm{C}$, with a minimum and maximum annual temperature of $6.5{ }^{\circ} \mathrm{C}$ and $9.6{ }^{\circ} \mathrm{C}$. Paleoclimatic deviations can be found in Fig. 6 of Sommer et al. (2008).

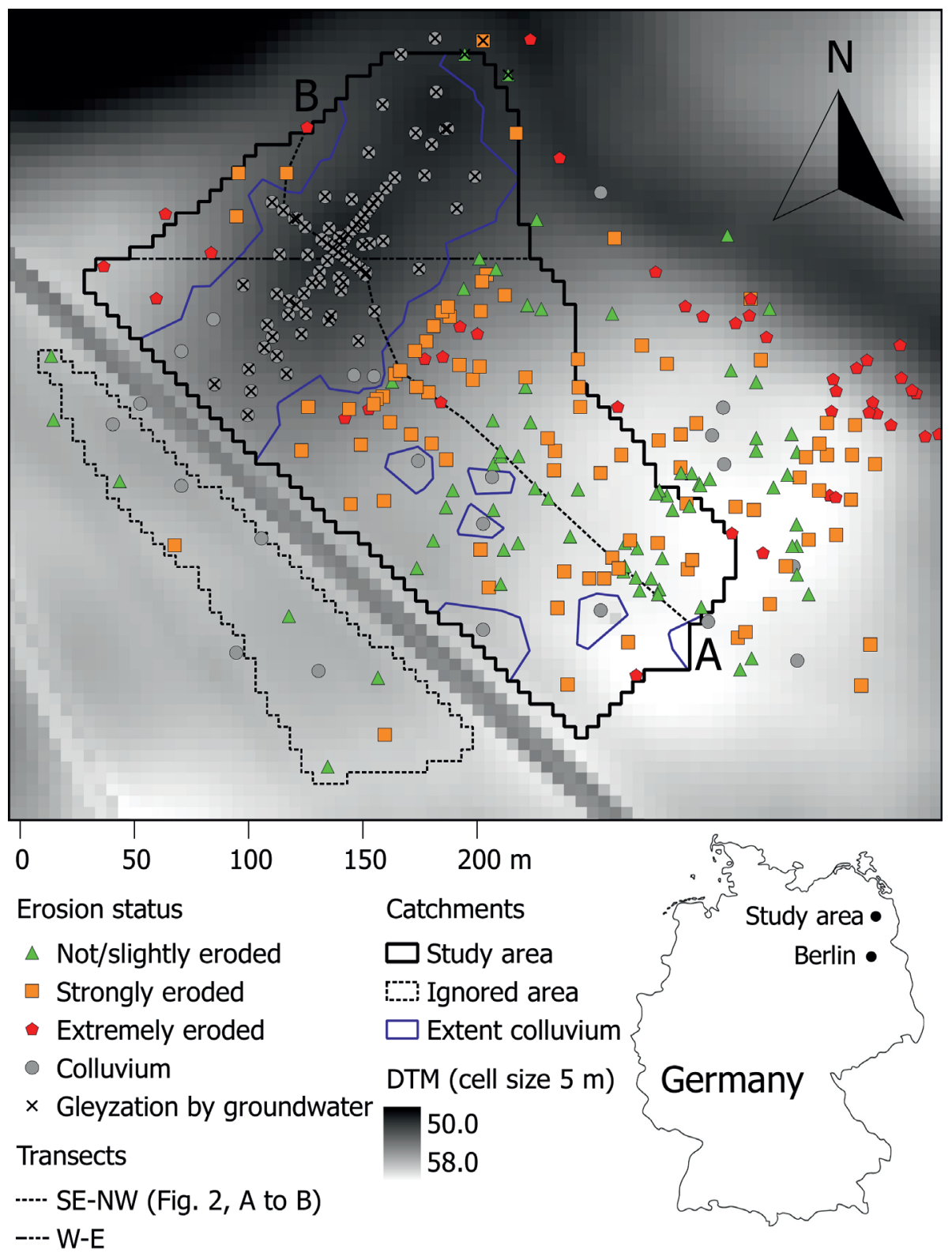

Figure 2.1: Map of the study area, with the different erosion statuses indicated with colored points. 


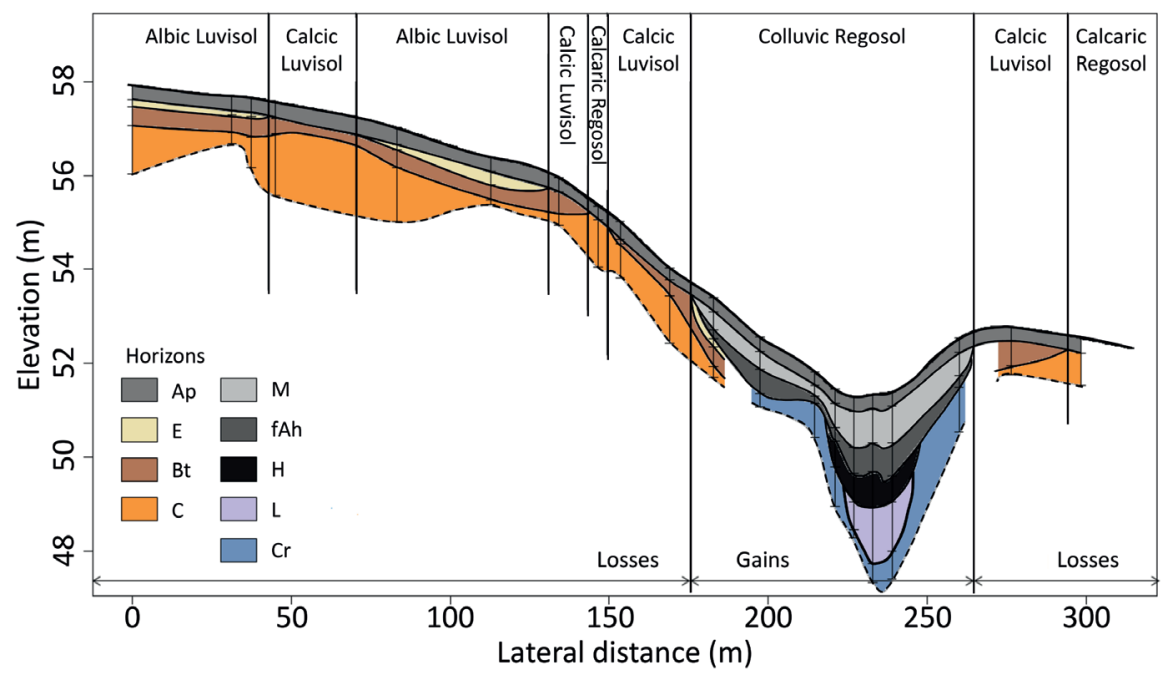

Figure 2.2: Cross-section through the study area (SE-NW, from A to B in Figure 2.1), showing the soil types with different erosion intensities. Below the colluvium (M), the former surface horizon (fAh), a peat layer $(\mathrm{H})$ and periglacial sediments $(\mathrm{L})$ were found. The glacial till below the depression is permanently reduced $(\mathrm{Cr})$. Horizon names are based on the FAO guidelines (FAO, 2006), except for the $M$ horizon, which is derived from the German soil classification system (Ad-hoc-AG Boden, 2005). Vertical exaggeration is 15-fold, for both elevation and horizon thickness. 


\subsection{Methods}

\subsubsection{Approaches}

The extraordinarily rich data position of CarboZALF-D provided the opportunity to test different approaches that use soil descriptions for topography reconstruction. Approaches differ in the amount and extent of required data and assumptions about the properties of the original system (Table 2.1). For every approach, the paleotopography was estimated by subtracting the estimated colluvium thickness from and adding the estimated erosion thickness to the current DTM. Elevation change was converted to a mass using a bulk density of $1.79 \mathrm{~g} \mathrm{~cm}^{-3}$ for in situ soil material $\left(B D_{\text {soil }}\right)$ and $1.73 \mathrm{~g} \mathrm{~m}^{-2}$ for colluvium $\left(B D_{\text {coll }}\right)$. These values were the average observed bulk densities for the respective materials (data not shown), with a significant difference $(\mathrm{p}=0.001)$ between bulk densities of in situ soil material $(n=297)$ and colluvial material $(n=80)$. We used a constant bulk density, due to the absence of a trend in bulk density values with soil depth in the current soils. Every approach used the same estimation of current soil thickness $\left(t h k_{\text {soil }}\right)$ and current colluvium thickness $\left(t h k_{\text {coll }}\right)$, since these estimations were not affected by the assumptions in the different approaches. The methods of constructing $t h k_{\text {soil }}$ and $t h k_{\text {coll }}$ are discussed in the next section. Erosion was assumed absent on places where colluvium was found.

Table 2.1: Overview of the different approaches

\begin{tabular}{l|llll}
\hline Approach & Method & $\begin{array}{l}\text { Redistribution } \\
\text { of sediments }\end{array}$ & Reference soil estimation & $\begin{array}{l}\text { Applied } \\
\text { equations }\end{array}$ \\
\hline 1a & Mass balance & Evenly & No & $\begin{array}{l}(2.1),(2.2), \\
(2.3)\end{array}$ \\
\hline $1 \mathrm{~b}$ & & Variable & No & $(2.1),(2.2)$, \\
& & & & $(2.4)$
\end{tabular}


Approaches 1a and $1 \mathrm{~b}$ aimed at solving the mass balance between erosion and deposition. For every cell $i$ where colluvium was present, the mass of colluvium $M_{\text {coll,i }}(\mathrm{kg})$ was calculated by multiplying the current colluvium thickness $t h k_{\text {coll,i }}(\mathrm{m})$ with the bulk density $B D_{\text {coll }}\left(\mathrm{kg} \mathrm{m}^{-3}\right)$ and surface area of the grid cell area $_{i}\left(\mathrm{~m}^{2}\right)$. The total mass of colluvium $M_{\text {coll }}$ was the sum of mass of all colluvial cells \#cells $s_{\text {coll }}$ (Eq. (2.1)). Elevation change for colluvial positions on a certain row $r$ and column $c$ of the raster $\left(\mathrm{dz}_{\mathrm{coll}, \mathrm{r}, \mathrm{c}}, \mathrm{m}\right)$ is the negative of current colluvium thickness for that location (Eq. (2.2)).

$$
\begin{aligned}
& M_{\text {coll }}=\sum_{i=1}^{\# \text { cells }}{ }_{\text {coll }} \text { thk } k_{\text {coll }, i} * B D_{\text {coll }} * \text { area }_{i} \\
& d z_{\text {coll }, r, c}=-t h k_{c o l l, r, c}
\end{aligned}
$$

For approach 1a, the total mass of colluvium $M_{\text {coll }}$ was evenly redistributed over all cells without colluvium (cells $s_{\text {ero }}$ ), leading to the same elevation change $d z_{\text {ero, }, c}(\mathrm{~m})$ for every noncolluvial position (Eq. (2.3)). This approach does not consider spatial variation in erosion intensity. However, we included it to test the importance of considering spatial variation of erosion intensity during topography reconstruction.

$$
d z_{\text {ero }, r, c}=\frac{M_{\text {coll }}}{\# \text { cellsero } * B D_{\text {soil }} * \text { area }_{i}}
$$

Approach $1 \mathrm{~b}$ required knowledge on current (eroded) soil depths $t h k_{\text {soil }}$. Redistribution of colluvium started on the thinnest, most eroded soils and gradually the redistribution included also thicker, less eroded soils, until the amount of redistributed material equaled the total colluvium $M_{\text {coll }}$ (Eq. (2.4)). The new thickness of the soils which received sediments (soilthick, m) during this process is constant. The thinnest soils thus received the most sediments, while soils thicker than the calibrated soil thickness soilthick did not receive any material at all.

$$
\begin{aligned}
& d z_{\text {ero }, r, c}=\left\{\begin{array}{r}
\text { soilthick }- \text { th } k_{\text {soil }, r, c}, t h k_{\text {soil }, r, c}<\text { soilthick } \\
0, t h k_{\text {soil }, r, c}>\text { soilthick }
\end{array}\right. \\
& \text { with soilthick so that eroded mass=deposited mass }
\end{aligned}
$$

In most settings where soil data is used for reconstructing topography, there is no information on the total amount of deposited sediments. Instead, a non-disturbed soil profile is used to estimate the initial mean soil thickness. Our second group of approaches used this principle. Five different reference soil depths were calculated from soils that we assumed to be undisturbed. These are soils with a standard Luvisol horizon sequence (Ap-E-Bt-Ck), where 
the $\mathrm{E}$ horizon is thicker than $10 \mathrm{~cm}$ and no other disturbances have been recorded $(\mathrm{n}=19)$. The five reference soil depths were the $25^{\text {th }}$ percentile, median, mean, $75^{\text {th }}$ and $90^{\text {th }}$ percentile of the thicknesses of these 19 reference soils (approaches 2a-2e, Table 2.1). For all these approaches, the estimated amount of erosion was the difference between current soil depth thk $k_{\text {soil }}$ and reference soil depth refsoil (m) for all non-colluvial positions (Eq. (2.5)). When the current soil depth exceeded the reference soil depth, the soil was assumed to be noneroded and no elevation change was recorded. On places with colluvium, erosion was also assumed to be absent.

$$
d z_{\text {ero } r, c}=\left\{\begin{array}{r}
\text { refsoil }- \text { th }_{\text {soil }, r, c}, t_{h k_{\text {soill,r,c }}}<\text { refsoil } \\
0, \text { th }_{\text {soil }, r, c} \geq \text { refsoil }
\end{array}\right.
$$

\subsubsection{Data preparation}

The soils were described in $2007-2010$ and 2016, following the German soil classification system (KA5, Ad-hoc-AG Boden, 2005). This system uses similar horizon codes as the standard FAO system (FAO, 2006), but distinguishes colluvial horizons separately as $\mathrm{M}$ horizons (see Tables S2.1 and S2.2 for translation of the KA5 to the FAO classification system). Diagnostic soil horizons were distinguished based on differences between color, morphology, texture and $\mathrm{CaCO}_{3}$ content as determined with $\mathrm{HCl}$. Transitional horizons were simplified to the dominantly occurring horizon in this study. Disturbances during the sampling may have led to uncertainty in the estimation of horizon thicknesses. A gouge auger (used at 169 locations) shows a very narrow soil profile, where transitions between different horizons can be smeared. The dominant material in the auger was used to determine the horizon boundaries. A percussion drill (used at 82 locations) collects a bigger sample, but can leave gaps in the soil core. This was corrected for by shifting lower soil material up to close the gap. Another 13 locations were described in a soil pit, which leaves only very limited uncertainty in the estimation of horizon thickness.

The workflow for estimating and evaluating elevation change is summarized in Figure 2.3, which includes data preparation as described below as well as how different approaches were validated (next section). Leave-one-out cross validation was used for uncertainty quantification, while all data points were considered together for the construction of the final maps. The estimation of semivariograms and interpolations using Ordinary Kriging were done in Rstudio (version 3.3.2), using the gstat package (Pebesma, 2004). 


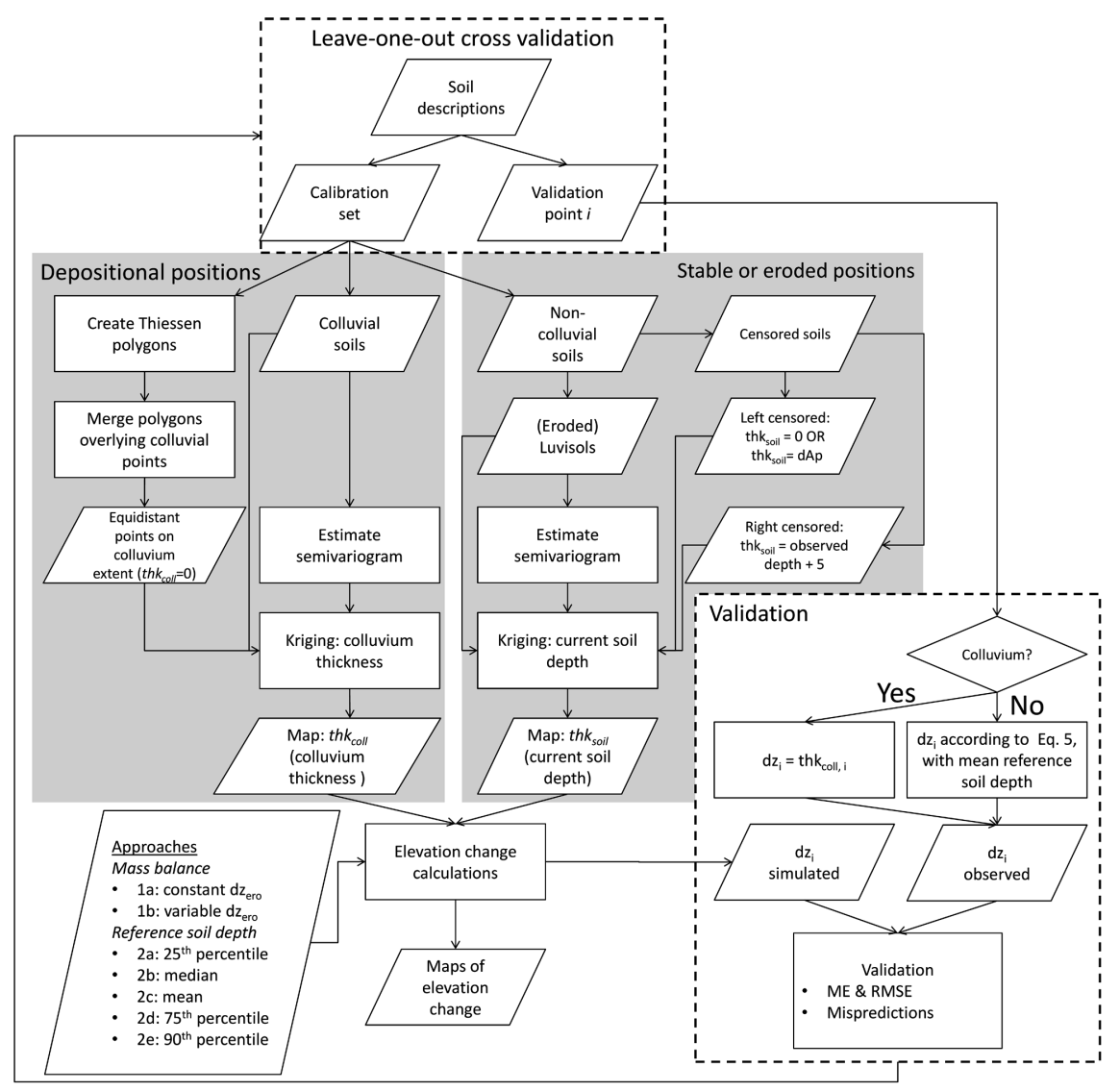

Figure 2.3: Workflow for the data preparation, map production and validation (in dashed boxes) of the steps described in this Section. Trapezoids indicate data or input variables, rectangles indicate processes or calculations and diamonds indicate a choice.

First, an exponential semivariogram was estimated from observed colluvium thicknesses. When working with the cross-validation, the validation point was left out of the estimation of the semivariogram. The boundaries of the lags were set to $5,10,20,40,50,75,100,125$, 150 and $200 \mathrm{~m}$. The extent of colluvium was determined using Thiessen polygons surrounding sampling locations. Polygons which covered multiple colluvial positions were merged (e.g. Figure 2.1). The high density of observations resulted in an average distance from the vertices of the colluvium extent to the first observed colluvial points of $13.2 \pm 4.3 \mathrm{~m}$, leaving little space for uncertainty in the estimation of the extent. Artificial points were created every $20 \mathrm{~m}$ along the outline of the colluvium. These pseudopoints were assigned a 
colluvium thickness of 0 and were used together with the observed points for the interpolation of colluvium thickness $\left(t h k_{c o l l}\right)$, using the earlier defined semivariogram and Ordinary Kriging. This way the colluvium thickness was forced towards zero at the borders of the colluvium, while only the observed spatial autocorrelation of colluvium thickness was considered.

Second, the map of current soil thickness $\left(t h k_{s o i l}\right)$ was created by interpolating observed depths to the calcaric parent material ( $\mathrm{Ck}$ horizon) using Ordinary Kriging with an exponential semivariogram. Also here the validation points were ignored when estimating the semivariograms during cross-validation. The lag sizes were set to the same distances as with the colluvium semivariogram. Assumptions about current soil depth needed to be made in two cases.

First, in very eroded soils where the parent material touches the Ap horizon or the soil surface, it is possible that also an unknown amount of parent material has been eroded. These points, indicated as left-censored data, were not included in the estimation of the semivariogram, to avoid an underestimation of the nugget (the variation at small distances). They were however included in the interpolation, under the assumption that no parent material has been erodedleading to a possible underestimation of erosion. $\mathrm{CaCO}_{3}$ from these eroded positions is only found in low quantities in Ap horizons downslope positions close to the heavily eroded locations, indicating only local redistribution and negligible exchange with the colluvial areas. Therefore, we assumed that this assumption did not have a large effect on the mass balance. It does however affect the estimation of paleotopography on those locations. Current soil depth was set to 0 for soils when the amount of $\mathrm{CaCO}_{3}$ was estimated the same for the $\mathrm{Ap}$ and $\mathrm{Ck}$ horizon $(\mathrm{n}=7)$. If that was not the case, the current soil depth was set at the border of $\mathrm{Ap}$ and $\mathrm{Ck}$ horizon $(\mathrm{n}=15)$.

Second, locations where the parent material was not reached during auguring were indicated as right-censored data. However, these points still contain valuable information concerning the minimum depth of parent material on these locations. When soil thickness was interpolated using only non-censored data, the estimated soil thickness is on average $22.4 \mathrm{~cm}$ thinner than the thickness of the observed right-censored profiles. To correct partly for this underestimation, the right-censored profiles were included in the interpolations under the assumption that parent material is located at $5 \mathrm{~cm}$ below the maximum observed depth. 
Although these assumed soil depths are probably not correct, they do improve the estimated soil thickness on those locations and the information these points contain is not ignored. Right-censored data do not occur in our observations for colluvium thickness.

\subsubsection{Validation}

The different approaches were cross-validated using the leave-one-out approach. 166 locations were suitable for the validation, as they were located inside the catchment and had information on depth to parent material or colluvium thickness. The censored data were not used for validation. The mean deviation (MD, Eq. (2.6)) and root mean squared deviation (RMSD, Eq. (2.7)) were calculated using the estimated $(\hat{y})$ and observed $(y)$ elevation change for all $n$ validation points. The MD indicates a bias, while the RMSD is used for illustrating absolute error differences between approaches. The spread in errors was used to indicate the sensitivity of the methods to input data.

$$
\begin{aligned}
& M D=\frac{1}{n} \sum_{i=1}^{n}\left(\hat{\mathrm{y}}_{i}-y_{i}\right) \\
& R M S D=\sqrt{\frac{1}{n} \sum_{i=1}^{n}\left(\hat{\mathrm{y}}_{i}-y_{i}\right)^{2}}
\end{aligned}
$$

The real elevation change $y$ at colluvial positions is equal to the observed colluvium thickness. However, for eroded locations, it is obviously not possible to measure the real elevation change. Therefore, the observed elevation change of the eroded validation points was calculated by subtracting observed soil thickness from an assumed reference thickness. We used the average undisturbed Luvisol thickness as reference, similar to other topography and erosion reconstruction studies (e.g. Rommens et al., 2005; Świtoniak, 2014). This assumption means that the validation of the different approaches is done using one of the approaches itself (approach 2c). This provides an advantage for the results from that approach. This does however not deliver perfect results due to the variation in the interpolated soil thickness map $t h k_{\text {soil }}$, which is used to select the current soil depth in the model. Simulated elevation change is positive for eroded positions and negative for depositional positions.

Overall, three different landscape positions can be identified in eroding undulating landscapes: i) eroded positions, where material is removed, ii) depositional positions, where material is added and iii) stable or transport positions, where no elevation change has occurred (e.g. Rodzik et al., 2014; Świtoniak et al., 2016). For this study, soils where no E 
horizon was observed were marked as eroded positions, as E horizons are continuously mixed into eroding Ap horizons, leading to removal of the E horizon. Observed non-eroded soils were more difficult to identify, because even when an E horizon was present, it could still have been partly eroded. Pragmatically, we assumed soils with an E horizon thicker than 10 $\mathrm{cm}$ to be non-eroded. This was the same criterion used for calculating the reference soil thicknesses. Soils where colluvium was observed were marked as depositional locations. Discrepancies between an observed and predicted landscape position indicated a misprediction. As an additional validation method, the amount of mispredictions was counted for every approach. Three types of mispredictions were selected:

1. Observed depositional position, while no deposition was simulated,

2. Observed eroded position, while a stable or depositional position was simulated, and

3. Observed stable position, while erosion or deposition was simulated.

\subsubsection{Comparison of methods}

In order to quantitatively make an overall comparison between the different approaches, the RMSD of predicted elevation change and the amount of mispredictions were proportionally normalized between 0 and 1, where 0 was appointed to the highest error and 1 to the lowest error (Eq. (2.8)).

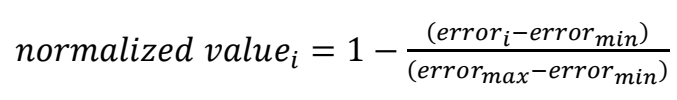

A lower error thus yielded a better performance. The MD of predicted elevation change was not considered, because this error was indirectly incorporated in the RMSD. Only two of the three types of mispredictions contributed to the absolute performance, because one type gave an equal amount of mispredictions for each approach (see Results). In order to give the RMSD the same weight as the mispredictions in the performance, the normalized RMSDs were multiplied by two. The sum of the normalized errors was used as an indicator of performance.

Several DTM derivatives were calculated from all reconstructed DTMs for visual analysis. These include slope (in degrees, Raster package in R, Hijmans, 2016), topographic position index with a window of $25 \mathrm{~m}$ (TPI, Weiss, 2001) and flow accumulation (Flow Accumulation (Top-Down) module in SAGA, with multiple flow direction, $\mathrm{m}^{2}$, Conrad et al., 2015). The natural logarithm of flow accumulation is shown for easier interpretation. 


\subsection{Results}

\subsubsection{Variation and uncertainty in reconstructed topography}

\subsubsection{Current soil and colluvium thickness}

The current thickness of soils in the study area ranges between 0 and $2 \mathrm{~m}$ (Figure 2.4), with an average and standard deviation of $0.74 \pm 0.36 \mathrm{~m}$. The median equals the mean. The peaks of extremely eroded soils at 0 and $30 \mathrm{~cm}$ contain the left-censored data. The peak of non/slightly eroded soils at $1.05 \mathrm{~m}$ contains most of the right-censored data. Current colluvium thickness ranges between 0.3 and $1.8 \mathrm{~m}$, with the highest density of observations around $1 \mathrm{~m}$. The average and standard deviation of colluvium thickness are $0.83 \pm 0.29 \mathrm{~m}$, with again an equal mean and median.

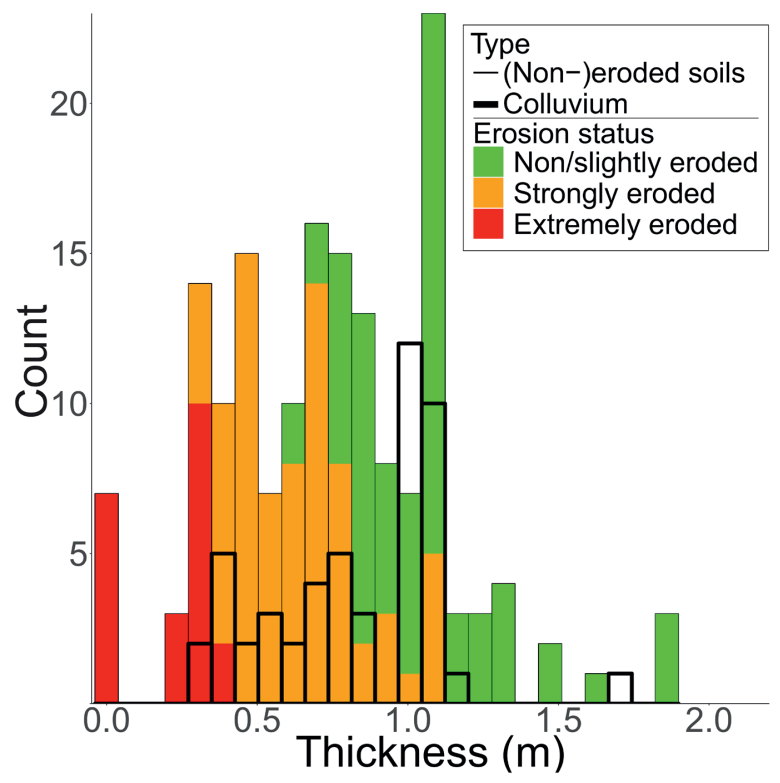

Figure 2.4: Histogram of current soil thickness (thin lines) and colluvium thickness (thick lines). Soil thickness is subdivided in the different erosion statuses (stacked colored bars). See Section 2.2 for the definition of the different erosion statuses 

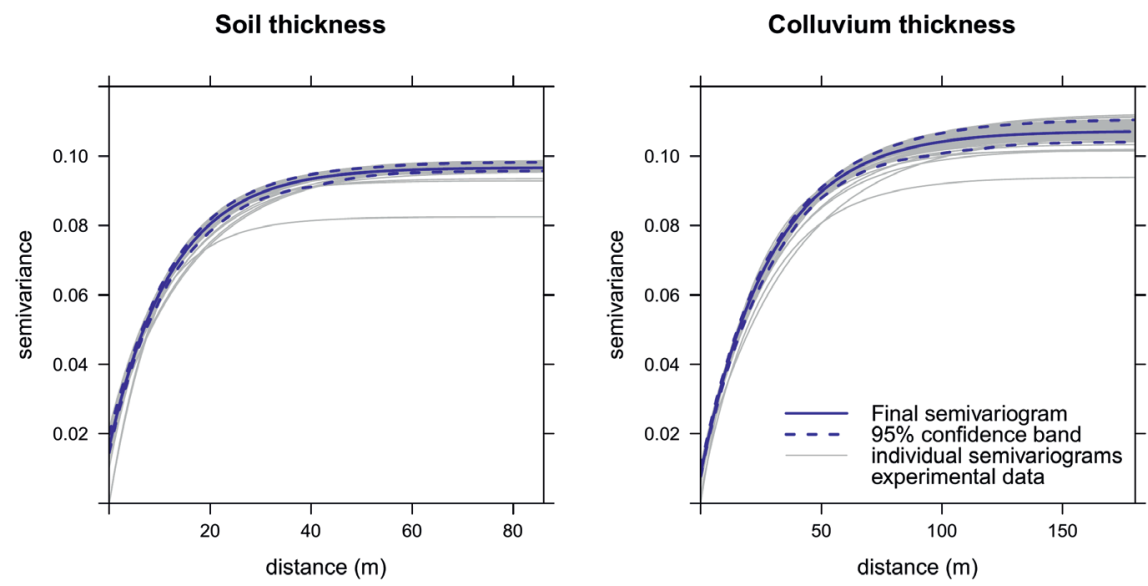

Figure 2.5: Semivariograms estimated from all available data (solid blue lines), with a $95 \%$ confidence band (dashed lines) calculated from the 166 individual semivariograms (grey lines) resulting from the cross-validation, for soil thickness (thksoil) and colluvium thickness (thkcoll). Note that the $\mathrm{x}$-axes have different ranges.

Figure 2.5 shows the semivariograms used to interpolate soil and colluvium thickness. For every cross-validation step, a new semivariogram was calculated, which excluded the validation point. These are presented as the grey lines. The blue dashed lines indicate the $95 \%$ confidence intervals of the semivariograms. The solid blue lines represent the semivariogram calculated from all available data, which was used for interpolation of soil and colluvium thickness (Figure 2.6) for the final topography reconstruction presented in Section 2.4.2. The average and standard deviation of the Kriging standard deviation (Figure 2.6) are $0.26 \pm 0.03$ and $0.18 \pm 0.02 \mathrm{~m}$, for soil and colluvium thickness respectively. For both maps, this is $35 \%$ of the average predicted mean. 


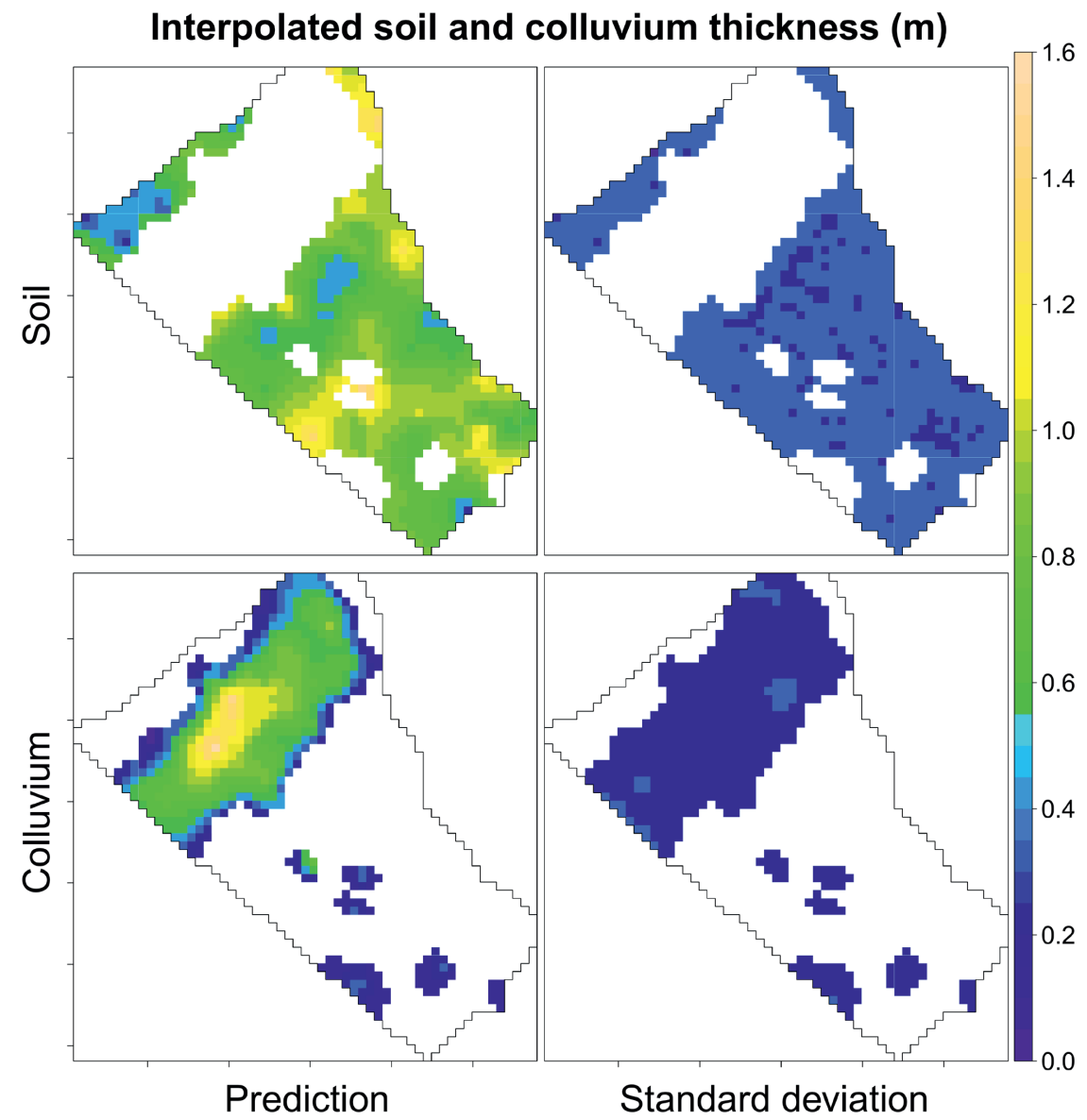

Figure 2.6: Interpolated soil and colluvium thicknesses (m), with corresponding standard deviation. The interpolations are limited by the boundaries of the colluvium.

\subsubsection{Comparison of approaches}

The large spread in reference thicknesses introduced large variation in simulated elevation changes and sediment budgets between packages $2 \mathrm{a}-2 \mathrm{e}$ (Table 2.2). Approaches $2 \mathrm{~d}$ and $2 \mathrm{e}$ show erosion quantities that exceed the deposited mass, while approaches $2 \mathrm{a}-2 \mathrm{c}$ show more deposition (Table 2.2). For approaches $1 \mathrm{a}$ and $1 \mathrm{~b}$ erosion and deposition are equal by definition. The initial soil thickness for which this occurs in approach $1 \mathrm{~b}$ is $1.06 \mathrm{~m}$, which is a bit thinner than the $75^{\text {th }}$ percentile of the reference profile thicknesses $(1.08 \mathrm{~m})$. 
Table 2.2: Eroded mass, average elevation change for eroded positions (dz), difference (diff.) between eroded and deposited mass (14.1 Gg for all approaches), mean deviation (MD) and root mean squared deviation (RMSD) from the cross-validation and calculated soil depths resulting from the different approaches.

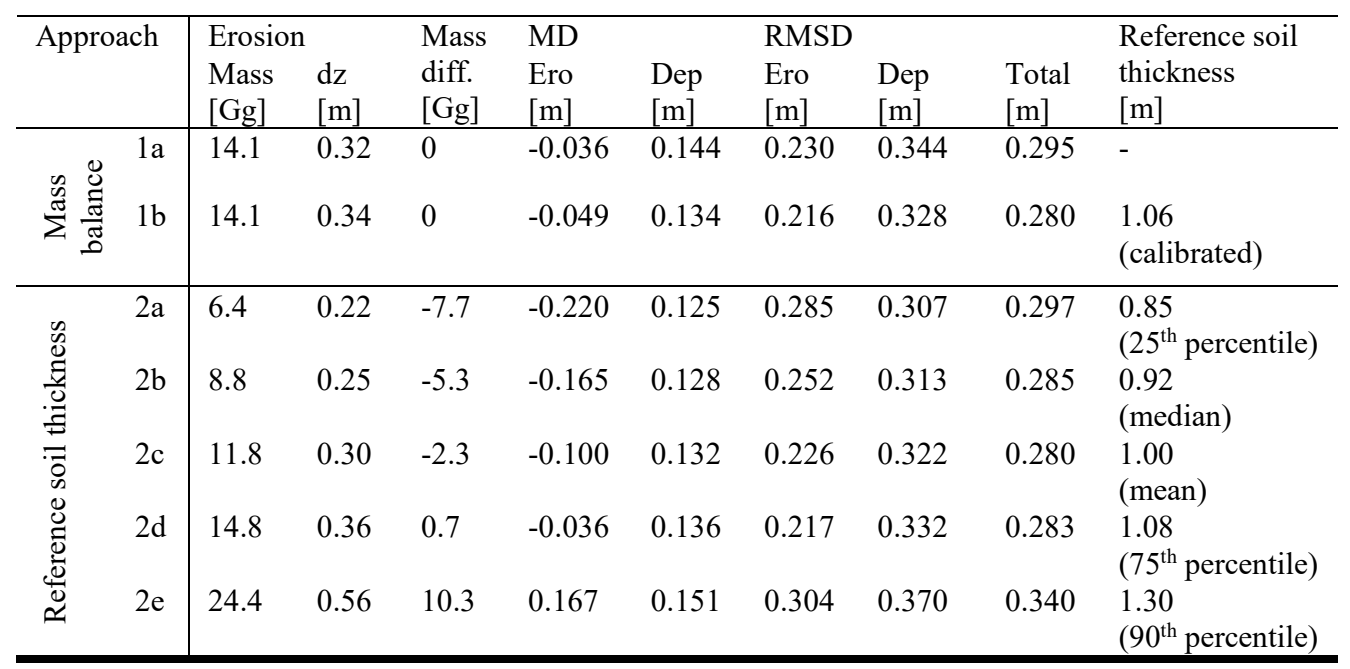

The MD and RMSD of erosion decrease up to approach $2 \mathrm{~d}$, and increase again with approach 2e. The MD and RMSD do not reflect the fact that the actual erosion was estimated using the same approach as $2 \mathrm{c}$ (Section 2.3.3), as the lowest deviations are recorded for approach $1 \mathrm{~b}$ and $2 \mathrm{~d}$. The MD for deposition was positive for each approach, which indicates an underestimation of deposition when considering that elevation change due to deposition was negative. This bias is probably introduced by the inclusion of the pseudopoints with a colluvium thickness of $0 \mathrm{~m}$ on the colluvium borders. The overall RMSE shows that approaches $1 \mathrm{~b}$ and $2 \mathrm{c}$ performed the best, followed by approach $2 \mathrm{~d}$.

Table 2.3: Counts of mispredictions during the cross-validation

\begin{tabular}{ll|ccccccc}
\hline \multicolumn{2}{l|}{ Type of misprediction } & $1 \mathrm{a}$ & $1 \mathrm{~b}$ & $2 \mathrm{a}$ & $2 \mathrm{~b}$ & $2 \mathrm{c}$ & $2 \mathrm{~d}$ & $2 \mathrm{e}$ \\
\hline 1 & Deposition observed, not simulated & 6 & 6 & 6 & 6 & 6 & 6 & 6 \\
2 & $\begin{array}{l}\text { Erosion observed, not simulated } \\
3\end{array}$ & 6 & 8 & 25 & 15 & 11 & 7 & 6 \\
& $\begin{array}{l}\text { Stable position observed, erosion or } \\
\text { deposition simulated }\end{array}$ & 20 & 20 & 8 & 16 & 18 & 20 & 20 \\
\hline
\end{tabular}




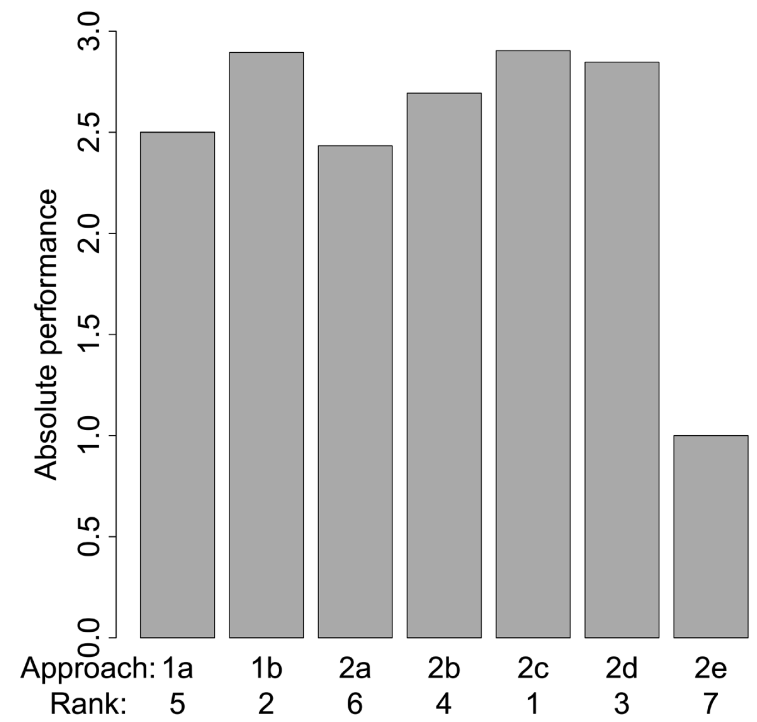

Figure 2.7: Absolute performance (sum of two times the normalized RMSD and the normalized mispredictions) of the different packages. The highest performance corresponds with the lowest uncertainty.

Six locations where deposition was observed were not simulated as depositional positions by all approaches (Table 2.3). Approach 2a made the most mispredictions for locations where erosion was observed, but not simulated (Table 2.3). Approaches using a thicker reference soil depth made fewer mispredictions. Approaches 1a and 2e show the least of this type of misprediction. Up to 20 observed stable positions were simulated as eroded or deposited. Approaches with thinner reference soils made fewer mispredictions.

The absolute performance, which was the sum of the normalized mispredictions type 2 and 3 and two times the normalized total RMSDs, shows that approach $2 \mathrm{c}$ performed best, very closely followed by $1 \mathrm{~b}$ and $2 \mathrm{~d}$ (Figure 2.7, table S2.3). Approaches 1a, 2a and $2 \mathrm{~b}$ had a lower absolute performance, although they were still in the same range. Approach $2 \mathrm{e}$ resulted in a substantially lower performance than the other approaches.

\subsubsection{Reconstructed topography}

The reconstructed DTMs and DTM derivatives all show a rougher topography than the current topography (Figure 2.8, Figure 2.9 and Figure 2.10). Some small depressions appear to have been present or became more pronounced on the hillslope. The effect of the increasing reference soil thickness from approach $2 \mathrm{a}$ to $2 \mathrm{e}$ is well visible in increasing reconstructed 
elevations (Figure 2.8, inset 1). Mainly the reconstructed terrain surrounding the depression shows a rougher topography, with steeper slopes compared to the present situation (Figure 2.8 , inset 2 ). The lines overlap in the main depression, because every approach used the same estimate of colluvium thickness. The ridge position in between the two depressions became more visible on the TPI map after removal of the colluvium (Figure 2.9). The kettle hole is more pronounced on the reconstructed DTMs, as are the smaller depressions on the hillslope. The reconstructed DTMs all show an interruption of flow accumulation halfway the slope due to these hillslope depressions, indicating less connectivity of the total catchment with the central depression in previous times. The maximum flow accumulation $\left(\mathrm{m}^{2}\right)$ in the current situation is two times higher than the average maximum flow accumulation of the reconstructed DTMs. Compared to the current elevation, the reconstructed DTMS contain more high and low elevation values, steeper slopes, more diverse TPI and lower flow accumulation (Figure 2.10). In general, the differences between the reconstructed DTMs are smaller than the difference with the current situation.

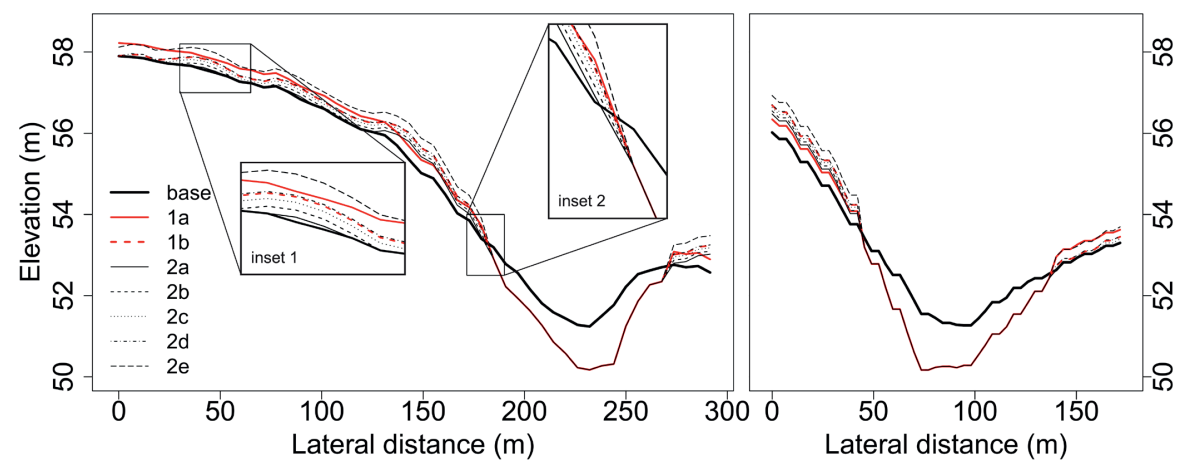

Figure 2.8: Elevation transects of current and reconstructed DTMs, crossing the study area from southeast to northwest and from west to east (see Figure 2.1 for locations). Vertical exaggeration is 20-fold. 
DTM change (m) slope $\left({ }^{\circ}\right)$
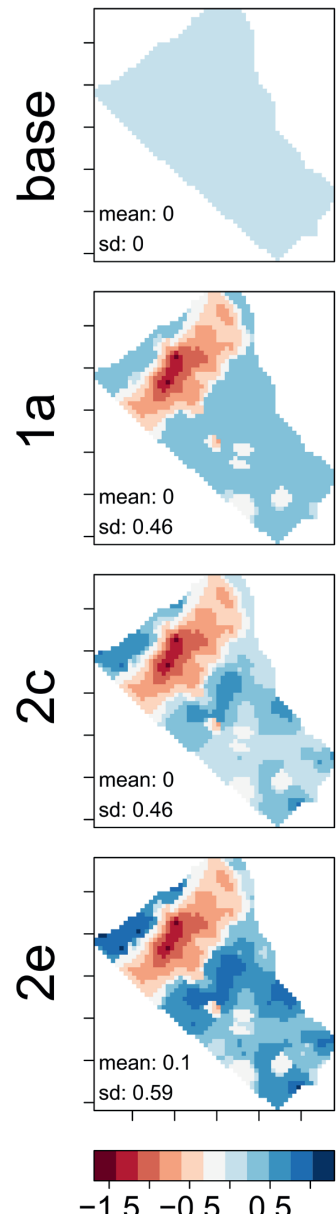

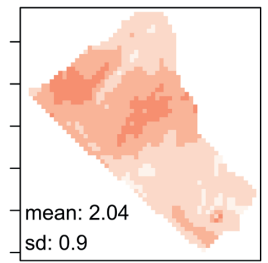

TPI
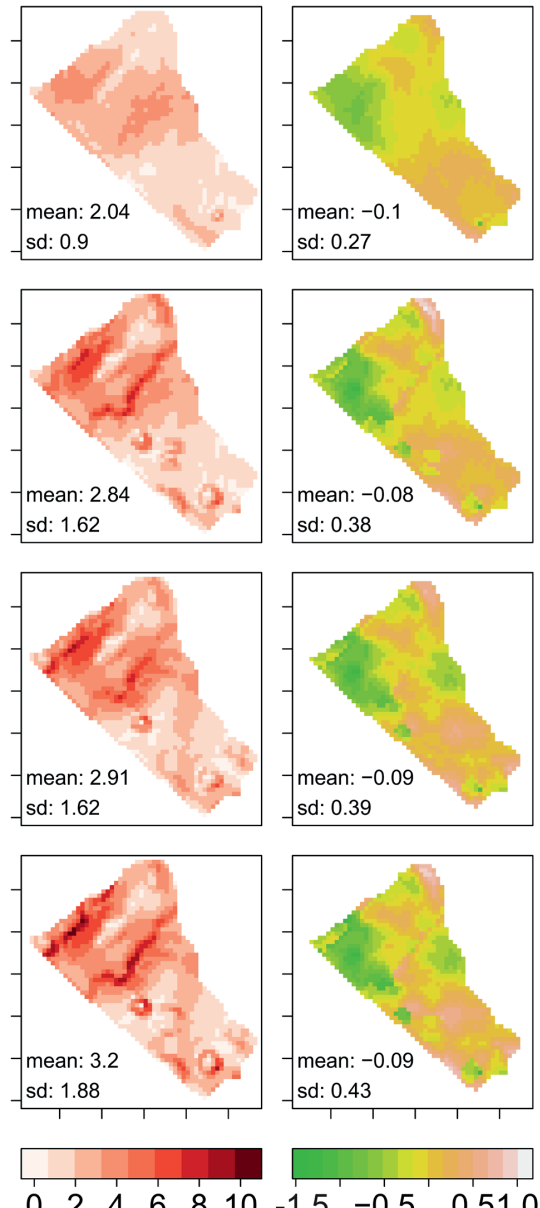
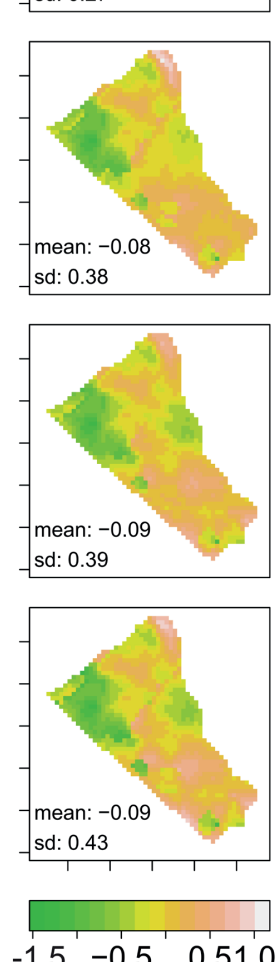

In flow acc
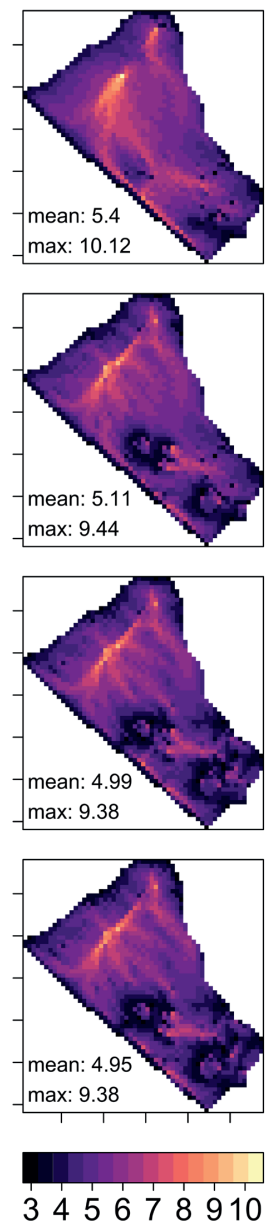

Figure 2.9: Elevation change and DTM derivatives (slope, TPI and the natural logarithm of flow accumulation (In flow acc) of different reconstructed topographies. Several approaches were selected for display. Approach 2c shows the reconstruction with the best performance. Approaches 1a and $2 \mathrm{e}$ were added to show the effects of equal redistribution of sediments (1a) and of a large reference soil thickness (2e) on the reconstructed topography. The current topography (base) is added for comparison. The elevation change and DTM derivatives of all approaches can be found in Supplement 2.2. 

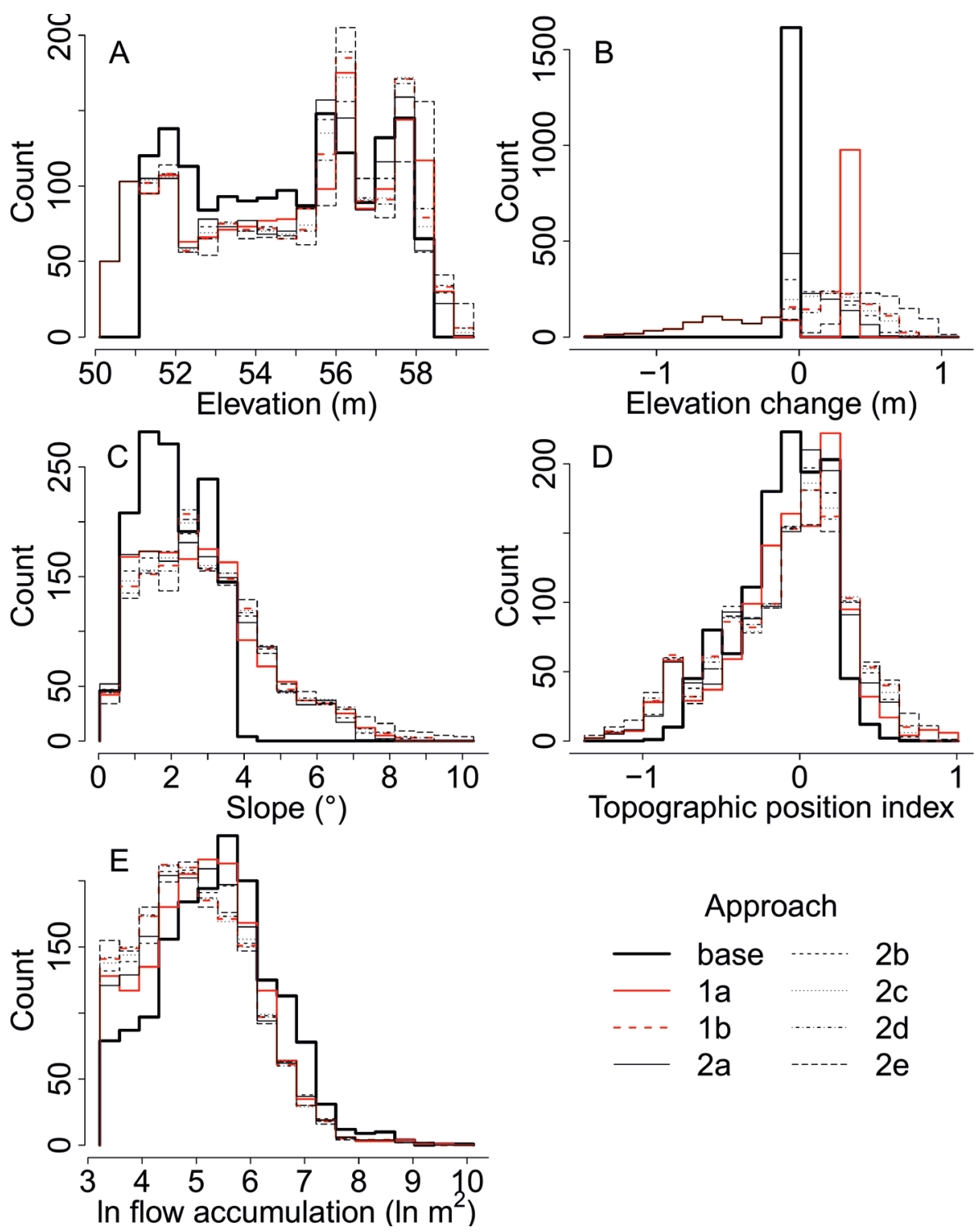

Figure 2.10: Histograms showing the pixel distribution of the (A) reconstructed DTMs, (B) elevation change, and their derivatives (C) slope, (D) topographic position index and (E) the natural logarithm of flow accumulation. 


\subsection{Discussion}

The discussion consists of two parts. First, we discuss how the choice of initial soil thickness, calculated sediment budgets and the changes in topography can be used to improve our understanding of erosion dynamics and current soil and topographic diversity in the hummocky terrain of north-east Germany. Second, several points of attention which were encountered during the reconstruction of the topography are discussed. These include both methodological and practical matters. We list these issues and their effect on reconstructed topographies as a guide for future topography reconstruction efforts.

\subsubsection{Evolution of soil thickness and topography}

\subsubsection{Initial soil thickness}

The variation between the different reconstructed topographies is attributable to the different assumptions made about the initial soil thickness pattern. Approach $2 \mathrm{c}$ shows the highest performance in reconstructing the initial topography. However, the performance of $1 \mathrm{~b}$ and $2 \mathrm{~d}$, which worked with different initial soil thicknesses, yielded comparable performances (Figure 2.7). We attribute this to the fact that uncertainty produced by the assumption of a spatially constant initial soil thickness was more dominant than uncertainty resulting from small deviations from the real average initial constant thickness. The soil thicknesses of these approaches $(1.00-1.08 \mathrm{~m})$ are comparable with the thickness of undisturbed soils in the surrounding Quillow catchment $\left(250 \mathrm{~km}^{2}\right)$, which have a thickness of $1.02 \pm 0.23 \mathrm{~m}(\mathrm{n}=121$, data not shown). In order to understand what order of magnitude and variation can be expected in initial soil thickness in NE Germany, regional and local factors influencing soil thickness, as well as the rate of soil formation, are discussed below.

Most topography reconstruction studies assume a spatially constant initial soil thickness to calculate erosion intensity. The average natural decalcification depth is commonly used as reference soil thickness in settings with calcareous parent material (Rommens et al., 2005; Świtoniak, 2014). We compared different settings, which show a large range in these natural decalcification depths (decimeters to meters, Table 2.4). This variation can be explained by differences in soil forming factors (Jenny, 1941). The selected study sites are all supposed to be undisturbed by erosion, so effects of relief in the form of erosion are negligible for all sites. Next to that, the age of the parent material in all studies is similar, namely deposits from the end of the last Ice Age. That leaves the soil forming factors climate (rainfall and 
Table 2.4: Overview of decalcification depths for studies with differing climatic, topographic, lithogenic and vegetative soil forming factors.

\begin{tabular}{|c|c|c|c|c|c|}
\hline Area & $\begin{array}{l}\text { Nodebais, } \\
\text { Belgium }\end{array}$ & $\begin{array}{l}\text { Kraichgau, } \\
\text { SW Germany }\end{array}$ & $\begin{array}{l}\text { Saskatoon, } \\
\text { Canada }\end{array}$ & $\begin{array}{l}\text { Brodnica } \\
\text { Lake District, } \\
\text { NE Poland }\end{array}$ & $\begin{array}{l}\text { CarboZALF-D, } \\
\text { NE Germany }\end{array}$ \\
\hline Reference & $\begin{array}{l}\text { (Rommens et } \\
\text { al., 2005; } \\
\text { Vanwalleghem } \\
\text { et al., 2010) }\end{array}$ & $\begin{array}{l}\text { (Clemens and } \\
\text { Stahr, 1994; } \\
\text { Kadereit et al., } \\
\text { 2010; Gocke et } \\
\text { al., 2011) }\end{array}$ & $\begin{array}{l}\text { (Pennock, } \\
\text { 2003; } \\
\text { Pennock et } \\
\text { al., 2011) }\end{array}$ & $\begin{array}{l}\text { (Gonet et al., } \\
2010 \text {; } \\
\text { Świtoniak, } \\
2014 \text { ) }\end{array}$ & $\begin{array}{l}\text { (Gerke and } \\
\text { Hierold, 2012), } \\
\text { this study }\end{array}$ \\
\hline Parent material & Loess & Loess & Glacial till & Glacial till & Glacial till \\
\hline Native soil type & $\begin{array}{l}\text { Luvisols, } \\
\text { Retisols }\end{array}$ & Luvisols & Chernozems & Luvisols & Luvisols \\
\hline $\begin{array}{l}\text { Current (native) } \\
\text { vegetation }\end{array}$ & $\begin{array}{l}\text { Deciduous } \\
\text { forest }\end{array}$ & Forest & Prairie grass & $\begin{array}{l}\text { Coniferous } \\
\text { (deciduous) } \\
\text { forest }\end{array}$ & $\begin{array}{l}\text { (Deciduous } \\
\text { forest) }\end{array}$ \\
\hline $\begin{array}{l}\text { Slope range or } \\
\text { mean } \pm \text { sd }\left(^{\circ}\right)\end{array}$ & $<1.7$ & $3.4-5.1$ & $3.4-8.5$ & $0-13$ & $\begin{array}{l}\text { Current: } \\
2.0 \pm 0.9 \\
\text { Past: } 2.9 \pm 1.7\end{array}$ \\
\hline $\begin{array}{l}\text { Yearly rainfall } \\
(\mathrm{mm})\end{array}$ & 800 & $700-780$ & 358 & $500-550$ & 489 \\
\hline $\begin{array}{l}\text { Initial } \mathrm{CaCO}_{3} \\
\text { content }(\%)\end{array}$ & $10-15$ & $30-40$ & $5-15$ & $3-9$ & $10-12$ \\
\hline $\begin{array}{l}\text { Yearly mean } \\
\text { temperature } \\
\left({ }^{\circ} \mathrm{C}\right)\end{array}$ & 9.9 & $8-9$ & 2 & $7-7.5$ & 8.6 \\
\hline Age & Weichselian & $\begin{array}{l}\text { Würm, } \\
30-15 \mathrm{ka}\end{array}$ & $\begin{array}{l}\text { Wisconsin, } \\
18-11 \mathrm{ka}\end{array}$ & $\begin{array}{l}\text { Weichselian, } \\
\sim 17-16 \mathrm{ka}\end{array}$ & $\begin{array}{l}\text { Weichselian, } \\
\sim 13 \mathrm{ka}\end{array}$ \\
\hline $\begin{array}{l}\text { Decalcification } \\
\text { depth }(m)\end{array}$ & $2-3.5$ & $1.0-1.2$ & $0.25-0.67$ & 1.0 & 1.0 \\
\hline
\end{tabular}

temperature), organisms (vegetation) and parent material (glacial till or loess deposits, initial $\mathrm{CaCO}_{3}$ content) to explain the differences in decalcification depth.

The largest differences in decalcification depth seem to be caused by yearly rainfall. Both loess sites have comparable rainfall. However, Nodebais has a much deeper decalcification than Kraichgau. This difference can be explained by the much higher initial $\mathrm{CaCO}_{3}$ content of Kraichgau. The shallowest decalcification is found in Saskatoon, due to the much lower amount of rainfall. Also the much lower temperature could have affected decalcification in Saskatoon by enhancing overland flow over frozen soils, leading to less infiltrating water required for the decalcification. Linear regression suggests that yearly rainfall and initial $\mathrm{CaCO}_{3}$ content explain most of the variation in decalcification depth $\left(\mathrm{R}^{2}=0.84, \mathrm{p}=0.08\right)$. It 
should be noted that the intercept $(p=0.18)$ and coefficient for initial $\mathrm{CaCO}_{3}$ content $(\mathrm{p}=0.11)$ are not significant.

The local, small scale variation in decalcification depth is more difficult to predict than the average initial soil thickness. Decalcification depth only correlates weakly at most with topographic predictors, because random effects such as variation in parent material or bioturbation by treefall disturb the effect of possible large scale topographical drivers on soil formation (Vanwalleghem et al., 2010; Finke et al., 2013).

Soil formation and soil erosion are seen as two distinct episodes of soil development in NE Germany (Sommer et al., 2008). However, when decalcification goes faster than expected, it can affect the estimation of erosion by increasing the soil thickness. With a back-of-theenvelope calculation we demonstrate the rate of decalcification. The $\mathrm{CaCO}_{3}$ content of the parent material at CarboZALF-D is around $12 \%$, with a dissolved inorganic carbon (DIC) leaching rate of $8.5 \mathrm{~g} \mathrm{~m}^{-2} \mathrm{y}^{-1}$ (Gerke and Hierold, 2012; Rieckh et al., 2014) and a soil bulk density of $1.79 \mathrm{~g} \mathrm{~cm}^{-3}$. If we assume all DIC is in the form of $\mathrm{HCO}_{3}^{-}$, and is formed from $\mathrm{CaCO}_{3}$ according to Eq. (2.9), the average decalcification rate is $7.0 \mathrm{~g} \mathrm{~m}^{-2} \mathrm{y}^{-1}$ or $3.2 * 10^{-5} \mathrm{~m} \mathrm{y}^{-1}$.

$$
\mathrm{CaCO}_{3}+\operatorname{soil~} \mathrm{CO}_{2}+\mathrm{H}_{2} \mathrm{O} \rightarrow \mathrm{Ca}^{2+}+2 \mathrm{HCO}_{3}^{-}
$$

When assuming a constant flux over the past century, this rate corresponds to an increased soil thickness of $\sim 3.5 \mathrm{~mm}$ over the period from the construction of the railroad up to the first soil profile descriptions (107 years). A change of this magnitude only affects the estimation of eroded mass slightly (cf. results from approach $1 \mathrm{~b}$ and $2 \mathrm{~d}$, Table 2.2). However, when erosion in former times played a more dominant role than is currently thought (e.g. Dreibrodt et al., 2010), the change in soil thickness can be in the order of centimeters to decimeters, varying with topographic position, which can have substantial influence on the estimation of erosion. Extrapolation of the decalcification rate over the 13.000 years from glacial retreat up to now should have resulted in a soil depth of $0.4 \mathrm{~m}$, which is in the same order of magnitude as the observed undisturbed soil thicknesses.

\subsubsection{Erosion history}

The initially closed kettle hole catchment of CarboZALF-D has been split by the construction of the railroad. We assumed that the area cut off by the railroad did not contribute 
substantially to the colluvium found in the study area. Nevertheless, a non-closing mass balance could have suggested otherwise and be used as indicator of erosion extent before the construction of the railroad. The best performing approach $2 \mathrm{c}$ suggests that the amount of colluvium exceeds the amount of erosion in the current catchment. Approaches $1 \mathrm{~b}$ and $2 \mathrm{~d}$, which performed comparably well, suggested equal erosion and deposition, or a slightly higher eroded mass. The latter can be expected in an unseparated kettle hole catchment, because part of the eroded material is still in transport in the Ap horizons. Nevertheless, our sediment budgets do not obviously point out the extent of colluvium before the construction of the railroad.

A comparison of the sediment budgets and elevation change resulting from this study with a study on recent carbon redistribution in CarboZALF-D does provide insight in the extent of past erosion events. The gross erosion rate in CarboZALF-D since 1954 was estimated to be $4.3 \mathrm{Mg} \mathrm{ha}^{-1} \mathrm{y}^{-1}$, based on ${ }^{137} \mathrm{Cs}$ measurements (Aldana Jague et al., 2016). This is $\sim 0.25 \mathrm{Gg}$ ha $^{-1}$ over the last 60 years, which is 20 times less than the total erosion of $\sim 5 \mathrm{Gg} \mathrm{ha}^{-1}$ simulated in this study. Aldana Jague et al. (2016) estimated the cumulative elevation change over the last 60 years due to erosion and deposition to be $0-0.1 \mathrm{~m}$ and $0-0.27 \mathrm{~m}$ respectively, which is again much lower than the total elevation changes of $0->1 \mathrm{~m}$ for eroded positions and 0 $-1.5 \mathrm{~m}$ for colluvial positions. The relatively small amount of recent soil redistribution indicates that erosion is already going on for a much longer time. When we assume a constant erosion rate, 1200 years of erosion are required to move the total amount of eroded sediments. This age span again contradicts with the age of an oak stem found in the peat just below the colluvium at CarboZALF-D $(1306 \pm 10 \mathrm{CE}$, dated with dendrochronology, data not shown). A future geochronological field campaign will shed more light on land-use history and intensity of past erosion episodes at CarboZALF-D.

\subsubsection{Changes in landforms and landscape functions}

The paleotopography differs in several aspects from the current topography. The most important differences influencing erosion processes are that i) the paleotopography has a much rougher topography with steeper, more convex slopes, and that ii) the plateau and slope positions are less connected to the depression in the paleotopography (flow accumulation in Figure 2.9) due to hillslope depressions (cf. Rodzik et al., 2014). One of the most pronounced features is the steep gradient from a plateau-like structure into the depression (Figure 2.8). 
The currently eroded soils surrounding the depression mark the former slopes of this plateau (Figure 2.1). These slopes were very sensitive to erosion, due to their convexity (De Alba et al., 2004). The plateau is not man-made, as the soils do not indicate any addition of soil material to create this landform. Rather, such a shape may be explained from the genesis of the landform; the melting of blocks of dead ice covered by glacial sediments (Andersson, 1998). The melting of the ice lowered the above-lying sediments and formed the current kettle hole, surrounded by the plateau. The small catchment area and forested vegetation prevented denudation of this plateau by water erosion. We observed similar plateaus surrounding some forested kettle holes $25 \mathrm{~km}$ south of CarboZALF-D. The reconstructed steep edge surrounding the kettle hole may be exaggerated by the assumption that no erosion occurred below the current colluvium, because the reconstruction removes the colluvium, while it adds material directly uphill from the transition. Consequently, this jump increases when a larger initial soil depth is assumed (Figure 2.8). In reality, it is likely that there has been some tillage erosion near the margins of the current colluvium prior to deposition. The eroded material from these positions were the first fillings of the lower parts of the depression, as tilled deposits are primarily redistributed locally and deposited in concave positions (Govers et al., 1996).

Kalettka and Rudat (2006) made a hydrogeomorphic classification of the agricultural kettle holes in north-east Germany. When looking at the reconstructed geomorphic properties of catchment 2c, the kettle hole would be classified as a 'small shallow shore overflow type'. The corresponding hydrologic properties are a periodic to permanent water body, with a tendency to overflow. The peat below the colluvium is a remnant of this former landscape type, which is common for many kettle hole catchments (e.g. Karasiewicz et al., 2014). The hydrological and ecological properties of the kettle hole thus changed significantly due the sediment cover and artificial drainage, as small water bodies harbor a relatively high proportion of e.g. aquatic biodiversity (Davies et al., 2008). On the other hand, the homogenization of the landscape eased agricultural practices for farmers and created more area for crops.

\subsubsection{Changes in erosion processes}

Redistribution of sediments by mainly tillage erosion levelled the topography, while increasing connectivity of the slopes with the central depression by filling depressions (Phong 
and Kumar, 2014) and reducing divergence of water flow by reducing convexity of hillslopes. This suggests that, on the catchment scale, long term tillage paves the way for water erosion processes by increasing hydrologic connectivity. This is in contrast to the micro scale, where a single tillage operation can create a temporarily rougher microrelief, with consequently more water storage in surface depressions (Guzha, 2004). It is unknown whether this feedback is substantial compared to the effect of changing land cover from forest to arable land. Modeling of long term landscape development by water and tillage erosion can improve our mechanistic understanding of spatial and temporal interactions between both types of erosion and land cover change (e.g. Van Oost et al., 2005b; Bouchoms et al., 2017; Vanwalleghem et al., 2017).

\subsubsection{Points of attention during topography reconstruction}

The quality of the reconstructed topography depends on interpolation methods, data availability and data quality. Moreover, human interventions in the landscape could complicate the estimation of sediment budgets. Here we list how these issues can affect the estimation of paleotopography, as guidance for future topography reconstruction efforts.

\subsubsection{Uncertainty from interpolations}

Cross-validation is often used to determine the quality of prediction models. In the case of Ordinary Kriging, this prediction model is the semivariogram estimated from all available data. With leave-one-out cross-validation, one observation is left out of the calibration set and the semivariogram is then used to predict the value at that location with the remaining data (Davis, 1987). For this study, we decided to also exclude the validation point during the estimation of the semivariogram, to make the prediction completely independent from the observation. This means that for every validation point, a unique semivariogram was estimated from the calibration points. The unique semivariograms show a spread that is increasing with distance (Figure 2.5). Exclusion of the validation point during the estimation of the semivariogram can thus yield different results than when using a fixed semivariogram for all interpolations. The kriging weight appointed to a certain observation depends on its distance to the target location, and on the spatial configuration of the data (Webster and Oliver, 2001). The predictions in this study did not differ much due to the variations in the semivariograms, because they mainly depended on observations close by due the high 
observation density. When observation density is lower, observations from further away, and thus the variation in the semivariograms, can start playing a bigger role.

Kriging provides the uncertainty of the predictions in the form of the Kriging variance, or standard deviation (Figure 2.6). The standard deviations are of the same order of magnitude as the lower ranges of the predictions and quite constant in space. For locations where thin soils or colluvium occur, this uncertainty plays a relatively larger role. For strongly to extremely eroded positions, the standard deviation can equal the predicted soil thickness. For very thin colluvium, the standard deviation can reach up to 25 times the predicted thickness. However, this only occurs occasionally in the small hillslope depressions. The Kriging standard deviations $(0.18 \& 0.26 \mathrm{~m})$ are several times larger than the differences in reference thickness of the best performing approaches $(0.08 \mathrm{~cm})$. The uncertainty of the maps used as basis for the reconstruction thus also determines the quality of the reconstructed topography.

\subsubsection{Data availability}

The estimation of paleotopography highly depends on the prediction of current soil and colluvium thickness, as they form the basis of the calculations. The quality of predictions using different kriging methods generally increases with increasing sample size (McBratney and Webster, 1983; Bourennane et al., 2000; Brus and Heuvelink, 2007; Zhu and Lin, 2010; Schmidt et al., 2014). The high data density of CarboZALF-D enabled a good estimation of spatial autocorrelation of soil and colluvium thickness. This estimation gets worse when less data is available. This is illustrated by comparing the standard deviations of the estimated eroded and deposited masses during cross-validation with a random subset of 25,50 and $75 \%$ of the total amount of locations (Table 2.5). The standard deviations increase rapidly with decreasing sample size, indicating that precision decreases with decreasing sample size. The effect of smaller sample size did not show a clear trend in the RMSD of the predictions of elevation change (not shown). This is probably due to the fact that a subset of the data gives a different view on the variation in current soil depth, as some small scale erosion patterns might be overlooked. In an area where a high local variation in soil properties can be expected, such as soil thickness in the hummocky terrain, small scale prediction quality increases with a higher sampling density (Miller et al., 2016). Other data sources, such as aerial photography or DTM (derivatives), can help determine the expected variation in certain soil properties and help establish a suitable sampling scheme to capture the small scale spatial 
variation in soil properties (Schmidt et al., 2014). Moreover, these types of data can be used in other interpolation techniques such as regression kriging.

Table 2.5: Standard deviations (tons) of the estimated eroded and deposited mass during crossvalidation with different Censored data and validation subsets $(25,50,75 \%)$ of the initial dataset $(\mathbf{1 0 0 \%})$. The value between brackets indicates the coefficient of variation (CV, ratio (\%) between standard deviation and mean of the estimated masses).

\begin{tabular}{|c|c|c|c|c|c|c|c|c|}
\hline & $\begin{array}{l}\% \text { of } \\
\text { data }\end{array}$ & $1 \mathrm{a}$ & $1 b$ & $2 a$ & $2 b$ & $2 \mathrm{c}$ & $2 \mathrm{~d}$ & $2 \mathrm{e}$ \\
\hline \multirow{4}{*}{ 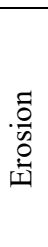 } & 25 & $896(6.9)$ & $896(6.9)$ & $325(12.2)$ & $396(7.8)$ & $452(5.5)$ & $507(4.5)$ & $672(3.2)$ \\
\hline & 50 & $157(1.1)$ & $157(1.1)$ & $345(11.0)$ & $309(5.2)$ & $290(3.1)$ & $284(2.3)$ & $300(1.4)$ \\
\hline & 75 & $86(0.6)$ & $86(0.6)$ & $152(3.7)$ & $143(2.2)$ & $141(1.5)$ & $147(1.2)$ & $181(0.8)$ \\
\hline & 100 & $77(0.5)$ & $77(0.5)$ & $121(1.9)$ & $122(1.4)$ & $124(1.1)$ & $129(0.9)$ & $152(0.6)$ \\
\hline \multirow{4}{*}{ 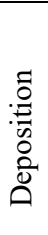 } & 25 & $896(6.9)$ & $896(6.9)$ & $896(33.7)$ & $896(17.6)$ & $896(10.9)$ & $896(8.0)$ & $896(4.3)$ \\
\hline & 50 & $157(1.1)$ & $157(1.1)$ & $157(5.0)$ & $157(2.6)$ & $157(1.7)$ & $157(1.3)$ & $157(0.7)$ \\
\hline & 75 & $86(0.6)$ & $86(0.6)$ & $86(2.1)$ & $86(1.3)$ & $86(0.9)$ & $86(0.7)$ & $86(0.4)$ \\
\hline & 100 & $77(0.5)$ & $77(0.5)$ & $77(1.2)$ & 77 (0.9) & $77(0.7)$ & $77(0.5)$ & $77(0.3)$ \\
\hline
\end{tabular}

Two types of censored data were present in our dataset. These were left-censored data, where it was unknown where the original border of the parent material was (extremely eroded soils) and right-censored data, where this border was deeper than the extent of the soil description. Censored data occur several environmental studies, where they can induce a bias. The inclusion of left- or right-censored data can for example affect kriging estimates, due to an overestimation of sill and underestimation of the range of the semivariogram (De Oliveira, 2012). Several methods have been developed to estimate the real value of censored data. These include maximum likelihood regression analysis to estimate the real value of rightcensored data (used for estimating peat thickness from electrical conductivity measurements, Knotters et al., 1995) or a Markov chain Monte Carlo algorithm with data augmentation to estimate the real values of left-censored data simultaneously with a semivariogram of all available data. This way the estimated real values for the censored data depend on the estimated spatial autocorrelation and vice versa (used for dioxin contamination levels, Fridley and Dixon, 2007). These methods were however not applied in this study. For the 
right-censored data, there was no correlation between current soil thickness and environmental predictors. For the left-censored data, the methodology of Fridley and Dixon (2007) was very complex and therefore outside the scope of this study. The effect of the censored data in this study was minimized by leaving out these values during the estimation of semivariograms and validation. However, bias was introduced by using an assumed value in the interpolations. Nonetheless, exclusion of these points would result in an even larger bias, as the censored data still provide a minimum or maximum for the current soil depths on their locations.

\subsubsection{Local disturbances}

The railroad crossing the catchment complicated the application of a mass balance approach in this project, by separating the originally closed catchment. The construction itself could also have impacted soils in the catchment. The railroad is dug into the ridge it crosses (Figure 2.1). A small part of the material originating from this trench was deposited on the edges of the trench, which is visible on the current DTM. The wide majority of material was probably removed, since there were no traces of the calcareous material in the studied depression or on the surrounding soils. If this material was redistributed over the study area, the estimates of erosion and deposition would be erroneous. It is therefore important to identify these types of human interventions in a landscape before assessing erosion or deposition budgets. Other examples of prehistoric or more recent interventions are former quarries or collapsed mines (Gillijns et al., 2005), construction of burial mounds (Dreibrodt et al., 2009), addition of mineral material as fertilizer (e.g. plaggen soils, Pape, 1970; McFadgen, 1980) or traces of past conflict in the form of bomb craters or defensive structures (Hesse, 2014). 


\subsection{Conclusions}

The hummocky landscape in north-east Germany underwent significant change due to erosion. This study reconstructed the pre-erosion topography (paleotopography) of agricultural kettle hole catchment CarboZALF-D on basis of soil profile descriptions. Different approaches, with different assumptions about the initial soil thickness, were tested. The following conclusions can be drawn from this study:

- The reconstructed topography from the approach which assumed a constant initial depth to the calcareous parent material of $1 \mathrm{~m}$ showed the highest performance. This average thickness of undisturbed soils in the catchment is comparable to the average undisturbed soil thickness of the surrounding region. Moreover, this thickness is in line with a surprisingly strong correlation between natural soil thickness and annual rainfall and initial $\mathrm{CaCO}_{3}$ content.

- However, the assumption of a spatially constant initial soil thickness induced more uncertainty than small variations in the assumed fixed initial soil thickness and dominated the assessment of the quality of the reconstructed topographies. Therefore, more effort should be put in understanding and predicting small scale variation in soil properties like decalcification depth.

- The uncertainty of the reconstructed topographies based on soil descriptions is mainly controlled by:

○ data quality and availability (sampling density, data configuration, amount of censored data),

○ uncertainty from interpolation of current soil and colluvium thickness (Kriging standard deviation),

$\circ \quad$ and the assumptions made about initial soil thickness patterns.

Integrated assessment of the development of soils and topography under changing land use and varying soil forming factors can improve the understanding of erosion processes and current soil diversity. This study provides a good approximation of paleotopography, which can serve as basis of this assessment. 


\subsection{Acknowledgements}

The authors are grateful to G.B.M. Heuvelink for his help with the geo-statistics. We thank the technical staff of ZALF e.V. for their support during the fieldwork and describing of the soil profiles. 


\section{Supplement 2.1 Descriptions of representative soils from CarboZALF-D}

Table S2.1: Soil horizon descriptions of four representative soil profiles for each erosion status, with corresponding soil classification. Horizons are described with the German system (KA5, Adhoc-AG Boden, 2005) and the international FAO system (FAO, 2006). For soil horizon properties, see Table S2.

\begin{tabular}{|c|c|c|c|}
\hline \multirow{2}{*}{\multicolumn{2}{|c|}{$\begin{array}{l}\text { Horizons } \\
\text { KA5 } \quad \text { FAO } \\
\text { Non/slightly eroded }\end{array}$}} & \multicolumn{2}{|c|}{$\begin{array}{l}\text { Depth Description } \\
{[\mathrm{cm}]}\end{array}$} \\
\hline & & \multicolumn{2}{|r|}{ (Albic Luvisol (Cutanic), LP4), from glacial till at flat summit $(2 \%, 58 \mathrm{~m}$ asl) } \\
\hline Al & E & -45 & Sandy loam (SL), 10 YR 6/3 + 5/4, weak subangular blocky \\
\hline $\mathrm{Bt}+\mathrm{Al}$ & $\mathrm{Bt} / \mathrm{E}$ & -62 & $\begin{array}{l}\text { Loam (L), } 10 \text { YR } 6 / 3+4 / 4 \text {, angular blocky, very few redox concentrations } \\
\text { (concretions) }\end{array}$ \\
\hline $\mathrm{Sd}-\mathrm{Bt}$ & Btg1 & -90 & $\begin{array}{l}\text { Loam (L), 10YR 4/4, prismatic to angular blocky, redox concentrations } \\
\text { (concretions) }\end{array}$ \\
\hline Sd-Bvt & Btg2 & -135 & $\begin{array}{l}\text { Sandy loam (SL), 10YR 4/6, weak angular blocky, redox concentrations (masses } \\
\text { and concretions) }\end{array}$ \\
\hline Sd-elCcv & $\mathrm{CBkg}$ & -200 & $\begin{array}{l}\text { Sandy loam (SL), } 10 \mathrm{YR} 6 / 4 \text {, coherent (in part layered), secondary carbonates } \\
\text { (crack surfaces, veins), redox depletions (veins) and few redox concentrations } \\
\text { (concretions) }\end{array}$ \\
\hline \multicolumn{2}{|c|}{ Strongly eroded } & \multicolumn{2}{|r|}{ (Calcic Luvisol (Cutanic), LP11N), from glacial till at NW-facing long slope $(6 \%, 54 \mathrm{~m}$ asl) } \\
\hline Ap & Ap & $0-31$ & Sandy loam (SL), 10YR 4/3, cloddy \\
\hline Sd-Bt & Btg & -70 & Sandy loam (SL), 10YR 4/4, angular blocky, redox concentrations (concretions) \\
\hline Sd-elCcv & $\mathrm{CBkg}$ & -105 & $\begin{array}{l}\text { Sandy loam (SL), } 10 \mathrm{YR} 6 / 4 \text {, coherent, secondary carbonates, (veins), redox } \\
\text { concentrations (concretions) }\end{array}$ \\
\hline elCv-Scd & BCkg & -175 & $\begin{array}{l}\text { Sandy loam (SL), 10YR 6/4 }+6 / 2 \text {, coherent, secondary carbonates, (veins), redox } \\
\text { concentrations (masses, concretions) and depletions }\end{array}$ \\
\hline II elCv-Scd & $2 \mathrm{BCkg}$ & -200 & $\begin{array}{l}\text { Silt loam (SiL), } 10 \text { YR } 5 / 4+6 / 3 \text {, coherent, secondary carbonates, (veins), redox } \\
\text { concentrations (masses) and depletions }\end{array}$ \\
\hline \multicolumn{2}{|c|}{ Extremely eroded } & \multicolumn{2}{|r|}{$\begin{array}{l}\text { (Calcaric Regosol (Densic), LP7O), from glacial till at NE-facing short slope }(13 \%, 54 \mathrm{~m} \\
\text { asl) }\end{array}$} \\
\hline eAp1 & Ap1 & $0-15$ & Sandy loam (SL), 10YR 4/3, cloddy \\
\hline eAp2 & Ap2 & -26 & Sandy loam (SL), 10 YR 4/3, cloddy \\
\hline sGo-elCcv & CBkl & -48 & $\begin{array}{l}\text { Sandy loam (SL), 10YR 5/4, coherent (layered, cracks), secondary carbonates } \\
\text { (veins), redox concentrations (masses at crack surfaces }>\text { concretions) }\end{array}$ \\
\hline esGco & Bk11 & -85 & $\begin{array}{l}\text { Sandy loam (SL), 10YR 5/4, coherent (cracks), secondary carbonates (veins), } \\
\text { redox concentrations (masses at crack surfaces }>\text { concretions) }\end{array}$ \\
\hline esGcro & $\mathrm{Bk} 12$ & -200 & $\begin{array}{l}\text { Sandy loam (SL), few sandy veins, } 10 \mathrm{YR} 6 / 3+5 / 6+7.5 \mathrm{YR} 4 / 6 \text {, coherent (few } \\
\text { cracks), secondary carbonates (veins), redox concentrations (masses > } \\
\text { concretions) and depletions }\end{array}$ \\
\hline \multicolumn{2}{|c|}{ Colluvial soil } & \multicolumn{2}{|r|}{$\begin{array}{l}\text { (Endogleyic Colluvic Regosol (Arenic), LP10N), from colluvium over peat at depression } \\
(3 \%, 52 \mathrm{~m} \text { asl) }\end{array}$} \\
\hline Ap & Ap & $0-30$ & Sandy loam (SL), 10YR 4/2, cloddy \\
\hline Go-M & Alb & -60 & $\begin{array}{l}\text { Sandy loam (SL), } 10 \text { YR } 5 / 3 \text {, weak subangular blocky, few redox concentrations } \\
\text { (concretions) }\end{array}$ \\
\hline M-Gro & BAlb & -85 & $\begin{array}{l}\text { Sandy loam (SL), } 10 \mathrm{YR} 5 / 2 \text {, weak subangular blocky, redox concentrations } \\
\text { (concretions) and depletions }\end{array}$ \\
\hline M-Gor & BArb & -112 & $\begin{array}{l}\text { Loam (L), } 10 \text { YR } 5 / 1 \text {, weak subangular blocky, reduced matrix, few redox } \\
\text { concentrations (masses) }\end{array}$ \\
\hline Gr & $\mathrm{Br}$ & -146 & $\begin{array}{l}\text { Sandy loam (SL), } 10 \text { YR 4/1, weak subangular blocky, reduced matrix, few redox } \\
\text { concentrations (concretions) }\end{array}$ \\
\hline $\mathrm{fHr}$ & $2 \mathrm{Hr}$ & -148 & Peat, 10YR 2/2, platy \\
\hline $\mathrm{jfHr}$ & 3Har & -162 & Highly decomposed peat, 10YR 3/1, anthropogenic disturbed \\
\hline $\mathrm{fHr}$ & $4 \mathrm{H}$ & -220 & Peat, 10 YR $2 / 1$ \\
\hline $\mathrm{fFr}$ & $5 \mathrm{Lr}$ & -240 & Limnic deposit, silt (Si) \\
\hline
\end{tabular}


Table S2.2: Soil horizon properties of the four representative soil profiles introduced in Table S1.

Horizons are described with the German system (KA5, Ad-hoc-AG Boden, 2005) and the international FAO system (FAO, 2006).

\begin{tabular}{|c|c|c|c|c|c|c|c|c|c|}
\hline \multicolumn{2}{|l|}{ Horizons } & \multirow{2}{*}{$\begin{array}{l}\text { Depth } \\
{[\mathrm{cm}]}\end{array}$} & \multirow{2}{*}{$\begin{array}{l}\text { Bulk density } \\
{\left[\mathrm{g} \mathrm{cm}^{-3}\right]}\end{array}$} & \multirow{2}{*}{$\begin{array}{l}>2 \mathrm{~mm} \\
\text { [wt.\%] }\end{array}$} & \multicolumn{3}{|c|}{ fine earth fractions [wt.\%] } & \multirow{2}{*}{$\begin{array}{l}\mathrm{CaCO}_{3} \\
{\left[\mathrm{~g} \mathrm{~kg}^{-1}\right]}\end{array}$} & \multirow{2}{*}{$\begin{array}{l}\mathrm{SOC} \\
{\left[\mathrm{g} \mathrm{kg}^{-1}\right]}\end{array}$} \\
\hline KA5 & FAO & & & & sand & silt & clay & & \\
\hline \multicolumn{2}{|c|}{ Non/slightly eroded } & \multicolumn{8}{|c|}{ (Albic Luvisol (Cutanic), LP4), from glacial till at flat summit ( $2 \%, 58 \mathrm{~m}$ asl) } \\
\hline Ap & Ap & $0-31$ & 1.76 & 3 & 59 & 32 & 9 & 0 & 7.8 \\
\hline $\mathrm{Al}$ & $\mathrm{E}$ & -45 & 1.79 & 2 & 51 & 39 & 10 & 0 & 3 \\
\hline $\mathrm{Bt}+\mathrm{Al}$ & $\mathrm{Bt} / \mathrm{E}$ & -62 & 1.67 & 4 & 49 & 35 & 16 & 0 & 3 \\
\hline Sd-Bt & Btg1 & -90 & 1.76 & 2 & 50 & 31 & 19 & 0 & 2.9 \\
\hline Sd-Bvt & Btg2 & -135 & 1.73 & 2 & 54 & 30 & 16 & 0 & 2.6 \\
\hline Sd-elCcv & CBkg & -200 & 1.79 & 3 & 53 & 34 & 13 & 122 & 0.4 \\
\hline \multicolumn{2}{|c|}{ Strongly eroded } & \multicolumn{8}{|c|}{$\begin{array}{l}\text { (Calcic Luvisol (Cutanic), LP11N), from glacial till at NW-facing long slope }(6 \%, 54 \mathrm{~m} \\
\text { asl) }\end{array}$} \\
\hline Ap & Ap & $0-31$ & 1.66 & 3 & 59 & 28 & 13 & 0 & 8.2 \\
\hline Sd-Bt & Btg & -70 & 1.74 & 3 & 55 & 27 & 19 & 0 & 4.4 \\
\hline Sd-elCcv & $\mathrm{CBkg}$ & -105 & 1.79 & 4 & 59 & 26 & 15 & 88 & 1.5 \\
\hline elCv-Scd & BCkg & -175 & 1.87 & 4 & 61 & 26 & 13 & 111 & 1.3 \\
\hline IIelCv-Scd & $2 \mathrm{BCkg}$ & -200 & 1.82 & 1 & 23 & 51 & 25 & 164 & 2.3 \\
\hline \multicolumn{2}{|c|}{ Extremely eroded } & \multicolumn{8}{|c|}{$\begin{array}{l}\text { (Calcaric Regosol (Densic), LP7O), from glacial till at NE-facing short slope }(13 \%, 54 \mathrm{~m} \\
\text { asl) }\end{array}$} \\
\hline eAp1 & Ap1 & $0-15$ & 1.73 & 4 & 60 & 28 & 12 & 101 & 4.7 \\
\hline eAp2 & Ap2 & -26 & 1.55 & 5 & 60 & 28 & 11 & 98 & 5.4 \\
\hline sGo-elCcv & CBkl & -48 & 1.66 & 4 & 61 & 27 & 12 & 117 & 1 \\
\hline esGco & Bkl1 & -85 & 1.86 & 3 & 61 & 27 & 12 & 117 & 0.2 \\
\hline esGcro & Bk12 & -200 & 1.84 & 4 & 61 & 26 & 13 & 118 & 0.3 \\
\hline \multicolumn{2}{|c|}{ Colluvial soil } & \multicolumn{8}{|c|}{$\begin{array}{l}\text { (Endogleyic Colluvic Regosol (Arenic), LP10N), from colluvium over peat at closed } \\
\text { depression }(3 \%, 52 \mathrm{~m} \text { asl) }\end{array}$} \\
\hline Ap & Ap & $0-30$ & 1.59 & 2 & 61 & 28 & 11 & 0 & 10.8 \\
\hline Go-M & Alb & -60 & 1.68 & 2 & 59 & 31 & 10 & 0 & 6.6 \\
\hline M-Gro & BAlb & -85 & 1.67 & 3 & 60 & 31 & 9 & 0 & 5.8 \\
\hline M-Gor & BArb & -112 & 1.41 & 1 & 47 & 40 & 13 & 0 & 10.4 \\
\hline $\mathrm{Gr}$ & $\mathrm{Br}$ & -146 & 1.74 & 2 & 56 & 34 & 10 & 0 & 5.7 \\
\hline $\mathrm{fHr}$ & $2 \mathrm{Hr}$ & -148 & 0.69 & 0 & - & - & - & 0 & 463 \\
\hline jfHr & $3 \mathrm{Har}$ & -162 & 0.69 & 14 & - & - & - & 0 & 140 \\
\hline $\mathrm{fHr}$ & $4 \mathrm{H}$ & -220 & 0.4 & 1 & - & - & - & 0 & 447 \\
\hline $\mathrm{fFr}$ & $5 \mathrm{Lr}$ & -240 & 0.23 & 0 & 7 & 86 & 7 & 0 & 44 \\
\hline
\end{tabular}




\section{Supplement 2.2 Supplementary results}

Table S2.3: Normalization (norm.) of the total RMSD and mispredictions. 1 indicates the lowest uncertainty and best score, while 0 represents the highest uncertainty and lowest score. The absolute performance was calculated by summing the individual normalized values, where the normalized RMSD is counted twice.

\begin{tabular}{|c|c|c|c|c|c|c|c|c|c|c|}
\hline \multirow{3}{*}{ package } & \multicolumn{8}{|c|}{ mispredictions (see Table 2.3 for descriptions) } & \multirow{2}{*}{\multicolumn{2}{|c|}{$\begin{array}{c}\text { Absolute } \\
\text { performance }\end{array}$}} \\
\hline & \multicolumn{2}{|c|}{ total RMSD } & \multicolumn{2}{|l|}{ Type 1} & \multicolumn{2}{|c|}{ Type 2} & \multicolumn{2}{|l|}{ Type 3} & & \\
\hline & Value & Norm. & Number & Norm. & Number & Norm. & Number & Norm. & Total & order \\
\hline $1 \mathrm{a}$ & 0.295 & 0.75 & 6 & 0.00 & 6 & 1.00 & 20 & 0.00 & 2.50 & 5 \\
\hline $1 b$ & 0.28 & 1.00 & 6 & 0.00 & 8 & 0.89 & 20 & 0.00 & 2.89 & 2 \\
\hline $2 \mathrm{a}$ & 0.297 & 0.72 & 6 & 0.00 & 25 & 0.00 & 8 & 1.00 & 2.43 & 6 \\
\hline $2 b$ & 0.285 & 0.92 & 6 & 0.00 & 15 & 0.53 & 16 & 0.33 & 2.69 & 4 \\
\hline $2 c$ & 0.28 & 1.00 & 6 & 0.00 & 11 & 0.74 & 18 & 0.17 & 2.90 & 1 \\
\hline $2 d$ & 0.283 & 0.95 & 6 & 0.00 & 7 & 0.95 & 20 & 0.00 & 2.85 & 3 \\
\hline $2 \mathrm{e}$ & 0.34 & 0.00 & 6 & 0.00 & 6 & 1.00 & 20 & 0.00 & 1.00 & 7 \\
\hline
\end{tabular}



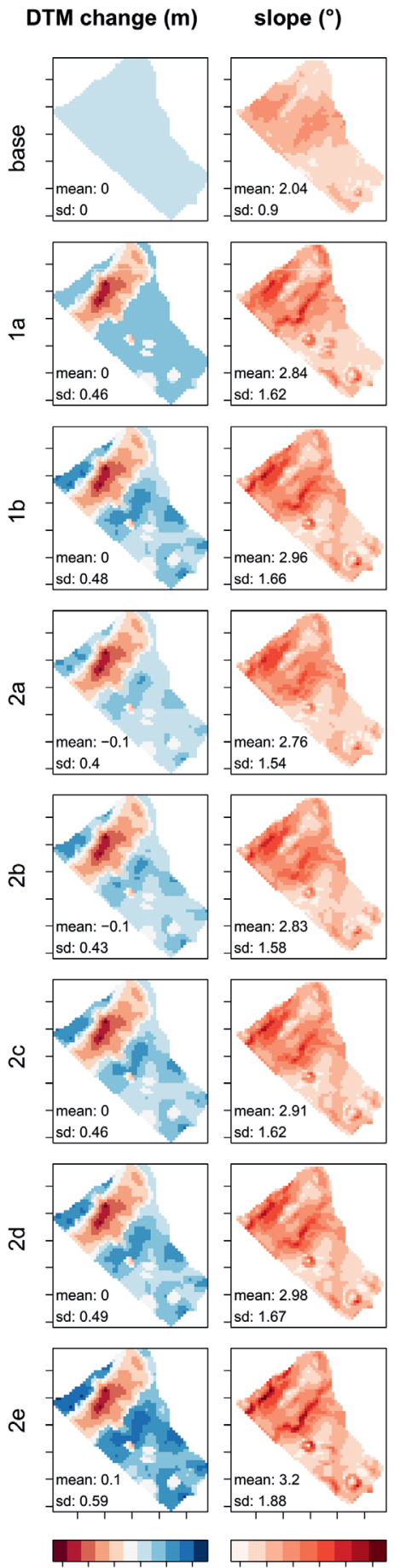

$\begin{array}{llllll}1.5 & -1.0 & -0.5 & 0.0 & 0.5 & 1.0\end{array}$ slope $\left({ }^{\circ}\right)$
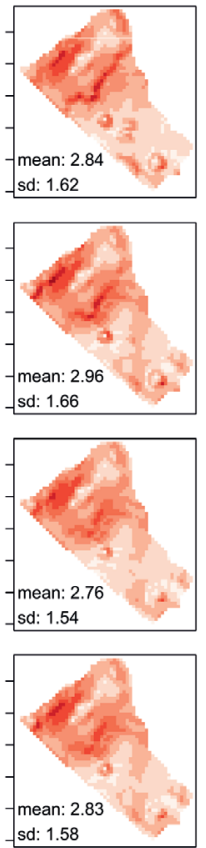

TPI
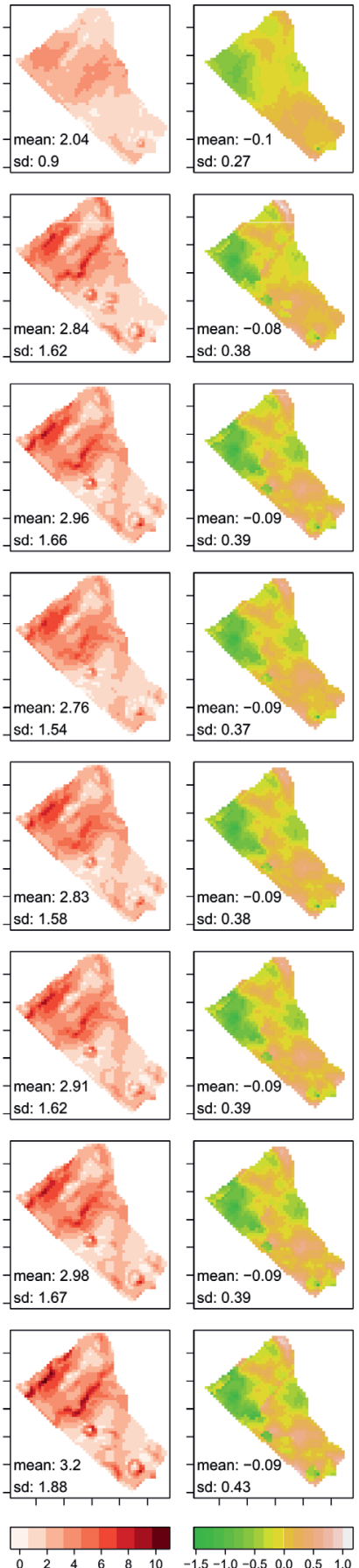

In flow acc
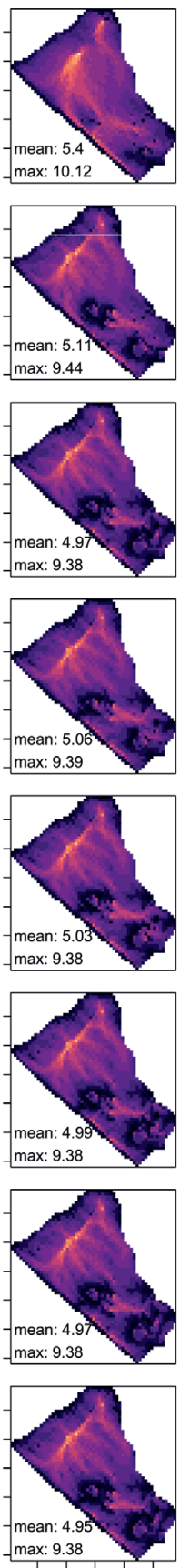

Figure S2.1: Elevation change and DTM derivatives of all the reconstructed topographies. 


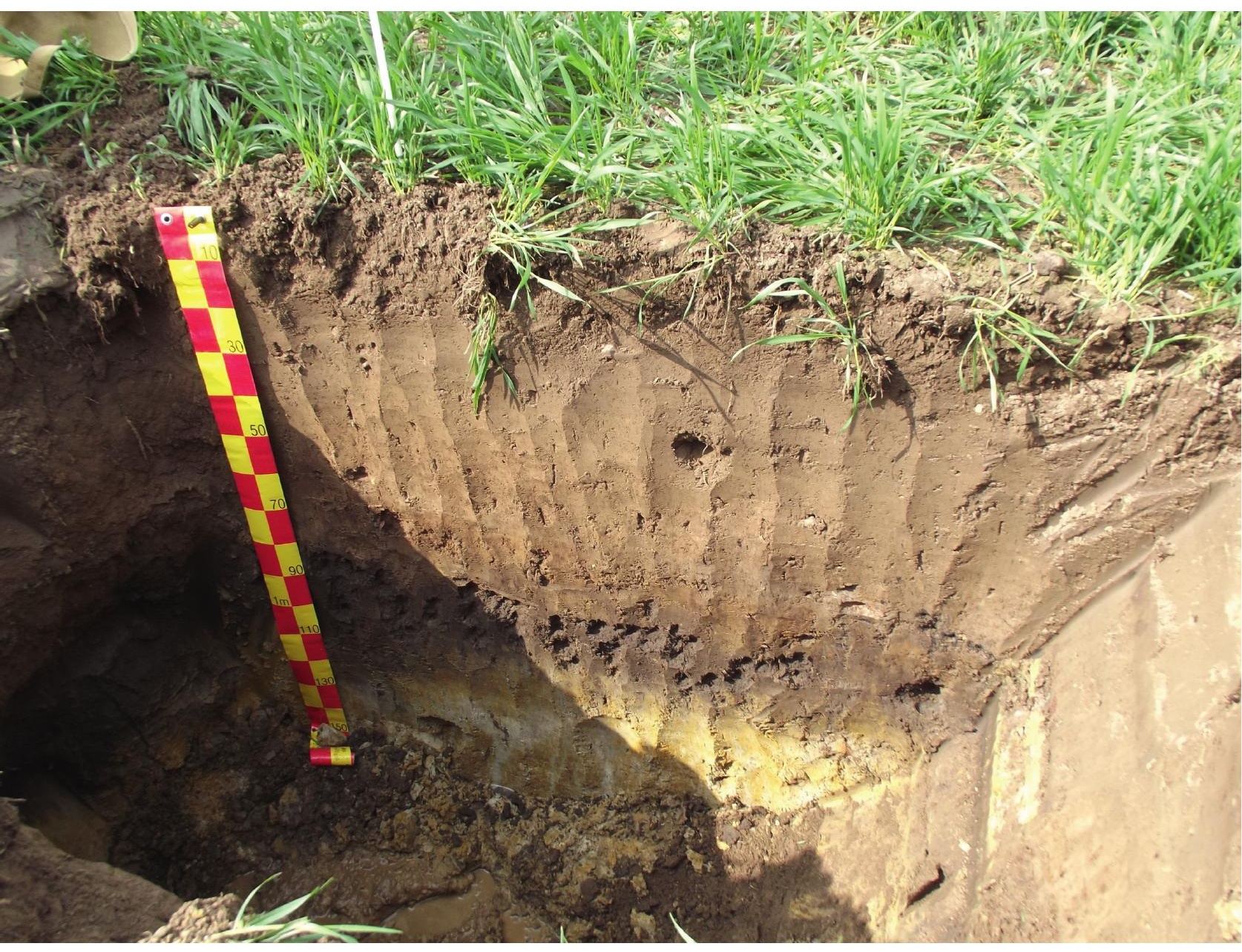


Chapter 3. Reconstructing rates and patterns of colluvial soil redistribution in agrarian (hummocky) landscapes

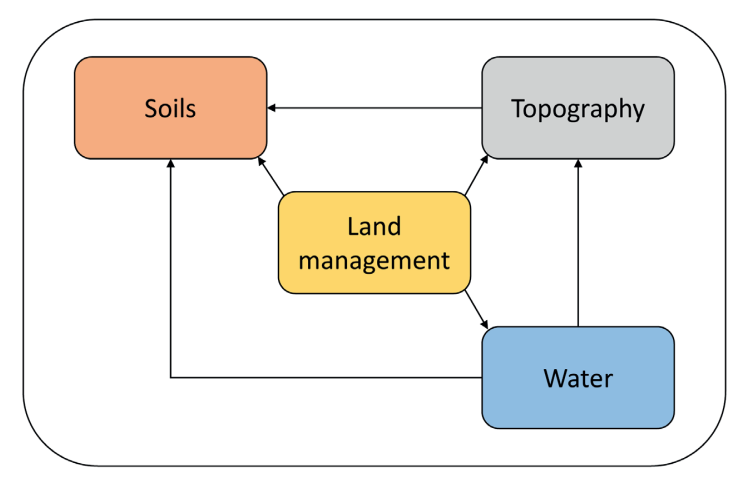




\begin{abstract}
Humans triggered or accelerated erosion processes since prehistoric times through agricultural practices. Optically Stimulated Luminescence (OSL) is widely used to quantify phases and rates of the corresponding landscape change, by measuring the last moment of daylight exposure of sediments. However, natural and anthropogenic mixing processes, such as bioturbation and tillage, complicate the use of OSL as grains of different depositional ages become mixed, and grains become exposed to light even long after the depositional event of interest. Instead, OSL determines the stabilization age, indicating when sediments were buried below the active mixing zone. These stabilization ages can cause systematic underestimation when calculating deposition rates. Our focus is on colluvial deposition in a kettle hole in the Uckermark region, northeastern Germany. We took 32 samples from five locations in the colluvium filling the kettle hole to study both spatial and temporal patterns in colluviation. We combined OSL dating with advanced age modeling to determine the stabilization age of colluvial sediments. These ages were combined with an archeological reconstruction of historical ploughing depths to derive the levels of the soil surface at moment of stabilization; the deposition depths, which were then used to calculate unbiased deposition rates.
\end{abstract}

We identified two phases of colluvial deposition. The oldest deposits ( $\sim 5 \mathrm{ka})$ were located at the fringe of the kettle hole and accumulated relatively slowly, whereas the youngest deposits $(<0.3 \mathrm{ka})$ rapidly filled the central kettle hole with rates of two orders of magnitude higher. We suggest that the latter phase is related to artificial drainage, facilitating accessibility in the central depression for agricultural practices. Our results show the need for numerical dating techniques that take archeological and soil-geomorphological information into account to identify spatiotemporal patterns of landscape change, and to correctly interpret landscape dynamics in anthropogenically influenced hilly landscapes.

Published as: Van der Meij, W.M., Reimann, T., Vornehm, V.K., Temme, A.J.A.M., Wallinga, J., Van Beek, R., Sommer, M., 2019. Reconstructing rates and patterns of colluvial soil redistribution in agrarian (hummocky) landscapes. Earth Surface Processes and Landforms 44: 2408-2422. https://doi.org/10.1002/esp.4671. 


\subsection{Introduction}

Soils are constantly changing by continuous or periodical redistribution and mixing of soil material. Humans have triggered and accelerated these processes since prehistoric times by agricultural practices (Van Andel et al., 1990; Favis-Mortlock et al., 1997; Dotterweich, 2008; Dreibrodt et al., 2010; Dotterweich et al., 2014). Over time, human-induced erosion and deposition rates in hilly areas increased and larger areas of land were subjected to these soil redistribution processes (Dreibrodt et al., 2010; Kołodyńska-Gawrysiak et al., 2018; Kappler et al., 2019). Currently, soil erosion is one of the major threats to global soil fertility and food security (Pimentel, 2006; Amundson et al., 2015). Although historical erosion may have contributed substantially to total soil erosion budgets (Enters et al., 2008), recent human-induced erosion rates far exceed those found in natural landscapes (Montgomery, 2007) and oftentimes largely exceed rates of soil production through weathering (Alewell et al., 2015). Improved soil conservation measures are urgently required to challenge land degradation and to sustainably conserve ecosystem services (Bouma, 2014). Design of efficient measures will benefit from insights in rates of natural and human-induced soil redistribution, and nature-based approaches may even seek to use those processes and the resulting changes in landforms. Therefore, quantitative data on past soil transport and deposition rates are required.

Human-induced erosion occurs either indirectly, by exposing soil to wind and water for example after deforestation, or directly by working the soil with ploughs. Vertical soil mixing processes are also intensified by humans. In a natural setting, bioturbation is the main mixing process, with the most active mixing in the top few centimeters of the soil (e.g. burrowing animals and root growth and decay, Gabet et al., 2003). Bioturbation often shows an exponential decline of mixing rates with depth (e.g. Reimann et al., 2017). With the introduction of ploughs, the thickness of the most active mixing layer increased to a few decimeters and mixing intensified. The resulting combination of lateral and vertical transport processes constitutes a complex system in which the rates of lateral and vertical transport of soil material are not easily distinguished (Johnson et al., 2014). Especially in colluvial settings, where tillage-related transport plays a dominant role, the constant vertical mixing complicates the determination of depositional ages through the application of conventional geochronological methods, e.g. by disturbing the stratigraphic order. This disturbance demands additional steps in the geochronological analysis. 
OSL (Optically Stimulated Luminescence) dating is often used to establish depositional ages and rates of colluvial sediments by measuring the OSL signal of grains (Fuchs and Lang, 2009). When buried, soil minerals such as quartz or feldspars build up an OSL signal from incoming ionizing radiation from the surrounding soil matrix and cosmic rays. When the grain is exposed to daylight, this OSL signal is reset, referred to as bleaching. OSL thus measures the last exposure of a grain to daylight: the moment of bleaching.

The application of OSL on colluvial sediments comes with several difficulties. First, burial age can be wrongly estimated due to insufficient bleaching of some grains during sediment transport, or due to entrainment of younger or older grains in the sediment by vertical mixing processes. However, Fuchs and Lang (2009) argue that there is only a small chance of insufficient bleaching in colluvial sediments, because the sediments are transported at the surface during many small events, providing sufficient opportunity for bleaching. Moreover, the constant vertical mixing during ploughing and through bioturbation also increases chances of bleaching by overturning the soil and might be an even more dominant process for the bleaching of colluvial sediments than lateral transport (Berger and Mahaney, 1990). When considering an eroding hillslope, there are thus three mechanisms of mixing and bleaching affecting the OSL chronology. These are: 1) pre-bleaching on the source location by vertical mixing (Reimann et al., 2017), 2) bleaching during lateral transport by water or tillage (Fuchs and Lang, 2009), and 3) post-bleaching on the target location by vertical mixing (Arnold and Roberts, 2009).

Second, while pre-bleaching and bleaching during transport reduce the chance of insufficient bleaching of the colluvial deposits, post-depositional bleaching prevents OSL signal buildup after the colluvium is deposited. The reworking of the topsoil through natural (bioturbation) or anthropogenic (ploughing) processes continuously exposes grains to light after their initial deposition and burial. In natural, non-eroding systems (Figure 3.1A), the bleaching by bioturbation leads to an OSL age that decreases exponentially towards the surface (Johnson et al., 2014; Román-Sánchez et al., 2019b). When such landscapes are exposed to ploughing and erosion, the age-depth patterns change substantially. Ploughing either draws furrows that fill up with sediments by water flow or successive plough activity (ard ploughs, Nyssen et al., 2011; Pavelka et al., 2017), or tilts entire sods of soil material (mouldboard ploughs, Andersen et al., 2016). Current plough activity with mouldboards homogenizes the plough horizons in just a few years (e.g. Schimmack et al., 1994; Schuller 
et al., 2004). Plough layers created by ards are also well-mixed, because the furrows fill up with material from the entire range that is reworked (Lewis, 2012). Soil reworking by ploughing thus causes continuously resurfacing of material in the plough layer, and induces bleaching of a part of the grains. As these grains get mixed over the entire plough layer, the original age-depth profile gets overprinted (Figure 1B; Huisman et al., 2018). As a further complication, not all surfaced sediments are always bleached, because part the sediments will be enveloped in large clumps or smaller aggregates (Šarauskis et al., 2008). This insufficient bleaching implies that the idealized age-depth profiles in Figure 3.1B will not be that clear in the field and additional actions are required to extract the age of the plough layer and buried colluvium.

The effects of mixing and erosion by ploughing on OSL ages differ per landscape position (Figure 3.1B). On non-eroding positions, ploughing will affect only the top layer of the soil, where the soil is actively reworked. This will cause a discontinuity in the age-depth profiles. On eroding positions, the original soil profile will be truncated and the OSL age of deeper layers gets reset when they get incorporated in the plough horizon. On positions with deposition, the supply of sediments leads to burial of colluvium below the active plough layer. In this stabilized colluvium, the soil is no longer actively reworked and the OSL age can build up. This implies that the burial age measured with OSL in colluvium indicates the moment of stabilization of a colluvial layer instead of the moment of deposition. Mixing depths by tillage change through time following agricultural development, and the depths where sediments get stabilized change accordingly. Therefore, there is an increasing bias in deposition rates when these are calculated with the stabilization ages and corresponding depths. We suggest that more realistic deposition rates can be calculated by correcting for this post-depositional bleaching effect, using the mixing depths at the moment of stabilization. 


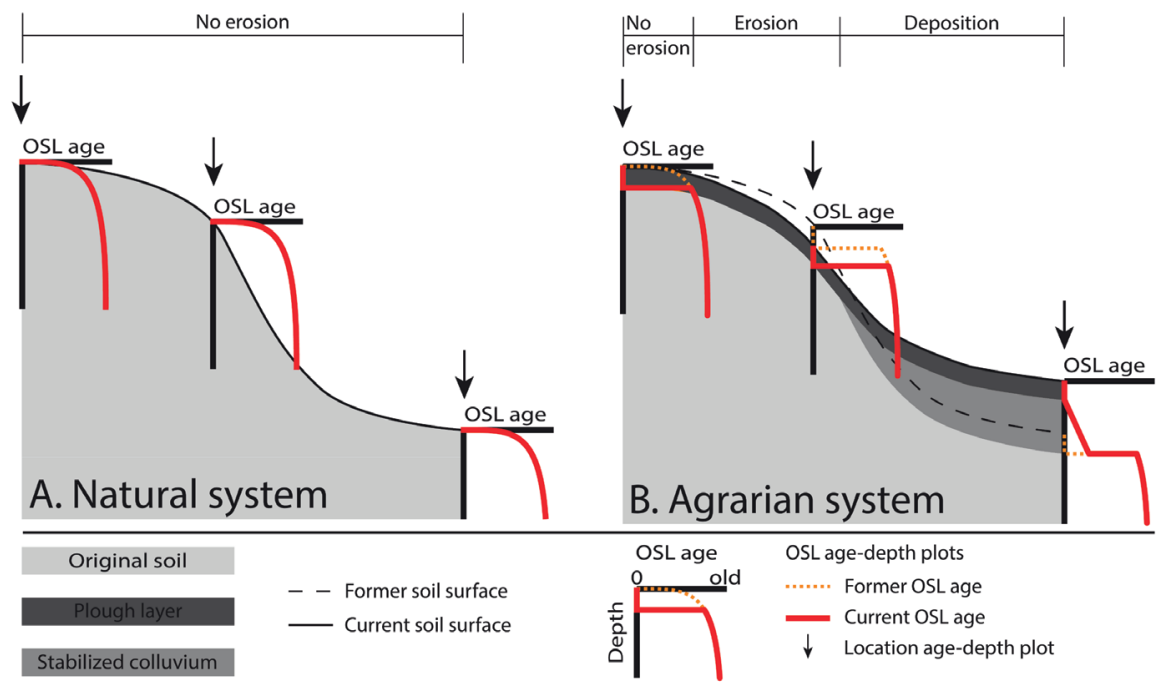

Figure 3.1: Conceptual diagram comparing expected OSL age-depth relations at different landscape positions in an idealized system, for A) natural systems, and B) agrarian systems. The natural system is expected to be stable (negligible erosion and deposition), with low OSL ages near the surface due to bioturbation. When such natural systems are converted to agrarian systems, the OSL age-depth relations will change accordingly. The non-eroded (hill-top plateau) position in B indicates how ploughing affects the OSL age in the top layer. The erosion (upper slope) and deposition (lower slope) positions indicate how the OSL age-depth relations change relative to the time when the fields were ploughed, but no erosion had yet occurred.

Our study site is the colluvial infilling of a kettle hole in the Uckermark region, northeastern Germany. In this lowland setting, we expect complex spatiotemporal patterns of colluviation due to very short transport distances and a history of increasingly intensive land use. Kettle holes are the centers of closed depressional catchments, which act as traps for the eroded sediments from the slopes. This means that kettle holes contain the complete geo-archive of the catchment, storing a very local and direct signal of soil redistribution. Kettle hole catchments in northeastern Germany nowadays are heavily influenced by erosion, mainly due to recent tillage ( $\mathrm{Li}$ et al., 2002; Sommer et al., 2008; Van Oost et al., 2009). The determination of accurate deposition rates requires dense vertical sampling of the colluvial soil to obtain a detailed chronology (e.g. Kołodyńska-Gawrysiak et al., 2018). However, current studies often ignore lateral spatial variation in a kettle hole by sampling only one location in the center of the depressions, where the colluvial layer often is thickest. Due to 
the complex topographical evolution of kettle holes under erosion (Van der Meij et al., 2017), we expect that there is considerable spatial variation in deposition rates, implying that a spatial sampling scheme is required to quantify the colluvial infilling history and hence erosion history.

The objectives of this study are 1) to tailor an OSL dating approach to quantitatively study soil redistribution in agrarian landscapes, solving the difficulties OSL dating faces in colluvial settings, and 2) to reconstruct spatial and temporal patterns of colluviation in an agrarian kettle hole. We first describe how we analyzed OSL measurements from colluvial settings where partially bleached and rejuvenated samples occur. Using this method, we derived stabilization ages for five densely sampled locations in the kettle hole catchment. Second, we determined the deposition depths corresponding to the different stabilization ages, using a reconstruction of plough depths in the study region. We used these deposition depths to calculate accurate deposition rates. Third, we propose a conceptual model describing the complex spatial and temporal colluvial infilling of agrarian kettle holes in hummocky landscapes. The presented methodology addresses the previously mentioned difficulties when dating colluvial settings and shows new possibilities for using OSL in intensively managed landscapes. 


\subsection{Methods}

\subsubsection{Study area}

The study area is located in the Uckermark district in the hummocky ground moraine landscape of Brandenburg, northeastern Germany (Figure 3.2). After retreat of the Weichselian ice cap ( 20 ka ago, Lüthgens et al., 2011), melting of dead ice formed an irregular pattern of kettle holes, or depressional catchments (Andersson, 1998). Most of these small catchments are not connected to the regional surface water drainage network and act as closed systems. The varying sizes and hydrological properties of the kettle holes are important factors for geo- and biodiversity in the hummocky landscape (Kalettka and Rudat, 2006).
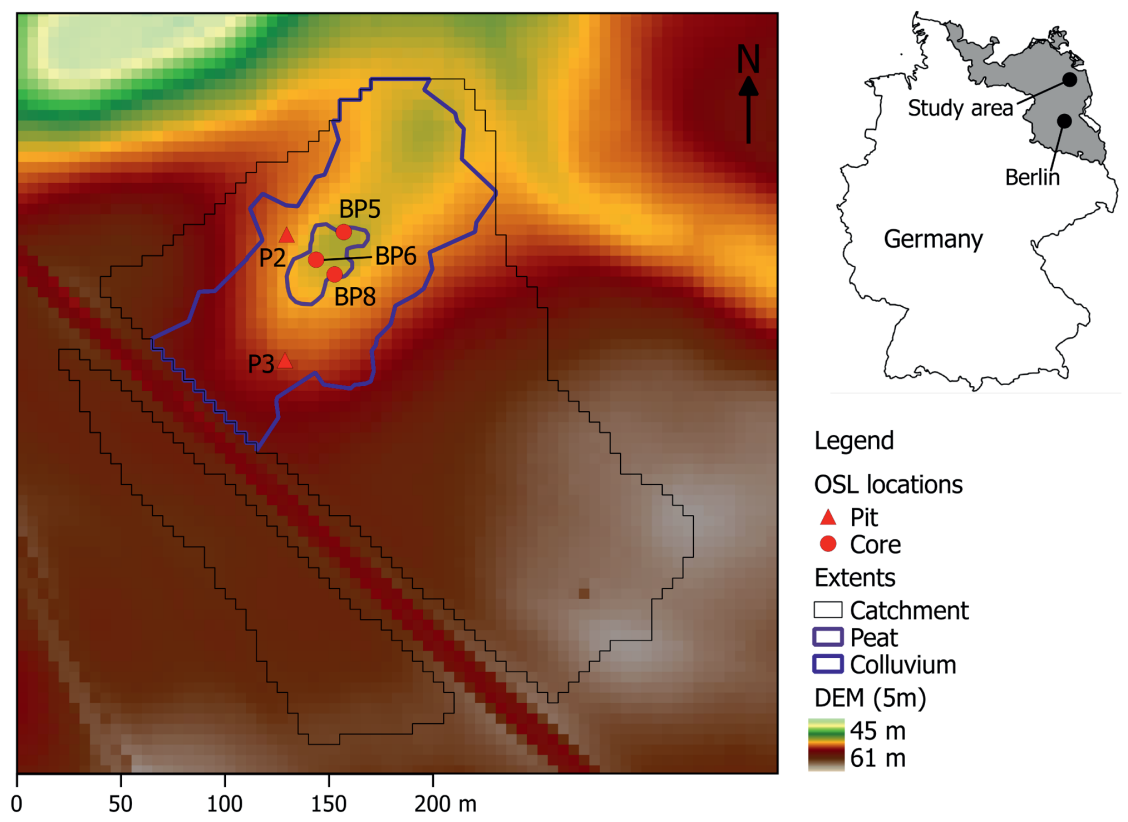

Legend

OSL locations

$\triangle$ Pit

- Core

Extents

$\square$ Catchment

$\square$ Peat

$\square$ Colluvium

$\operatorname{DEM}(5 \mathrm{~m})$

$45 \mathrm{~m}$

Figure 3.2: Overview of the sampling locations in the study area CarboZALF-D, located in the young morainic landscape of northeast Germany (grey area in inset. Source: BGR, 2008). The linear feature is a railroad track constructed in 1900.

The current climate of the Uckermark region is characterized as sub-continental, with a negative water balance (potential evapotranspiration $>$ rainfall). Average annual rainfall in the period of 1996 to 2017 was 479 mm (Grünow meteorological station, DWD Climate Data 
Center (CDC), 2018b). The highest rainfall amount and intensity occurred in the summer months. In winter, precipitation mainly fell as snow, which can trigger surface run-off when melting. Average annual temperature in the same period was $9.1^{\circ} \mathrm{C}$, with $0.6^{\circ} \mathrm{C}$ and $17.7^{\circ} \mathrm{C}$ as average winter and summer temperature (DWD Climate Data Center (CDC), 2018a). The study site is part of the experimental field "CarboZALF-D" (Sommer et al., 2016), which represents a landscape laboratory with a research focus on the feedbacks between erosion processes and carbon dynamics (Rieckh et al., 2015; Aldana Jague et al., 2016; Gerke et al., 2016; Hoffmann et al., 2018). Before the establishment of the CarboZALF-D experimental site in 2009, an extensive coring - based on a GIS analysis of soil forming factors - took place in the surrounding Quillow catchment $\left(165 \mathrm{~km}^{2}\right)$ to assure representativeness of the soil pattern at the regional scale. Closed depressions make up $\sim 12 \%$ of the arable land in the Quillow catchment (Deumlich et al., 2010), of which $50 \%$ are covered by colluvial sediments.

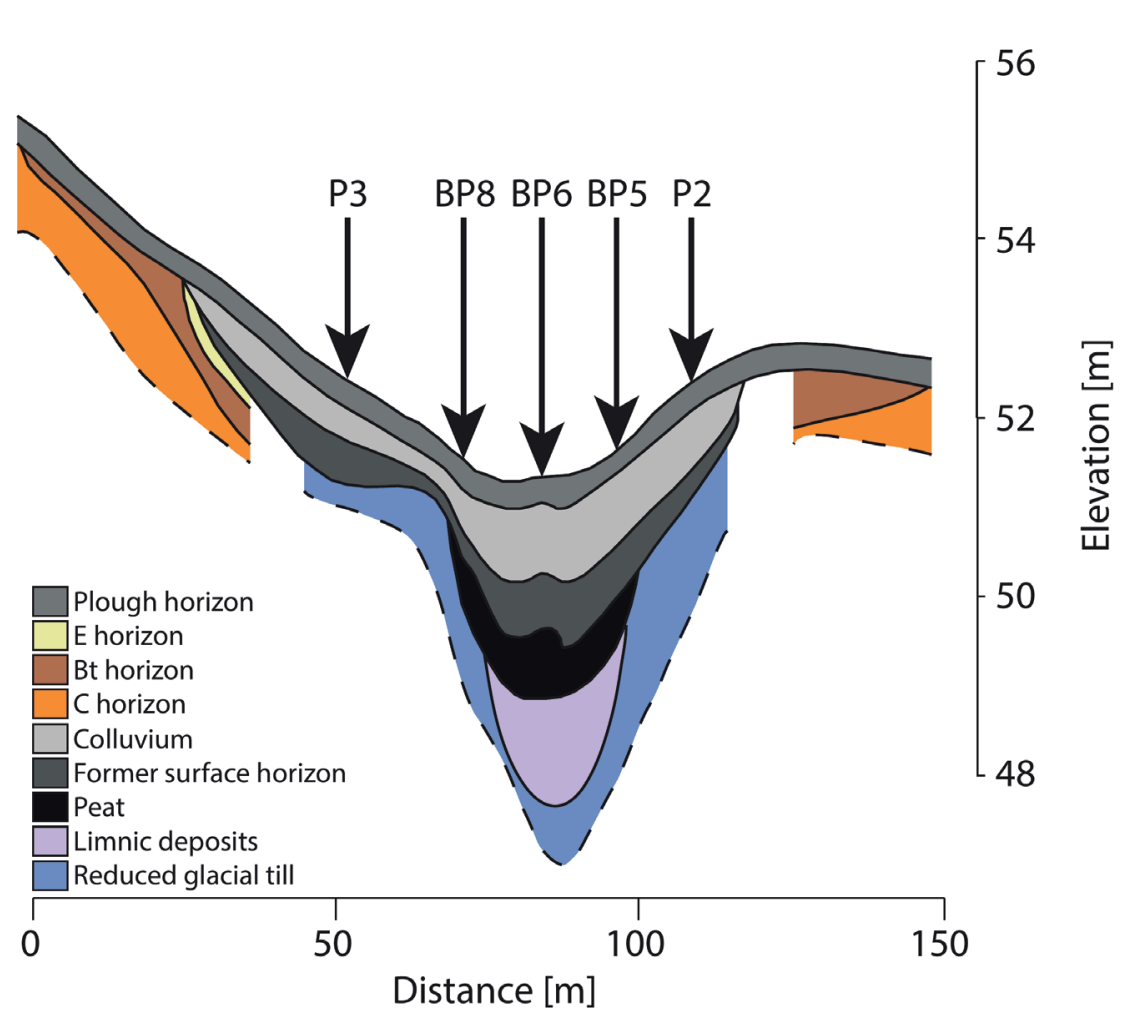

Figure 3.3: Position of the sampling locations projected on a SE-NW transect through the depression. Modified from Van der Meij et al. (2017). 
With the introduction of agriculture in the area, the natural vegetation made way for agricultural use. This agricultural use triggered soil erosion and is thus essential for understanding erosion dynamics and landform evolution (De Alba et al., 2004). The habitation development and land-use history in the immediate vicinity of the kettle hole were difficult to reconstruct in great detail, because local archeological data is limited. However, the main trends in land use, with a focus on changes in plough use, during the Holocene in northeast Germany could be relatively well reconstructed using a literature survey, including published work on comparable lowland settings in neighboring parts of Germany, Poland and southern Scandinavia. We provide this reconstruction in Supplement 3.1. The outcomes of the reconstruction are used as an approximation of the most likely land-use development at the study site. Key elements for our study are the timing of the adoption and expected soil impact of the ard plough and mouldboard plough, and the moment that the kettle hole was artificially drained (Table 3.1).

Table 3.1: Overview of introduction and impact of different plough types and artificial drainage in the Uckermark region.

\begin{tabular}{|c|c|c|c|c|c|}
\hline $\begin{array}{l}\text { Management } \\
\text { type }\end{array}$ & $\begin{array}{l}\text { Introduction year } \\
\text { of management } \\
\text { type }\end{array}$ & $\begin{array}{l}\text { Impact on soil } \\
\text { and landscape }\end{array}$ & $\begin{array}{l}\text { Mixing } \\
\text { depth }\end{array}$ & Source & $\begin{array}{l}\text { Code in } \\
\text { Figure } 3.5 \& \\
\text { Figure } 3.8\end{array}$ \\
\hline Ard plough & $\begin{array}{l}3700-3200 \\
\text { BCE }\end{array}$ & $\begin{array}{l}\text { Narrow, } \\
\text { shallow } \\
\text { furrows in the } \\
\text { soil. }\end{array}$ & $5-7 \mathrm{~cm}$ & $\begin{array}{l}\text { (Herrmann, 1985; } \\
\text { Kirsch, 1994; } \\
\text { Behre, 2008) }\end{array}$ & PT5 \\
\hline $\begin{array}{l}\text { Medieval } \\
\text { mouldboard } \\
\text { plough }\end{array}$ & $200-900 \mathrm{CE}$ & $\begin{array}{l}\text { Turning of the } \\
\text { soil, creating } \\
\text { high-backed } \\
\text { ridges. }\end{array}$ & $8-15 \mathrm{~cm}$ & $\begin{array}{l}\text { (Lerche, 1994; Van } \\
\text { den Broeke, 2005; } \\
\text { Behre, 2008; } \\
\text { Andersen et al., } \\
\text { 2016; Larsen, 2016) }\end{array}$ & PT4 \\
\hline $\begin{array}{l}\text { Early modern } \\
\text { mouldboard } \\
\text { plough }\end{array}$ & $1795-1800 \mathrm{CE}$ & & $\begin{array}{l}15-17 \\
\mathrm{~cm}\end{array}$ & $\begin{array}{l}\text { (Thaer, 1803; } \\
\text { Opitz, 1938) }\end{array}$ & PT3 \\
\hline $\begin{array}{l}\text { Contemporary } \\
\text { mouldboard } \\
\text { plough }\end{array}$ & $1954-1965 \mathrm{CE}$ & & $\begin{array}{l}25-30 \\
\mathrm{~cm}\end{array}$ & $\begin{array}{l}\text { (Sommer et al., } \\
\text { 2008), current field } \\
\text { observations }\end{array}$ & PT2 \\
\hline $\begin{array}{l}\text { Current } \\
\text { mouldboard } \\
\text { plough }\end{array}$ & $1989 \mathrm{CE}$ & & $20 \mathrm{~cm}$ & (Verch, 2018) & PT1 \\
\hline $\begin{array}{l}\text { Artificial } \\
\text { drainage }\end{array}$ & $1787-1826 \mathrm{CE}$ & $\begin{array}{l}\text { Lowering wate } \\
\text { the kettle hole, } \\
\text { its accessibility } \\
\text { ploughing }\end{array}$ & $\begin{array}{l}\text { evel in } \\
\text { creasing } \\
\text { or }\end{array}$ & $\begin{array}{l}\text { (von Schmettau, } \\
\text { 1787; Preußische } \\
\text { Urmesstischblätter, } \\
1826 \text { ) }\end{array}$ & \\
\hline
\end{tabular}




\subsubsection{Data collection and preparation}

\subsubsection{Data collection}

For OSL dating, two quantities need to be determined. The first quantity is the equivalent dose $\left(D_{e}\right)$; the estimation of radiation dose received by quartz grains since the last bleaching event. The second quantity is the dose rate (DR); the yearly absorbed radiation dose, based on radionuclide contents of the deposit, sample depth and water content.

We took OSL samples from five locations, with varying colluvium thickness $(78-110 \mathrm{~cm})$, topographic position, and underlying material (Figure $3.2 \&$ Figure 3.3). The soils were described following FAO guidelines (FAO, 2006; IUSS Working Group WRB, 2015) and the German soil classification system (KA5, Ad-hoc-AG Boden, 2005). At two sites on the fringes of the depression (P2, P3), soil pits were dug and OSL samples were collected horizontally from the pit walls using PVC tubes of $5 \mathrm{~cm}$ in diameter. In the center of the depression, samples were obtained at three sites (BP5, BP6, BP8) by coring using vertical PVC cores of $5 \mathrm{~cm}$ in diameter. For each of these three locations, three cores were sampled. The first core was used for profile descriptions. The second and sometimes third core was used to extract material for $\mathrm{D}_{\mathrm{e}}$ and $\mathrm{DR}$ determination from $5 \mathrm{~cm}$ increments. The vertical distance between samples was mostly $10 \mathrm{~cm}$, with some larger distances up to $18 \mathrm{~cm}$.

\subsubsection{Lab analysis}

The samples were opened and prepared in subdued amber light conditions at the Netherlands Centre for Luminescence dating (NCL, Wageningen University \& Research). The material was carefully selected from the center of the cores to prevent possible mixing and contamination effects due to smearing along the sample tube edges. The 180-250 $\mu \mathrm{m}$ sand fraction was obtained by wet-sieving, and chemically treated with $\mathrm{HCl}(10 \%)$ and $\mathrm{H}_{2} \mathrm{O}_{2}$ $(10 \%)$ to remove carbonates and organic matter, respectively. The quartz fraction of the samples was obtained using density separation and then etched using $40 \%$ HF for 45 minutes to remove remaining feldspar contamination and the outer alpha-exposed rim of the quartz grains. The remaining quartz grains were sieved again over a $180 \mu \mathrm{m}$ sieve to avoid grains that were heavily affected by the etching.

The identification of unbleached or rejuvenated grains optimally requires $D_{e}$ measurements on single grains, to avoid averaging of the OSL signal (Duller, 2008). As previous research 
in this region showed that less than 5\% of the quartz grains carry an OSL signal that fulfilled all quality requirements (Lüthgens et al., 2011), we decided to use very small aliquots (1 mm) containing only 15-20 grains as a proxy for single-grain quartz $\mathrm{D}_{\mathrm{e}}$ determinations. We applied the SAR protocol of Murray and Wintle (2003). On average 31\% of our measured aliquots passed standard rejection criteria mainly associated to the small aliquot size, i.e. few OSL emitting quartz grains.

The DRs were determined from the remaining soil material in the soil cores. The samples were dried overnight at $105^{\circ} \mathrm{C}$ to determine gravimetric moisture content. LOI at $450{ }^{\circ} \mathrm{C}$ was used to estimate organic matter content. The remaining material was ground and mixed with wax in a 70-30 sediment-wax ratio and molded into 1 or $2 \mathrm{~cm}$ thick pucks, depending on available material.

The pucks were used to measure radionuclide activity concentrations for K-40 and several nuclides of the $\mathrm{U}$ and $\mathrm{Th}$ decay chains using high-resolution broad range gamma ray spectrometry. The measured activity concentrations were converted to infinite matrix beta and gamma dose rates using the conversion factors of Guérin et al. (2011). DRs were then calculated taking into account attenuation effects of organic matter and moisture (Madsen et al., 2005), as well as grain size dependent attenuation of beta dose (Mejdahl, 1979), the site and depth-dependent contribution of cosmic dose (Prescott and Hutton, 1994), internal alpha dose rate $(0.010 \pm 0.005 \mathrm{~Gy} / \mathrm{ka}$, Vandenberghe et al., 2008) and the contribution of gamma radiation from different soil layers (Aitken, 1985).

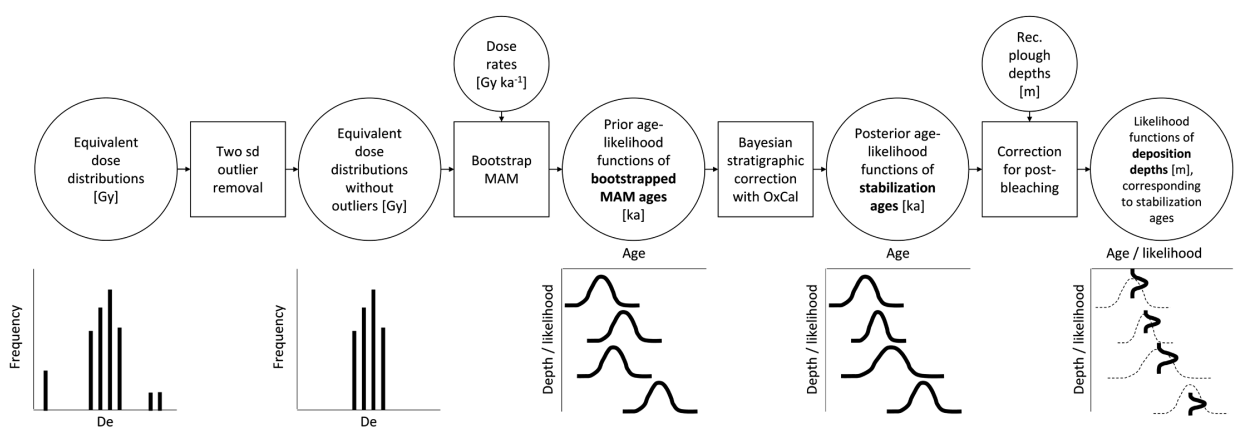

Figure 3.4: Analytical steps to determine the stabilization ages and corresponding deposition depths from the calculated DRs, measured De distributions, with corresponding terminology and data types of the intermediate results. 


\subsubsection{Data analysis}

We took several steps to determine the stabilization ages and deposition depths of our samples. These steps are summarized in Figure 3.4 and explained in detail below. The complex analysis is required as the measured $\mathrm{D}_{\mathrm{e}}$ distributions result from several soil mixing and transport processes (Figure 3.1).

\subsubsection{Age modeling for determining stabilization ages}

The OSL age is calculated by dividing the palaeodose, which is the best estimate of the dose received during burial, by the DR. An age model is required to compute the palaeodose from the measured $\mathrm{D}_{\mathrm{e}}$ distribution of a sample. Most commonly used age models are the Central Age Model (CAM) and the Minimum Age Model (MAM) (Galbraith et al., 1999; Arnold et al., 2009). The CAM assumes the OSL sample to be unaffected by partial bleaching and/or post-depositional mixing, and is similar to a weighted mean of the measured $\mathrm{D}_{\mathrm{e}} \mathrm{s}$. If some part of the grains has an age older than the event of interest (e.g. due to partial bleaching or mixing), part of the measured $\mathrm{D}_{\mathrm{e}}$ distribution should be ignored for palaeodose estimation. The MAM provides a means to do this (Galbraith et al., 1999; Galbraith and Roberts, 2012) and the bootstrapped version of the model (Cunningham and Wallinga, 2012) has been shown to provide robust results for small aliquots of both well-bleached and heterogeneously bleached quartz (Chamberlain et al., 2018). A drawback of the MAM is that it is very sensitive to $\mathrm{D}_{\mathrm{e}}$ outliers at the low end of the distribution.

We expect $\mathrm{D}_{\mathrm{e}}$ distributions for our samples to be highly over-dispersed, mainly due to mixing of grains with different depositional ages, and inclusion of grains that were surface exposed after stabilization. We are interested in the doses representing the stabilization of the sediment below the active mixing zone. However, some grains exhibit higher $\mathrm{D}_{\mathrm{e}}$ as they were not surfaced by mixing, and some exhibit lower $D_{e}$ as a consequence of sporadic deep bioturbation beyond the active mixing zone (e.g. beetle burrows or roots). This requires additional processing steps which are outlined in the following sections. From the $\mathrm{D}_{\mathrm{e}}$ distributions, we iteratively calculated the two standard deviations range of the mean and removed the $\mathrm{D}_{\mathrm{e}} \mathrm{s}$ which fell outside that range window. This process was repeated until no more outliers were identified. The process removed outliers both at the low and high end of the distribution; removal of low outliers is required, while removal of high outliers has no effect on the results obtained in the next step 


\subsection{Bootstrapped MAM}

The bootstrapped MAM was used to derive likelihood functions of palaeodoses from the $\mathrm{D}_{\mathrm{e}}$ distribution (Cunningham and Wallinga, 2012). We used the logged version of the MAM, except when there were $D_{e} s$ with negative values. In those cases we used the unlogged version. The bootstrapped MAM requires information on the expected over-dispersion of the $\mathrm{D}_{\mathrm{e}}$ distribution in absence of mixing or heterogeneous bleaching (i.e. the over-dispersion that would be obtained for a well-bleached unmixed sample of these sediments). Assuming that some of our samples are well-bleached and unmixed, we can obtain the minimum overdispersion as the best estimate of $\sigma_{b}($ sigma $b)$ for our set of samples $(n=32)$, by applying the bootstrapped MAM to the corresponding dataset of over-dispersion values of our samples calculated through the CAM (Chamberlain et al., 2018). We expect no over-dispersion in our data-set of over-dispersions. Therefore, we set the $\sigma_{\mathrm{b}}$ at 0 for determining the $\sigma_{\mathrm{b}}$ of our dataset. This approach robustly selects the $\sigma_{b}$ from the lowest over-dispersions present in our measurements. For our samples this approach provided $a \sigma_{b}$ of $15 \pm 1 \%$, which is reasonable for this aliquot size and this type of sediment. This minimum scatter observed in wellbleached and unmixed $\mathrm{D}_{\mathrm{e}}$ distributions is most likely caused by unaccounted experimental uncertainties and beta dose rate heterogeneity in the surrounding of the sample. The distribution of palaeodoses was divided by the DR to obtain the distribution of bootstrapped MAM ages.

The age likelihood distributions should contain all uncertainties in DR estimates, and all unshared errors, both random and systematic. The unshared errors consist of random errors and the unshared systematic error (USS). The USS is a systematic error inside one sample, but a random error in between samples (Rhodes et al., 2003). We calculated the unshared errors by summing the errors resulting from determination of moisture and organic matter, and the errors associated with the selected grain size, the cosmic dose determination and the counting statistics of the gamma-spectrometer. These errors were inserted in the uncertainty during bootstrapping. Additional errors, the shared errors, are associated with the calibration of the beta source, the estimation of internal alpha radiation (Vandenberghe et al., 2008) and the conversion of radionuclide activity to DR (Guérin et al., 2011). These shared errors (2.4\%) were added to all presented ages with their uncertainty after the OxCal analysis (next Section). 


\subsection{Bayesian age modeling}

For samples with known stratigraphic relationships, information on the order can be combined with the age likelihoods to further refine ages and identify inconsistencies using Bayesian approaches. We used the online program OxCal 4.3 (Bronk Ramsey, 2009) to constrain the prior age likelihood functions (bootstrapped MAM ages) with the stratigraphy into posterior age likelihood functions, which represent the stabilization ages (Rhodes et al., 2003; Bronk Ramsey, 2008; Cunningham and Wallinga, 2012). We selected the sequencedeposition model, which only uses the relative stratigraphic position of the samples. Other, more complex models can also process information on the absolute depth of the samples, shape of the depositional curve and the number of depositional events in a chronology (Bronk Ramsey, 2008). However, these extra data and parameters are difficult to estimate for our dataset and therefore, we only used relative stratigraphic information.

\subsubsection{Deposition depths and rates}

\subsection{Deposition depths}

The ages resulting from OxCal represent the moment that the sediments were buried below the active soil mixing zone in which they were more or less continuously mixed. The actual deposition age is thus overprinted by post-bleaching of the sediments due to ploughing (Figure 3.1). To derive correct deposition rates, we need to correct for this post-bleaching in the active soil mixing zone. We focus here on soil mixing by ploughing rather than natural bioturbation, because ploughing is currently the dominant soil mixing process. We cannot accurately estimate the deposition age at the sample depth, but we can estimate the level of the soil surface at the moment of stabilization, using the reconstructed plough depths (Table 3.1). We refer to this level as the deposition depth. The deposition depth equals the sample depth, minus the mixing depth at time of stabilization (Figure 3.5). The deposition age corresponding to this deposition depth is identical to the stabilization age at the stabilization, i.e. the sample depth. Over a period with constant plough depth, deposition rates calculated using either stabilization or deposition depths and ages will be identical. However, when an increase in plough depth occurs in between two ages, the rates calculated from deposition depths and ages will show that the actual deposition rates were actually higher than those calculated with conventional stabilization depths and ages. Often, the current soil surface is included in the calculation of deposition rates from stabilization ages and depths. This will also lead to incorrect results if the depths of the dated samples are not corrected for post- 
bleaching. Sediments on the surface are not yet stabilized, so the surface represents a deposition age and depth of zero. Therefore, it should not be compared with stabilization depths of dated subsurface sediment layers. The steep red curve in Figure 3.5 shows the resulting overestimation in deposition rates.

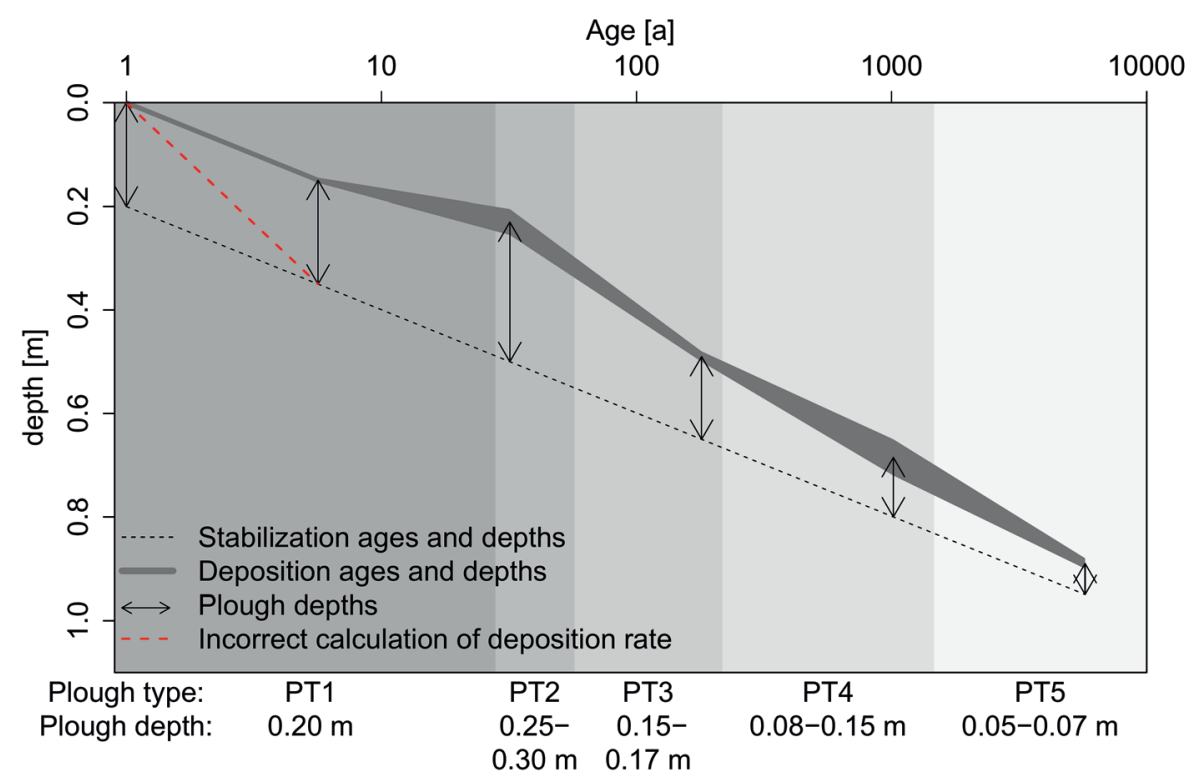

Figure 3.5: Conceptual overview of the relation between ages and depths from the moments of stabilization and deposition, see Table 3.1 for plough codes. The stabilization ages can be derived through OSL \& OxCal analysis. By subtracting the plough depth from the stabilization depths, the corresponding deposition depths are calculated. The uncertainty in plough depth reconstruction propagates into the deposition depths, visualized by the grey uncertainty band. The red line shows the incorrect calculation of deposition rates when comparing stabilization ages and depths of the samples with the deposition age and depth of zero at the soil surface. This conceptual figure does not show the uncertainties associated with the ages, merely the uncertainty associated with ploughing depths.

In some cases, uncertainty in stabilization ages and introduction dates of the different plough types may prevent attribution to one historical plough regime, causing two possible sets of deposition depths for one stabilization depths. Likewise, the uncertainty in plough depth propagates into deposition depths (Figure 3.5). To account for these uncertainties in the final deposition rates, we used a Markov Chain Monte Carlo (MCMC) approach where we iteratively resampled stabilization ages $(n=5000)$ from their likelihood curves and plough 
regimes to calculate the corresponding deposition depths. We assumed uniform distributions for the introduction ages and mixing depths of the ploughs. Ultimately, the resulting collection of 5000 deposition depths per sample was used to calculate a final probability function of deposition depths. The deposition ages, which are identical to the stabilization ages, and deposition depths were then used to calculate deposition rates.

\subsection{Deposition rates}

During our analysis, we derived likelihood functions of the deposition ages and depths. These likelihood functions are not normally distributed and can therefore not be presented as an average age with standard deviation. Instead, we used the notation used in radiocarbon dating (e.g. Van der Plicht, 1993) showing the most probable age or depth range (one-sigma, 68.3\%) for each sample. In the case of bi-modal likelihood functions, the one-sigma interval may comprise two distinct age ranges.

From these age $(a,[\mathrm{a}])$ and depth $(d[\mathrm{~cm}])$ ranges we calculated deposition rates (dep.rate $\left[\mathrm{cm} \mathrm{a}^{-1}\right]$ ) between two samples. We assumed the one-sigma age and depth ranges to be normally distributed and used the average value of these ranges as age or depth of the samples used in Eq. (3.1). In case of two distinct ranges caused by bi-modal distributions, we assumed that the age or depth ranged from the overall minimum to the overall maximum of both ranges. The average of this new range was used as input for Eq. (3.1). This approach recognizes the larger uncertainty associated with the bi-modal distributions, but uses an average value which may not fall in the one-sigma probability range.

To calculate the uncertainty of the deposition rates ( $\varepsilon_{\text {dep.rateAtoB }}\left[\mathrm{cm} \mathrm{a}^{-1}\right]$, using Eq. (3.2), we used half of the one-sigma probability range to represent the one-standard deviation uncertainty of the ages and depths $\left(\varepsilon_{a}[\mathrm{a}]\right.$ and $\left.\varepsilon_{d}[\mathrm{~cm}]\right)$. We assigned a standard deviation of $1 \mathrm{~cm}$ to the sample depths, to account for the $5 \mathrm{~cm}$ depth ranges in sampling.

$$
\begin{aligned}
& \text { dep.rate }_{A t o B}=\frac{d_{B}-d_{A}}{a_{B}-a_{A}} \\
& \varepsilon_{\text {dep.rate }_{A t o B}}=\sqrt{\left(\left(\frac{\sqrt{\varepsilon_{d_{A}}^{2}+\varepsilon_{d_{B}}^{2}}}{d_{B}-d_{A}}\right)^{2}+\left(\frac{\sqrt{\varepsilon_{a_{A}}^{2}+\varepsilon_{a_{B}}^{2}}}{a_{B}-a_{A}}\right)^{2}\right)} * \text { dep.rate } \text { AtoB }
\end{aligned}
$$




\subsection{Results}

\subsubsection{Field and lab results}

The five sampled locations varied in their horizonation and properties. A detailed overview of the soils is given in Supplement 3.2. In brief, locations P2 and P3, on the slopes, contain a layer of colluvium of 75 and $78 \mathrm{~cm}$ thick respectively. The colluvium is underlain with soil developed from glacial till. Both profiles display macro- and micromorphological signs of clay migration. P2 shows an eluvial and illuvial horizon in the colluvium above the fossil Ah. P3 shows only an eluvial horizon in the colluvium, indicating that the clay migrated to the soil below, which is documented by clay cutans along pores in thin sections (data not shown). There is no former surface horizon recognizable above the eluvial horizons. Locations BP5, BP6 and BP8 were sampled from the center of the depression and are underlain by peat. These profiles contain a layer of colluvium of 93, 91 and $68 \mathrm{~cm}$ and show redoximorphic (gleyic) properties below 71, 61 and $30 \mathrm{~cm}$ respectively, without evidence of clay migration.

Table 3.2 shows the details of the OSL sample preparation and analysis. Soil organic matter content of the colluvium ranges between 2.1 and 3.6\% (average 2.1\%). Soil organic matter content in the peaty buried surfaces was much higher $(7,13$ and $40 \%)$. Total DR for the colluvial samples ranged between $2.04 \pm 0.09 \mathrm{~Gy} / \mathrm{ka}$ and $2.65 \pm 0.10 \mathrm{~Gy} / \mathrm{ka}$. For the two peaty samples with significantly higher sample moisture and organic matter content (NCL7317060 and -061$)$ the total DR is much lower $(1.25 \pm 0.11$ and $1.85 \pm 0.13 \mathrm{~Gy} / \mathrm{ka}$, respectively. The DR and radionuclide measurements show no correlation with age, depth or location. Combined with the absence of sedimentologically different layers in the colluvium, the fine texture (sandy loam) and the constant reworking of the sediments after deposition, we don't expect any substantial extra heterogeneity in beta DR that is not accounted for by incorporation of $\sigma_{\mathrm{b}}$ in the age modeling.

\subsubsection{Age results}

We summarized the age results of every step in our analysis (Figure 3.4) in age-likelihood plots (Supplement 3.3 and Figure 3.6). The different curves demonstrate how the age likelihood of a sample changes through the steps in the analysis. The obvious young and old outliers were removed from the measurements during the outlier removal phase, resulting in narrower age distributions. The maximum age of the old outliers is much higher for the fringe positions (P2\&P3, 10-50 ka), than the depression positions (BP5-8, $1-5 \mathrm{ka}$, with one outlier 
at $10 \mathrm{ka}$ at BP8). This difference in maximum age of the outliers either indicates that during the transport of material from the fringes to the depression, previously partially or unbleached grains were bleached, or that there was no new uptake of old grains from the soil below by deep bioturbation. Some samples have very young outliers (e.g. NCL-7317039, -065, -150, Supplement 3.3). These outliers are sporadically present in the samples and do not follow a stratigraphic order for the different locations when present.

The bootstrapped MAM selected the younger $\mathrm{D}_{\mathrm{e}} \mathrm{s}$ from the measured $\mathrm{D}_{\mathrm{e}}$ distributions. This results in a narrow age distribution reflecting the younger part of the age likelihood distribution after removal of outliers (Figure 3.6B, C, E). Adding stratigraphic constraints using $\mathrm{OxCal}$ results in some alterations in the likelihood functions, compared to the MAM ages. In some cases the OxCal-based stabilization ages are similar to the bootstrapped MAM ages (Figure 3.6B, C, E), while for other samples there is a considerable difference between MAM and stabilization ages. The stabilization ages can either be younger (Figure 3.6D, G) or older (Figure 3.6F) than the MAM ages.

Following the increasing plough depth over time (Table 3.1), the differences between stabilization depths and deposition depths increase with time (Figure 3.7). For samples with stabilization ages ranging over multiple periods of reconstructed land use, the deposition depths show multiple depth ranges (e.g. the top of BP6, Figure 3.7). 

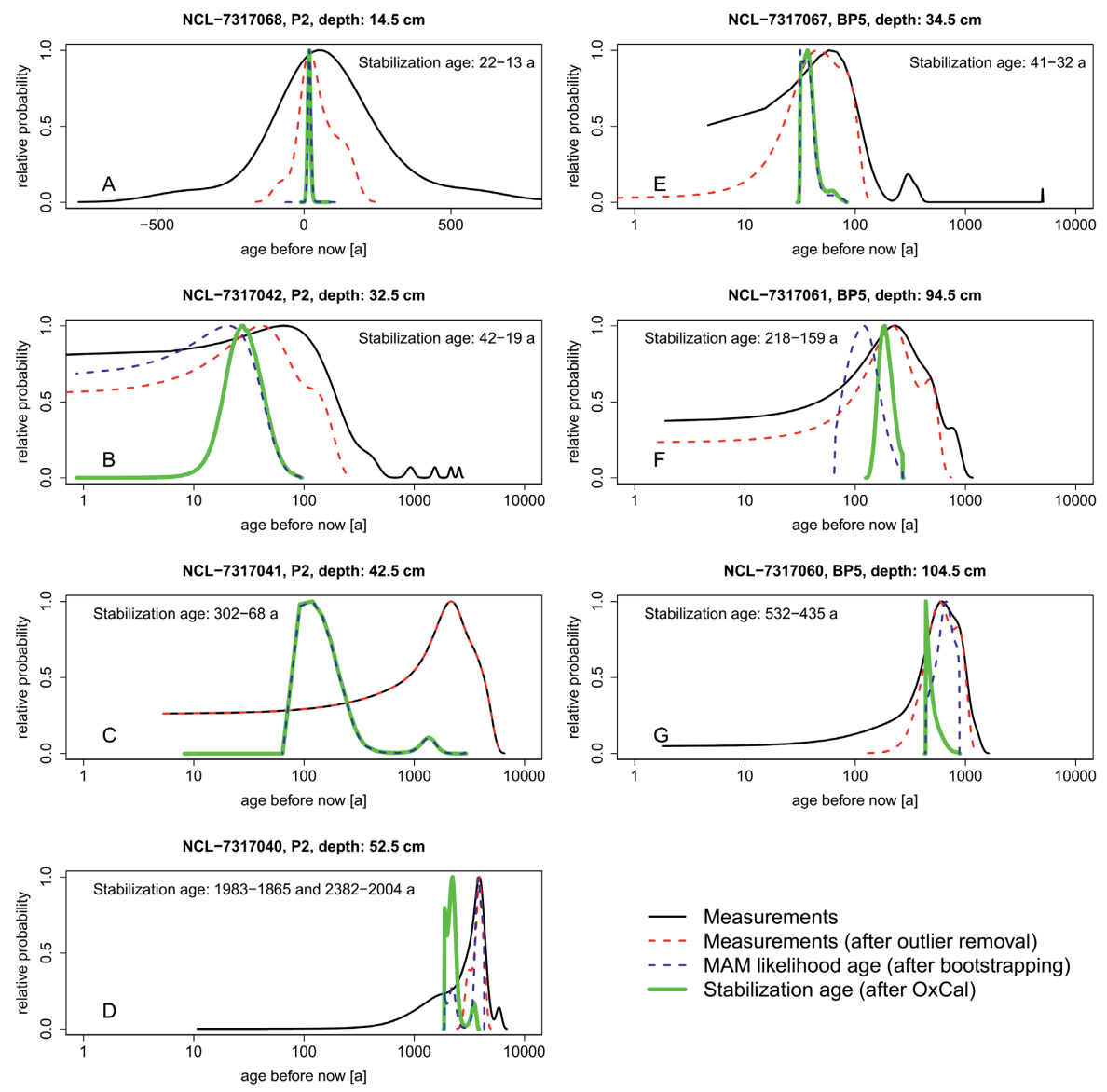

- Measurements

- - - Measurements (after outlier removal)

- - MAM likelihood age (after bootstrapping)

- Stabilization age (after OxCal)

Figure 3.6: Selection of age-likelihood plots for a few representative samples. Data for all samples is provided in Supplement 3.3. The plots on the left (A-D) are from location P2 and the plots on the right (E-G) are from location BP5. Note that for plot $A$ a linear $X$ axis is used to allow visualization of the differences around the zero-year mark. The curve representing the measurements corresponds to the De distribution. The other curves correspond to ages at various steps in our analysis (see Figure 3.4). 
Table 3.2: Age and rate results of the OSL analysis. Stabilization ages and deposition depths are presented in one-sigma ranges. Deposition rates are presented as average and one-sigma uncertainty. The rates are calculated between the sample and the next higher sample or the soil surface. Details of the OSL sample preparation and intermediate age results during the analysis are provided in Supplement 3.4.

\begin{tabular}{|c|c|c|c|c|c|}
\hline Loc. & $\begin{array}{l}\text { Depth } \\
{[\mathrm{cm}]}\end{array}$ & Sample code & Stabilization age [a] & Deposition depths [cm] & $\begin{array}{l}\text { Deposition } \\
\text { rates }\left[\mathrm{cm} \mathrm{a}^{-1}\right]\end{array}$ \\
\hline P2 & 14.5 & NCL-7317068 & 22 to $13 \mathrm{a}$ & - & - \\
\hline $\mathrm{P} 2$ & 32.5 & NCL-7317042 & 42 to $19 \mathrm{a}$ & $\begin{array}{l}2.7 \text { to } 7.3 \text { and } \\
11.5 \text { to } 13.8 \mathrm{~cm}\end{array}$ & $0.29 \pm 0.13$ \\
\hline P2 & 42.5 & NCL-7317041 & 302 to 68 a & 24.4 to $30.6 \mathrm{~cm}$ & $0.12 \pm 0.10$ \\
\hline $\mathrm{P} 2$ & 52.5 & NCL-7317040 & $\begin{array}{l}1983 \text { to } 1865 \text { and } \\
2382 \text { to } 2004 \text { a }\end{array}$ & 45.3 to $47.7 \mathrm{~cm}$ & $0.01 \pm 0.00$ \\
\hline P2 & 62.5 & NCL-7317039 & 3629 to $2913 \mathrm{a}$ & 55.3 to $57.7 \mathrm{~cm}$ & $0.01 \pm 0.00$ \\
\hline $\mathrm{P} 2$ & 72.5 & NCL-7317038 & 3983 to $3479 \mathrm{a}$ & 65.3 to $67.7 \mathrm{~cm}$ & $0.02 \pm 0.02$ \\
\hline $\mathrm{P} 2$ & 87.5 & NCL-7317037 & 4895 to $4170 \mathrm{a}$ & 80.3 to $82.6 \mathrm{~cm}$ & $0.02 \pm 0.01$ \\
\hline P3 & 32.5 & NCL-7317070 & $\begin{array}{l}-13 \text { to }-36 \text { and } \\
49 \text { to } 17 \mathrm{a}\end{array}$ & $\begin{array}{l}4.3 \text { to } 5.8 \text { and } \\
10.6 \text { to } 14.4 \mathrm{~cm}\end{array}$ & $2.17 \pm 8.71$ \\
\hline P3 & 42.5 & NCL-7317147 & $\begin{array}{l}19 \text { to }-5 \text { and } \\
55 \text { to } 25 \text { a }\end{array}$ & $\begin{array}{l}13.3 \text { to } 16.7 \text { and } \\
20.7 \text { to } 24.4 \mathrm{~cm}\end{array}$ & $0.52 \pm 0.61$ \\
\hline P3 & 52.5 & NCL-7317146 & 1238 to $887 \mathrm{a}$ & 38.1 to $44.3 \mathrm{~cm}$ & $0.02 \pm 0.01$ \\
\hline P3 & 62.5 & NCL-7317145 & 2011 to $1479 \mathrm{a}$ & 54.9 to $57.9 \mathrm{~cm}$ & $0.02 \pm 0.01$ \\
\hline P3 & 72.5 & NCL-7317069 & 2374 to $1630 \mathrm{a}$ & 65.2 to $67.8 \mathrm{~cm}$ & $0.04 \pm 0.07$ \\
\hline P3 & 84.5 & NCL-7317144 & 2699 to $1720 \mathrm{a}$ & 77.4 to $79.8 \mathrm{~cm}$ & $0.06 \pm 0.17$ \\
\hline BP5 & 34.5 & NCL-7317067 & 41 to $32 \mathrm{a}$ & 4.9 to $9.1 \mathrm{~cm}$ & $0.19 \pm 0.06$ \\
\hline BP5 & 44.5 & NCL-7317066 & 79 to $65 \mathrm{a}$ & 27.3 to $29.6 \mathrm{~cm}$ & $0.60 \pm 0.16$ \\
\hline BP5 & 54.5 & NCL-7317065 & 93 to $80 \mathrm{a}$ & 37.4 to $39.7 \mathrm{~cm}$ & $0.70 \pm 0.49$ \\
\hline BP5 & 64.5 & NCL-7317064 & 108 to $90 \mathrm{a}$ & 47.3 to $49.7 \mathrm{~cm}$ & $0.79 \pm 0.71$ \\
\hline BP5 & 74.5 & NCL-7317063 & 151 to $122 \mathrm{a}$ & 57.3 to $59.7 \mathrm{~cm}$ & $0.27 \pm 0.13$ \\
\hline BP5 & 84.5 & NCL-7317062 & 178 to $145 \mathrm{a}$ & 67.4 to $69.7 \mathrm{~cm}$ & $0.40 \pm 0.36$ \\
\hline BP5 & 94.5 & NCL-7317061 & 218 to 159 a & 76.9 to $80.3 \mathrm{~cm}$ & $0.37 \pm 0.47$ \\
\hline BP5 & 104.5 & NCL-7317060 & 532 to $435 \mathrm{a}$ & 90.4 to $95.5 \mathrm{~cm}$ & $0.05 \pm 0.01$ \\
\hline BP6 & 37.5 & NCL-7317156 & 102 to $41 \mathrm{a}$ & $\begin{array}{l}8.6 \text { to } 10.9 \text { and } \\
18.9 \text { to } 23.8 \mathrm{~cm}\end{array}$ & $0.22 \pm 0.10$ \\
\hline BP6 & 49.5 & NCL-7317155 & 115 to 88 a & 32.3 to $34.7 \mathrm{~cm}$ & $0.61 \pm 0.69$ \\
\hline BP6 & 61.5 & NCL-7317154 & 132 to $106 \mathrm{a}$ & 44.3 to $46.7 \mathrm{~cm}$ & $0.68 \pm 0.71$ \\
\hline BP6 & 74.5 & NCL-7317153 & 150 to $124 \mathrm{a}$ & 57.3 to $59.7 \mathrm{~cm}$ & $0.73 \pm 0.74$ \\
\hline BP6 & 87.5 & NCL-7317152 & 178 to $136 \mathrm{a}$ & 70.3 to $72.7 \mathrm{~cm}$ & $0.66 \pm 0.83$ \\
\hline BP6 & 97.5 & NCL-7317151 & 201 to 147 a & 80.2 to $82.8 \mathrm{~cm}$ & $0.58 \pm 1.15$ \\
\hline BP8 & 37.5 & NCL-7317150 & 129 to $91 \mathrm{a}$ & 20.4 to $22.7 \mathrm{~cm}$ & $0.20 \pm 0.04$ \\
\hline BP8 & 47.5 & NCL-7317149 & 156 to $124 \mathrm{a}$ & 30.3 to $32.6 \mathrm{~cm}$ & $0.33 \pm 0.27$ \\
\hline BP8 & 57.5 & NCL-7317143 & 218 to $172 \mathrm{a}$ & 40.0 to $43.0 \mathrm{~cm}$ & $0.18 \pm 0.10$ \\
\hline BP8 & 67.5 & NCL-7317148 & 258 to 203 a & 50.8 to $57.3 \mathrm{~cm}$ & $0.35 \pm 0.37$ \\
\hline BP8 & 77.5 & NCL-7317142 & 300 to $220 \mathrm{a}$ & 63.0 to $68.5 \mathrm{~cm}$ & $0.40 \pm 0.68$ \\
\hline
\end{tabular}



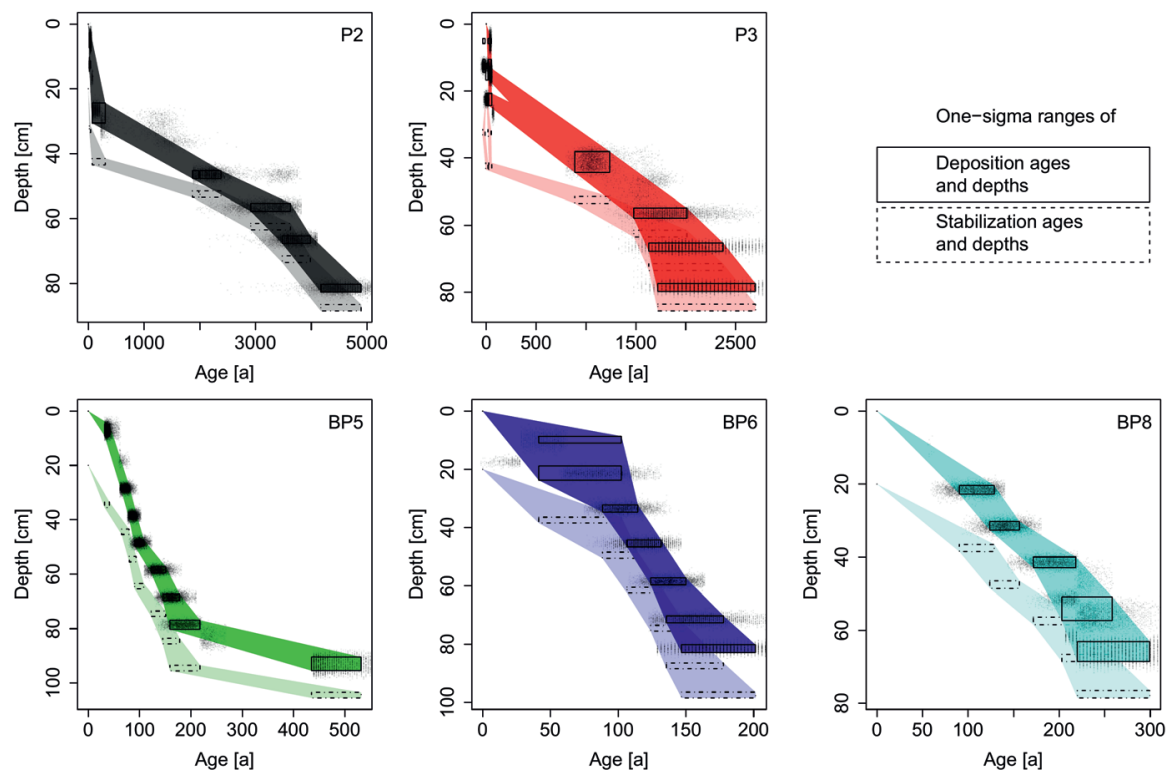

Figure 3.7: Age-depth plots showing the one-sigma ranges for the stabilization ages with the stabilization depths (light shading, dotted lines) and the corresponding deposition depths (dark shading, solid lines). The point clouds indicate the MCMC samples of deposition ages and depths, on which the one-sigma boxes were based. Note that axes differ between plots. In a few cases, bimodal distributions of age or deposition depth resulted in two possible solutions, shows as two separate boxes.

\subsubsection{Deposition rates}

The rates calculated with the stabilization and deposition depths (stabilization rates and deposition rates, respectively) are similar, but represent different processes: stabilization rates represent the speed at which sediments get stabilized below the active mixing layer, and deposition rates represent the actual process of deposition on top of the soil. The two rates differ in between samples where a change in plough regime has occurred: the deposition rates are higher. Stabilization rates between the uppermost samples and the soil surface are much higher than the deposition rates, with the most extreme rate being the one near the surface of location P3. The stabilization rates show an increase from 0.005 to $0.787 \mathrm{~cm} \mathrm{a}^{-1}$ (157-fold increase), with one outlier: a highly uncertain rate of $3.098 \mathrm{~cm} \mathrm{a}^{-1}$ (sample NCL-7317070). For the deposition rates, which are corrected for deposition depths, the range is from 0.008 to $0.788 \mathrm{~cm} \mathrm{a}^{-1}$ (99-fold increase), with the same very uncertain sample with a high rate of $2.168 \mathrm{~cm} \mathrm{a}^{-1}$ (Figure 3.8). The relative uncertainties of the deposition rates increased with an 
average of $7 \%$ when the deposition depths were used, which reflects the uncertainty associated with the reconstructed plough regimes.

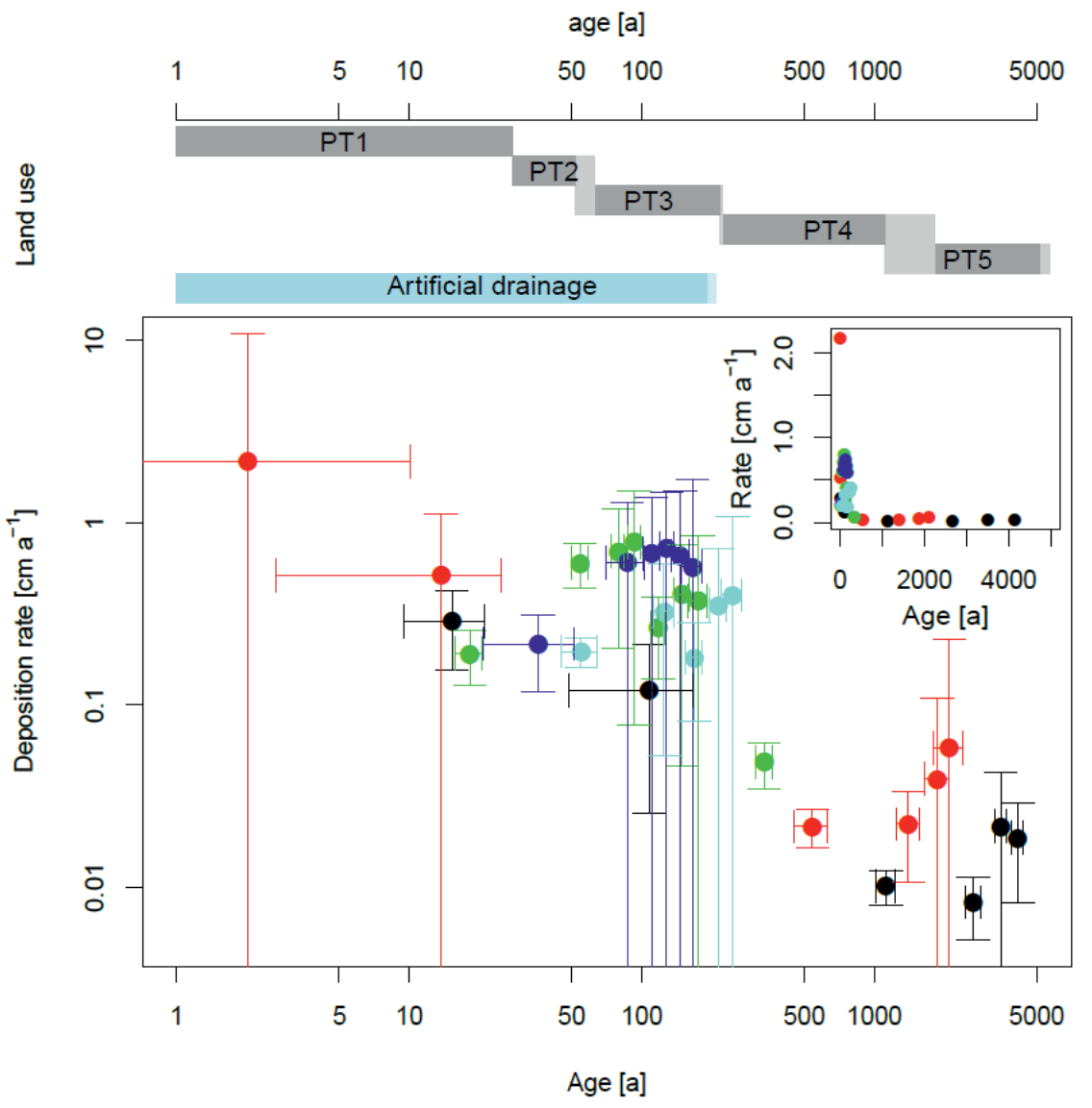

Figure 3.8: One-sigma ranges of age and corresponding deposition rate calculated with the deposition depths. The grey bars in the top indicate the age ranges of different plough use (for codes, see Table 3.1), with lighter colors for the transition zones. The blue bar indicates the period of artificial drainage. Note that the graph has double log-scale axes. The inset shows the deposition rates on linear axes. Colors of the points and lines refer to the different sampling locations and correspond to the colors in Figure 3.7. Note that deposition in the depression appears to start around the time artificial drainage commenced.

At the fringes of the depression (P2 and P3), colluviation started respectively 2900-2200 BCE and $700 \mathrm{BCE}-300 \mathrm{CE}$. In the central depression, this process started much later. BP5 and BP8, on the edges of the peat body, started receiving sediments a few hundred years ago; 
1480-1600 CE and 1710-1800 CE. BP6, close to the center of the depression, has the youngest onset of colluviation, 1820-1870 CE. This shows a gradual infilling of the depression from the sides. Deposition rates have increased substantially over time (Figure 3.8). The rates at the onset of colluviation, from $\mathrm{P} 2$ and $\mathrm{P} 3$, were in the order of $0.01 \mathrm{~cm} \mathrm{a}^{-1}$. These rates have increased by two orders of magnitude up to $\sim 1 \mathrm{~cm} \mathrm{a}^{-1}$ in recent times. 


\subsection{Discussion}

\subsubsection{The benefit of advanced age and rate modeling in colluvial settings}

OSL dating has been widely applied in colluvial settings (Eriksson et al., 2000; Fuchs and Lang, 2009; Dreibrodt et al., 2010; Kappler et al., 2018; Kołodyńska-Gawrysiak et al., 2018). Colluvial deposits often undergo active soil formation (e.g. bioturbation) and land use (e.g. tillage), and this is likely to induce post-bleaching of sediments after deposition (Arnold and Roberts, 2009). On the other hand, transport and mixing processes can also promote postdepositional uptake of older grains. Consequently, colluvial sediments can contain nonbleached grains and post-bleached grains in their corresponding $\mathrm{D}_{\mathrm{e}}$ distributions, which is clearly demonstrated in our samples (Figure 3.6, Supplement 3.3). The young outliers are only sporadically present and their ages do not follow a stratigraphic order. These grains thus represent a more recent mixing process than post-depositional tillage, e.g. bioturbation (Wilkinson et al., 2009). To avoid an influence of these grains on the MAM, these outliers were removed before applying the MAM. One could argue that young and old outliers even each other out, allowing the use of a simple Central Age Model to calculate the age. However, that would be true only coincidence and in fact we found different amounts of rejuvenated and un-bleached outliers in most of our $\mathrm{D}_{\mathrm{e}}$ distributions, invalidating such an approach. Therefore, in colluvial settings with a high probability of post-depositional overprinting of the OSL ages, for example by intensive agrarian land use, a more advanced OSL data analysis is inevitable. Our analytical framework that deals with these young and old outliers combined an outlier removal approach with a bootstrapped Minimum Age Model, and constrained age distributions with stratigraphic information (OxCal). Finally, we corrected the stabilization depths for the post-bleaching effect using archaeological information, allowing us to calculate deposition rates.

We described in the Introduction how ploughing mixes the entire plough horizon, so we expect a homogeneous distribution of bleached grains throughout the entire plough horizon. We illustrate the validity of our framework to extract the ages of these bleached grains with sample NCL-7317068 (Figure 3.6A), which was taken from the plough layer of location P2. We expected this sample to have an age close to zero years, because of its constant reworking. The age will not be completely zero, because it takes some years for the recently-bleached grains to be reworked through the plough layer (cf. Schimmack et al., 1994). The measured 
$D_{e}$ distribution of this sample corresponds to a one-sigma age range of -225 to 389 a (mean: 82 a). This wide distribution is partly caused by the occurrence of non-bleached grains and shows that grains in the active mixing zone are not all completely bleached. The different analysis steps (Figure 3.4) gradually resulted in decreasing uncertainty and diminishing OSL age towards zero years. After outlier removal the one-sigma age range was -25 to 109 a (mean: 42 a), analysis through the MAM resulted in ages of 14-23 a (mean: 18.5 a), and after Bayesian modeling the final age estimate was 13-22 years (mean: $17.5 \mathrm{a}$ ). This finding shows that using a MAM and OxCal to calculate stabilization ages from heterogeneous colluvial samples substantially decreases age uncertainty and provides a reasonable age for a plough layer. The small deviation from the zero age may represent the time it takes for bleached grains to get reworked into the plough layer, or it can represent the lower dating limits of our framework due to methodological and statistical limitations (Madsen and Murray, 2009; Wallinga and Cunningham, 2013). The two patterns we see for sample NCL-7317068 are also visible in most other samples (Supplements 3.3 and 3.4): 1) the uncertainty of the OSL ages reduces substantially during all steps in the analysis, and, 2) the stabilization age often corresponds well to the mode of the density function of the measured age before outlier removal. The second point indicates that the samples contain sufficient grains that have been bleached during ploughing. There were also differences between stabilization ages and measured ages, e.g. with bi-modal distributions (sample NCL-7317040, -151), or stratigraphic discontinuities (sample NCL-7317041). Our framework favored the younger, lower peak of the distributions, because we used a MAM, or because the younger ages differed the most from the ages of the samples above and below the sample. Such complex age distributions can thus result in a loss of age information following our framework. Nonetheless, the age we are interested in, the younger stabilization age, gets selected. Another limitation of $\mathrm{OxCal}$ is the changing of some ages for no apparent reason, such as the lowest sample at BP5 (NCL-7317060, Figure 3.6G). This was the lowest sample taken at this location, in the former surface horizon. There was no chronologic information present below this sample, so there was no clear reason to reduce the age of this sample. This effect did not occur in the samples from the former surface horizons of the other locations.

Only the near-surface sample NCL-7317068 allowed a formal validation, because we know the age of this sample should be close to zero. Additionally, the stratigraphic consistency of the measured age distributions, similar age patterns in most samples, and the correlation of 
our ages to archaeological indices of land-use change (next Section) give us confidence that our methodology successfully extracts the stabilization ages from the heterogeneous $D_{e}$ distributions. Our approach could be applied to other colluvial settings as well, after adjustments to local archaeological information.

By bootstrapping the MAM and calculating the deposition depths using a Markov Chain Monte Carlo approach, we created a robust model to calculate stabilization ages and associated deposition depths. The ages and depths comprised the uncertainties resulting from the lab analysis as well as from the archeological reconstruction, while avoiding disturbance by unbleached and rejuvenated grains. Results of our study clearly show the impact of the post-bleaching effect on calculation of deposition rates (Figure 3.7). Deposition depths, corrected for this post-bleaching, are located substantially shallower in the soil than the conventional stabilization depths. Rates derived from these deposition depths indicate more intensive deposition before agricultural intensification than rates derived from stabilization depths. Also, the high deposition rates near the surface that would be obtained when using stabilization depths were shown to be significantly lower in reality. The correction for postdepositional mixing increased the uncertainty of the deposition rates. If the post-depositional mixing is ignored and stabilization depths and ages are used to calculate rates the uncertainty would be lower. However, this approach would calculate rates of stabilization rather than the rates of deposition in which we are interested. The two types of rates are correlated, but represent a different process. Because we know post-depositional mixing occurs in agrarian settings, and we know that the uncertain reconstructed ploughing depths affect the deposition rates, this uncertainty must be considered in the calculation of deposition rates. On top of that, the relative uncertainty of deposition rates is on average only $7 \%$ higher than the uncertainty of stabilization rates, indicating that the stabilization ages contribute the majority of uncertainty to the deposition rates.

OSL is not the only geochronological method that must take the effect of post-depositional mixing into account. Our reasoning also applies to radiocarbon dating, which dates organic soil particles such as pollen, organic matter and charcoal, and radionuclide dating (e.g. Cs137, Alewell et al., 2014). These particles are also mixed through the soil by bioturbation and tillage. The depths at which these particles are found therefore do not necessarily correspond to the layer at which they were deposited. 


\subsubsection{Spatial and temporal patterns of deposition}

\subsubsection{Spatially varying onset of deposition}

Our sampling design with high spatial density revealed unexpected patterns in colluviation. The sediment ages can be grouped in two age groups: older sediments ( $>300$ years) and recent sediments ( $<300$ years). The onset of colluviation varied several thousands of years over very small distances, in two distinct phases of mass movement (Figure 3.3, Figure 3.7 \& Figure 3.9) which are discussed below. This demonstrates that sampling locations for geochronological studies in colluvial settings should be selected with great care and, specifically, not solely placed at positions with the thickest colluvium.

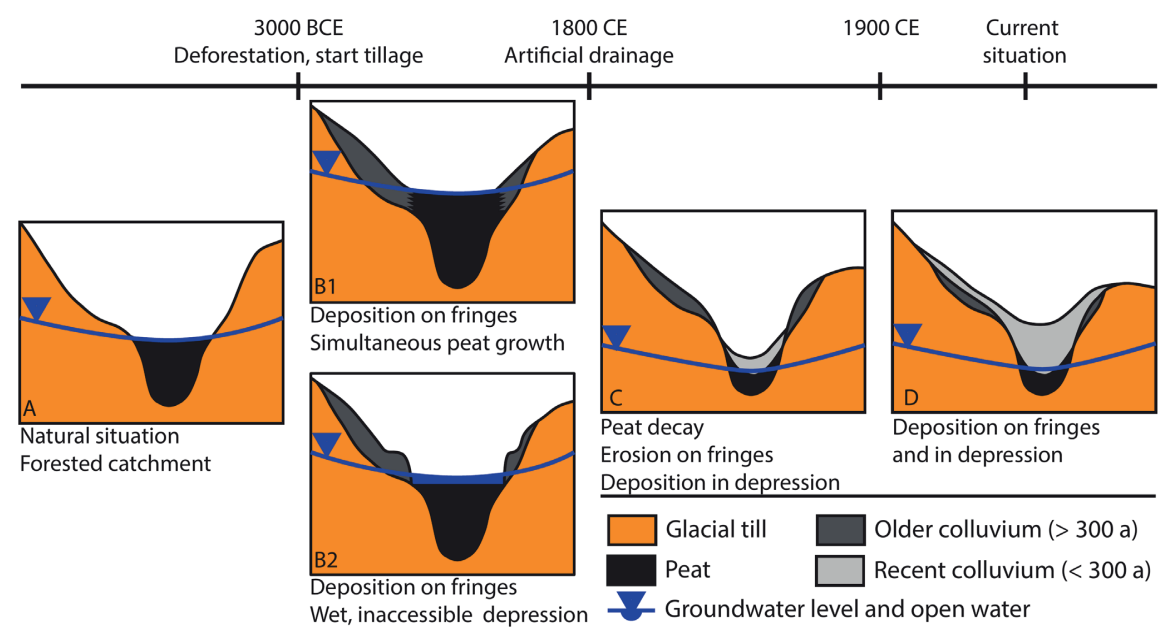

Figure 3.9: Conceptual model of kettle hole development over time.

An explanation for the two phases of deposition can be found in changes in the hydrological situation of these kettle holes. Originally, the depressions were filled with water and peat (kettle lakes, Figure 3.9A). With deforestation and the start of agriculture (Table 3.1), slope sediments were exposed and started to move towards the depression, where they were deposited around the kettle lake (old sediments in Figure 3.9). Deforestation also led to wetter conditions in the kettle hole by reduced evaporation (Twine et al., 2004; Lamentowicz et al., 2008; Mao and Cherkauer, 2009), increasing the water level and peat growth simultaneously with sediment deposition. There are two plausible blocking mechanisms preventing the sediments from entering the central depression: 1) the rising groundwater level and resulting 
peat formation following deforestation (Figure 3.9B1), and 2) a terrace-like landform, formed by (pre)historic ploughing around the depression (Figure 3.9B2). These terrace-like shapes surrounding kettle holes can still be observed in currently forested kettle holes (Van der Meij et al., 2017) as well as in a large number of agrarian kettle holes in the Uckermark region which are currently filled with water. Both blocking mechanisms may have co-existed and both would be related to the wet conditions inside the central depression.

In the $18^{\text {th }}$ century population density increased substantially after the Thirty Years' War (Hinze, 1981). The higher demand for agricultural land forced people to drain the wet depressions in the landscape. The construction of drainage ditches and tile drainage enabled the reclamation of these wet spots in the landscape. In the last centuries, agricultural drainage greatly reduced the amount and extent of water bodies in kettle holes (Kochanowska et al., 1998). In our land-use reconstruction (Table 3.1, Supplement 3.1), we used historical maps to show the construction of a ditch draining our kettle hole in between 1787 and $1826 \mathrm{CE}$. Larger areas of peatlands in the Uckermark were drained even earlier (Behre, 2008; Kaiser et al., 2012; Kaiser et al., 2014). The lower water level made the central depression accessible for agricultural use. The start of artificial drainage coincides with the oldest colluvium ages at locations BP5 and BP6 (Figure $3.7 \&$ Figure 3.8). The sample from the former surface horizon in BP5 and the lowest samples from BP8, located at the edges of the colluvium, show ages which are $\sim 100$ years older than the introduction of artificial drainage, indicating earlier deposition at the edges of the peaty depression. The drainage substantially increased deposition rates in the depression, forming a layer of young sediments, which originated from the fringe positions and higher upslope areas (Figure 3.9C). Ultimately, the entire kettle hole became covered with young sediments (Figure 3.9D). This conceptual model shows that spatial and temporal variation in deposition has to be considered in geochronological studies in colluvial settings. Geochronological approaches such as ours can prevent incorrect correlation of colluvial layers, by separating colluvial layers with different ages.

The interpretation above indicates that the fringes of the depression have two depositional phases, which are visible in their age-depth profiles (Figure 3.7). These phases correspond with a hiatus in soil horizonation in the colluvium. The old colluvium in P2 and P3 shows signs of clay migration (lessivation). In the recent sediments, these signs are not optically visible, indicating a different pedogenesis; closer the center of the depression, upward movement of water and gleyzation become more important. The absence of a former surface 
horizon in between the two layers in P2 and P3 indicates either erosion of a part of the earlier colluvium, or incorporation of the former surface horizon into the newly added colluvium by ploughing. The presence of clay migration features thus can be used as a proxy for colluvium age, as these features are more frequently observed in old colluvial infillings of depressions, but not in the younger ones (e.g. Kołodyńska-Gawrysiak et al., 2018). A consequence of possible erosion on the fringes is underestimation of deposition rates through the hiatus, because part of the old sediments would have been removed.

The two distinct phases of colluvial infilling we observed in our study area should be expected in other kettle holes underlain with peat as well, which are the dominant type of kettle holes in the Uckermark region (see Study Area Section). Another geochronological study covering four kettle holes in the Uckermark region showed substantially different stratigraphies and chronologies, but none of those locations had a substantial peat body in the subsurface (Kappler et al., 2018). Rather, the peat that was observed was interlaid with colluvial deposits. This regional diversity in kettle hole infilling again stresses the importance of understanding the stratigraphy in a study area first before taking geochronological samples. Each location might have experienced a different geomorphic and land-use history, affecting the chronology of the deposits and representability of the results for a larger area.

\subsubsection{Phases and rates of deposition}

As indicated before, two phases of colluvial soil redistribution could be distinguished in our kettle hole. The start of the oldest phase corresponds to the timing of (pre)historic settlement (Kappler et al., 2018). Colluviation at location P2, 2900-2200 BCE, started a few hundred years earlier than the first ages of Kappler et al. (2018), but the acceleration of colluvial dynamics between $1500 \mathrm{CE}$ and now is detected in both study sites. The oldest ages at P2 coincide with the habitation increase and agricultural intensification in the Neolithic in the area (Jahns, 2000, 2001), and a general increase of luminescence ages derived from colluvium in NE Germany (Kappler et al., 2019). The start of colluviation at P3, 700 BCE$300 \mathrm{CE}$, coincides with settlement during the Iron Age and Roman Age (Jahns, 2001). The different upslope topography of positions P2 and P3 could also have caused the differences in onset of colluviation. P2 had a steeper upslope area, with a much shorter distance to the crest. The shorter transport distances and higher erosion potential could have caused this 
position to accumulate colluvium at an earlier stage than P3, where the transport distance was much larger.

The deposition rates at CarboZALF-D increased by two orders of magnitude between the start of colluviation and present (Figure 3.8). Recent deposition rates are similar to those reported for other kettle holes (e.g. Frielinghaus and Vahrson, 1998). The increase in deposition rates coincides with increase in population density and agricultural intensification from the $18^{\text {th }}$ century onwards (Hinze, 1981; Dotterweich, 2008). The more intensive agricultural practices, together with larger, more connected fields (Dotterweich, 2008), increased the sediment flux towards the depression. The recent high deposition rates found in the central depression should however not only be attributed to this agricultural intensification, but also to the reclamation of the central depression. The reclamation created a large elevation gradient, which promoted transport of previously deposited sediments from the fringes into the depression (Figure 3.9). The deposition rate is thus dependent on landscape position and does not correspond one-to-one with increased erosion rates in the catchment.

The deposition rates we found are comparable to the erosion rates found in various Central European loess catchments, as compiled by Kołodyńska-Gawrysiak et al. (2018). It is however difficult to make a quantitative comparison between erosion and deposition rates from different studies, due to their dependence on local topography and land-use history. This also complicates evaluation of our improved methodology to calculate deposition rates from colluvial sediments; deposition rates calculated with deposition ages and depths show the same trends as the rates calculated with stabilization ages and depths, except for the youngest rates. Nonetheless, we believe our approach yields more realistic results than conventional methods, because it considers the effects of incomplete bleaching and postbleaching, which are processes that affect sediments in every setting where tillage plays a role in sediment mixing and transport. 


\subsection{Conclusions}

Determining timing and rates of erosion and deposition is difficult due to various mixing and transport processes. This hampers linking deposition histories to land-use history, and assessing the landscape responses to e.g. deforestation and ploughing. OSL methods are often used to determine deposition histories, but the effect of post-bleaching by e.g. tillage at the location of deposition is often not considered. We present a novel approach to include tillage effects in the calculation of stabilization ages of colluvial sediments and corresponding deposition rates. We applied this framework to 32 OSL samples to study the complex spatial and temporal infilling of a kettle hole in an agrarian hummocky landscape in northeastern Germany. Our main findings were:

- Colluvial deposits show a large spread in the level of bleaching of the grains. However, OSL ages can be extracted using advanced age modeling techniques and corresponding deposition rates can be derived using an archeological reconstruction of plough depths.

- The combination of outlier removal, a bootstrapped Minimum Age Model and stratigraphic correction substantially reduces the age uncertainty of colluvial deposits. If colluvial deposits are ploughed after deposition, a correction for postbleaching by tillage is required to derive deposition ages and depths from the stabilization ages determined by OSL dating. Although this procedure results in slightly greater uncertainty, the deposition age estimates are more accurate.

- The calculated stabilization ages generally coincide with the mode of the measured $\mathrm{D}_{\mathrm{e}}$ distributions, indicating that a substantial amount of grains is well-bleached during post-depositional mixing.

- The investigated kettle hole shows a complex infilling, with the oldest colluvium at the fringes of the depression, and the youngest colluvium in the center of the depression and overlying the older colluvium at the fringes. This was probably as a consequence of changing hydrological situation. The start of deposition varied 1000 s of years over a distance of tens of meters.

- Deposition rates in the kettle hole increased by two orders of magnitude between the start of colluviation $(\sim 3000 \mathrm{BCE})$ and present. The spatial and temporal deposition patterns depend heavily on landscape position and land use, such as 
artificial drainage. Therefore, a local increase in deposition rates does not necessarily imply increased erosion rates throughout the catchment.

This study demonstrates that determination and interpretation of colluvial sediment ages and deposition rates is possible using state-of-the-art OSL dating methods. We recommend the use of numerical dating techniques in combination with thorough soil-geomorphological field surveys and historical analysis of land use to elucidate complicated spatiotemporal patterns of landscape change. 


\section{Supplement 3.1 Archaeological reconstruction of land-use history in the Uckermark region}

Here we provide a reconstruction of land use in the Uckermark region from prehistoric times up to now. We focus on the use of ploughs and the application of artificial drainage. The main findings are summarized in Table S3.1 and were used for reconstruction of deposition rates in the study area.

The first marked human impact on the environment in northeast Germany, during the Neolithic, is - as in most parts of northwestern Europe - linked to the adoption of an agrarian subsistence economy. In northern Germany and southern Scandinavia this was a complex and regionally diverse process (Hartz et al., 2007; Schier, 2009; Kirleis et al., 2012). The first agrarian societies in the Brandenburg region belong to a northernmost outlier of the Linearbandkeramik Culture, roughly dated to the early 5th millennium BCE, followed by the Rössen Culture (Gralow, 1981; Leciejewicz and Gringmuth-Dallmer, 1996; Fischer-Zujkov, 2001). These societies practiced a primitive, small-scale form of agriculture, probably using simple tools such as hoes and sticks to work the soil (Bogaard, 2004; Schier, 2009). The palynological records at the Felchowsee site near the studied kettle hole do not show a marked human impact on the vegetation in this phase (Jahns, 2000). This changes with the appearance of the Funnel Beaker Culture, in the 4th millennium BCE (Kirsch, 1994). This cultural group is generally linked to the introduction of the ard plough in northern Europe. This plough type consists of a beam to which a stilt or handle was attached and to which the draught animals, generally oxen, were harnessed. These two parts are fixed in the sole or share beam (Fussell, 1966). The ard creates narrow and relatively shallow furrows with a depth between 5 and $6 \mathrm{~cm}$, without turning the soil (Herrmann, 1985). Although soil mixing will have been less efficient than with current soil turning practices, we expect the effective mixing depth to equal the furrow depth, as grains will fall into the farrows after ploughing.

It is generally accepted, partly based on experiments using replicas of prehistoric finds, that the use of an ard was only suitable for lighter, sandy soils (e.g. Hansen et al., 1969; Pavelka et al., 2017). The glacial till in the Uckermark is partly covered with a thin layer of cover sands. Clay lessivation during soil development on glacial tills without cover sands led to a similar high and content in topsoils. Both processes enabled the use of the ard. The oldest evidence for the use of ards is formed by furrows discovered underneath various (megalithic) 
barrows. The available radiocarbon dates for these sites, mainly recorded in southern Scandinavia (Sherratt, 1981; Mischka, 2011; Sørensen and Karg, 2014), cluster between 3700-3200 BCE. As various Funnel Beaker sites have been found in the Brandenburg region (e.g. Kirsch, 1994) and pollen records show an accelerated human impact in this phase (Jahns, 2000, 2001) we will use this date in our model as well. The ard stayed in use until the introduction of the mouldboard plough, millennia later, and it is likely that both types coexisted until well into the Middle Ages (Van den Broeke, 2005; Behre, 2008).

Table S3.1: Overview of introduction and impact of different plough types and artificial drainage in the Uckermark region.

\begin{tabular}{|c|c|c|c|c|}
\hline Management type & $\begin{array}{l}\text { Introduction year of } \\
\text { management type }\end{array}$ & $\begin{array}{l}\text { Impact on soil } \\
\text { and landscape }\end{array}$ & $\begin{array}{l}\text { Mixing } \\
\text { depth }\end{array}$ & Source \\
\hline Ard plough & $3700-3200 \mathrm{BCE}$ & $\begin{array}{l}\text { Narrow, } \\
\text { shallow } \\
\text { furrows in the } \\
\text { soil. }\end{array}$ & $5-7 \mathrm{~cm}$ & $\begin{array}{l}\text { (Herrmann, 1985; } \\
\text { Kirsch, 1994; Behre, } \\
\text { 2008) }\end{array}$ \\
\hline $\begin{array}{l}\text { Medieval } \\
\text { mouldboard plough }\end{array}$ & $200-900 \mathrm{CE}$ & $\begin{array}{l}\text { Turning of the } \\
\text { soil, creating } \\
\text { high-backed } \\
\text { ridges. }\end{array}$ & $8-15 \mathrm{~cm}$ & $\begin{array}{l}\text { (Lerche, 1994; Van } \\
\text { den Broeke, 2005; } \\
\text { Behre, 2008; } \\
\text { Andersen et al., } \\
\text { 2016; Larsen, 2016) }\end{array}$ \\
\hline $\begin{array}{l}\text { Early modern } \\
\text { mouldboard plough }\end{array}$ & $1795-1800 \mathrm{CE}$ & & $15-17 \mathrm{~cm}$ & $\begin{array}{l}\text { (Thaer, 1803; Opitz, } \\
\text { 1938) }\end{array}$ \\
\hline $\begin{array}{l}\text { Contemporary } \\
\text { mouldboard plough }\end{array}$ & $1954-1965 \mathrm{CE}$ & & $25-30 \mathrm{~cm}$ & $\begin{array}{l}\text { (Sommer et al., } \\
\text { 2008), current field } \\
\text { observations }\end{array}$ \\
\hline $\begin{array}{l}\text { Current mouldboard } \\
\text { plough }\end{array}$ & $1989 \mathrm{CE}$ & & $20 \mathrm{~cm}$ & (Verch, 2018) \\
\hline Artificial drainage & $1787-1826 \mathrm{CE}$ & \multicolumn{2}{|c|}{$\begin{array}{l}\text { Lowering water level in the } \\
\text { kettle hole, increasing its } \\
\text { accessibility for ploughing }\end{array}$} & $\begin{array}{l}\text { (von Schmettau, } \\
\text { 1787; Preußische } \\
\text { Urmesstischblätter, } \\
1826 \text { ) }\end{array}$ \\
\hline
\end{tabular}

When the mouldboard plough was introduced in northern Europe is a matter of debate. Andersen et al. (2016) date the widespread adoption of the mouldboard around 900-1000 CE, linking this important innovation to the medieval agricultural revolution. However, they do not exclude the possibility of an earlier introduction in certain regions. Indeed, Danish archaeological evidence points to an introduction around $200 \mathrm{CE}$ (Larsen, 2016). Furthermore, an origin in the last centuries BCE has been suggested for the sandy coastal areas of the Netherlands and northwest Germany, too (Van den Broeke, 2005; Behre, 2008). Current archaeological information on the Brandenburg region does not allow a definitive 
decision. That is why we use the more general introduction age of the mouldboard plough from NW Europe, which is 200-900 CE. What is known from the Uckermark region, is that it was temporarily abandoned during the Migration Period $\left(6^{\text {th }}\right.$ and $7^{\text {th }}$ century CE) and in the Late Middle Ages (14th and 15th century, Fischer-Zujkov, 2001), implying a period without agriculture and thus probably without substantial anthropogenic soil reworking.

The mouldboard plough consists of three elements: an asymmetric plough share, which cuts the soil horizontally, a coulter, which cuts the soil vertically, and a mouldboard that turns the cut sods aside to create a deep furrow (Andersen et al., 2016). The plough produces highbacked ridges. Compared to the ard, its main advantages are a better weed control, improved drainage, applicability in a wider variety of soil types (including clay) and a higher timeefficiency. Due to the active turning of the soil, a mouldboard plough is very efficient in mixing the complete plough layer.

We assume the mixing and OSL bleaching depth of the first, medieval, mouldboard plough to range between 8-15 cm (Lerche, 1994). These depths are comparable to other studies describing with medieval ploughs (12 cm, Behre, 2008; 10-20 cm, Pavelka et al., 2017). At the start of the $19^{\text {th }}$ century, the plough depth of the early modern mouldboard plough was 15-17 cm (Thaer, 1803; Opitz, 1938). In the 1920s CE, the first trials were done on increasing the plough depth from 15-17 to 26-30 cm (Opitz, 1938). After the Second World War, between 1954 and $1960 \mathrm{CE}$, small agricultural fields were collectivized and agricultural practices were modernized. The plough depth of the contemporary mouldboard plough increased from the 1960s to the mid-1970s from 25 to $30 \mathrm{~cm}$ as a result of increased tractor power and the new GDR intensification strategy, called 'Komplexmelioriation'. The increased plough depth is still documented in the average Ap horizon thickness of $30 \mathrm{~cm}$ in the Quillow catchment (Sommer et al., 2008). Since re-unification of Germany in 1989, tillage systems in the Uckermark are characterized by a reduction of the current ploughing depth to $\sim 20 \mathrm{~cm}$ due to the increase in fuel costs for farmers. No-till systems are not widely used.

Artificial drainage of wetlands via open ditches started several hundred years ago. Larger peatlands and lakes were the first areas to be drained (Behre, 2008; Kaiser et al., 2012; Kaiser et al., 2014). With increasing population and higher food demand smaller colluvial depressions were started to be drained as well. Tile drainage was not applied before the 
middle $19^{\text {th }}$ century as the first manufactures for clay tubes in Berlin started production from 1850 onwards (Wulf et al., 2010). From historical maps we can confine the onset of drainage at our CarboZALF-D (Figure S3.1). Whereas in the late $18^{\text {th }}$ century surrounding kettle holes were already drained, the studied kettle hole was not (Figure S3.1, left). In the first Prussian Land Survey Map (1826) a ditch between the CarboZALF-D kettle hole and the next larger wetland clearly can be identified (Figure S3.1, right). As the drainage system was successively improved we can assume a continuous drainage of the studied depression since approximately 200 years.
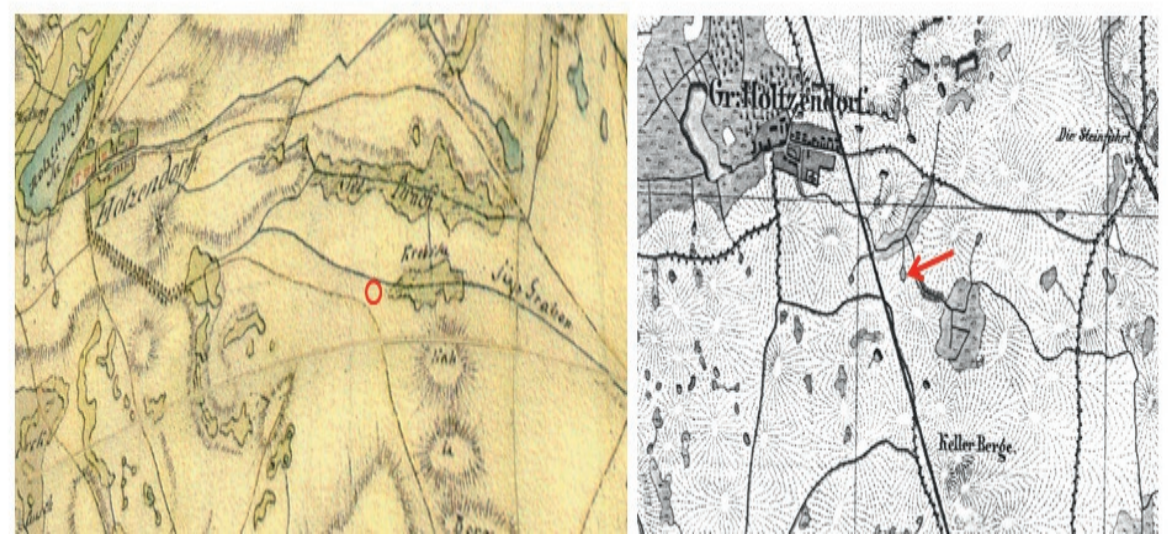

Figure S3.1: The location of the CarboZALF-D experimental site in historical maps: red circle in Schmettau Map 1767-87 (left, von Schmettau, 1787); red arrow in first Prussian Land Survey Map 1826 (right, Preußische Urmesstischblätter, 1826). 


\section{Supplement 3.2 Photos and descriptions of the sampled profiles}

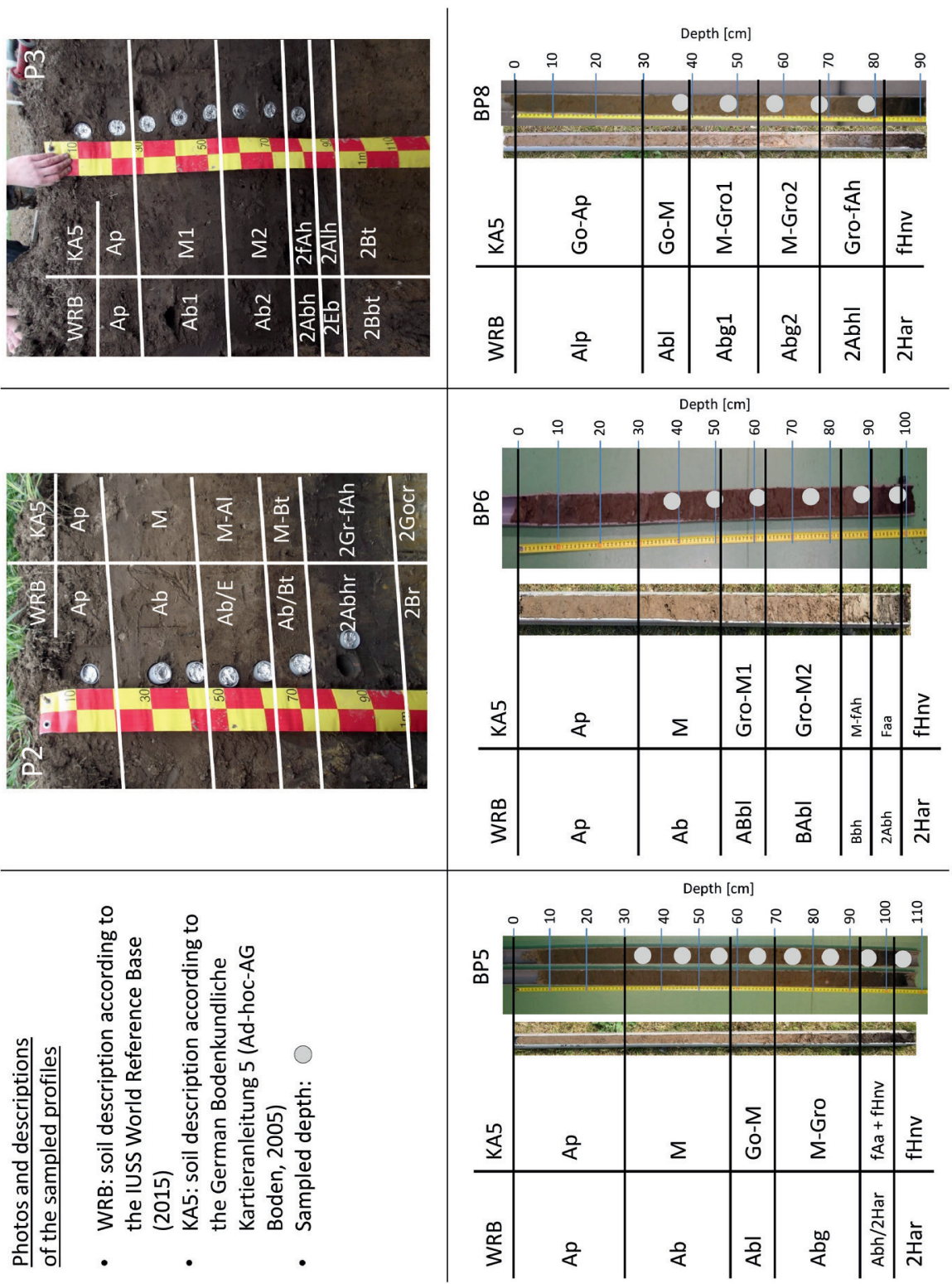

Figure S3.2: Photos and descriptions of the sampled profiles 


\section{Supplement 3.3 Age-density plots of all samples, for each step in the analysis}
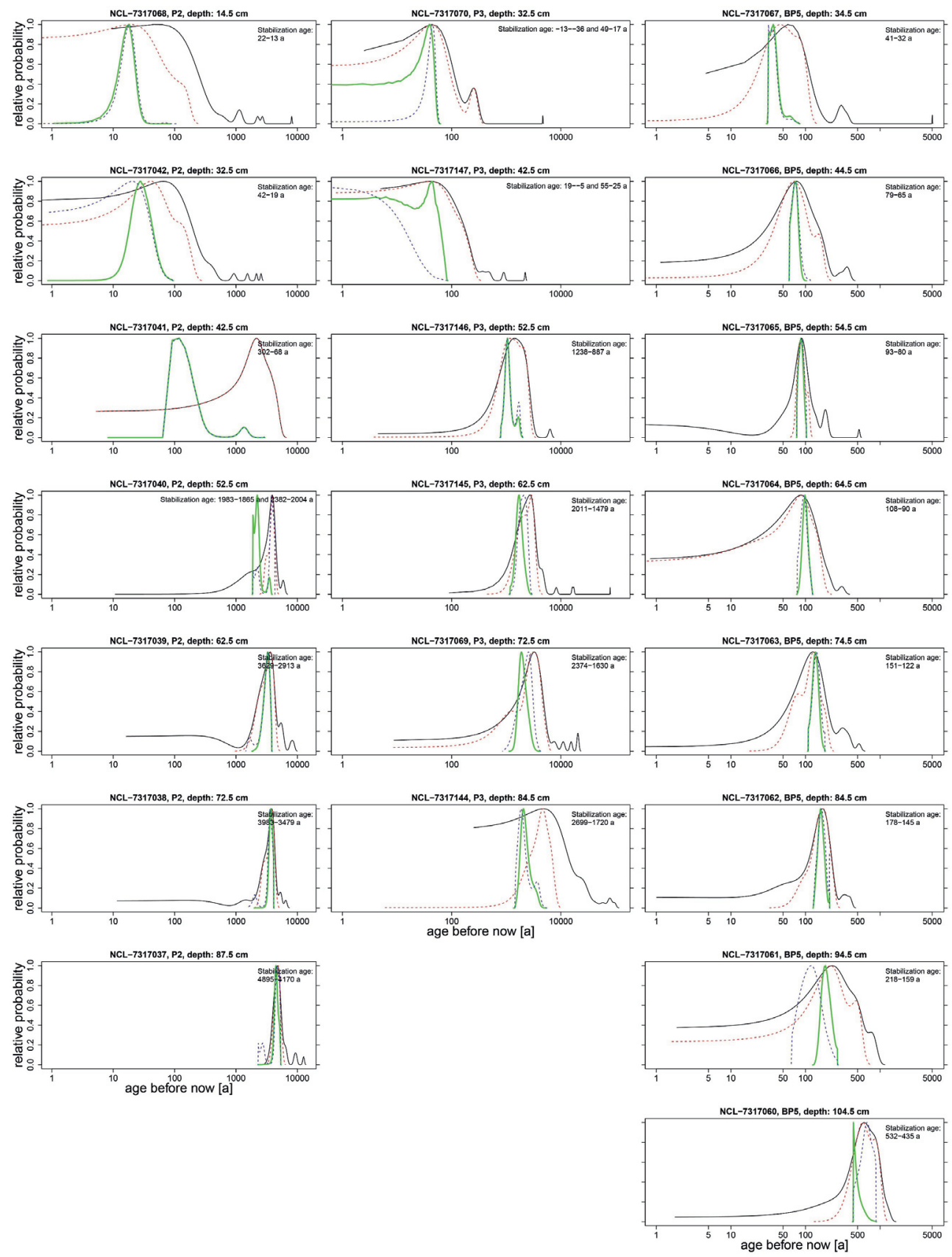

Figure S3.3: Age-density plots of all samples, for each step in the analysis 

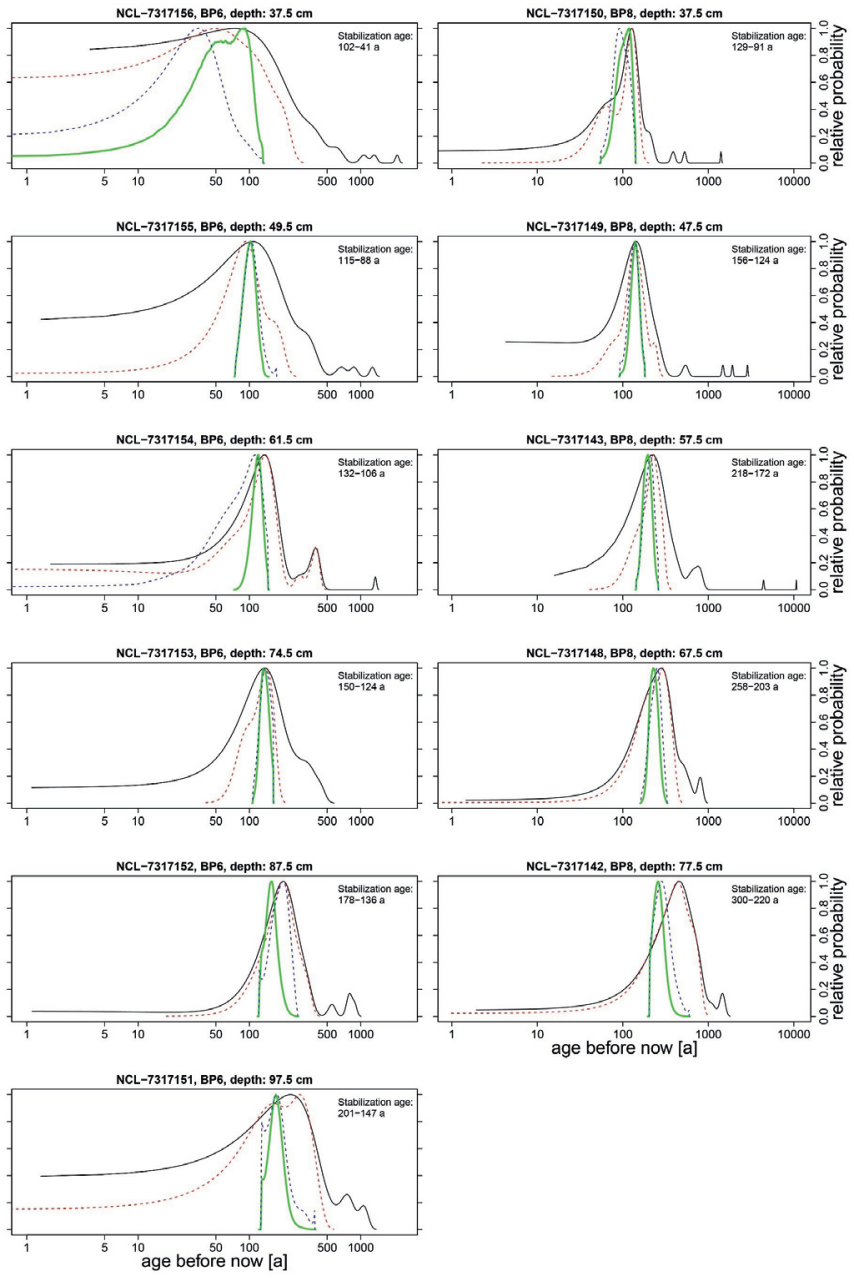

Age density plots with logarithmic $\mathrm{x}$-axis

Measurements

- - Measurements (after outlier removal)

- - - MAM likelihood age (after bootstrapping)

Stabilization age (after OxCal)

Figure S3.3, continued 


\section{Supplement 3.4 Lab results and reconstructed ages and rates for each sample in each step in the analysis}

Table S3.2: Lab results for each sample

\begin{tabular}{|c|c|c|c|c|c|c|c|c|}
\hline Loc. & $\begin{array}{l}\text { Depth } \\
{[\mathrm{cm}]}\end{array}$ & Sample code & $\begin{array}{l}\text { Number of } \\
\text { aliquots } \\
\text { (+accepted) }\end{array}$ & $\begin{array}{l}\text { Water } \\
\text { content } \\
(+ \text { error) } \\
{\left[\mathrm{g} \mathrm{kg}^{-1}\right]} \\
\end{array}$ & $\begin{array}{l}\text { Soil } \\
\text { organic } \\
\text { matter } \\
\text { content } \\
\text { (+error) } \\
{\left[\mathrm{g} \mathrm{kg}^{-1}\right]}\end{array}$ & $\begin{array}{l}\text { Dose rate } \\
\text { (+error) } \\
{\left[\mathrm{Gy} \mathrm{ka}^{-1}\right]}\end{array}$ & $\begin{array}{l}\text { Total } \\
\text { shared } \\
\text { error } \\
{[\%]}\end{array}$ & $\begin{array}{l}\text { Total } \\
\text { unshared } \\
\text { error } \\
{[\%]}\end{array}$ \\
\hline P2 & 14.5 & NCL-7317068 & $24(15)$ & $171(43)$ & $24(6)$ & $2.14(0.09)$ & 2.4 & 3.3 \\
\hline P2 & 32.5 & NCL-7317042 & $27(18)$ & $119(30)$ & $20(5)$ & $2.28(0.08)$ & 2.3 & 2.6 \\
\hline P2 & 42.5 & NCL-7317041 & $30(30)$ & $118(30)$ & $17(4)$ & $2.38(0.08)$ & 2.4 & 2.5 \\
\hline $\mathrm{P} 2$ & 52.5 & NCL-7317040 & $33(22)$ & $161(40)$ & $17(4)$ & $2.4(0.09)$ & 2.4 & 3 \\
\hline P2 & 62.5 & NCL-7317039 & $32(24)$ & $161(40)$ & $21(5)$ & $2.55(0.1)$ & 2.4 & 3 \\
\hline P2 & 72.5 & NCL-7317038 & $29(23)$ & $169(42)$ & $20(5)$ & $2.47(0.1)$ & 2.4 & 3.1 \\
\hline P2 & 87.5 & NCL-7317037 & $25(20)$ & $181(45)$ & $17(4)$ & $2.47(0.1)$ & 2.4 & 3.3 \\
\hline P3 & 32.5 & NCL-7317070 & $24(22)$ & $148(37)$ & $22(5)$ & $2.23(0.08)$ & 2.3 & 2.9 \\
\hline P3 & 42.5 & NCL-7317147 & $27(23)$ & $139(35)$ & $25(6)$ & $2.24(0.08)$ & 2.3 & 2.8 \\
\hline P3 & 52.5 & NCL-7317146 & $26(24)$ & $129(32)$ & $14(4)$ & $2.33(0.08)$ & 2.4 & 2.7 \\
\hline P3 & 62.5 & NCL-7317145 & $38(29)$ & $136(34)$ & $17(4)$ & $2.34(0.09)$ & 2.4 & 2.8 \\
\hline P3 & 72.5 & NCL-7317069 & $23(18)$ & $171(43)$ & $24(6)$ & $2.25(0.09)$ & 2.4 & 3.1 \\
\hline P3 & 84.5 & NCL-7317144 & $31(19)$ & $149(37)$ & $19(5)$ & $2.37(0.09)$ & 2.4 & 2.9 \\
\hline BP5 & 34.5 & NCL-7317067 & $27(15)$ & $161(40)$ & $27(7)$ & $2.59(0.1)$ & 2.4 & 3 \\
\hline BP5 & 44.5 & NCL-7317066 & $28(23)$ & $165(41)$ & $28(7)$ & $2.65(0.1)$ & 2.4 & 3.1 \\
\hline BP5 & 54.5 & NCL-7317065 & $31(16)$ & $168(42)$ & $26(6)$ & $2.52(0.1)$ & 2.4 & 3.1 \\
\hline BP5 & 64.5 & NCL-7317064 & $28(25)$ & $175(44)$ & $24(6)$ & $2.34(0.09)$ & 2.4 & 3.2 \\
\hline BP5 & 74.5 & NCL-7317063 & $27(20)$ & $186(47)$ & $24(6)$ & $2.18(0.09)$ & 2.3 & 3.3 \\
\hline BP5 & 84.5 & NCL-7317062 & $27(20)$ & $263(66)$ & $36(9)$ & $2.1(0.1)$ & 2.3 & 4.1 \\
\hline BP5 & 94.5 & NCL-7317061 & $32(26)$ & 557 (139) & $120(30)$ & $1.85(0.13)$ & 2.3 & 6.7 \\
\hline BP5 & 104.5 & NCL-7317060 & $32(28)$ & $1527(382)$ & 409 (102) & $1.25(0.11)$ & 2 & 8.8 \\
\hline BP6 & 37.5 & NCL-7317156 & $36(22)$ & $140(35)$ & $15(4)$ & $2.32(0.09)$ & 2.4 & 2.8 \\
\hline BP6 & 49.5 & NCL-7317155 & 27 (17) & $157(39)$ & $19(5)$ & $2.28(0.09)$ & 2.4 & 3 \\
\hline BP6 & 61.5 & NCL-7317154 & $25(22)$ & $156(39)$ & $18(5)$ & $2.23(0.08)$ & 2.3 & 3 \\
\hline BP6 & 74.5 & NCL-7317153 & $27(16)$ & $203(51)$ & $21(5)$ & $2.26(0.1)$ & 2.4 & 3.5 \\
\hline BP6 & 87.5 & NCL-7317152 & $25(20)$ & 277 (69) & $35(9)$ & $2.44(0.12)$ & 2.4 & 4.4 \\
\hline BP6 & 97.5 & NCL-7317151 & $24(17)$ & $631(158)$ & $130(32)$ & $2.09(0.15)$ & 2.3 & 6.8 \\
\hline BP8 & 37.5 & NCL-7317150 & $27(19)$ & $157(39)$ & $12(3)$ & $2.31(0.09)$ & 2.4 & 3 \\
\hline BP8 & 47.5 & NCL-7317149 & $25(17)$ & $174(44)$ & $15(4)$ & $2.18(0.09)$ & 2.3 & 3.2 \\
\hline BP8 & 57.5 & NCL-7317143 & 27 (17) & $195(49)$ & $19(5)$ & $2.04(0.09)$ & 2.3 & 3.9 \\
\hline BP8 & 67.5 & NCL-7317148 & $25(19)$ & 195 (49) & $15(4)$ & $2.11(0.09)$ & 2.3 & 3.4 \\
\hline BP8 & 77.5 & NCL-7317142 & $27(22)$ & $433(108)$ & $76(19)$ & $2.24(0.14)$ & 2.4 & 5.6 \\
\hline
\end{tabular}


Table S3.3: reconstructed ages and rates for each step in the analysis

\begin{tabular}{|c|c|c|c|c|c|c|c|}
\hline Loc. & $\begin{array}{l}\text { Depth } \\
{[\mathrm{cm}]}\end{array}$ & $\begin{array}{l}\text { Measured } \\
\text { age } \\
\text { [a] }\end{array}$ & $\begin{array}{l}\text { Measured } \\
\text { age, without } \\
\text { outliers } \\
\text { [a] }\end{array}$ & $\begin{array}{l}\text { Bootstrapped } \\
\text { MAM age } \\
{[\mathrm{a}]}\end{array}$ & $\begin{array}{l}\text { Stabilization } \\
\text { age } \\
\text { [a] }\end{array}$ & $\begin{array}{l}\text { Deposition } \\
\text { depths } \\
{[\mathrm{cm}]}\end{array}$ & $\begin{array}{l}\text { Deposition } \\
\text { rates } \\
(+ \text { error }) \\
{\left[\mathrm{cm} \mathrm{a}^{-1}\right]}\end{array}$ \\
\hline $\mathrm{P} 2$ & 14.5 & 389 to -225 & 109 to -25 & 23 to 14 & 22 to 13 & - & - \\
\hline $\mathrm{P} 2$ & 32.5 & 252 to -78 & 133 to 1 & 39 to -2 & 42 to 19 & $\begin{array}{l}2.7 \text { to } 7.3 \text { and } \\
11.5 \text { to } 13.8\end{array}$ & $0.29(0.13)$ \\
\hline P2 & 42.5 & 4027 to 1062 & 4027 to 1062 & 305 to 68 & 302 to 68 & 24.4 to 30.6 & $0.12(0.10)$ \\
\hline $\mathrm{P} 2$ & 52.5 & 4639 to 2621 & 4376 to 3438 & 4267 to 3590 & $\begin{array}{l}1983 \text { to } 1865 \\
\text { and } 2382 \text { to } \\
2004\end{array}$ & 45.3 to 47.7 & $0.01(0.00)$ \\
\hline $\mathrm{P} 2$ & 62.5 & 4588 to 1994 & 4212 to 2639 & 3660 to 2874 & 3629 to 2913 & 55.3 to 57.7 & $0.01(0.00)$ \\
\hline $\mathrm{P} 2$ & 72.5 & 4449 to 2675 & 4326 to 3148 & 3975 to 3362 & 3983 to 3479 & 65.3 to 67.7 & $0.02(0.02)$ \\
\hline $\mathrm{P} 2$ & 87.5 & 5658 to 3828 & 5256 to 4140 & 5238 to 4394 & 4895 to 4170 & 80.3 to 82.6 & $0.02(0.01)$ \\
\hline P3 & 32.5 & $\begin{array}{l}139 \text { to }-46 \\
\text { and } 286 \text { to } \\
220\end{array}$ & $\begin{array}{l}117 \text { to }-22 \\
\text { and } 278 \text { to } \\
230\end{array}$ & 52 to 35 & $\begin{array}{l}-13 \text { to }-36 \text { and } \\
49 \text { to } 17\end{array}$ & $\begin{array}{l}4.3 \text { to } 5.8 \text { and } \\
10.6 \text { to } 14.4\end{array}$ & $2.17(8.71)$ \\
\hline P3 & 42.5 & 186 to -67 & 146 to -44 & 11 to -20 & $\begin{array}{l}19 \text { to }-5 \text { and } 55 \\
\text { to } 25\end{array}$ & $\begin{array}{l}13.3 \text { to } 16.7 \\
\text { and } 20.7 \text { to } \\
24.4\end{array}$ & $0.52(0.61)$ \\
\hline P3 & 52.5 & 2412 to 827 & 2250 to 890 & $\begin{array}{l}1238 \text { to } 888 \text { and } \\
1759 \text { to } 1636\end{array}$ & 1238 to 887 & 38.1 to 44.3 & $0.02(0.01)$ \\
\hline P3 & 62.5 & 3609 to 1357 & 3269 to 1785 & 2424 to 1716 & 2011 to 1479 & 54.9 to 57.9 & $0.02(0.01)$ \\
\hline P3 & 72.5 & 5262 to 920 & 4597 to 2046 & 3037 to 1850 & 2374 to 1630 & 65.2 to 67.8 & $0.04(0.07)$ \\
\hline P3 & 84.5 & $\begin{array}{l}22289 \text { to }- \\
5815\end{array}$ & 6671 to 3075 & $\begin{array}{l}2617 \text { to } 1466 \text { and } \\
3767 \text { to } 3585\end{array}$ & 2699 to 1720 & 77.4 to 79.8 & $0.06(0.17)$ \\
\hline BP5 & 34.5 & 132 to -61 & 90 to 31 & 40 to 32 & 41 to 32 & 4.9 to 9.1 & $0.19(0.06)$ \\
\hline BP5 & 44.5 & 162 to 26 & $\begin{array}{l}122 \text { to } 35 \\
\text { and } 153 \text { to } \\
145\end{array}$ & 81 to 64 & 79 to 65 & 27.3 to 29.6 & $0.60(0.16)$ \\
\hline BP5 & 54.5 & $\begin{array}{l}135 \text { to } 49 \\
\text { and } 194 \text { to } \\
175\end{array}$ & 99 to 76 & 96 to 80 & 93 to 80 & 37.4 to 39.7 & $0.70(0.49)$ \\
\hline BP5 & 64.5 & 150 to 23 & 141 to 37 & 106 to 84 & 108 to 90 & 47.3 to 49.7 & $0.79(0.71)$ \\
\hline BP5 & 74.5 & 214 to 45 & 161 to 75 & 158 to 124 & 151 to 122 & 57.3 to 59.7 & $0.27(0.13)$ \\
\hline BP5 & 84.5 & 242 to 81 & 214 to 125 & 185 to 146 & 178 to 145 & 67.4 to 69.7 & $0.40(0.36)$ \\
\hline BP5 & 94.5 & 562 to 47 & $\begin{array}{l}373 \text { to } 109 \\
\text { and } 513 \text { to } \\
412\end{array}$ & 161 to 80 & 218 to 159 & 76.9 to 80.3 & $0.37(0.47)$ \\
\hline BP5 & 104.5 & 982 to 424 & 922 to 471 & 828 to 572 & 532 to 435 & 90.4 to 95.5 & $0.05(0.01)$ \\
\hline BP6 & 37.5 & 306 to -124 & 155 to -4 & 59 to 12 & 102 to 41 & $\begin{array}{l}8.6 \text { to } 10.9 \\
\text { and } 18.9 \text { to } \\
23.8\end{array}$ & $0.22(0.10)$ \\
\hline BP6 & 49.5 & 308 to -13 & 147 to 50 & 120 to 88 & 115 to 88 & 32.3 to 34.7 & $0.61(0.69)$ \\
\hline BP6 & 61.5 & $\begin{array}{l}210 \text { to } 22 \\
\text { and } 428 \text { to } \\
353\end{array}$ & $\begin{array}{l}191 \text { to } 52 \\
\text { and } 415 \text { to } \\
379\end{array}$ & 134 to 69 & 132 to 106 & 44.3 to 46.7 & $0.68(0.71)$ \\
\hline BP6 & 74.5 & 267 to 52 & 169 to 104 & 156 to 126 & 150 to 124 & 57.3 to 59.7 & $0.73(0.74)$ \\
\hline BP6 & 87.5 & 323 to 106 & 274 to 135 & 230 to 160 & 178 to 136 & 70.3 to 72.7 & $0.66(0.83)$ \\
\hline BP6 & 97.5 & 478 to -15 & 353 to 110 & 207 to 128 & 201 to 147 & 80.2 to 82.8 & $0.58(1.15)$ \\
\hline BP8 & 37.5 & 177 to 40 & $\begin{array}{l}69 \text { to } 60 \text { and } \\
156 \text { to } 95\end{array}$ & 119 to 78 & 129 to 91 & 20.4 to 22.7 & $0.20(0.04)$ \\
\hline BP8 & 47.5 & $\begin{array}{l}-6 \text { to }-8 \text { and } \\
264 \text { to } 36\end{array}$ & 190 to 100 & 156 to 119 & 156 to 124 & 30.3 to 32.6 & $0.33(0.27)$ \\
\hline BP8 & 57.5 & 402 to 70 & 288 to 172 & 233 to 179 & 218 to 172 & 40.0 to 43.0 & $0.18(0.10)$ \\
\hline BP8 & 67.5 & 420 to $119 \mathrm{a}$ & 357 to 170 & 284 to 211 & 258 to 203 & 50.8 to 57.3 & $0.35(0.37)$ \\
\hline BP8 & 77.5 & 750 to 225 & 677 to 262 & 352 to 219 & 300 to 220 & 63.0 to 68.5 & $0.40(0.68)$ \\
\hline
\end{tabular}




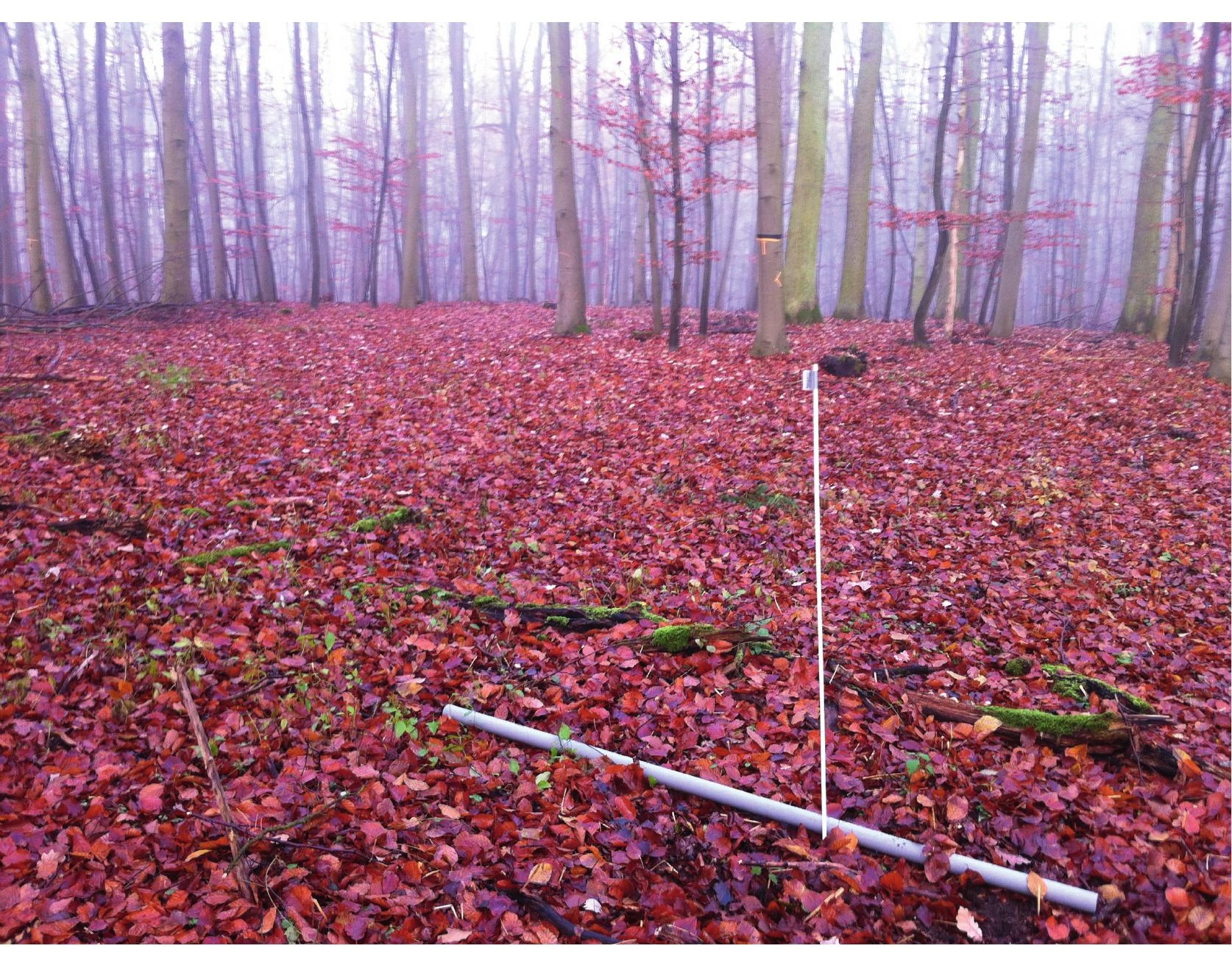


Chapter 4. On the role of hydrologic processes in soil and landscape evolution modeling: concepts, complications and partial solutions

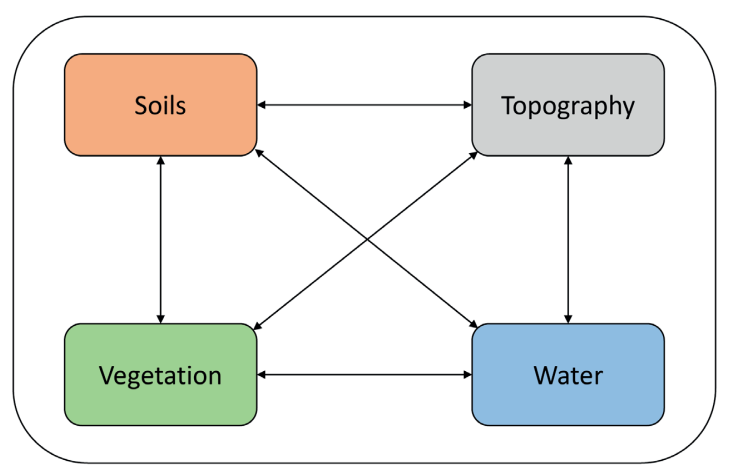




\section{Abstract}

The ability of water to transport and transform soil materials is one of the main drivers of soil and landscape development. In turn, soil and landscape properties determine how water is distributed in soil landscapes. Understanding the complex dynamics of this co-evolution of soils, landscapes and the hydrological system is fundamental in adapting land management to changes in climate. Soil-Landscape Evolution Models (SLEMs) are used to simulate the development and evolution of soils and landscapes. However, many hydrologic processes, such as preferential flow and subsurface lateral flow, are currently absent in these models. This limits the applicability of SLEMs to improve our understanding of feedbacks in the hydro-pedo-geomorphological system. Implementation of these hydrologic processes in SLEMs faces several complications related to calculation demands, limited methods for linking pedogenic and hydrologic processes and limited data on quantification of changes in the hydrological system over time.

In this contribution, we first briefly review processes and feedbacks in soil-landscapehydrological systems. Next, we elaborate on the development required to include these processes in SLEMs. We discuss the state-of-the-art knowledge, identify complications, give partial solutions and suggest important future development. The main requirements for incorporating hydrologic processes in SLEMs are: 1) designing a model framework that can deal with varying timescales for different sets of processes, 2) developing and implementing methods for simulating pedogenesis as a function of water flow, 3) improving and implementing knowledge on the evolution and dynamics of soil hydraulic properties over different timescales, and 4) improving the database on temporal changes and dynamics of flow paths.

Published as: Van der Meij, W.M., Temme, A.J.A.M., Lin, H.S., Gerke, H.H., Sommer, M., 2018. On the role of hydrologic processes in soil and landscape evolution modeling: concepts, complications and partial solutions. Earth-Science Reviews, 185, 1088-1106. https://doi.org/10.1016/j.earscirev.2018.09.001 
Table 4.1: List of abbreviations used in this Chapter

\begin{tabular}{l|l}
\hline Abbreviation & Meaning \\
\hline CN & Curve Number \\
DE-WRC & Double Exponential Water Retention Curve \\
EEMT & Effective Energy and Mass Transfer \\
HCC & Hydraulic Conductivity Curve \\
Ks & Saturated hydraulic conductivity \\
PTF & Pedo-Transfer Function \\
RE & Richards' Equation \\
RMSD & Root Mean Squared Difference \\
SLEM & Soil and Landscape Evolution Model \\
WRC & Water Retention Curve \\
\hline
\end{tabular}

\subsection{Introduction}

Water is one of the main drivers in the formation of soil landscapes. It facilitates transformation of rock and soil material by weathering and pedogenic processes (Fiedler and Sommer, 2004; Lin, 2010a) and transportation of materials by erosion and translocation processes. In turn, soil and landscape properties, such as relief, infiltration capacity, soil structure and stagnating soil layers, influence to a large degree how water, sediments and solutes are transported through a soil landscape (Sommer and Schlichting, 1997; Sommer, 2006; Ticehurst et al., 2007; Lin et al., 2008; Lin, 2010b). The relevant timescale of hydrologic processes differs substantially from that of pedogenic and geomorphic processes. Pedogenic and geomorphic processes are generally relatively slow and cumulative and act on, or have a return period of, decadal to millennial timescales. Hydrologic processes show fast and cyclic patterns, such as daily patterns of infiltration and capillary rise or seasonal patterns of rainfall and groundwater fluctuations (Lin, 2011). The behavior of the fast hydrologic processes is controlled by soil architecture, the configuration of soil units over a range of scales (De Jonge et al., 2012; Lin, 2012a). Soil architecture in turn is a product of long-term soil and landscape development. The interplay of hydrologic, pedogenic and geomorphic processes leads to a complex dynamic system, where direction and rate of individual processes is variable in time and space (Phillips, 2001; Ameli et al., 2017). 
Understanding the functioning and dynamics of the soil-landscape-hydrological system over multiple timescales, and its response to changing external forces, is fundamental for current day land management (e.g. via nature-based solutions, European Commission, 2015), and helps prepare for and mitigate the effects of the changing climate on the soil and landscape system (Davidson and Janssens, 2006; Bouma, 2014; Schuur et al., 2015).

The evolution of soils has been quantitatively modeled extensively (Hoosbeek and Bryant, 1992; Minasny et al., 2008; Samouëlian et al., 2012; Opolot et al., 2015; Keyvanshokouhi et al., 2016; Vereecken et al., 2016). Models with different degrees of complexity have been applied to increase the understanding of pedogenic change and interactions in a variety of soil types. For example, the genesis of equatorial Podzols has been modeled by Doupoux et al. (2017) by tracking carbon pools and fluxes with a compartment model. Luvisol development is extensively studied using the models SoilGen and its successor SoilGen2 (Finke and Hutson, 2008; Finke, 2012; Finke et al., 2015; Keyvanshokouhi et al., 2016). SoilGen2 simulates the development of the entire soil profile and considers processes that change soil texture, soil chemistry, soil organics and soil moisture. The different soil properties co-evolve through feedbacks between different processes and changing external forcing. Soil genesis modeling is not limited to natural soils. Leguédois et al. (2016) proposed a framework for modeling the genesis of Technosols; soils dominated by human-made materials (IUSS Working Group WRB, 2015). This framework explored modeling techniques and process rates suited for the unusual parent material of Technosols. The examples mentioned above are all mass-based models. Another type of pedogenic models is energy-based models, which use the energy state of the soil as proxy for soil development. For example, thermodynamic entropy can be used to indicate the degree of order or disorder of a soil (Lin, 2010b). Without input of external energy, soils tend to increase entropy, leading to homogenization of soil. Input of external energy is needed for organizing processes, such as horizon formation or structure formation. This energy can be in the form of mass, heat and others. This flux of energy is also called Effective Energy and Mass Transfer (EEMT, $\mathrm{kJ} \mathrm{m}^{-2} \mathrm{y}^{-1}$, Rasmussen and Tabor, 2007). EEMT proved to be a good statistical predictor of soil properties, such as soil thickness, clay content and soil chemical indices (Rasmussen and Tabor, 2007; Shepard et al., 2017). In this Chapter, we will focus on mass-based models, because these provide a mechanistic base for quantitative simulation of evolution of soil properties, rather than a statistical one. 
A general limitation of pure soil profile modeling is the absence of feedbacks with the landscape that the profile is located in (Opolot et al., 2015). Distributed profile modeling partly solves this limitation (Sauer et al., 2012; Zwertvaegher et al., 2013; Minasny et al., 2015). In this modeling strategy, the boundary conditions, such as the water and sediment balance, of several 1D model runs are adjusted for the landscape position where the modeled profile is located. However, in this approach the landscape effects are imposed and not a consequence of changes elsewhere in the soil landscape. This means that there is still no dynamic lateral exchange of water, soil and solutes between two adjacent soils, even though this exchange is a fundamental basis for soil evolution in actual landscapes.

Models that do consider the dynamic exchange of water and sediments are Soil and Landscape Evolution Models (SLEMs). These models are increasingly developed and used to study the complex dynamics of the soil-landscape system over centennial to millennial timescales, acknowledging the role of geomorphic redistribution of soil materials in the development of soil landscapes (Minasny et al., 2015; Willgoose, 2018). SLEMs simulate a variety of pedogenic and geomorphic processes in a simplified way, leading to results with sufficient detail, while reducing calculation demands. The architecture and process coverage of the models are often based on the modeling goal (Table 4.2). For example, the multi-layer models CREEP and SPEROS-C were built to study carbon dynamics on hillslopes and thus only consider these processes (Rosenbloom et al., 2001; Van Oost et al., 2005a). Yoo and Mudd (2008) simulated the chemical evolution of hillslopes and consider only chemical weathering and translocation processes in their model with a mobile and immobile soil layer. The model Be2D simulates the redistribution of meteoric Beryllium-10 on a hillslope and hence considers processes related to transport of Beryllium-10 (Campforts et al., 2016). The models mARM5D and SSSPAM focus on the evolution of soil texture and consider mainly physical weathering processes (Cohen et al., 2015; Welivitiya et al., 2016; Welivitiya et al., 2019). MILESD and Lorica calculate a variety of soil forming processes, which interact in the development of the entire soil profile (Vanwalleghem et al., 2013; Temme and Vanwalleghem, 2016). Depending on the included geomorphic processes, soils are connected via erosion processes acting on the soil surface or via creep processes acting throughout the entire profile, but none of the models so far considers subsurface lateral flow to connect soils (Table 4.2). 
The simplified representation of processes in SLEMs limits application of these models in some settings. Here we discuss three main simplifications:

1. The liquid and gaseous soil phase is excluded from the models, and with it often soil chemistry and soil thermodynamics. Instead, depth below the surface is often used as a proxy for moisture and temperature dynamics, and used to control process rates (Vanwalleghem et al., 2013). This leads to laterally uniform simulations of soil properties in landscapes where soil redistribution is (almost) absent, whereas field evidence testifies that lateral soil diversity under such conditions is actually large (Vanwalleghem et al., 2010). Moreover, depth below the surface as proxy for process intensity cannot capture impacts of changing climate and land use (Minasny et al., 2015). Hence, such models cannot be used to simulate the impact of such changes.

2. The millennial timescales of the simulations, simplified process formulations and a small set of included processes promote large time steps in these models that lead to acceptably low calculation times. A downside of these larger time steps is the inability to model the effect of extreme events. In erosion modeling, erosion increases disproportionally with rainfall intensity (González-Hidalgo et al., 2009), but it is argued that these extreme events might be averaged to a mean annual erosion rate over long timescales (Baartman et al., 2013). In soil evolution modeling this averaging will not work, because extreme events can change the direction of water flow and thus pedogenic processes from vertical to lateral (Lin, 2006). Smaller time steps are thus required to capture short-term lateral water flow, as well as pedogenic threshold phenomena (Chadwick and Chorover, 2001).

3. Pedogenic processes in current SLEMs are solely 1D vertically oriented. Because of that, laterally oriented subsurface processes such as transport of solutes (Jin et al., 2011), organic matter, mobile Al and Fe (Sommer et al., 1997; Sommer et al., 2000; Bourgault et al., 2015) and clay (Brooks et al., 2012) currently cannot be simulated. These processes are essential in hillslope scale redistribution of solutes and solids. Without them, models can wrongly predict the mass balance of these soil constituents at a pedon scale, leading to wrong interpretation of soil and landscape genesis. 
In short, current architecture of SLEMs does not allow the simulation of laterally oriented water flow and pedogenic processes, although these processes are responsible for redistributing of solutes and solids on the short term and result in soil diversity in the long term. There is thus a need to improve the hydrological component of SLEMs, to study the feedbacks between the fast hydrologic and slow pedogenic and geomorphic processes, and to increase our understanding of form and function of soils over time (Ma et al., 2017). The need for this improvement is demanded from the fields of pedology (Sommer et al., 2008; Minasny et al., 2015), hydrology (Yu et al., 2014; Clark et al., 2015; Troch et al., 2015), geomorphology (Zhang et al., 2016) and Critical Zone science (Lin, 2010a; Chorover et al., 2011; Ameli et al., 2017).

The objective of this Chapter is to review the main challenges with respect to including fast hydrologic processes in SLEMs and provide possible solutions for some of these challenges discussed above. For those challenges that cannot be solved with presently available knowledge, we outline what research would be needed to solve the remaining difficulties. Section 4.2 provides a brief review of feedbacks between pedogenic, geomorphic and hydrologic processes. Section 4.3 outlines the challenges of improving hydrologic processes in SLEMs. Section 4.4 summarizes our recommendations for further research. Although we fully acknowledge that biotic controls on soil-landscape evolution may be equally relevant, the focus of this contribution is on hydrologic processes. 


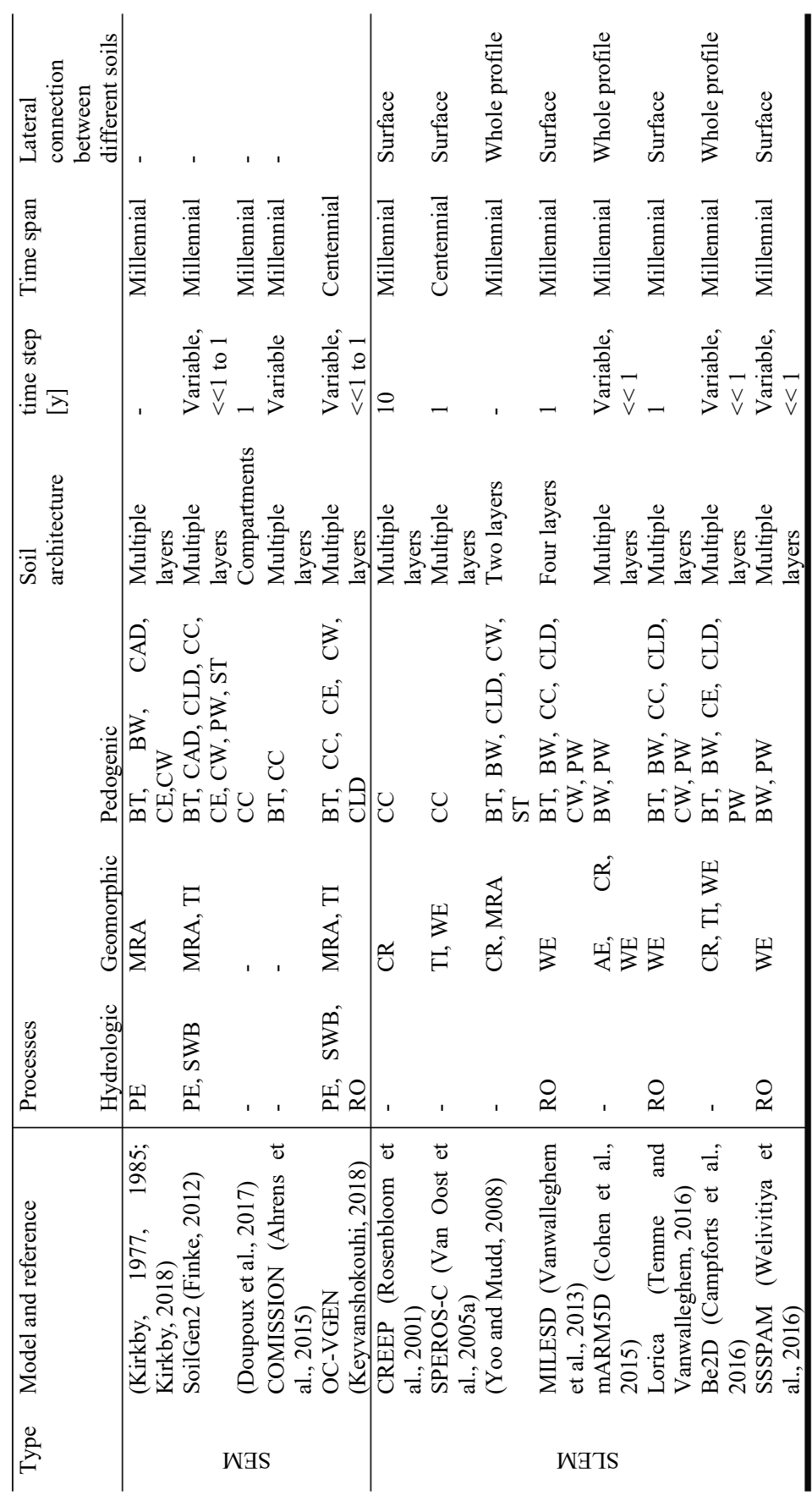

Table 4.2: Overview of several soil evolution models (SEMs) and soillandscape evolution models (SLEMs), showing process coverage, soil architecture, temporal discretization and the level of lateral connection between different soil profiles. The processes are abbreviated.

Hydrologic processes include: PE: percolation / vertical soil water flow, RO: surface run-on and run-off, SWB: surface water balance.

Geomorphic processes include: AE: aeolian deposition, CR: creep, TI: tillage, MRA: manual removal from / addition to top layers, WE: water erosion and deposition.

Pedogenic processes include: BT: bioturbation, BW: bedrock weathering, CAD: cation dynamics, CC: carbon cycle, CE: chemical equilibria / processes, CLD: clay dynamics, CW: chemical weathering, PW: physical weathering, ST: solute transport.

The variable time steps are part of models based on differential equations, which can adjust time steps to converge to a solution. Time steps are usually sub-daily. 


\subsection{Review of relations between water flow and soil- landscape properties}

This Section gives a brief overview of how pedogenic, geomorphic and hydrologic processes change soil and landscape properties over different spatial and temporal scales. These changes affect the partitioning of water over time, leading to feedbacks between pedogenic, geomorphic and hydrologic processes. We illustrate these feedbacks with two examples. The objective here is to identify relevant spatial and temporal scales for SLEMs, conceptualize important feedbacks in soil-landscape evolution and pinpoint key factors in controlling the type and rate of processes involved in these feedbacks.

\subsubsection{Landscape development}

Geomorphic processes change surface morphology and soil properties by removing, redistributing and depositing soil materials and sediments. The resulting changes in landforms and soil properties then feed back to affect the spatial pattern and rates of water flow and erosion (Van Oost et al., 2000). Geomorphic processes become apparent on different spatial scales. Water erosion and aeolian processes affect the landscape on a catchment and larger scales. When the quantity of flowing water and slope angle exceed a threshold, water flow can detach and transport soil material. This material gets deposited when the material in transport exceeds the transport capacity, or is otherwise removed from the catchment. Aeolian processes redistribute sediments by wind. The uptake and deposition patterns are controlled by topography, vegetation, and grain size of the sediment in transport (Zender et al., 2003). These catchment scale processes mainly affect the surface of the landscape (with the exception of processes such as piping erosion). On a sub-catchment scale, peat formation can occur in areas with permanent surface water. This can for example occur in areas with stagnating soil layers (Anderson et al., 1982) or local depressions in landscapes with high groundwater levels (Karasiewicz et al., 2014). On a hillslope scale, redistribution of soil material is gravity driven. In contrast to the earlier mentioned processes, these hillslope processes can transport complete packages of soil or sediments downslope. The slope steepness strongly controls the type and quantity of sediment flux (Roering et al., 2001b). Low slopes favor the slow and continuous processes of soil creep (e.g. West et al., 2013), while steeper slopes favor event-based landsliding (Roering et al., 2001a). These different types of mass movements are further controlled by soil moisture, clay content and the 
occurrence of previous landslides (Shi et al., 2016; Samia et al., 2017). Most of these geomorphic processes occur at very low rates in natural, undisturbed landscapes. Human activity in the form of deforestation and cultivation has intensified or reset these geomorphic processes (Butzer, 1974; Jahn, 1989; Zheng, 2006). Moreover, the use of ploughs introduced a new erosion process, called tillage erosion, which currently dominates erosion in several agricultural landscapes (Van Oost et al., 2005b).

\subsubsection{Soil development}

Soil development is a function of parent material, topography, climate, biota and time (Jenny, 1941). These factors influence the type and rate of pedogenic processes that occur in a soil. The processes change soil mineralogy, texture and organics, and act on different timescales. Over millennial timescales, weathering processes break down coarser soil particles and dissolve minerals, such as carbonates. The solutes reprecipitate or leach from the soil profile (Becze-Deàk et al., 1997; Ma et al., 2011). Another process acting on these timescales is the translocation and neoformation of clay, which can create eluvial and clay illuvial horizons (Zaidel'man, 2007; Quénard et al., 2011). In all these processes, water plays an important role by controlling transport rates of solutes and particles (Cornu et al., 2014). On decadal to centennial timescales, decomposing plant and animal residues lead to accumulation of soil organic matter. This organic matter can break down again, be reworked in the subsoil by bioturbation processes or be transported in dissolved state (Wilkinson et al., 2009; Rumpel and Kögel-Knabner, 2011). In acid, coarse-textured soils, decomposition of organic material leads to the formation of soluble organic acids. These acids are transported down the soil profile, while forming complexes with metals such as aluminum and iron, which is the socalled podzolization process (Lundström et al., 2000). The dense organic illuvial horizon can become a stagnating layer over time, which inhibits penetration of roots and biota (Mackney, 1961; Beerten et al., 2012). On sub-annual timescales, (temporary) saturation of soils by groundwater or perched water can change soil chemistry and structure via redox and other processes (He et al., 2003).

\subsubsection{Soil architecture}

Soil architecture refers to the cross-scale organization of soils, which controls the connectivity of flow and reactions in soils (Sommer, 2006; Lin, 2012a). Soil architecture can be divided into soil structural units and soil-landscape units, based on spatial extent. 
Soil structural units concern scales smaller than a soil profile, such as soil aggregates, macropores and soil horizons. At these scales, the pore network controls water flow. Biotic activity and changes in soil texture and organics create a multiscale heterogeneous pore system in the soil. At the smallest scale, the soil is structured in aggregated units. These primary aggregates are composed of mineral, organic and inorganic soil particles, glued together through various biogeochemical processes. The occurrence, type and stability of soil aggregates are controlled by land use and management, mount and type of organic matter and clay as well as wetting-drying and freezing-thawing cycles (Roulier and Jarvis, 2003; Bronick and Lal, 2005; Abiven et al., 2009; Barto et al., 2010; Alaoui et al., 2011). A pore network exists in between the aggregates; the inter-aggregate pore space. Soil biota (i.e. plant roots and soil animals) create larger pores or biopores, which can reach over several soil horizons or the complete pedon. These macropores are more extensive in the topsoil where most activity is, but can reach deep into the subsoil (Jarvis, 2007). While the vertically oriented pores are mostly studied, these macropores can also be oriented laterally (Lin, 2006). The connectivity, stability, size and strength of the different pores are controlled by soil management (Kasper et al., 2009), temperature fluctuations (Kværnø and Øygarden, 2006) and moisture dynamics (Rainer et al., 2014). For an extensive review on macropore types, we refer to Hendrickx and Flury (2001) and Beven and Germann (2013). The largest soil structural units are soil horizons, often displaying different textural, structural and hydrological properties. These different properties can prevent or promote root growth, erosion or stagnation and lateral flow of water. The type and properties of soil horizons change over time.

Soil-landscape units pertain to scales larger than the soil profile, such as hillslopes, landscapes, watersheds or the earth system. Structures such as relief, stagnating soil layers and sedimentological layers control lateral connectivity of different pedons, hillslopes or catchments. Gerke et al. (2013) provided an example of soil-landscape units in an artificially created hydrological catchment constructed in 2004 (Hühnerwasser, Gerwin et al., 2009). They defined several process domains, which were characterized by the occurrence of certain groups of processes. For example, vegetated regions were related to higher infiltration rates and higher moisture contents, while areas with soil surface crusts were linked to run-off generating processes. Domains with frequent and continuous water saturation were linked to the occurrence of redoximorphic processes. These examples clearly show the relation 
between soil-landscape units and their hydrological functioning. Although the pedogenic and geomorphic change recorded in the developing Hühnerwasser catchment is still limited, the soil-landscape units already give an indication of changes to be expected in the future.

\subsubsection{Flow paths}

The evolving soil architecture changes the way water flows through the soil landscape (Figure 4.1). Topsoil properties determine which fraction of rainwater will infiltrate the soil and which fraction will become surface runoff by controlling infiltration rate. Coarse textured or organic-rich topsoils generally facilitate rapid infiltration, except when surface crusts, hydrophobicity or frozen surfaces develop. Coarse-textured soils generally have a higher hydraulic conductivity for infiltration, while organic-rich layers retain water by acting as a sponge (Lin et al., 2006). Low infiltration can occur in fine-textured soils, if not structured or perforated by biopores. Surface crusting by fine deposits can lead to considerably higher surface runoff rates (Cerdan et al., 2002). However, fine-textured soils often develop cracks at the surface upon drying, that can drain a large portion of the water input (Novak et al., 2000). A frozen soil layer also substantially reduces, or even prevents infiltration by acting as an impermeable layer (Gray et al., 2001; Hayashi et al., 2003).

Also topography affects infiltration. Although different studies sometimes find conflicting results, in general the infiltration rate decreases with increasing slope steepness (Morbidelli et al., 2018). The amount of water that does not infiltrate leaves the catchment via surface runoff or evaporation, or re-infiltrates at locations where infiltration capacity is higher, or where the water is retained, such as surface depressions (Hayashi et al., 2003; Gerke et al., 2010).

Infiltrated water percolates dominantly vertically through the unsaturated part of the soil, driven by gravity. Flow velocity increases with pore size, but larger pores can only contain water when the matric potential is high enough to provide a water-filled pore space. In general, flow velocities and solute transport rates increase with soil structural development (Kodešová et al., 2009). Subsurface flow can also occur laterally (Sommer and Schlichting, 1997; Sommer et al., 1997; Vepraskas and Craft, 2016). Lin et al. (2006) identified four dominant downslope flow pathways in a forested catchment. These pathways are representative for most landscapes (Figure 4.1). The first pathway is lateral flow through macropores consisting of animal burrows and root channels; this network can quickly 
transport water downslope during periods of increased flow, caused by large rainfall or snowmelt. The second pathway is lateral flow over horizon boundaries, caused by differences in texture, structure and/or hydraulic properties; this phenomenon is for instance visible in glacial till catchments at the interface with parent material (Filipović et al., 2018), on clay illuvial horizons in steep sloped loess areas (Brooks et al., 2012) or on stagnating spodic horizons (lateral podzolization, Sommer et al., 2000; Lucas et al., 2012; Bourgault et al., 2015). This flow type is not necessarily connected over the entire hillslope. Heterogeneity in hydraulic conductivities and subsurface topography can lead to storage in subsurface depressions in the stagnating layer (fill and spill hypothesis, Tromp-van Meerveld and McDonnell, 2006; Du et al., 2016; Jackson et al., 2016). The third pathway is return flow of water in lower areas by saturation of the soil, leading to surface runoff; the concept of variable source area hydrology is based on this type of saturation excess surface runoff and has been successfully used to predict runoff patterns in glacial till overlying bedrock (Mehta et al., 2004). The fourth pathway is flow at the interface of soil and weathered bedrock. Flow through shallow fractured bedrock can also substantially transport water along a hillslope (Guo et al., 2019). In addition to these four pathways identified by Lin et al. (2006), we identified an additional pathway in landscapes with small surface depressions. Water infiltrated in the depression recharges groundwater levels and is then transported laterally to the fringes, when it is pulled to the surface by capillary action driven by evapotranspiration, the so-called edge effect (Daniels and Gamble, 1967; Knuteson et al., 1989; Pennock et al., 2011). The connectivity of water and matter flow along a hillslope or in a catchment can be described and quantified using the T-TEL method of Ali et al. (2018), using the time scales, thresholds, excesses and losses related to the water and matter flow. 


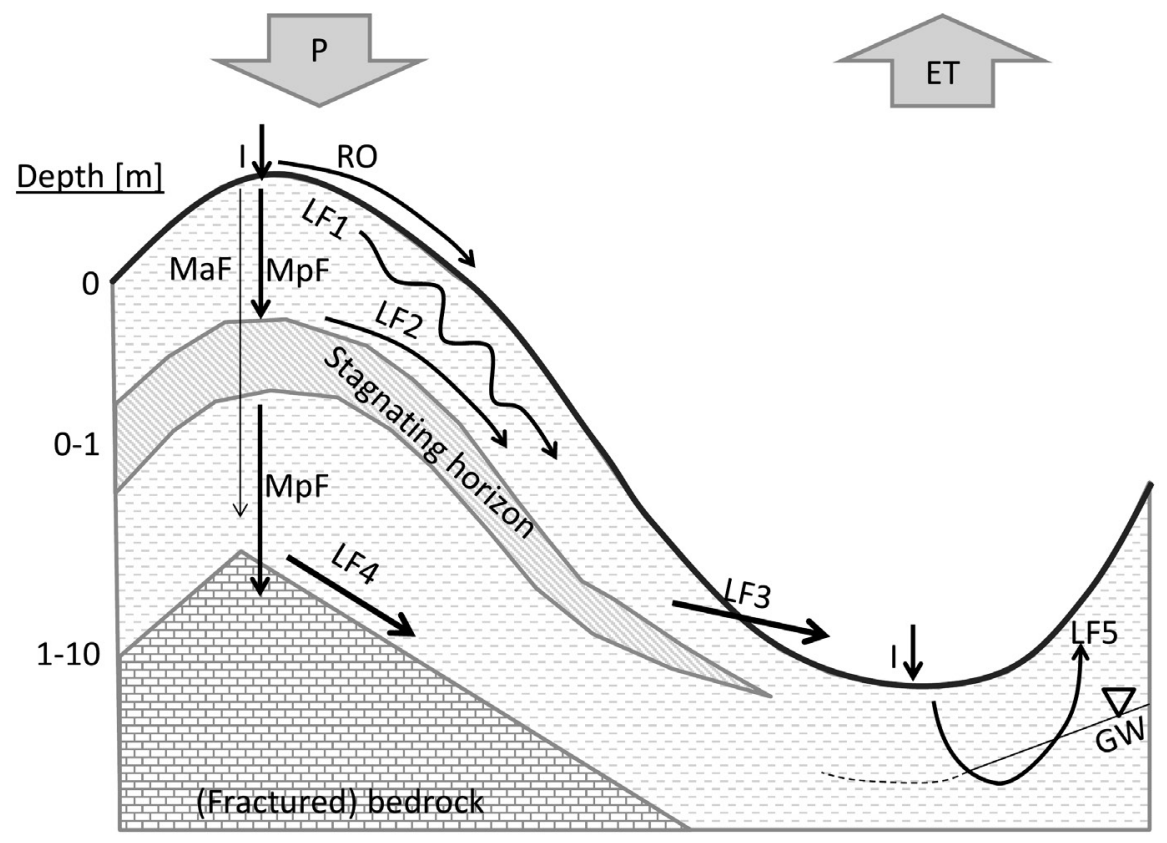

Figure 4.1: Schematic overview of different flow paths in soil landscapes. Legend: P: precipitation, ET: evapotranspiration, I: infiltration, RO: surface run-off, MaF: matrix flow, MpF: macropore flow, GW: groundwater, LF: lateral flow. LF1: LF through root channels and animal burrows, LF2: LF over horizon boundaries, LF3: return flow, LF4: LF over (fractured) bedrock, LF5: LF in fringes of topographic depressions.

\subsubsection{Two examples}

The hydrology in soil landscapes and its effect on pedogenesis and geomorphology is complex and dynamic in space and time, as discussed above. Here we give two examples of complex interactions between soil, landscape and hydrology. These examples are meant to illustrate the complexity of soil-landscape evolution.

\subsubsection{Triple stagnation in a drift sand area}

The Drents-Friese Wold National Park in the north of the Netherlands is a reactivated drift sand landscape, based on Pleistocene cover sands (http://www.nationaalpark-drents-friesewold.nl/serviceblok/english_1/). This area is home to complex soil profiles (Figure 4.2), caused by alternating dominance of pedogenic and geomorphic processes, which affected soil hydrology. Our discussion on the genesis of this profile below is based on field interpretations by employees of Wageningen University and Research in the Netherlands. 
Eluviation of organic matter and dissolved metals (iron and aluminum) caused the formation of Podzols in the cover sands (3E, 3Bh, 3Bhs and 3BC horizons, Figure 4.2). The illuvial Bh horizon became less permeable over time, due to pore infillings of organometallic complexes. The increasingly reduced conditions in and on top of the $\mathrm{Bh}$ horizon led to re-dissolution of the precipitated organometallic complexes. Below the Bh horizon, the aerobic conditions caused re-precipitation of the metals, mainly iron, causing the formation of an iron pan in the 3Bhs horizon (Anderson et al., 1982).

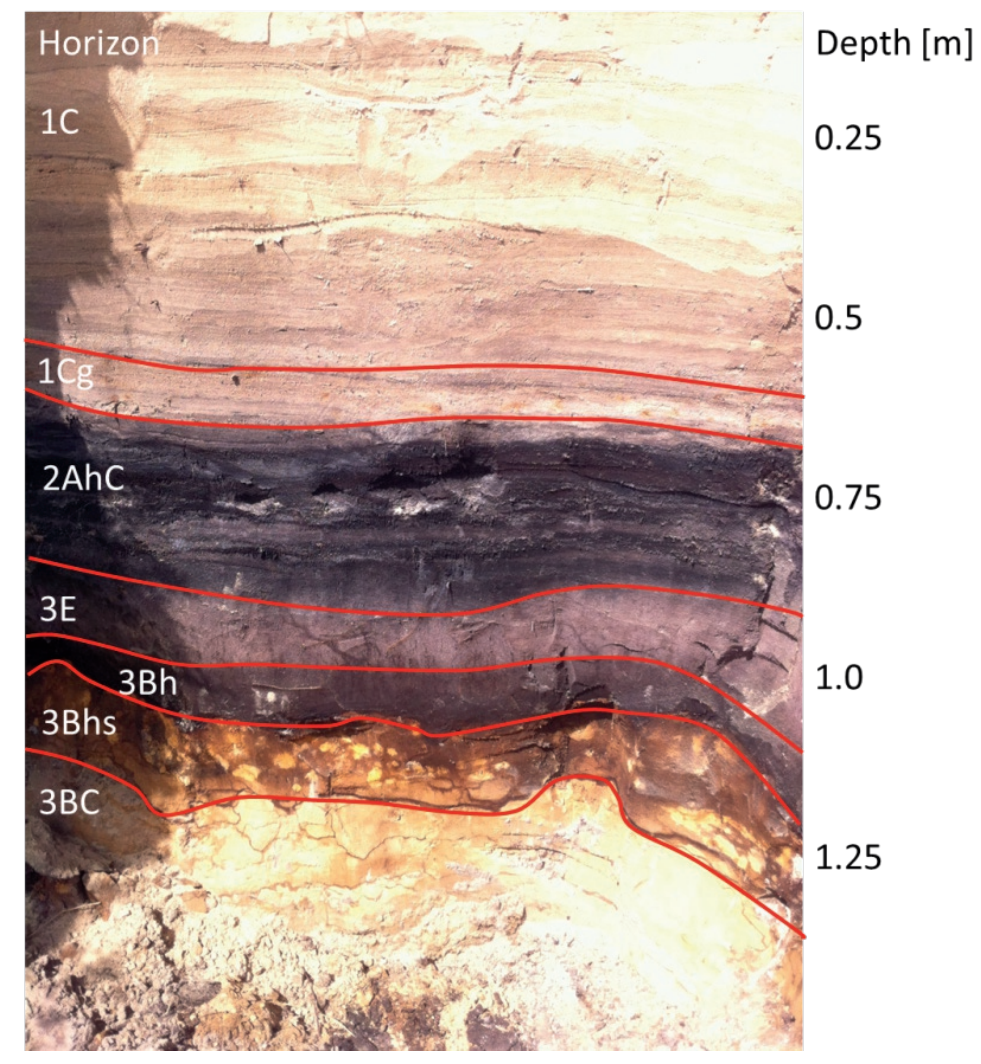

Figure 4.2: Soil profile from the Drents-Friese Wold National Park in the Netherlands, showing the effects of alternating pedogenic, geomorphic and hydrologic processes. Photo taken by W.M. van der Meij

Stagnation on the almost impermeable iron pan led to saturation of the above-lying profile, accumulation of surface water in this low position and consequently peat formation (Sevink et al., 2013). The peat is interlayered with drift sand deposits (2AhC horizon, Figure 4.2). Increasing human disturbance in the landscape increased the rate of aeolian erosion and 
deposition (1C and $1 \mathrm{Cg}$ horizons, Figure 4.2). The peat was resistant to aeolian erosion, causing relief inversion by leaving the formerly low landscape position intact and eroding the surrounding higher cover sands. The thick package of aeolian deposits led to compaction of the intermediate peat. This created a final stagnating layer, evidenced by iron mottles $(1 \mathrm{Cg}$ horizon, Figure 4.2).

In summary, three stagnating layers were formed by interplay of pedogenic, hydrologic and geomorphic processes in this profile and the surrounding landscape positions. Each stagnating layer initiated or affected different processes acting to form another stagnating layer.

\subsubsection{Contrasting hydrology of Bt horizons}

The process of clay translocation leads to the formation of Luvisols or Albeluvisols. The typical horizon sequence of a Luvisol is (O-)Ah-E-Bt-C, where clay from the topsoil is translocated into the Bt horizon. The hydraulic functioning of this Bt horizon can be very different: the Bt horizon can be impermeable (fragipan, e.g. Fig. 4 in Lin, 2010b; Szymański and Skiba, 2011), or the Bt can be highly permeable (e.g. Rieckh et al., 2012). Intuitively, the illuviation of clay in a soil horizon should decrease hydraulic conductivity by clogging of the pores in the soil. However, clay is also an important building block of soil aggregates. Increased clay content can thus also lead to increased structure formation of soils, with higher permeability as a result. Here we explore what can cause this difference in end products of the clay translocation process.

Roulier and Jarvis (2003) studied macropore flow in pedons on different landscape positions. They found a decreasing extent of macropore flow from hilltops to a landscape depression. They attributed this decrease to variations in soil structure caused by drying and wetting. Lower landscape positions showed less drying and wetting dynamics due to lateral subsurface influx of water and therefore less soil structure. Drying and wetting is also the cause of fragipan deformation in Albeluvisols (Szymański et al., 2011; Nikorych et al., 2014). The increasing concentration of swelling clay minerals in a Bt horizon can cause cracking by shrinking of the Bt horizon when drying. These cracks or macropores lead to a high effective hydraulic conductivity, with consequences for the partitioning of water in the soil profile. The shrinking capacity of soils depends on clay type and clay content (Boivin et al., 2004). 
The examples above indicate that drying and wetting cycles have a large effect on the hydraulic properties of Bt horizons. We can identify three pedogenic pathways of changing hydraulic conductivity of Bt horizons (Figure 4.3):

1. Increase of hydraulic conductivity by structure formation;

2. Decline of hydraulic conductivity by clogging of pores, resulting in a pedogenic fragipan;

3. First a decrease and then an increase of hydraulic conductivity by cracking of the Bt horizon or fragipan.

The type of pedogenic pathway is thus a function of moisture dynamics and hence landscape position. However, parent material, clay type, temperature, surrounding horizon properties and land management also determine to a large degree the hydraulic functioning of $\mathrm{Bt}$ horizons. For example, the construction of artificial drainage can reactivate or enhance the leaching process and remove swelling clay minerals (Montagne et al., 2008). Perhaps, there are other threshold effects that can change the direction of the evolution of soil hydraulic properties, influenced by climate, pedogenic feedbacks or human activity in the form of ploughing. An integrated assessment of the evolution of soil hydraulic properties under a variety of boundary conditions is necessary to disentangle the effect of individual drivers, and to predict soil hydraulic properties as a function of them.

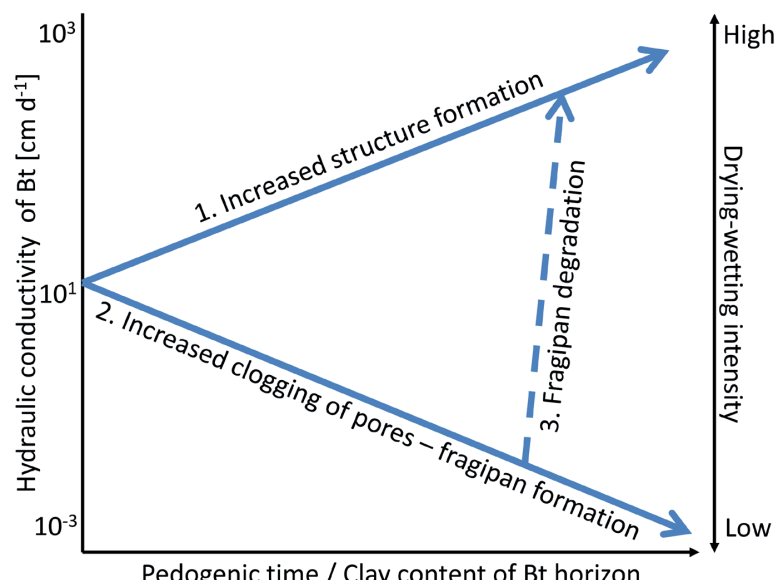

Figure 4.3: Schematic of three pedogenic pathways of change in hydraulic conductivity of a Bt horizon as a function of soil development or clay content and drying-wetting intensity. 


\subsection{Challenges for modeling hydrology in SLEMs}

There is an abundance of soil hydrological models, groundwater models, soil evolution models and soil-landscape evolution models. Successful couplings have been made between different hydrological models and pedogenic processes (e.g. Jarvis et al., 1999; Jacques et al., 2008; Finke, 2012; Shan and Wang, 2012). However, couplings with SLEMs are currently lacking (Ma et al., 2017), despite the fact that this development is essential to make SLEMs suitable for studies in a global change context (Minasny et al., 2015). That raises the question of what has prevented the development of such a coupling thus far.

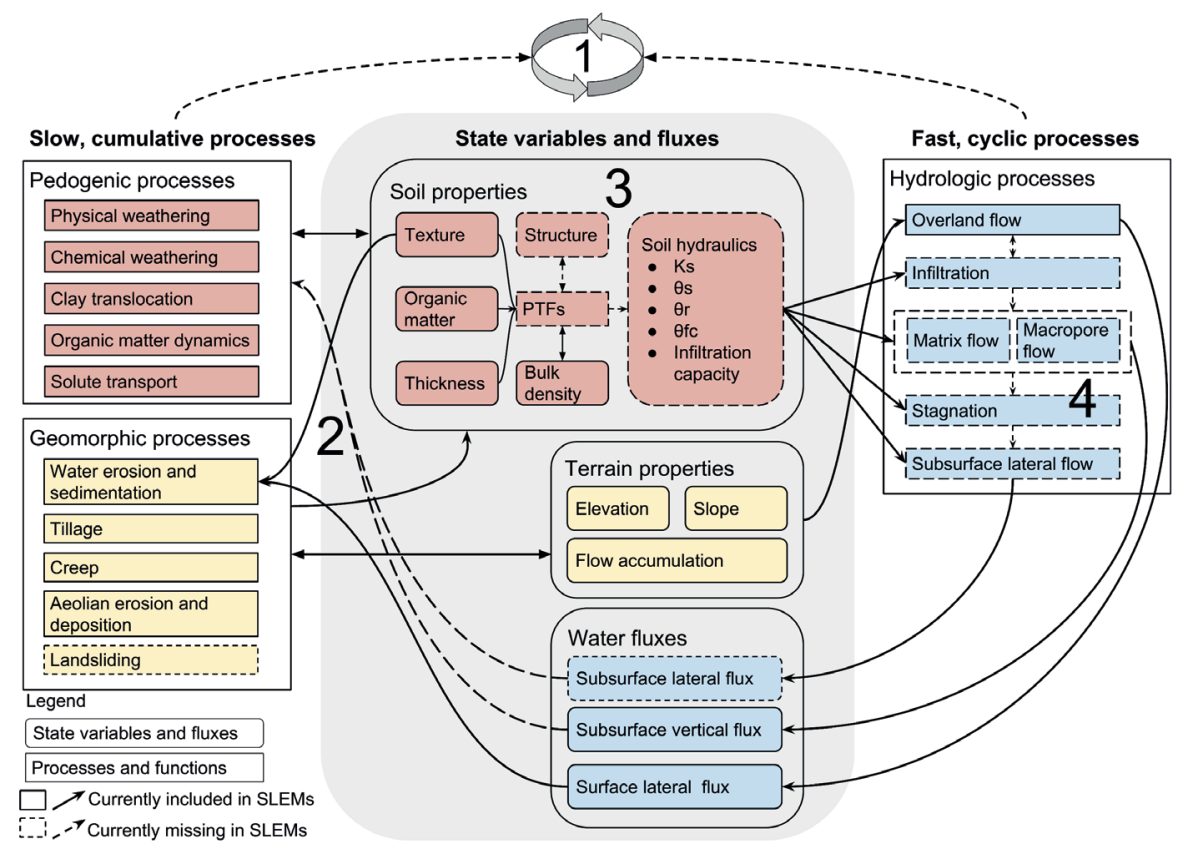

Figure 4.4: Conceptual design of a SLEM, where pedogenic, geomorphic and hydrologic processes interact by changing and depending on the same state variables and fluxes. The solid lines indicate connections that currently exist in various SLEMs. Dashed lines and numbers indicate areas where development is needed. 1: Integrated modeling of processes acting on different timescales; 2: The role of water flow in pedogenic processes; 3: The estimation of soil hydraulic properties; 4 : The partitioning of water along different flow paths.

Soil and landscape evolution occur on different spatial and temporal scales than soil hydrologic processes. Soil hydrology is often described from a pore scale to pedon scale, while soil and landscape evolution covers horizons to whole catchments. Changes in soil and 
landscape properties become apparent after 100s or 1000s of years, while soil hydrologic processes show sub-daily to seasonal changes (Figure 4.5). Somehow, these fast cyclic changes of soil hydrology co-evolve with the slow accumulative changes of pedogenesis and geomorphology (Lin, 2011). These differences in process timescale complicate the incorporation of hydrologic processes in SLEMs. The fine scale hydrologic processes are practically impossible to simulate over millennial timescales on a catchment scale, due to the high computational demands of current modeling approaches.

Despite these computational difficulties, the conceptual framework in Figure 4.4 shows an example of what the design of an integrated soil-landscape-hydrology model could look like. Currently, SLEMs are able to only simulate some of these interactions and processes. We indicate the parts where development is required with dashed lines in Figure 4.4. This Section discusses the current problems with and possible solutions for these areas of needed development. These areas of development are:

1. Modeling with variable time steps in SLEMs, to capture the dynamics of processes acting on different timescales (\#1 in Figure 4.4);

2. The role of water flow in several pedogenic processes (\#2 in Figure 4.4);

3. Increase in our understanding of large scale soil hydrology, mainly regarding

a. Evolution and dynamics of soil hydraulic properties and structure through time

b. Feedbacks between soil structure and soil hydrologic processes, and methods to estimate soil structure and soil hydraulic parameters (\#3 in Figure 4.4);

c. Quantification and modeling of subsurface lateral flow via temporally changing flow paths over long timescales (\#4 in Figure 4.4).

Possible solutions to the above mentioned areas of needed development are further discussed in the following Sections. 


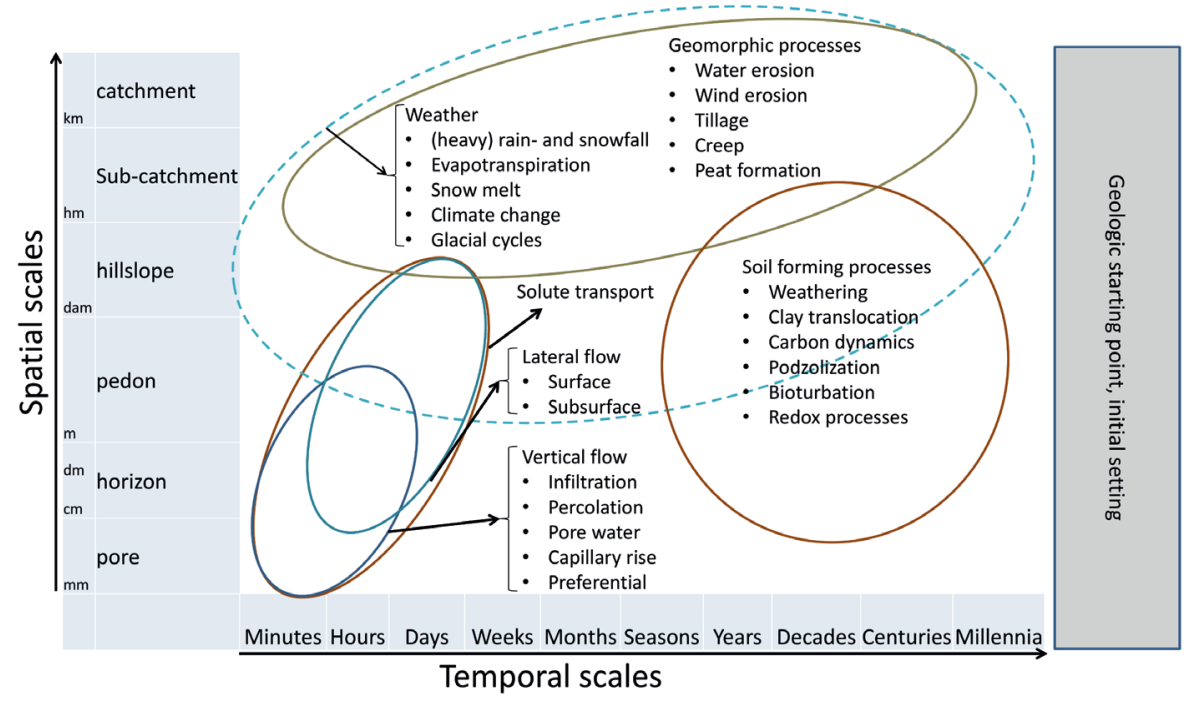

Figure 4.5: A sketch of the spatial and temporal scales over which the effects of different types of processes, represented by different ellipses, become apparent.

\subsubsection{Modeling processes with different timescales}

The fast dynamics of hydrologic processes require different modeling techniques than the slower soil and landscape forming processes (Blöschl and Sivapalan, 1995; Vereecken et al., 2016; Temme et al., 2017). Here we discuss two options for linking the different types of processes: 1) the coupling or integration of an existing hydrological model with a SLEM and 2) the development of a simplified hydrological component tailor-made for a specific SLEM, that only simulates the essential hydrological phenomena.

\subsubsection{Coupling existing models}

Existing soil hydrological models are often used for analyzing water resources for agriculture and simulating pollution spreading, which require detailed simulations of water and solute fluxes. These models often use the Richards' equation (RE) with the water retention curve (WRC) to simulate water flow (e.g. MODHMS, Panday and Huyakorn, 2004; HYDRUS, Šimůnek et al., 2006). Soil water flow in these models is driven gradients in hydraulic head. Solute transport is coupled with water flow through convection-dispersion equations. The water retention curve (WRC) is used to calculate hydraulic heads and hydraulic conductivity based on the moisture content of different soil layers. The most common function to describe the WRC is the van Genuchten-Mualem model (VGM, Van Genuchten, 1980). RE is a 
nonlinear partial differential equation that is numerically solved to calculate the soil water balance. The numerical solution of RE can only converge with a sufficiently small time step (seconds to minutes, Kavetski et al., 2001) and a sufficiently small spatial discretization (mm to $\mathrm{dm}$ for homogeneous soils, Downer and Ogden, 2004; Vogel and Ippisch, 2008). RE has been successfully used in simulating water flow and solute transport in structured soils (Šimůnek et al., 2003), for example by coupling a low permeability matrix component with a high permeability fracture component (Gerke and Van Genuchten, 1993). RE has also been successfully used in several soil evolution studies (e.g. Finke, 2012). However, Vereecken et al. (2016) claimed that RE based models are not suitable for all soil types, particularly soils with high clay and organic matter contents. Shallow groundwater levels, preferential flow, swelling-shrinking, hydrophobicity, and wettability of these soils cause heterogeneous flow paths through the soils. These processes are currently not captured by RE, because RE assumes a rigid, non-changing, pore system.

The use of RE in SLEMs is thus not feasible for several practical reasons. First, RE requires detailed input: the boundary conditions (e.g. rainfall) should preferably be provided with subhourly detail and multiple hydraulic parameters have to be estimated to describe the WRC. The hydraulic parameters and boundary conditions have to be estimated over millennial timescales, which introduces additional large uncertainty to model simulations. This uncertainty likely exceeds any increased level of accuracy to be gained from using RE in SLEMs due to stacking of uncertainties from parameters and processes (Christiaens and Feyen, 2001; Perrin et al., 2001; Loosvelt et al., 2011).

The second complication for using RE in SLEMs is that the small spatial and temporal discretization of RE leads to immense calculation demands for 3D simulations over millennial timescales. For example, soil evolution model SoilGen2 (Finke, 2012) uses RE to simulate vertical water flow in a $1 \mathrm{D}$ soil column over millennial timescales. The runtime of one simulation takes several days. In a 3D setting, this runtime will increase supra-linearly with the increasing number of cells and dimensions.

\subsubsection{Tailor-made hydrological modules}

When designing a hydrological model specific for SLEMs, the desired level of detail and the appropriate scale can be chosen by the developer. The selection of the appropriate level of detail of the hydrological module can significantly reduce data demands and calculation time 
by simplifying the complex hydrological dynamics. Another advantage of a tailor-made module is that it can consider the architecture of the existing soil-landscape model, which in itself can be quite complex (e.g. layer thicknesses that vary in four dimensions, Temme and Vanwalleghem, 2016). The coupling with an existing model would require transformation of data for communication between the two models. Here we discuss what the minimum hydrological components are for SLEMs and how processes with different time steps can be coupled with a tailor-made hydrological module.

\subsection{Model components}

For soil and landscape evolution, the minimum required amount of hydrological detail for determining rate and direction of pedogenic processes is the quantification of net water flux along each different flow path (Figure 4.1). In many landscapes, lateral flow over the surface or over subsurface stagnating layers only occurs episodically after high rainfall or snowmelt, and thus, individual events will need to be considered to determine what whether and what amount of water will flow laterally. Here we will discuss several methods that can be used to achieve this.

Surface runoff can be caused by rainfall exceeding the infiltration capacity (infiltration excess) or by saturation of the soil (saturation excess). Several simplified methods exist to estimate infiltration, often operating with an hourly time step and requiring limited input parameters (Green and Ampt, 1911; Horton, 1941; Philip, 1957). Input parameters can be the saturated hydraulic conductivity (Ks) of the soil and the hydraulic gradient between surface and wetting front. Surface runoff is the fraction of the rainfall that exceeds the infiltration capacity as calculated by these methods. Another method often used to calculate the partitioning between infiltration and runoff is the runoff Curve Number (CN, USDA-SCS, 1972). $\mathrm{CN}$ is an empirical method that uses a lookup table to determine the threshold rainfall for initiating surface runoff, based on soil type, land use and antecedent moisture conditions. This method is very simple to implement and has been used in models such as SWAT (King et al., 1999) and MCST models (Van Oost et al., 2004). These models use CN to determine runoff at a point or hillslope scale. However, Garen and Moore (2005) pointed out that CN is developed as a lumped model and that it is not suitable for smaller scales such as pedons. Garen and Moore (2005) mentioned several reasons for this. First, CN estimates the amount of water leaving a catchment as streamflow. This water is generated by more processes than solely infiltration excess surface runoff and spatial variability of generated runoff in a 
catchment is not included. Second, $\mathrm{CN}$ is not suitable to calculate daily flows, because it has been developed to estimate streamflow of extreme events (floods). A last concern is that $\mathrm{CN}$ does not consider topographical effects on runoff generation, which might play an important role in steep landscapes.

Saturation excess runoff occurs when infiltrating water stagnates in the subsurface creating perched water tables and saturates the soil above. To determine if this type of runoff occurs, several parameters are required. The Ks of all soil layers has to be known to identify stagnating layers, and the porosity and moisture content of the soil above have to be known to determine storage capacity. The required timescale to model this process depends on the magnitude of the incoming pulse of water, but often a daily time step will suffice.

Subsurface lateral flow occurs with a sufficiently large lateral hydraulic gradient of a perched water table, for example in landscapes with steep slopes (Brooks et al., 2012; Lv et al., 2013), or with soil horizons with large differences in conductivity (Gerke et al., 2015; Wilson et al., 2017). The resulting redistribution of water can lead to saturation excess runoff in lower parts of the landscape. This type of surface runoff is called Variable Source Area hydrology (VSA, Hewlett and Hibbert, 1967; Dunne and Black, 1970). This concept has been successfully applied in several models, such as TOPmodel (Beven et al., 1984) and the Soil Moisture Routing model (SMR, Mehta et al., 2004). With few parameters, such as hydraulic conductivity, total porosity and current moisture content the lateral subsurface flow and saturation excess runoff can be calculated. These models only have a limited consideration of vertical and lateral heterogeneity of soil properties and do not consider changes in soil and landscape properties over time.

The various approaches discussed above show that several methods are available for the different elements of a hydrological module for a SLEM. All these methods require less parameters and calculation time than RE-based models. However, actual implementation still faces several difficulties. Many complications lie in the estimation of hydraulic parameters, as will be discussed in Section 4.3.4.3. Moreover, these event-based methods are very sensitive to the selected time step. In simulations, lateral flow occurs less frequently and in smaller quantities when calculating with larger time steps (Boll et al., 2015). This emphasizes the need to select appropriately small time steps, which can mean that concessions have to 
be made regarding calculation time or accuracy of the boundary conditions. The next section discusses a possible framework to link processes working on different timescales.

\subsection{Coupling timescales in a SLEM}

Several methods exist to couple processes acting on different timescales. Zhang et al. (2016) describe two methods: offline updating and online updating. With offline updating, fast hydrologic processes are summarized over longer timespans and used as input for slower processes. For example, daily surface flow can be summed over a year, and then be used for annual erosion calculations. With online updating, a scaling factor is used to amplify the effect of hydrologic processes on soils and landscapes, i.e. the response of soils and landscape to flowing water in a certain time span is multiplied with the scaling factor to reduce calculation time and bridge the different timescales of the processes. For example, the amount of sediment that is transported by water flow in one year is multiplied by a scaling factor of 100, to represent sediment transport in 100 years. This reduces the amount of runs for the erosion process by 100 . The scaling factor has to be calibrated for each model using several model runs. Too large scaling factors can result in biased results. Online updating is suitable for models consisting of a set of ordinary differential equations, where small time steps are required for all processes. For SLEMs, offline coupling is more suitable for two reasons: 1) the constantly changing soil-landscape system and rainfall intensity lead to changes in the partitioning of water over time, and 2) pedogenic and geomorphic process descriptions in SLEMs are often developed for large time steps, facilitating offline coupling.

Figure 4.6 gives an example of how to design such an offline coupling. This framework suggests the use of three different time steps: daily, monthly and yearly. The basis of the hydrological module is a monthly soil water balance where total rainfall and evapotranspiration can be calculated from daily input values and equations for the monthly topsoil water balance from Pistocchi et al. (2008). This monthly time step can capture subannual variation in rainfall, evapotranspiration and snowfall. Groundwater fluctuations and capillary rise of groundwater can also be simulated on this timescale. A threshold based on infiltration capacity or lateral hydraulic gradients can be used to switch to a daily timestep when required for simulating event-based lateral surface or subsurface flow. Surface runoff would be initiated when rainfall intensity exceeds the infiltration capacity. If water is stagnating in the subsurface and the lateral gradient is large enough to enable lateral flow through multiple cells, lateral flow routing would be initiated. Surface runoff routing at daily 
timescale can then be computed with a kinematic wave approach (e.g. Tucker and Hancock, 2010) and subsurface lateral flow can be calculated with Darcy's equation. To reduce data and calculation demands, an average soil moisture profile can be estimated as basis for the subsurface lateral flow, using equations for average monthly topsoil moisture content (Pistocchi et al., 2008) and calibration with field soil moisture measurements. All lateral fluxes and (re-)infiltration will be summed over a year and used as input for the annual update of soil and landscape properties, together with soil hydraulic properties.

The proposed concept currently cannot be completely implemented. In the next Sections, we will first discuss components that can be implemented, which will be demonstrated in Section 4.3.3. Next, we discuss remaining obstacles that currently hamper implementation of this and similar concepts.

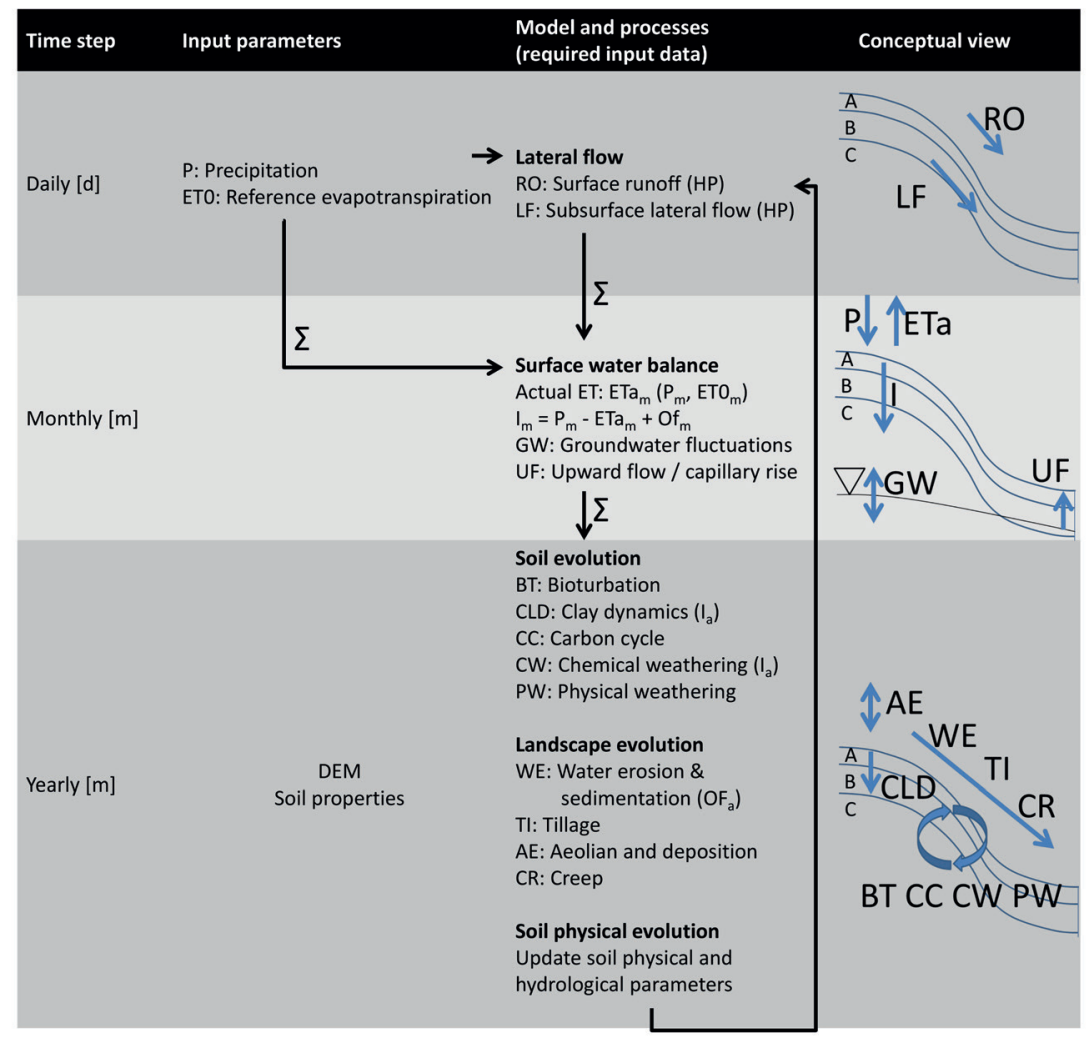

Figure 4.6: Conceptualization of modeling hydrologic, pedogenic and geomorphic processes with an offline coupling. The terms in parentheses indicate required input from parameters or other model components. 


\subsubsection{Missing links between pedogenesis and hydrology}

Next to the role of soil properties on water flow, the role of water flow on soil forming processes also has to be improved in SLEMs. Many soil forming processes have been studied in detail, with detailed physical equations to describe the process (e.g. Finke, 2012; Ahrens et al., 2015). Equations describing soil development in SLEMs are however often simplified and empirically based, in order to reduce complexity and calculation demands. This translation of physical based equations to empirical equations should be done with consideration of the controlling role of water on the processes (Minasny et al., 2015). The main soil forming processes controlled by water are chemical weathering including decarbonization, clay translocation, podzolization, and gleyzation.

Chemical weathering is often described with simplified functions that do include water and soil moisture as drivers. For example, Saco et al. (2006) used a wetness index as proxy for soil moisture effects on soil production. Egli and Fitze (2001) developed empirical models to calculate decalcification rates as function of rainfall and percolation. Finke (2012) used a calibrated version of this model in SoilGen2.

With clay translocation, water controls mobilization and transport of clay particles. The amount of transport depends on the quantity of water flowing, but also flow velocity, detachment of particles by impact of raindrops and hydrological regime of the soil (Jarvis et al., 1999; Zaidel'man, 2007). This level of detail is too high for SLEMs, where clay translocation currently is modeled with simplified processes and larger time steps (Vanwalleghem et al., 2013; Campforts et al., 2016; Temme and Vanwalleghem, 2016). Current methods in SLEMs to calculate clay translocation are based on limited data, with uniform rate constants in space and time. A similar approach as done by Egli and Fitze (2001) for decalcification can be done for clay translocation: using an empirical relation between percolation and depth to an illuvial horizon to scale the rate of clay translocation using spatially variable infiltration. However, additional field data on clay translocation rates are required for the establishment of such a relation.

Ahrens et al. (2015) gave an example of a mechanistic model (COMISSION) to simulate vertical SOC concentrations and dynamics in a Podzol. The combined simulations of microbial interactions, sorption to minerals and vertical transport resulted in accurately simulated radiocarbon ages through the soil profile, where different sources of carbon can be 
distinguished. Again this level of detail is not feasible for SLEMs, due to high calculation demands and required input parameters. Moreover, the vertical transport in COMISSION is not controlled by a water flux, but by an advection equation with a certain particle velocity and average pore water velocity, while the maximum sorption to minerals at a certain depth is currently also a fixed value. This means that the model does not respond dynamically to changes in water flow and soil properties, something that is required for integrated soil and landscape evolution. Sorption to minerals is an essential process in podzolization, as these organometallic complexes form the poorly permeable Bh horizon. The production of these minerals can be linked to chemical weathering processes. In turn, weathering rate can be linked to the formation of organic acids, as they promote weathering processes (Lundström et al., 2000). The quantity of leaching organic matter can be linked to annual percolation. Hydraulic conductivity of soil layers can control the partitioning between vertical and lateral podzolization (Lucas et al., 2012; Gannon et al., 2014).

Finally, a more detailed hydrological module in SLEMs does not only enable more accurate simulations of existing processes in SLEMs, but also enables additional processes to be included. Minasny et al. (2015) pointed out that the coverage of soil forming processes in SLEMs is limited compared to soil evolution models. An improved hydrological module would for instance enable inclusion of more processes such as carbonate dynamics, solute transport, gleyzation and salinization.

\subsubsection{Illustration of a hydrological SLEM}

We now illustrate the potential of an improved hydrological module for soil-landscape evolution modeling, using the Lorica model (Temme and Vanwalleghem, 2016). Lorica is a SLEM that calculates a variety of pedogenic and geomorphic processes with an annual time step (Table 4.2). Rates of pedogenic processes are a partial function of depth below the surface. As explained above, this means that in a landscape without geomorphic processes and with uniform starting conditions, every soil would be identical, because there would be no spatial variation in soil depth. We now show how variable pedogenic process rates as function of infiltration result in simulated pedodiversity in such geomorphically stable landscapes.

We simply incorporated the dynamic time stepping as described in Figure 4.6 in Lorica, for calculating daily run-off events, caused by infiltration excess or snowmelt. The subsequent 
redistribution of water in the landscape led to spatially variable infiltration rates, which were used to scale chemical weathering and clay translocation processes. We ran the normal version of Lorica (Conventional Lorica) and the adjusted version of Lorica (Hydrological Lorica) on a 2D undulating hillslope with initial clay content of $33 \%$, to illustrate the differences between the two model setups (Figure 4.7). An overview of the model adjustments and equations is provided in Supplement 4.1. Note that this example acts as an illustration of the potential of an improved infiltration module on simulating pedogenic diversity, rather than a fully parametrized case study.

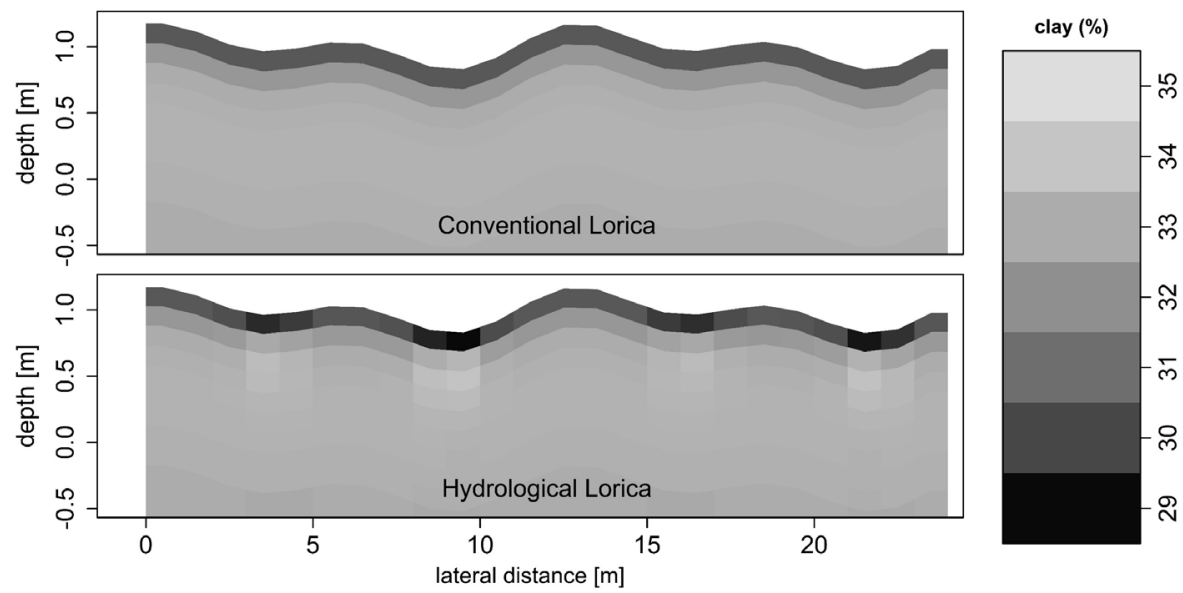

Figure 4.7: Simulated clay content in an undulating transect. The upper graph (Conventional Lorica) shows the results from the normal version of Lorica. The lower graph (Hydrological Lorica) shows the results when pedogenic process rates are scaled with spatially variable infiltration.

Figure 4.7 shows the simulated clay in the short stretch of undulating terrain. Due to the small spatial extent and low slope, elevation change by geomorphic processes is absent. Consequently, the results of Conventional Lorica show identical soils throughout the whole landscape. A small amount of clay is detached from the topsoil and translocated downward. Hydrological Lorica shows increased clay translocation in the surface depressions, caused by higher infiltration rates. This pattern matches field evidence of small scale variation in pedogenesis. For example, Knuteson et al. (1989) showed the occurrence of clay translocation by downward flow in shallow surface depressions, while that process was absent in surrounding areas with a net upward movement of water. Šamonil et al. (2016) 
showed that small depressions caused by tree throw facilitated accelerated podzolization, likely due to increased litter and water input. Depending on the properties of the soil, this can lead to either convergence or divergence in soil evolution (Šamonil et al., 2018).

The small alteration in the hydrological module of Lorica already enables simulation of similar patterns as found in these studies. Further implementation and refinement of the hydrologic and pedogenic processes would enable simulation of landscape scale redistribution of water and soil formation in a wide variety of settings. However, additional development of methods for simulating large scale soil hydrologic processes is necessary before these processes can be simulated in SLEMs, as will be discussed in the next Sections.

\subsubsection{Current obstacles with soil hydrological parameters}

Changes in soil and landscape properties change the way water is redistributed through the soils and landscapes over time. However, even with the modest improvements shown in Figure 4.7, accurate simulations of these changes in water partitioning are currently difficult to perform in SLEMs for several reasons. First, there is limited data on how soil hydrology changes over long timescales. Second, effective soil hydraulic parameters are difficult to measure due to scale dependency of these properties and measurements. Third, there are no accurate methods to estimate soil hydraulic parameters from readily available soil data in SLEMs. The last problem is mainly caused by varying effects of soil structure and macroporosity on soil hydrology. We recommend concrete research objectives to solve these issues in Section 4.4.

\subsubsection{Unknown evolution of the soil hydrological system}

The evolution of soils over time is often studied with the use of chronosequences: a range of soils where age is the major varying soil-forming factor. Differences in soil properties can thus be attributed to soil-development stage (Vreeken, 1975; Birkeland, 1992; Sauer et al., 2015). Soil chronosequences can be used for determining weathering rates (Van der Meij et al., 2016), quantifying soil physical properties such as clay content (Shepard et al., 2017), and studying the integral evolution of soil profiles (Schülli-Maurer et al., 2007; Sauer et al., 2012; Temme et al., 2016).

Chronosequences have been successfully used to study the evolution of soil hydraulic properties of several soil types. For example, Brooks and Richards (1993) measured and 
calculated hydraulic conductivity of Podzols on a series of river terraces. Saturated hydraulic conductivity was a strong function of soil texture and bulk density. They found an order of magnitude decrease in hydraulic conductivity in surface horizons, while the illuvial horizon showed fluctuations in conductivity over time. They suggest that variation in parent material may have contributed to this variation. Beerten et al. (2012) measured changes in hydraulic conductivity due to podsolization in a vertical sequence of aeolian deposits and showed that hydraulic conductivity already changes substantially in the first centuries of soil development. Young et al. (2004) studied changes in hydraulic conductivity of desert pavements in California. Saturated hydraulic conductivity decreased 100-fold over $100 \mathrm{ka}$, due to the formation of a plinthite or hardpan layer at the surface. To our knowledge, such quantitative studies on the evolution of hydraulic parameters are scarce in loamy and clayey soils. Available studies only describe conceptual frameworks, or use limited sampling locations that do not allow the formulation of continuous equations (Lohse and Dietrich, 2005).

Next to slow temporal evolution, soil hydraulic parameters also show more rapid fluctuations. Near-saturated conductivity, effective macroporosity and mean pore radius show (intra)seasonal fluctuations due to wetting and drying cycles, while total porosity can be affected by rainfall intensity ( $\mathrm{Hu}$ et al., 2009; Bodner et al., 2013; Herbrich and Gerke, 2017). Seasonal freezing of the soil substantially decreases infiltrability and promotes runoff after snowmelt (Gray et al., 2001; Hayashi et al., 2003).

Non-seasonal fluctuations are caused by management practices. Tillage temporarily decreases hydraulic conductivities by disconnecting pores and removing macropores (Logsdon et al., 1990), while also temporarily changing the ratio between vertical and horizontal hydraulic conductivity (Petersen et al., 2008). Moreover, compaction by heavy machinery and trampling creates a weakly permeable layer below the plough horizon, especially when ploughing happens when the soil is moist (Alaoui et al., 2011). Soils with these plough pans stay saturated longer and become more susceptible to erosion due to higher runoff (Bertolino et al., 2010). Land management can also stop, restart or substantially accelerate natural pedogenic processes. Clay illuviation and redox processes can be accelerated by artificial drainage (Montagne et al., 2008). Yli-Halla et al. (2009) suggested that this is caused by increased macroporosity due to drying of the loamy soil after drainage. 
Disruption of the topsoil by tillage leads to a higher release of clay particles, and an increase of illuviation.

The combination of fluctuations and gradual changes of soil hydraulic properties creates a complex and dynamic system which influences speed and direction of soil and landscape development. On the long term, soil formation leads to changes in soil structural units that drive water partitioning. On sub-yearly timescales, these soil structural units can change in porosity and conductivity, causing different hydrological behavior in, for example, summer and winter. Quantification and timing of these changes are necessary for understanding the changes in hydrologic functioning of soils over time. Before this dynamic system can reliably be simulated with SLEMs, more field data on the evolution of soil hydraulic parameters and hydraulic functioning are required. For long term evolution of soil hydraulic properties, we propose to include measurements of soil hydraulic properties in future soil chronosequence studies for calibration of SLEMs. To understand short term fluctuation of soil hydraulic properties, we propose seasonal measurements of soil hydraulic properties in different horizons, to correct long-term soil hydraulic properties for moisture conditions and temperature.

\subsubsection{Sample sizes for measuring effective soil hydraulic properties}

Accurate determination of effective soil hydraulic properties is crucial in determining soil hydraulic functioning. Measured hydraulic properties often show large variation depending on size and location of the sample, because every sample can contain different macro- and microporosity (Anderson and Bouma, 1973; Bouma et al., 1989). To avoid this variation, a sample should be of a sufficient size (representative elementary volume, REV, Lauren et al., 1988) to capture this heterogeneity. For a structured clay soil, this minimum sample size can be as large as $50,000 \mathrm{~cm}^{3}$. Unfortunately, samples of these sizes are impractical to take in the field and smaller samples (infiltration rings, $300 \mathrm{~cm}^{3}$ ) are often used. Small samples can both over- and underestimate the effective hydraulic conductivity of a soil horizon, and should be used with care when comparing hydraulic functioning of different soils. Brooks et al. (2004) mentioned three limitations of using small scale conductivity measurements for estimating hillslope conductivity: 1) the number of samples is often too small for proper statistical analysis, 2) averaged conductivity measurements are often biased by manual removal of (unrealistically) high values caused by macroporosity, and 3) small scale conductivity might 
not represent large scale conductivity due to missing connectivity of macropores, causing dead ends for preferential flow. Although scaling methods for soil and hydraulic properties are numerous (Pachepsky and Hill, 2017), their performance is generally poor due to the absence of consideration of anisotropy in soil architecture. Anisotropy can be included in scaling methods when measurements are done at various scales and this scale is included as variable in scaling method (Pachepsky and Hill, 2017). At larger scales, other factors such as topography can play larger roles in determining soil hydraulic properties and should also be considered when scaling (Jana and Mohanty, 2012). Studies on hillslope hydrology should work with larger samples representing whole horizons instead of small infiltration rings to avoid these scaling issues and directly measure representative hydraulic properties.

\subsubsection{Problems with estimating soil hydraulic properties}

The estimation of soil physical and hydraulic properties introduces uncertainty in the model outputs. These properties are often estimated using pedotransfer functions (PTFs). PTFs are functions that describe soil properties that are difficult to obtain as a function of easily obtainable soil properties. The functions range from lookup tables (class PTFs) to regression trees (e.g. for water retention, Pachepsky and Rawls, 2003), continuous equations resulting from multiple linear regressions (e.g. soil hydraulic parameters, Wösten et al., 2001; bulk density, Tranter et al., 2007) and neural network analyses (e.g. soil hydraulic parameters, Schaap et al., 2001). The development of PTFs is ongoing, with state-of-the-art improvements on the issues of upscaling, uncertainty and heterogeneity (Tóth et al., 2015; Van Looy et al., 2017). For more details on PTFs, we refer to the numerous (review) papers on this topic (e.g. Pachepsky and Rawls, 2003; Pachepsky et al., 2006; Zacharias et al., 2009; Vereecken et al., 2010; Van Looy et al., 2017).

There are several limitations for the application of PTFs in SLEMs, which are mainly due to the architecture of SLEMs. First, SLEMs only keep track of a limited set of soil properties; usually several texture classes and organic matter. This means that there is limited information available as input for PTFs, whereas PTFs generally perform better with more input variables (Vereecken et al., 2010). For example, soil bulk density would be a valuable input for PTFs that predict hydraulic variables. Although soil bulk density itself can also be estimated with PTFs, using parameters estimated with PTFs as input for other PTFs is not recommended, because the substantial uncertainty of each estimated parameter propagates 
through the different functions. More detailed PTFs are thus not necessarily the best options for SLEMs. For example, Al Majou et al. (2007) showed that simple class PTFs perform as well as more complex continuous functions in a French dataset. We propose that tests on accuracy and error propagation of input of PTFs should be the basis of the selection procedure for hydrological modeling studies (Brown and Heuvelink, 2006; Loosvelt et al., 2011; Sawicka and Heuvelink, 2016). Second, not all types of PTFs are suitable for application in SLEMs. A continuous equation or class PTF is most suitable for SLEMs, because these methods enable real-time estimation of the parameters without the need for calling an external model. These methods also require little calculation time. Third, the PTF has to be representative for the study domain. PTFs are developed using training data sets. Extrapolation of the functions outside of this training set likely results in increased uncertainty. This counts both for extrapolation over geographical regions (McBratney et al., 2002) and extrapolation over different scales (Pringle et al., 2007). There are several suggestions on how to deal with these extrapolations. Pachepsky and Hill (2017) recommended including a scale metric in PTFs, and PTFs can be calibrated with local data to improve the accuracy of the predictions (e.g. Romano and Palladino, 2002; Gerke and Hierold, 2012). Lin et al. (2014) recommended inclusion of landscape features, climate and land use to connect PTFs with their environmental settings. Large datasets covering multiple geographical regions and scales are required for the development of broadly applicable PTFs.

\subsubsection{Discrepancies between measurements and PTFS}

As an exploration of similarities and discrepancies between methods of determining hydraulic properties, we compared water retention curves from measured and estimated hydraulic properties. This example illustrates how different methods can yield contrasting results in some cases. We discuss probable causes for the discrepancies and give recommendations for dealing with these discrepancies when using PTFs in SLEMs.

Rieckh et al. (2012) measured the water retention and hydraulic conductivity of horizons of several loamy soils in different stages of erosion. Samples were taken with a $300 \mathrm{~cm}^{3}$ cylinder, with 5 replicates for each depth. The water retention curve (WRC) and hydraulic conductivity curve (HCC) were fitted on measurements at different suctions, using the van Genuchten-Mualem model (Van Genuchten, 1980). For comparison, we separately estimated the van Genuchten-Mualem parameters using the PTFs of Wösten et al. (2001). The resulting 
WRC and HCC were plotted together with the measured curves in the same graph (Figure 4.8). The soil hydraulic data from Rieckh et al. (2012) and the estimated van GenuchtenMualem parameters are provided in Supplement 4.2. The different curves were grouped per major soil horizon as indicated in the insets. The root mean squared deviations $(R M S D=$ $\sqrt{\text { mean(modeled } \theta s-\text { fitted } \theta s)^{2}}$ ) of moisture contents calculated from hydraulic heads were used as a measure of similarity between the fitted and modeled WRCs. The RMSDs were summarized over the different horizon types.

Most horizons show some deviation between the fitted and modeled curves (Figure 4.8). Only a small number of horizons show a good fit. The redoximorphic horizons show the best fit between the two types of curves, followed by the plough horizons. The illuvial horizons show the largest average deviation, but also a large standard deviation, indicating a large spread in the RMSDs. Especially striking are the large deviations, up to two orders of magnitude, in saturated hydraulic conductivity of the illuvial horizons. This difference may result from the absence of soil structure effects in the PTFs: structure and cracks in Bt horizons can lead to high permeability rates compared to other soil horizons (Kodešová et al., 2009). Mirus (2015) showed similar discrepancies between measured and modeled WRCs and attribute the difference to absence of structure and hysteresis effects of wetting and drying. The redoximorphic horizons might be less influenced by the effects of wetting and drying cycles, due to their wetter soil conditions and landscape positions.

This example shows that PTFs can give very different hydraulic properties than can be measured in the lab. This is either due to simplifications of the PTFs or due to the representability of the measurements. However, we cannot judge which hydraulic properties are more reliable or more representative for field conditions. The lesson to learn from this example is that the applicability of PTFs should be tested against representative field measurements for each model study. Special care should be given to the consideration of hydrological regime of soils and soil properties not included in the PTFs, such as soil structure. Hydraulic parameters can be tested using detailed soil hydrological models (e.g. HYDRUS-2D or 3D, Šimůnek et al., 2006), and validated using tracer experiments. 

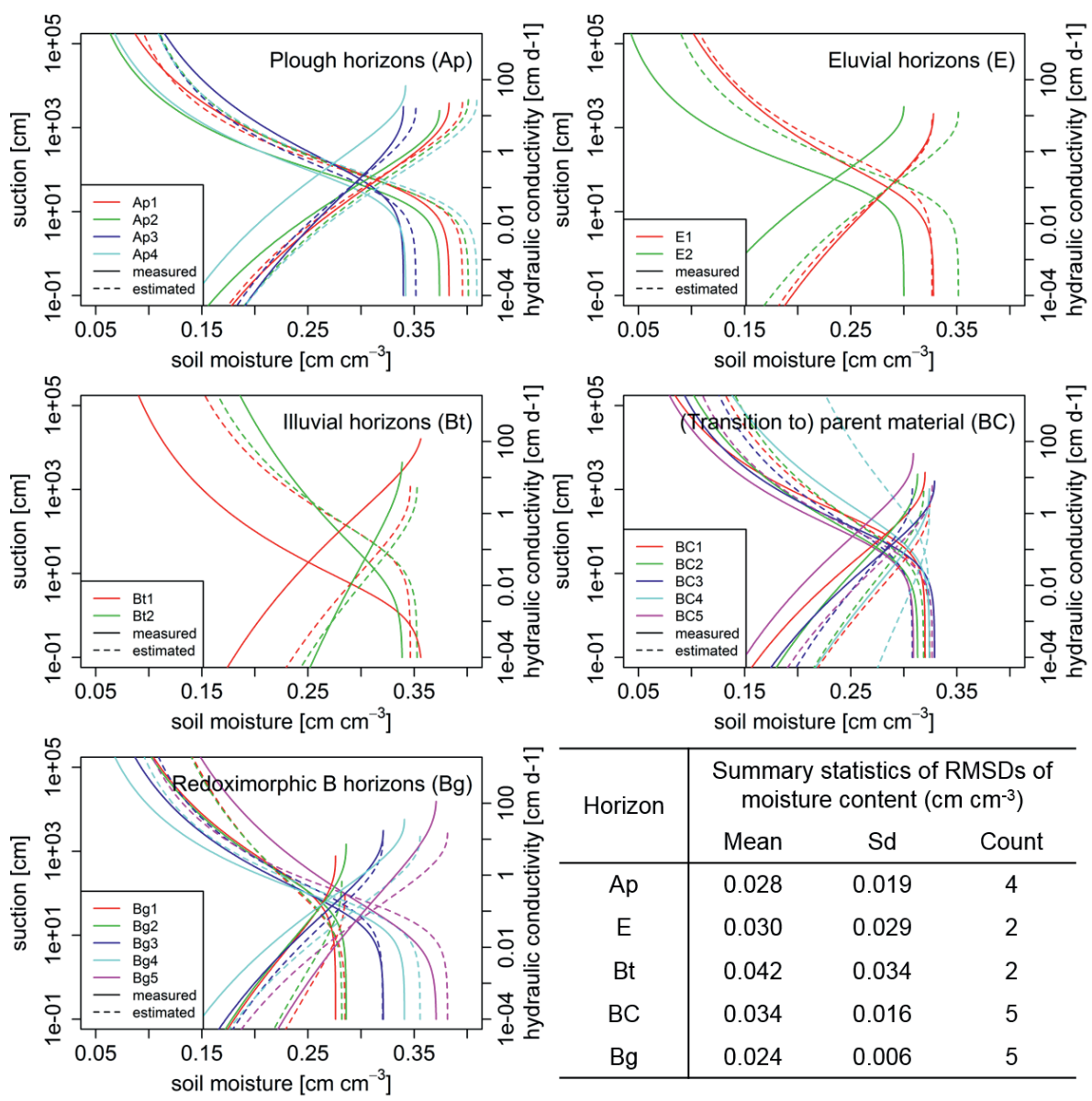

\begin{tabular}{|c|c|c|c|}
\hline \multirow[t]{2}{*}{ Horizon } & \multicolumn{3}{|c|}{$\begin{array}{l}\text { Summary statistics of RMSDs of } \\
\text { moisture content }\left(\mathrm{cm} \mathrm{cm}^{-3}\right)\end{array}$} \\
\hline & Mean & Sd & Count \\
\hline Ap & 0.028 & 0.019 & 4 \\
\hline 5 & 0.030 & 0.029 & 2 \\
\hline $0 . \frac{0}{5}$ & 0.042 & 0.034 & 2 \\
\hline 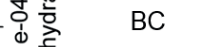 & 0.034 & 0.016 & 5 \\
\hline $\mathrm{Bg}$ & 0.024 & 0.006 & 5 \\
\hline
\end{tabular}

Figure 4.8: Measured water retention curves of Rieckh et al. (2012) (solid lines) and the estimated water retention curves for the same horizons using the PTFs of Wösten et al. (2001) (dashed lines). The table shows the summary statistics of the root mean squared deviations of moisture content between the water retention curves from the different methods. The horizon codes refer to Supplement 4.2, where we provide soil and hydrological data of each horizon.

\subsubsection{Soil structural effects on soil hydrology}

Soil structure and macroporosity play a pivotal role in soil hydrology by controlling macropore and preferential flow (Lin et al., 1999). However, they are not often considered yet in PTFs and soil modeling studies (Pachepsky and Rawls, 2003; Samouëlian et al., 2012). The absence of macroporosity in PTFs is one of the main reasons PTFs have a low performance in structured soils. For example, Nemes et al. (2003) remarked that the WRC calculated with the VGM model gives higher errors near saturation, due to the exclusion of 
macroporosity. Mirus (2015) found that PTFs that do not include soil structure can overestimate surface runoff, leading to errors in the water balance. Pedotransfer functions including soil structure do exist. For example, Pachepsky et al. (2006) developed a class PTF for estimating soil water retention in soils with different textures, structure types and structure grades and has been used in a study on the effect of palaeosols on present-day hydrology (Temme et al., 2012). However, this approach does not consider macroporosity leading to preferential flow. Existing methods to consider macroporosity in soil hydrological models include dual permeability models (Gerke and Van Genuchten, 1993; Kodešová et al., 2009) and the use of parameters to correct hydraulic conductivity for macropore effects (Mehta et al., 2004). To develop methods which consider soil structural effects in soil hydrology, form and functioning of relevant soil structural units have to be determined (e.g. Guo et al., 2014; Angermann et al., 2017; Jackisch et al., 2017), and related to easily measurable soil properties or landscape attributes through PTFs. Van Looy et al. (2017) reviewed the use of pedotransfer functions in earth sciences and identified several points for development. First, they called for multimodal models instead of unimodal models such as the Van Genuchten-Mualem model to describe soil water retention, as multiple-porosity models can include multimodal pore-size distributions created by soil structure. Next, they argued that incorporation of macroporosity and stoniness in PTFs is needed to improve infiltration modeling in land surface models (Hlaváčiková et al., 2016). Lastly, incorporation of time-dependent variables in PTFs, such as vegetation parameters or climate, can help consider the effect of soil structure dynamics under moisture fluctuations and different management practices. These developments are essential for the use of PTFs at the appropriate scale for SLEMs, which can include the dynamic effects of soil structure and macroporosity. However, thus far these developments have proved to be difficult (Van Looy et al., 2017).

An alternative for these time-dependent PTFs is the development of PTFs that estimate occurrence, type and grade of soil structural units. This information can then be fed into structure-dependent PTFs for soil hydraulic properties. Although we warned earlier against using PTF output as input for other PTFs (Section 4.3.4.3), we believe that a representation of soil structure through PTFs is essential for more accurate soil hydrological modeling and therefore outweighs additional uncertainty from the stacking of PTFs. Soil structural units can be observed in the field, or even quantified in the lab (Vogel and Roth, 2001; Schlüter and Vogel, 2016). However, methods to estimate soil structural units such as structure type 
and macroporosity using PTFs are scarce, with some attempts to link structure to soil moisture (Armstrong et al., 2000; Greco, 2002). Ideally, all factors controlling soil structural units should be included in the functions. These are physical factors, such as organic matter, moisture and clay content, and environmental factors, such as management type, climate and soil type (Bronick and Lal, 2005; Jirků et al., 2013). Another complication is the fact that macropores should be connected before they can act as preferential flow paths. For example, pores formed by freeze-thaw and wetting-drying are often isolated and small (Naveed et al., 2013). These micro-environmental factors should thus also be included in estimations of soil structural unit type and extent to give more accurate results.

Recent advances in linking pore size distributions to soil physical properties such as texture show promising results. Naveed et al. (2013) measured soil pore parameters on intact soil columns along a clay gradient, using X-ray computed tomography. Functional macropore networks and pore types could be identified and were related to clay content. They found a decrease of macropore size and connectivity with increasing clay content. Ding et al. (2016) correlated different texture fractions to a double exponential water retention curve (DEWRC), where the different modes represent matrix and structural porosity, with residual porosity as asymptote (Dexter et al., 2008). Clay content correlated with residual porosity, while sand content correlated with structural porosity. The shape of the DE-WRC depended on relative presence of different texture sizes.

These quantifications of links between soil water retention and soil texture can form a solid basis for structure-based PTFs. Similar studies are necessary for quantifying links between soil structure and management practices, climatic regions and seasons. With these links, widely applicable, structure-based PTFs can be formulated for application in SLEMs and hydrological modeling in general.

\subsubsection{Identification and quantification of flow paths}

The performance of a hydrological SLEM depends on its ability to accurately estimate the partitioning of water along all possible flow paths (Figure 4.1). For the development and evaluation of such a model, detailed field information on water flow through different flow paths is required, but not currently available.

Surface runoff has been widely quantified using several methods, such as flumes and weirs at catchment outlets and modeling (e.g. Chanasyk et al., 2003). Different sources of water 
can be distinguished (McGlynn and McDonnell, 2003) and flow of water can be tracked along a hillslope (Masselink et al., 2017). Subsurface lateral flow is much more difficult to measure. The concept of hydropedology (Lin, 2003, 2012b) links hydrology and pedology, which can help classifying soils and soil horizons according to their hydrologic functioning and quantify water flow along different flow paths. The classification of soil layers into hydropedological units can help simulating soil water balances more accurately, by giving effective soil hydraulic parameters to each unit (Mirus, 2015). The same can be done for hillslopes, describing the hydrologic functioning of soils along different catenae (Van Tol et al., 2013). At a catchment scale or larger, hydrological soil types can describe hydrologic functioning (Boorman et al., 1995).

Identification and quantification of preferential flow and lateral flow can be done using soil moisture sensor networks (Lin, 2006), proximal sensing techniques (Guo et al., 2014), tracer experiments (Stumpp and Hendry, 2012), soil morphology analysis (Lin et al., 1999; Lin et al., 2014; Vepraskas and Craft, 2016), numerical modeling (Weiler and McDonnell, 2007), hydraulic connectivity analysis (Ali et al., 2018; Zimmer and McGlynn, 2018), and analysis of landscape scale redistribution of elements such as manganese, iron (redox properties) and calcium carbonates (Sommer and Schlichting, 1997; Bedard-Haughn and Pennock, 2002; Fiedler and Sommer, 2004; Bouma, 2006). Nonetheless, current technologies require further development for identifying and measuring preferential flow, because they currently are not precise enough for measuring complex preferential flow pathways and patterns (Graham and Lin, 2012; Guo and Lin, 2018).

Well studied field sites, such as Critical Zone Observatories (Anderson et al., 2008) or artificial catchments (Gerwin et al., 2009), can act as test beds for PTF and model development, when both hydrological and pedological datasets are available. 


\subsection{Recommendations}

In this contribution, we have reviewed needs and current obstacles for improving hydrological modeling in soil-landscape evolution models. This improvement is necessary, because current models do not respond to changes in climatic forcing and water partitioning, although these feedbacks are essential for understanding pedodiversity and, consequently, soil functioning at a landscape scale.

We summarize the obstacles and required development in Table 4.3. To overcome these obstacles, related to model architecture, the estimation of soil hydraulic properties and hydraulic functioning of soil landscapes, there is a need for:

a. A modeling framework that can link processes acting on different timescales;

b. Simple pedogenic functions with annual water flow as driver, derived from chrono-, hydro- and climosequence studies;

c. Methods to accurately estimate the evolution of soil hydraulic parameters over time, derived from soil hydraulic chronosequence studies; and

d. Methods to estimate partitioning of water through the soil landscape, based on extensive field evidence.

Part of these requirements ( $\mathrm{a}$ and $\mathrm{b}$ ) can currently be solved, as we have shown in Sections 4.3.1-4.3.3. Additional research is required to solve the other issues at hand. Table 4.3 provides studies focusing on these issues, or studies that can be used as inspiration to solve them.

With the advances in hydrological and pedological sciences, new concepts and functions are continuously formed and updated with a constantly increasing level of detail. We urge to take a step back and see how these relations fit in an integrated assessment of soils, landscapes and hydrology. SLEMs are ideal tools to study these relationships, because they force the user to summarize their knowledge and use that to test hypotheses on feedbacks in the hydropedo-geomorphological system. We encourage the use of SLEMs in studies concerning soillandscape interactions, environmental change and landscape scale soil hydrology. With the recommendations suggested in this Chapter, we hope that SLEMs will grow into the appropriate tools to perform these studies. 
Table 4.3: Overview of problems and proposed development for incorporating more complex hydrology in SLEMs.

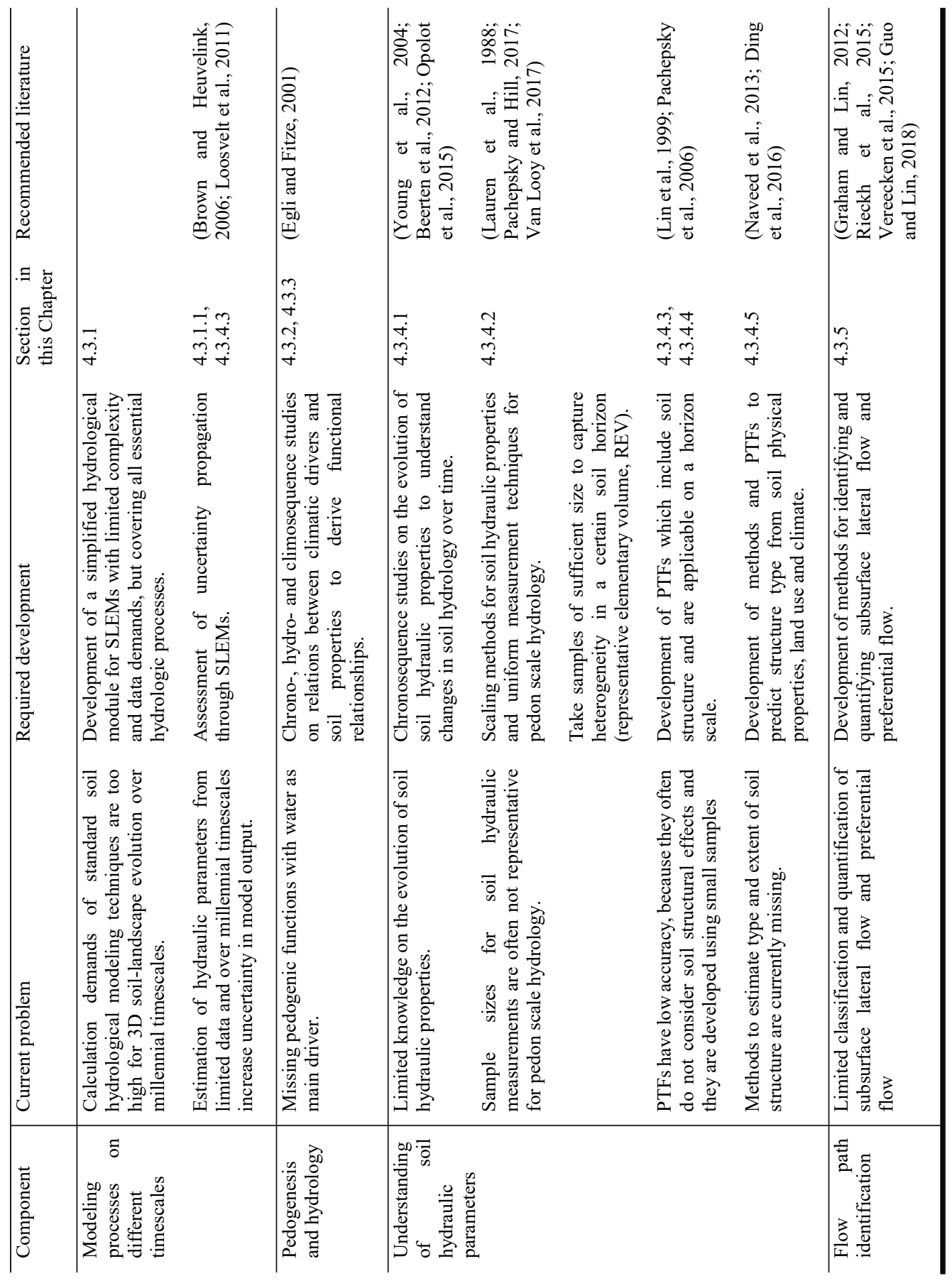




\subsection{Acknowledgements}

We would like to thank Ype van der Velde, Jan Boll and Erin Brooks for their help in the search for possible hydrological models to use together with SLEMs. Marijn van der Meij and Arnaud Temme thank Fei Jiang for her help and hospitality during their visit to Pennsylvania State University. Furthermore, we would like to thank Gert Peek for his interpretation of the genesis of the Podzol profile in the Drents-Friese Wold National Park. 


\section{Supplement 4.1 Adjustments to Lorica for daily water flow}

We adjusted the hydrological module of the Lorica model (Temme and Vanwalleghem, 2016) to simulate spatially varying pedogenesis as a function of surface redistribution of water. This Supplement describes 1) the equations used to simulate hydrologic and pedogenic processes on different timescales, and 2) the initial and boundary conditions, and process parameters.

\section{S4.1.1 Daily processes}

Daily reference evapotranspiration $E T_{0, d}$ is calculated with the Hargreaves-Samani equation (Hargreaves and Samani, 1985):

$$
E T_{0, d}=0.0023\left(T_{a v g}+17.78\right) \sqrt{T_{\max }-T_{\min }} R_{a}
$$

where $T_{\text {avg }}$ is the daily average temperature $\left[{ }^{\circ} \mathrm{C}\right]$ and $T_{\max }-T_{\min }$ is the difference between daily maximum and minimum temperature, and $R_{a}$ is incoming solar radiation [converted to $\mathrm{mm}$ $\mathrm{d}^{-1}$ ] (Allen et al., 1998):

$$
R_{a}=\frac{24 * 60}{\pi} G_{s c} d_{r}\left[\omega_{s} \sin (\varphi) \sin (\delta)+\cos (\varphi) \cos (\delta) \sin \left(\omega_{s}\right)\right] * 0.408
$$

where $G_{s c}$ is the solar constant $\left(0.0820 \mathrm{MJ} \mathrm{m}^{-2} \mathrm{~min}^{-1}\right), d_{r}$ is inverse relative distance EarthSun (Eq. (S4.3)), $\omega_{s}$ is the sunset hour angle (Eq. (S4.4)), $\varphi$ is the latitude of the study area [radians] and $\delta$ is the solar declination [radians] (Eq. (S4.5)), as functions of the number of the day in the year $J$.

$$
\begin{aligned}
& d_{r}=1+0.033 \cos \left(\frac{2 \pi}{365} J\right) \\
& \omega_{s}=\arccos [-\tan (\varphi) \tan (\delta)] \\
& \delta=0.409 \sin \left(\frac{2 \pi}{365} J-1.39\right)
\end{aligned}
$$

Snow melt is calculated using Eq. (S4.6) from Hock (2003): 


$$
M=\left\{\begin{array}{r}
f_{m}\left(T_{a v g}-T_{0}\right), T_{a v g}>T_{0} \\
0, T_{a v g} \leq T_{0}
\end{array}\right.
$$

where $M$ is daily snow melt [m], $T_{0}$ is a threshold temperature beyond which snowmelt occurs, which we set to $0{ }^{\circ} \mathrm{C}$, and $f_{m}$ is a melt factor $\left[0.004 \mathrm{~m}^{\circ} \mathrm{C}^{-1}\right]$. Snowfall and snowmelt is assumed to be spatially constant.

Infiltration capacity $I C_{x y}\left[\mathrm{~m} \mathrm{~h}^{-1}\right]$ on location $(x, y)$ is calculated as the saturated hydraulic conductivity of averaged soil properties in the top $0.5 \mathrm{~m}$ of the soil, following the pedotransfer functions of Wösten et al. (2001):

$$
\begin{aligned}
& I C_{x y}=\exp \left(7.755+0.03252 \mathrm{~S}_{\mathrm{xy}}+0.93-0.967 \mathrm{BD}_{\mathrm{xy}}^{2}-0.000484 \mathrm{C}_{\mathrm{xy}}^{2}-\right. \\
& 0.000322 \mathrm{~S}_{\mathrm{xy}}^{2}+\frac{0.001}{\mathrm{~S}_{\mathrm{xy}}}-\frac{0.074}{\mathrm{OM}_{\mathrm{xy}}}-0.643 \mathrm{Log}\left(\mathrm{S}_{\mathrm{xy}}\right)-0.01398 \mathrm{BD}_{\mathrm{xy}} \mathrm{C}_{\mathrm{xy}}- \\
& \left.0.1673 \mathrm{BD}_{\mathrm{xy}} \mathrm{OM}_{\mathrm{xy}}+0.02986 \mathrm{C}_{\mathrm{xy}}-0.03305 \mathrm{~S}_{\mathrm{xy}}\right) * \frac{\cos \left(\theta_{x y}\right)}{2400}
\end{aligned}
$$

with $S_{x y}$ as the silt content [\%], $C_{x y}$ as the clay content [\%], $B D_{x y}$ as bulk density $\left[\mathrm{g} \mathrm{cm}^{-3}\right]$ and $O M_{x y}$ as organic matter content [\%, with a minimum of 0.5$]$ of the topsoil on location $(x, y)$, and $\theta_{x y}$ as the surface slope on location $(x, y)$ [radians] (Morbidelli et al., 2018).

Surface run-off occurs when rainfall intensity or incoming water exceeds infiltration capacity in a certain cell, or when snowmelt occurs:

$$
\text { Qout }_{d, x y}=\text { Qout }_{p, x y}+M
$$

with

$$
\text { Qout }_{p, x y}=\left\{\begin{array}{r}
\left(P_{d}+Q i n_{d, x y}\right)-\frac{I C_{x y}}{D_{d}}, \frac{\left(P_{d}+Q i n_{d, x y}\right)}{D_{d}}>I C \\
0, \frac{\left(P_{d}+Q i n_{d, x y}\right)}{D_{d}} \leq I C
\end{array}\right.
$$

where Qout $_{d, x y}$ is daily surface run-off on location $(x, y)[\mathrm{m}]$, Qout $_{p, x y}$ is run-off triggered by infiltration excess on location $(x, y), P_{d}$ is daily precipitation $[\mathrm{m}], D_{d}$ is the daily rainfall duration [h] and $\operatorname{Qin}_{d, x y}$ is daily run-on on location $(x, y)$ from higher located cells [m]. Note that this calculation only considers one rainfall event per day. Multiple rainfall events would require a different approach. 
Surface run-off can leave the catchment, re-infiltrate in cells with a higher infiltration capacity, or re-infiltrate in local depressions in the landscape. The water reaching such a depression is redistributed evenly over the sink cell and its neighbors in such a way that a smooth water level is created. When the water level exceeds the highest cell of the depression, the excess water flows over to the next cell. All water captured in a depression infiltrates according to the level of ponding on a certain cell.

\section{S4.1.2 Monthly processes}

The monthly actual evapotranspiration $E T_{a, m}[\mathrm{~m}]$ is calculated according to Pistocchi et al. (2008) as

$$
E T_{a, m}=\frac{P_{m}}{\left(\alpha+\left(\frac{P_{m}}{E T_{0, m}}\right)^{\beta}\right)^{\frac{1}{\beta}}}
$$

where $P_{m}$ and $E T_{0, m}$ are the monthly sums of precipitation and reference evapotranspiration.

Monthly infiltration $I_{m, x y}$ is calculated as:

$$
I_{m, x y}=P_{m}-E T_{a, m}-Q o u t_{m, x y}+Q i n_{m, x y}
$$

where $Q_{o u t}$ and $\operatorname{Qin}_{m}$ are monthly sums of surface run-off and surface run-on.

\section{S4.1.3 Yearly processes}

The yearly sum of infiltration $I_{a, x y}$ is used to scale rates of certain pedogenic processes where water or water flow is the dominant driver. These processes are chemical weathering and clay translocation. The infiltration scaling factor on location $(x, y) I_{c f, x y}$ is allowed to range between 1 and 2, where 1 is for locations with minimum infiltration and 2 is for the location with maximum infiltration. $I_{c f, x y}$ is calculated as:

$$
I_{c f, x y}=1+\frac{I_{a, x y}-\min \left(I_{a}\right)}{\max \left(I_{a}\right)-\min \left(I_{a}\right)}
$$

where $\min \left(I_{a}\right)$ and $\max \left(I_{a}\right)$ are the minimum and maximum annual infiltration in the study area. Process rates, such as the mass of clay that is translocated from one cell to the next, or the part of a certain texture fraction that will be weathered are multiplied with the infiltration scaling factor. This means that pedogenic rates currently do not depend on external changes in rainfall, but only to internal redistribution of water. 
$I_{c f, x y}$ is currently linearly scaled with infiltration, which can cause a disproportionally high rate of pedogenesis in depressional cells with a large upstream area. In our case study this function works well. In other studies, scaling can be done with, for example, a logarithmic relation.

Pedogenic processes are the same as described in Temme and Vanwalleghem (2016), except for clay translocation, where an additional depth function has been added:

$$
\begin{aligned}
& \Delta M_{t r, f \text { ine clay }, l \text { to } l+1}=\left(c_{t r}\left(1-\exp \left(-c 11 * f_{\text {fine clay }, l}\right)\right)\right) * \exp \left(-c_{c t d} *\right. \\
& \text { depth })
\end{aligned}
$$

where $\Delta M_{\text {tr.fine clay, }, \text { to } l+l}$ is the mass of fine clay $[\mathrm{kg}]$ that is translocated from layer $l$ to layer $l+1, c_{t r}$ is the maximum eluviation $[\mathrm{kg}], c 11$ is the saturation constant [-], $c_{c t d}$ is the depth constant for clay translocation $\left[\mathrm{m}^{-1}\right]$, set to 2 in this study, and depth is the depth below the surface $[\mathrm{m}]$.

To avoid immense input datasets of daily weather for simulations over millennial timescales while considering changing climatic conditions, we developed functions to scale measured annual time series of daily weather variables with reconstructed annual temperature and rainfall. This reduces input data demands, while maintaining realistic variation in weather. Required inputs are 1) one or several annual time series of daily rainfall and minimum, maximum and mean temperature, and 2) time series of reconstructed annual rainfall or mean temperature.

Reconstructed rainfall $P_{i, r}$ on day $i$ of the year is calculated as:

$$
P_{i, r}=P_{i} * \frac{P_{a, r}}{P_{a}}
$$

where $P_{i}$ is measured rainfall on day $i$ from the provided time series, $P_{a}$ is the total annual rainfall of the provided time series, and $P_{a, r}$ is the reconstructed total annual rainfall. Rainfall duration is currently not changed during the simulations.

Reconstructed mean, minimum or maximum temperatures $T_{i, r}$ on day $i$ of the year are calculated as: 


$$
T_{i, r}=T_{i}+\left(\overline{T_{a, r}}-\overline{T_{a}}\right)
$$

where $T_{i}$ is measured mean, minimum or maximum temperature on day $i$ from the provided time series, $\overline{T_{a}}$ is mean annual temperature of the provided time series, and $\overline{T_{a, r}}$ is the reconstructed mean annual temperature.

\section{S4.1.4 Boundary conditions and process parameters}

We based our simulations on the hummocky terrain of northeast Germany, where large and small depressions in the landscape control pedogenesis, and surface run-off is triggered by intense summer rain showers and snowmelt (Gerke et al., 2010; Van der Meij et al., 2017). The latitude of the study area is $53^{\circ} 22^{\prime}$. We used 6 complete years of measured hourly precipitation and daily temperature from weather station Grünow (DWD Climate Data Center (CDC), 2017a, b), scaled to a standard annual precipitation of $700 \mathrm{~mm}$ and a mean annual temperature of $10^{\circ} \mathrm{C}$.

The initial particle size distribution of the soil was $34 \%$ sand, $33 \%$ silt and $33 \%$ coarse clay. The fine clay fraction, which could eluviate, was formed by the clay neoformation process. The 2D elevation map was constructed manually, with the purpose of having several surface depressions with different catchment sizes.

Simulated geomorphic and pedogenic processes are:

- Water erosion and sedimentation

- Physical weathering

- Chemical weathering

- Clay translocation

- Bioturbation

Process parameters were identical to the ones mentioned in Temme and Vanwalleghem (2016), except when mentioned otherwise in this document. 


\section{Supplement 4.2: Soil and hydraulic properties used for the water retention curves}

Table S4.1: Soil and hydraulic properties of the soil horizons as measured by Rieckh et al. (2012), and estimated hydraulic properties using pedotransfer functions of Wösten et al. (2001).

Table starts at next page. 


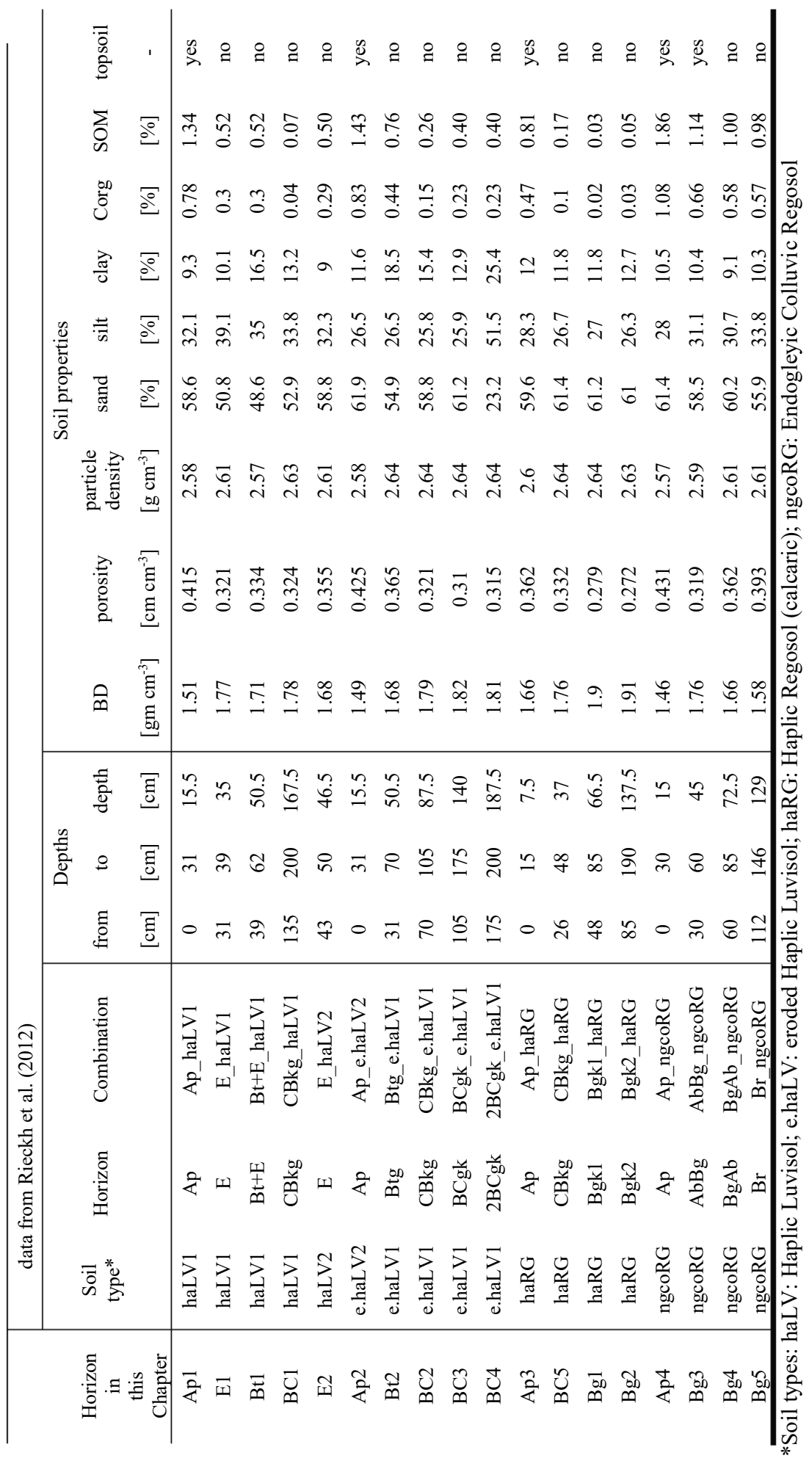




\section{Table S4.1, continued}

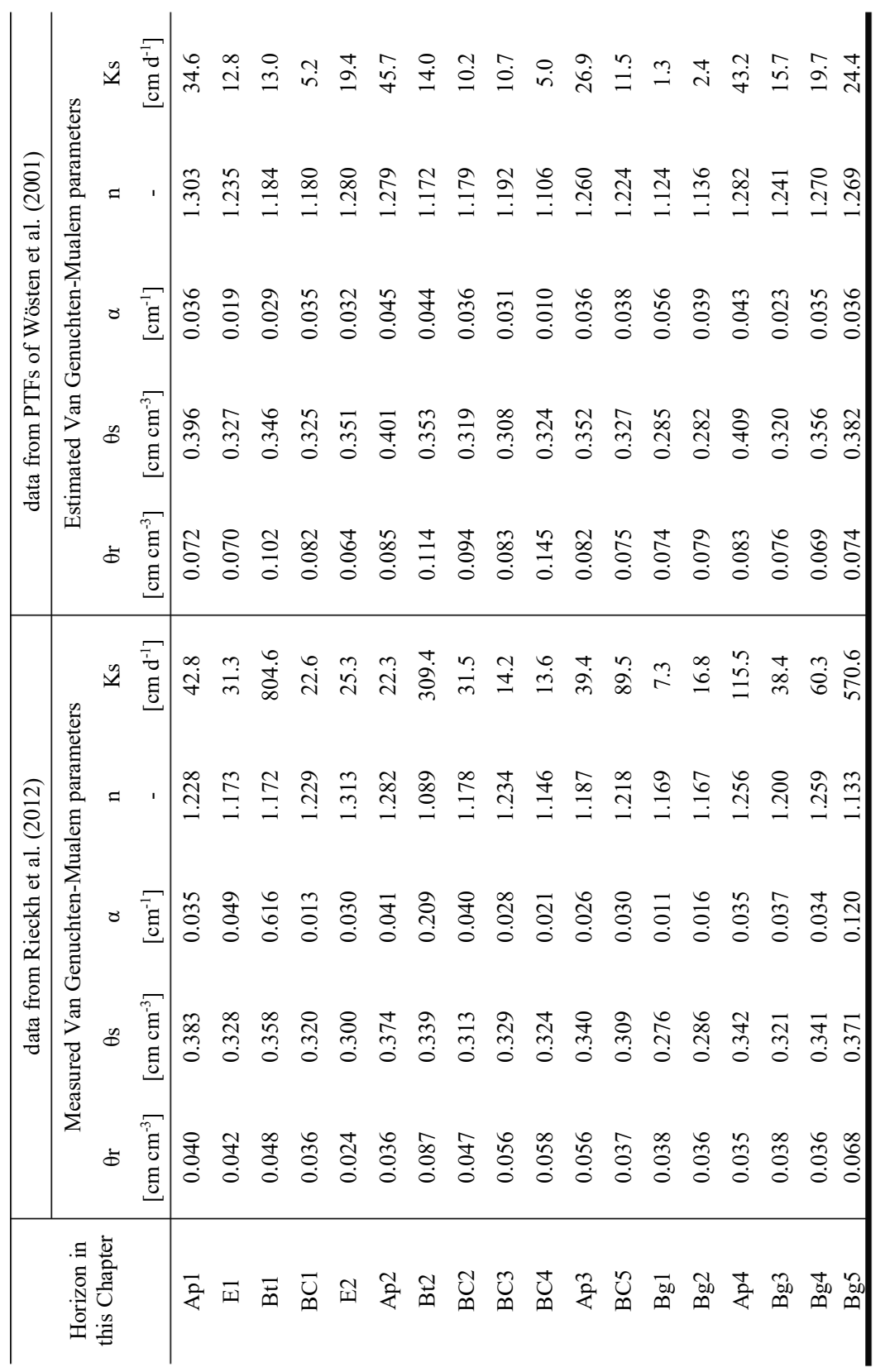




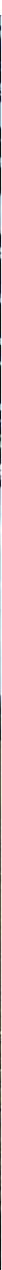


Chapter 5. Modeling soil and landscape evolution - the effect of rainfall and land-use change on soil and landscape patterns

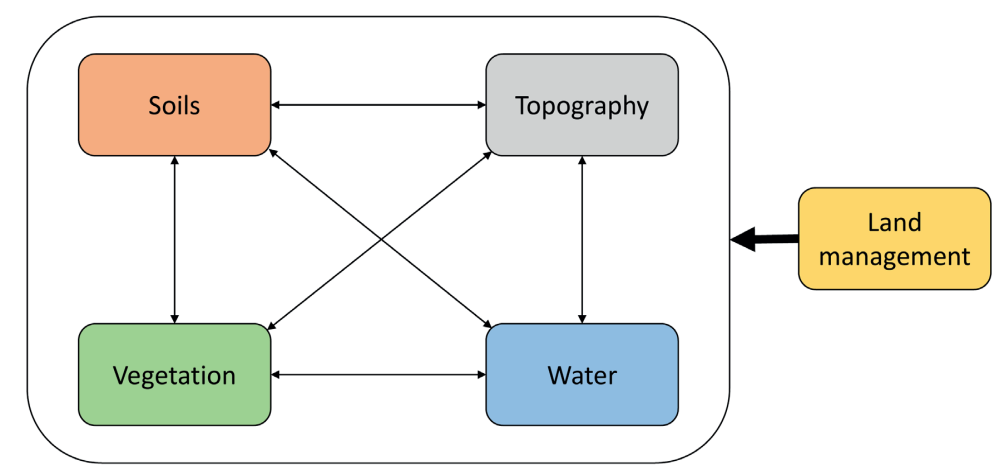




\begin{abstract}
Humans have substantially altered soil and landscape patterns and properties due to agricultural use, with severe impacts on biodiversity, carbon sequestration and food security. These impacts are difficult to quantify, because we lack data on long-term changes in soils in natural and agricultural settings and available simulation methods are not suitable to reliably predict future development of soils under projected changes in climate and land management. To help overcome these challenges, we developed the HydroLorica soillandscape evolution model, that simulates soil development by explicitly modeling the spatial water balance as driver of soil and landscape forming processes. We simulated 14500 years of soil formation under natural conditions for three scenarios of different rainfall inputs. For each scenario we added a 500-year period of intensive agricultural land use, where we introduced tillage erosion and changed vegetation type.
\end{abstract}

Our results show substantial differences between natural soil patterns under different rainfall input. With higher rainfall, soil patterns become more heterogeneous due to increased tree throw and water erosion. Agricultural patterns differ substantially from the natural patterns, with higher variation of soil properties over larger distances and larger correlations with terrain position. In the natural system, rainfall is the dominant factor influencing soil variation, while for agricultural soil patterns landform explains most of the variation simulated. The cultivation of soils thus changed the dominant factors and processes influencing soil formation, and thereby also increased predictability of soil patterns. Our study highlights the potential of soil-landscape evolution modeling for simulating past and future developments of soil and landscape patterns. Our results confirm that humans have become the dominant soil forming factor in agricultural landscapes.

Under review as: Van der Meij, W. M., Temme, A. J. A. M., Wallinga, J., and Sommer, M. 2019. Modelling soil and landscape evolution - the effect of rainfall and land use change on soil and landscape patterns, SOIL Discussions, https://doi.org/10.5194/soil-2019-82, in review. 


\subsection{Introduction}

Soils provide valuable functions for nature and society by supporting plant growth and agriculture, managing water and solute flow, sequestering carbon, preserving archaeological heritage, creating habitats for plants and animals and providing support for infrastructure (Dominati et al., 2010; Greiner et al., 2017). However, soils are currently degrading by agricultural intensification and climate change, forming one of the largest threats to global food security and biodiversity (Bai et al., 2008; Tscharntke et al., 2012; Montanarella et al., 2016). A drastic change in land management is needed to restore healthy soils and soil functions (IPCC, 2019). Combating soil degradation and promoting sustainable land management therefore stands high on the agenda of the soil-science community (Bouma, 2014; Kust et al., 2017; Minasny et al., 2017; Cowie et al., 2018; Keesstra et al., 2018a).

The first step towards sustainable land management and a return to healthy, natural soils is a fundamental understanding of the development and characteristics of natural soil patterns, and how these change under human influence. Therefore, we will focus in this Chapter on gently to strongly sloping undulating landscapes that are suitable for agricultural use (max slope $\sim 20 \%$, Bibby and Mackney, 1969). Soil forming processes are controlled by at least five environmental factors: climate, organisms, relief, parent material and time (the ClORPT model, Jenny, 1941). Different factors dominate in natural and agricultural settings. In natural flat or undulating settings soil erosion by water and tillage generally occurs at very low rates or is absent (Wilkinson, 2005; Alewell et al., 2015). Some soil redistribution can occur as a consequence of creep or tree throw (Gabet et al., 2003). More importantly, tree throw creates local pits and mounds, which temporarily change hillslope hydrology and act as local hotspots for soil development due to a larger influx of water (Šamonil et al., 2015; Shouse and Phillips, 2016). These seemingly random processes create a high degree of heterogeneity in soil patterns, which shows little to no correlation with relief (Vanwalleghem et al., 2010). In contrast, agricultural landscapes show soil patterns that closely follows the relief (Phillips et al., 1999; Van der Meij et al., 2017). Erosion processes are relief-dependent and this propagates into the soil patterns. The switch from such natural to agricultural soil systems can occur abruptly, e.g. by deforestation or the implementation of highly mechanized agriculture in a few decades. Sommer et al. (2008) described this switch in boundary conditions and its implications with a time-split approach: Over a short time period - relative to Holocene soil evolution - the soil system changes from natural, progressive pedogenesis, 
where profile deepening and horizon formation dominate erosive processes, to regressive pedogenesis, where - vice versa - erosion and deposition dominates progressive pedogenic processes (Johnson and Watson-Stegner, 1987).

The coexistence of both progressive and regressive processes in a defined period of time has been described by several authors. In a progressive phase there are also regressive processes that change soils, terrain and hydrological pathways (Phillips et al., 2017; Šamonil et al., 2018). In a regressive phase, progressive processes still have a substantial effect on soil development (Montagne et al., 2008; Doetterl et al., 2016). Colluvic soils might be influenced by groundwater or subject to continuous clay illuviation (Leopold and Völkel, 2007; Zádorová and Pení žek, 2018; Van der Meij et al., 2019, SI). Furthermore, the changes in boundary conditions are not always abrupt as e.g. deforestation. Historic erosion processes with rates much lower than current erosion processes might have given pedogenic processes the time to alter soil and colluvium(Van der Meij et al., 2019).

To disentangle complex history and causes of soil formation, data is required on both natural and agricultural soils that have formed under similar conditions, and preferably from the same region. However, there is limited undisturbed natural land left, often rapidly declining, in places that are unsuitable for agriculture, and/or indirectly influenced by anthropogenic climate change (e.g. tropical and boreal zones, IPCC, 2019). Moreover, (historical) cultivation occurred in areas and soils most suitable for agriculture (Pongratz et al., 2008; Vanwalleghem et al., 2017), leaving less suitable land undisturbed. This complicates comparison and empirical inference. Because of the complex interactions between pedogenic and geomorphic processes, and the lack of field data, we heavily depend on process knowledge and model simulations for mechanistic inference about how natural soil patterns develop as function of their environments and how this changes in agricultural settings (Opolot et al., 2015).

Soil evolution models simulate a range of physical, chemical and biotic processes that affect the properties of soils through space and time (Minasny et al., 2015; Vereecken et al., 2016; Stockmann et al., 2018). Such models have been developed for a range of scales, varying from 1D soil profiles to 3D soil landscapes (Finke, 2012; Minasny et al., 2015; Temme and Vanwalleghem, 2016). One-dimensional soil profile models generally provide a high level of detail and process coverage, but they lack the simulation of essential feedbacks and 
interactions that can occur between soils on a landscape scale (Van der Meij et al., 2018). For example, the spatial redistribution of water or the exchange of soil material through erosion and deposition processes affect soils differently at different landscape positions. Soillandscape evolution models (SLEMs) do simulate lateral distribution of solids by geomorphic processes and consider soils as continua rather than discrete units. Current SLEMs perform reasonably well in landscapes where lateral soil movement is substantial (e.g. Van Oost et al., 2005b; Temme and Vanwalleghem, 2016). However, these models are not developed to simulate soil development in relatively stable landscapes where lateral water redistribution is the dominant driver causing soil heterogeneity, because this hydrologic control is not explicitly modeled (Van der Meij et al., 2018).

To summarize, we are currently lacking data and methods that can quantify the effect of changing soil forming factors on soil development and spatiotemporal soil patterns, whereas this knowledge is essential for the transition to sustainable land management and adaptation to the changing climate. Therefore, the objective of this study is to develop a suitable model to quantify the variation and predictability of soil patterns as a function of varying environmental factors. We will address three questions:

1. What are the basic characteristics of soil patterns in natural and agricultural landscapes?

2. What are the major factors driving soil formation in natural and agricultural landscapes?

3. How does the predictability of soil patterns change through time and after cultivation?

We developed a soil-landscape evolution model that can simulate natural soil and landscape evolution by incorporating dominant natural processes such as soil creep, tree throw, vegetation dynamics and infiltration-dependent pedogenesis driven by the soil forming factors climate, organisms, relief, parent material and time. We simulated soil formation for 14500 years under three scenarios of rainfall (dry, humid, wet) to quantify the effect of water availability and distribution on soil variation in natural systems. Each run was concluded with 500 years of agricultural land use, where we introduced the process of tillage erosion.

We expect that before cultivation, spatial soil heterogeneity will be larger for greater rainfall, due to more intense erosion and translocation processes, and effects of vegetation. Moreover, 
we expect that the spatial heterogeneity increases by erosion processes under cultivation, also resulting in larger correlations between soil properties and topographic properties, because of the topographic dependence of erosion processes. This would imply that soil patterns become more predictable due to cultivation.

For our simulations, we created a hypothetical loess-covered, hilly landscape with a range of characteristic slope positions as spatial setting. We choose loess, because it is a relatively homogeneous parent material, widely spread globally and favored for agricultural practices due to its high water holding capacity and resulting fertility (Catt, 2001). The long-term use of loess areas for agriculture and unsustainable management has resulted in severe land degradation (e.g. Zhao et al., 2013). 


\subsection{Methods}

In this section, first we describe the model architecture and process formulations. Second, we describe the general spatial setting we developed for our modeling study. Last, we describe how we analyze the very extensive model output.

\subsubsection{Model}

Here we describe our model named HydroLorica. HydroLorica is based on the model Lorica (Temme and Vanwalleghem, 2016), but includes explicit simulation of water flow and water availability as drivers of natural soil, landscape and vegetation change (Van der Meij et al., 2018). HydroLorica is a reduced-complexity model, which means that it simulates the most important processes affecting soil and landscapes using simplified process descriptions. Reducing model complexity promotes critical evaluation of essential processes, reduces calculation time and prevents extensive data requirements and over-parameterization (Hunter et al., 2007; Temme et al., 2011a; Snowden et al., 2017; Kirkby, 2018; Marschmann et al., 2019).

\subsubsection{Model architecture}

HydroLorica is a raster-based model, where a Digital Elevation Model (DEM) determines the shape of the terrain. Below each raster cell of the DEM there is a predetermined number of soil layers with layer thicknesses variable in space and time. Each layer contains a specific mixture of gravel, sand, silt and clay and two types of organic matter. Pedogenic and geomorphic processes affect the contents of the layers, leading to differences in soils in space and time. Changes in soil properties modify layer thicknesses and surface elevation through pedotransfer functions of bulk density (Tranter et al., 2007). We refer to Temme and Vanwalleghem (2016) for more information about the spatial model architecture of Lorica, which we maintained in our adaptation HydroLorica. In this project, we worked with 25 soil layers, with an initial uniform thickness of $0.15 \mathrm{~m}$. When a layer got very thick or very thin ( $55 \%$ thicker or thinner than its initial value), the layer was split or combined with another layer.

The annual changes in texture classes tex $[\mathrm{kg}]$ and organic matter classes $o m[\mathrm{~kg}]$ in layer $l$ at location $x y$ and time $t$ are governed following Eqs. (5.1) and (5.2) (for abbreviations of processes, see Table 5.1). The changes in mass of texture and organic matter are converted 
to a change in layer thickness [m] using a pedotransfer function (PTF, Tranter et al., 2007). The sum of changes in layer thickness of all layers $L$ result in the annual change of elevation $z$ (Eq. (5.3)). Clay translocation and water erosion are directly driven by the total annual water flow, while occurrence of tree throw and rates of creep, bioturbation and organic matter uptake are indirectly driven by water availability via vegetation controls. Infiltration $I$ is the difference between precipitation $P$ and spatially explicit actual evapotranspiration $E T a$, runon ROnn and runoff ROff (Eq. (5.4)). HydroLorica works with dynamic time steps as suggested by Van der Meij et al. (2018) to capture process dynamics at their relevant scales, while optimizing calculation time. Hydrologic processes are calculated with a daily, monthly, or yearly time step, with smaller timesteps selected during wetter conditions for more accurate simulation. Annual sums of infiltration and overland flow are used to drive geomorphic, pedogenic and biotic processes.

$$
\begin{aligned}
& \Delta \operatorname{tex}_{l, x y, t}=\Delta \operatorname{tex}_{C R, l, x y, t}+\Delta \operatorname{tex}_{W E, l, x y, t}+\Delta \operatorname{tex}_{T T, l, x y, t}+\Delta t e x_{T I, l, x y, t}+ \\
& \Delta t e x_{C T, l, x y, t}+\Delta t e x_{B T, l, x y, t} \\
& \Delta o m_{l x y t}=\Delta o m_{C R, l, x y, t}+\Delta o m_{W E, l, x y, t}+\Delta o m_{T T, l, x y, t}+\Delta o m_{T I, l, x y, t}+ \\
& \Delta o m_{C U B, l, x y, t}+\Delta o m_{B T, l, x y, t} \\
& \Delta z_{x y, t}=\sum_{l=1}^{L} P T F_{B D}\left(\sum \Delta t e x_{l, x y, t}+\sum \Delta o m_{l, x y, t}\right) \\
& I_{x y t}=P_{t}-E T a_{x y, t}+R O n n_{x y, t}-R O f f_{x y, t}
\end{aligned}
$$




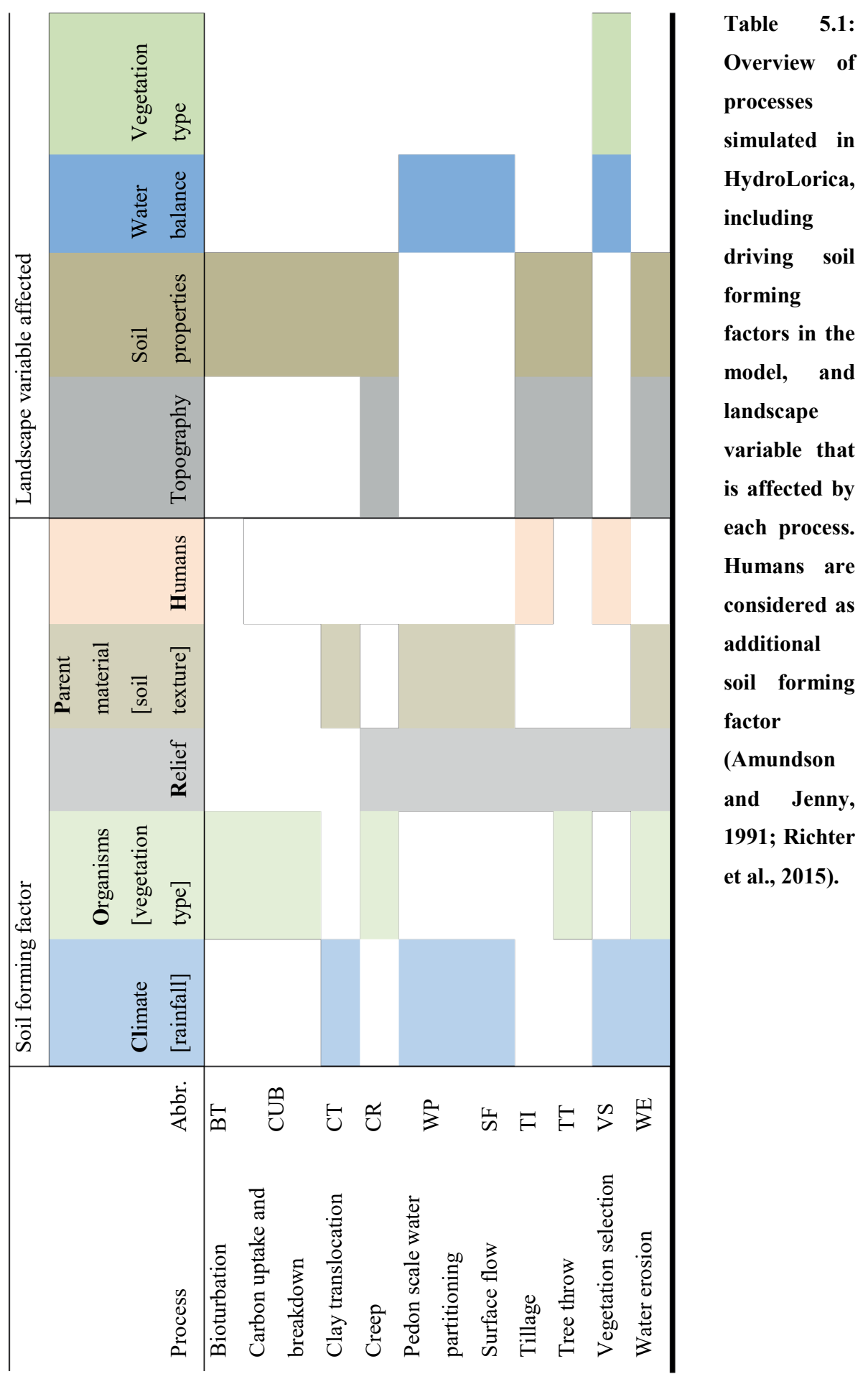




\subsubsection{Process formulation and parameters}

In our model we considered only the impact of physical and biological processes on soil properties. The current model architecture does not facilitate the simulation of soil chemical processes. The selected processes are described below. Drivers and impacts of each process are summarized in Table 5.1. We summarized the drivers per soil forming factor. We mostly used the processes and parameters of Lorica as reported in Temme and Vanwalleghem (2016), which we summarize here. When we added a new process, or changed its parameters, the adjustments are reported in this Section. We provided a detailed overview of the equations and selected parameters in the Supplement 5.1.

We aim to understand the functioning of general soil-landscape systems. Therefore, we parametrized and calibrated the model processes using regional data or process rates from literature that are valid for larger regions. We didn't calibrate the parameters on data from one specific study site to avoid the effect of any idiosyncrasies that can be present in that data. For other processes where there was no regional data available, we estimated the parameters so that the effects of those processes were in the same order of magnitude as processes with rates based on literature. An overview of the process parameters is provided in table S1.

\subsection{Hydrologic processes}

The hydrological module partitions rainfall $(\mathrm{P})$ into three spatially explicit components: evapotranspiration (ET), infiltration (I) and surface flow (Ronn \& ROff, Eq. (5.4)). Potential ET is calculated from prescribed temperature using the Hargreaves-Samani equation (Hargreaves and Samani, 1985), and corrected for topographical position (Swift Jr, 1976) and vegetation type (Allen et al., 1998). Surface flow is calculated on a daily basis, and only when rainfall intensity [amount / duration, $\mathrm{mm} \mathrm{hr}^{-1}$ ] exceeds the saturated hydraulic conductivity of the topsoil, which is a function of soil properties and slope (Wösten et al., 2001; Morbidelli et al., 2018). The excess water is routed over the surface using the multiple flow algorithm (Holmgren, 1994) and can re-infiltrate in places with higher hydraulic conductivity, in local surface depressions, or can leave the catchment. HydroLorica can thus deal with DEMs that contain depressions, and actively forms depression by simulating tree throw. The annual sum of daily surface flow is used to calculate annual water erosion and deposition using the stream power law. To account for seasonal differences, actual ET is 
calculated on a monthly basis from the potential ET and rainfall using the topsoil water budget model of Pistocchi et al. (2008). Infiltration is the sum of (re-)infiltrated surface water and the monthly difference between rainfall and actual ET (Eq. (5.4)). The annual water balance is used as a driver of various geomorphic and pedogenic processes, and to determine vegetation type. The hydrological module is described in detail in Supplement 4.1 of Chapter 4.

\subsection{Determination of vegetation type}

We considered two types of natural vegetation: grassland, forest. The vegetation type depends on the water availability; where rainfall plus re-infiltration exceeds potential evapotranspiration, there is no water stress and forests can grow. Otherwise, there is water stress and there will be grassland. This threshold is based on a hypothesis from Thompson et al. (2010), who used the Budyko curve (Budyko and Miller, 1974) to estimate vegetation type. By extending this relationship with re-infiltration, this relation can be used to assess local, but spatially explicit vegetation type. Vegetation type influences evapotranspiration (Allen et al., 1998), bioturbation and creep rate (Gabet et al., 2003), the occurrence of tree throw, and also controls organic matter input. Under agricultural use, the vegetation type changes to arable crops. We assume that soil and landscape processes are similar to landscapes under arable crops and grassland. and with grassland vegetation. The differences are that arable crops have lower potential evapotranspiration and the process of tillage is introduced.

Our method of estimating vegetation type can cause annual differences in vegetation types. However, as we are interested in long time periods, we present the results aggregated over multiple decades, where the simulated vegetation type is interpreted as the main occurring species. Interannual variation represents the uncertainty associated with this dominant type.

\subsubsection{3 (Bio-)geomorphic processes}

The main (bio-)geomorphic processes affecting topography in loess areas are soil creep, tree throw, water erosion and tillage erosion. Soil creep is a bio-geomorphic process that causes a diffuse movement of soil material on a hillslope, driven by various factors such as (micro)climate, organisms and terrain (Roering et al., 2002; Pawlik and Šamonil, 2018; Regmi et al., 2019). The potential creep rate is a function of vegetation type and slope (Gabet et al., 2003). We adopt higher creep rates in forested areas, because of the deeper rooting 
depth and higher root abundance. We divided the potential creep rate at a certain location over all soil layers, with exponentially decreasing rates deeper in the soil. The transport of soil material from a layer to layers in its lower lying neighboring cells is proportional to the surface slope and shared layer boundaries.

Tree throw is a bio-geomorphic process that has a distinct effect on the terrain and water routing; the created pit can act as hotspot for soil formation by the increased infiltration of water (Šamonil et al., 2018). We simulated tree throw as a random process, with on average 0.2 trees falling per hectare per year. This rate is lower than other rates found in natural forests around the world (0.3-1.5 trees $\mathrm{ha}^{-1} \mathrm{a}^{-1}$, Gallaway et al., 2009; Finke et al., 2013; Phillips et al., 2017), because some factors controlling tree uprooting like shallow rooting depth and steep slopes are not present in our spatial setting. The dimensions of the root clump that is transported by tree throw were scaled with the age of the falling tree, which was also randomly selected. We assumed that tree growth occurs in the first 150 years of a tree's existence, after which size remains stable until a maximum age of 300 years. These numbers and trends are loosely based on Rozas (2003).

Water erosion and deposition are calculated using the same approach as the original Lorica model (Temme and Vanwalleghem, 2016). Sediment uptake and deposition are calculated as function of discharge and surface gradients (Schoorl et al., 2002). Sediment uptake is selective, where smaller particles are easier to erode and more difficult to deposit. Organic matter behaves the same as clay under erosion, because we assumed that organic matter occurs in associations with clay particles. Water erosion is limited by the occurrence of coarse soil particles (surface armoring) and vegetation. The role of water erosion in forested loess catchments is limited (Vanwalleghem et al., 2010); the vegetation protects the soil below from erosion. However, disturbances such as forest fires can temporarily increase erodibility of the soil. Therefore, we did simulate water erosion in forested landscapes, but with lower rates than in grassland. We simulated this by including a high vegetation protection constant (value of 1) in forested sites. In grasslands we used the aridity index between 0 and 1 as vegetation protection constant.

Tillage erosion was simulated as a diffusive process, similar to creep, with some differences: tillage homogenized the soil over the reach of the plough depth, erosion only occurred from 
the top layer contrary to the whole soil profile as with creep, and the erosion rates were much higher due to the intensive land management.

\subsubsection{4 (Bio-)pedogenic processes}

We simulated three dominant (bio-)pedogenic processes that change texture and organic matter properties in loess landscapes. These are clay translocation, bioturbation and soil organic matter uptake and breakdown.

We adapted a new way of simulating clay translocation, using the advection equation of Jagercikova et al. (2017). The diffusive part of clay translocation as described by Jagercikova et al. (2017) is separately modeled by bioturbation. We scaled the parameters of clay translocation with local infiltration to develop an infiltration-dependent equation. Not all clay in the soil is available for translocation. Part of it is not available to the percolating water, because it is bonded to other minerals and organic matter. We used the equations of Brubaker et al. (1992) to estimate the part of the clay that is water-dispersible, i.e. that is available for translocation by water. We estimated the required CEC with a pedotransfer function from Ellis and Foth (1996). This approach is similar to the one used in soil profile model SoilGen2 (Finke, 2012).

Bioturbation works as a diffusive processes, homogenizing the soil vertically (Yoo et al., 2011). We used the same rates for bioturbation as for creep, because these processes are driven by the same organisms reworking the soil. The potential bioturbation rate was divided over each soil layer by integrating the exponential depth function over the layer thickness, and then dividing by the integration of the function over the entire soil profile. Every layer exchanges a certain fraction of its contents, based on initial bioturbation rate and depth, with all other layers. The amount of exchange between two layers decreases with increasing distance.

Soil organic matter (SOM) uptake and breakdown was simulated as in earlier soil-landscape evolution models (Yoo et al., 2006; Minasny et al., 2008; Vanwalleghem et al., 2013; Temme and Vanwalleghem, 2016). Uptake of SOM is controlled by the potential input and depth in the soil. The uptake is divided over a young and old SOM pool using a fractionation factor. These pools differ in their rate of decomposition. We calibrated the SOM cycle in agricultural settings with the average depth distribution of organic carbon in agricultural soils on the Chinese loess plateaus (Liu et al., 2011). We simulated 5000 years of soil development using 
different process parameters. We selected the parameter set that simulated an organic matter distribution most similar to the reference distributions from Liu et al. (2011). The reported depth distributions for pasture and forest soils by Liu et al. (2011) were not useful for this project. Soils under these vegetation types on the Chinese loess plateau generally contain lower SOM stocks than natural landscapes, because these positions often have recently been replanted to combat soil erosion or because they occur on topographic positions which are not favorable for plant growth and agriculture. Instead, we calculated reference carbon stocks for forest and grassland soils by adjusting the agricultural carbon stocks of Liu et al. (2011) with changes in carbon stocks after conversion from forest to crop and from forest to pasture (Guo and Gifford, 2002). With the resulting reference carbon stocks for natural vegetation we ran additional calibrations to calculate the potential SOM input for forest and grassland.

\subsubsection{Experimental setup}

We developed an artificial topographic setting in which we performed our simulations. The use of an artificial setting rather than a field setting avoids the effect of local disturbances and idiosyncrasies which can disturb general signals we look for in the model results.
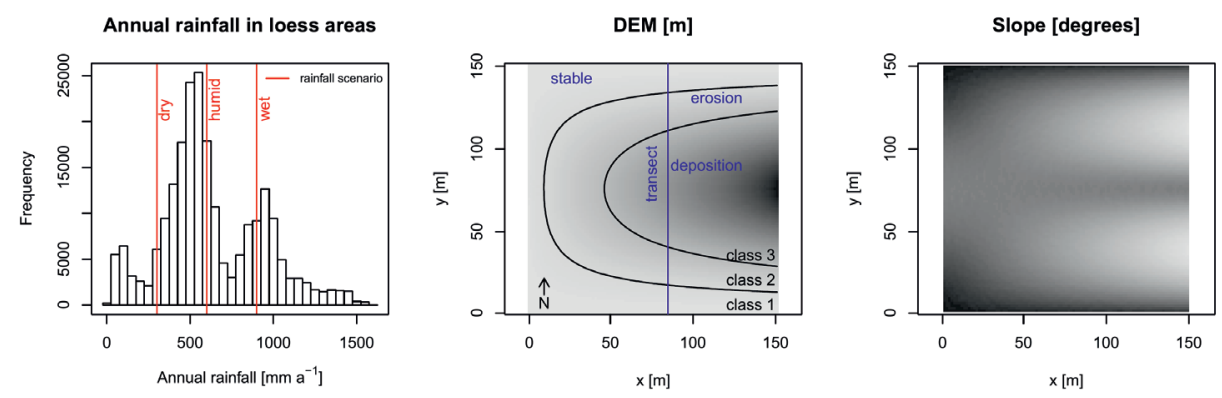

Figure 5.1: Left: Annual rainfall in loess areas, derived from WorldClim. Red lines indicate the rainfall scenarios in this study: 300 (dry), 600 (humid) \& 900 (wet) mm per year. Right: Maps of input DEM with corresponding slope map. Extent of the DEM is $150 * 150$ meter, with a cell size of 1.5 meter. The different classes indicate elevation classes used in the ANOVA (Table 5.3). The blue dots and line indicate the location of the soil profiles and transect displayed in Figure 5.2 and Figure 5.3.

The input DEM is an artificially created U-shaped valley of 150 by 150 meters, with a cell size of 1.5 meters (Figure 5.1). The slopes facing north- and southward have a sinusoid form, and valley depth increases eastward, from 0 to 9 meters. Random noise of max $1 \mathrm{~cm}$ was 
added. The maximum slope is $12^{\circ}(21 \%)$, which reaches the limit for agricultural use (Bibby and Mackney, 1969). The small cell size of 1.5 meters is required to simulate the effect of pit and mound topography created by tree throw on spatial infiltration patterns. The landscape was designed to display typical topographic features present in loess areas, but we exaggerated the spatial variation of slope positions to limit catchment size and reduce calculation time.

As parent material we chose a homogeneous loess without carbonates and a soil texture of $15 \%$ sand, $75 \%$ silt and $10 \%$ clay, which falls in the typical range of loess deposits (Pécsi, 1990; Muhs, 2007). The model requires a latitude to calculate solar inclination on the slopes. We selected the latitude of 50 degrees north, which is in the center of the range for loess occurrence reported by Muhs $\left(2007,40-60^{\circ} \mathrm{N}\right)$. We selected the rainfall scenarios based on most common rainfall in loess areas. For this, we made an overlay of a coarse resolution global loess map (Dürr et al., 2005) with a global annual rainfall map (Fick and Hijmans, 2017). The distribution of rainfall from the overlay showed peaks at $\sim 600$ and $\sim 900 \mathrm{~mm}$ (Figure 5.1). We selected these annual quantities of rainfall as input for our scenarios and we added a scenario of $300 \mathrm{~mm}$ to capture a wider range of climates. The model requires as input daily data on rainfall $[\mathrm{m}]$, rainfall duration $[\mathrm{h}]$, and minimum, mean and maximum temperature $\left[{ }^{\circ} \mathrm{C}\right]$. Rainfall amount is required to calculate how much water flows through the soil landscape. Rainfall intensity is required to determine whether and how much overland flow occurs, by comparing rainfall intensity with soil hydraulic conductivity. Rainfall intensity is calculated by dividing the rainfall amount by the daily duration $\left[\mathrm{m} \mathrm{hr}^{-1}\right]$. Temperature data is required to calculate potential evapotranspiration (Hargreaves and Samani, 1985). As we want to simulate general trends in soil and landscape evolution, we do not need site-specific data for the different scenarios. Instead, an arbitrary weather dataset was scaled to the total amount of rainfall from the different climate scenarios. We used weather data from the German weather station Grünow, which is located at $53.3^{\circ} \mathrm{N}, 13.9^{\circ} \mathrm{E}$ (DWD Climate Data Center (CDC), 2018a, b). The potential evapotranspiration is around $600 \mathrm{~mm} \mathrm{a}^{-1}$ for this dataset and is applied to all simulations. Combined with the rainfall scenarios, the scenarios can roughly be classified as dry (300 $\mathrm{mm}$ rainfall), humid (600 $\mathrm{mm}$ rainfall) and wet (900 $\mathrm{mm}$ rainfall). In the rest of this Chapter, we will use the terms dry, humid and wet to refer to the different rainfall scenarios. 
We simulated the development of soils and landscapes for 15000 years, resembling the age of most post-glacial soils. In the first 14500 years of the simulations, soil and landscape development occurred under natural conditions and land cover. In the last 500 years of the simulations, we introduced agricultural land use by changing vegetation type and introducing tillage erosion. This duration was selected because it loosely reflects the onset of Medieval intensive agriculture in many areas (Van der Meij et al., 2019) and should be seen as upper limit of onset of intensive tillage.

\subsubsection{Analysis and evaluation}

The model potentially outputs all soil properties for each layer at each location at each time step. Additionally, elevation change resulting from all processes at each location at each time step can be saved. In order to be able to interpret the results, we had to aggregate the results in several ways. We focused on select soil and terrain properties. The selected soil properties are soil organic matter stock $\left[\mathrm{kg} \mathrm{m}^{-2}\right]$, which is the total amount of SOM in a soil column, and the depth to the $\mathrm{Bt}$ horizon $[\mathrm{m}]$, which we defined as the depth where the clay content first exceeds the initial clay fraction of the soil. The selected terrain properties are slope [degrees], topographic position index (TPI [m]), calculated at two levels with square windows of $5 * 5$ and $15 * 15$ cells ( $7.5 * 7.5$ and $22.5 * 22.5 \mathrm{~m}$ respectively), and the topographic wetness index (TWI [-]). In most figures, we present two moments in time. These are the end of the natural phase $(t=14500)$ and the end of the agricultural phase $(t=15000)$. We present the results in the following ways:

- To show the development of soils and catenae, we show transects across the catchment (Figure 5.2), and plots of soil profile evolution, for three landscape positions and three rainfall scenarios (Figure 5.3);

- To compare natural and agricultural soil properties, we show catchment-averaged depth distributions of clay and SOM fractions (Figure 5.4).

- To show the impact of geomorphic processes on the terrain, we show cumulative elevation changes at the end of the natural and agricultural phase, and we show contributions to elevation change for each geomorphic process over time (Figure $5.5)$.

- To quantify the spatial heterogeneity of the selected soil and terrain properties, we calculated empirical semivariograms (Figure 5.6), using the gstat package in $\mathrm{R}$ 
(Pebesma, 2004). Empirical semivariograms give a measure of the variation between properties of soils as a function of distance between soils. We compared the semivariograms of depth to the Bt horizon with semivariograms made from field observations in a natural and agricultural site.

- To visualize soil-landscape relations, we show how the selected soil properties and terrain properties are correlated and how these correlations change through time (Figure 5.7).

- To disentangle the effect of various factors on soil properties, we performed an analysis of variance (Table 5.3). We selected the depth to Bt and the carbon stock at the end of the natural and agricultural phase as dependent variables. As independent variables we selected climate [three rainfall classes], land cover or use [natural or agricultural], and landforms [three elevation classes with equal elevation ranges, representing plateau, slope and valley (Figure 5.1)]. 


\subsection{Results}

Here we present the results from the HydroLorica model. Section 3.1 shows the patterns, distributions and changes of soil and terrain properties in space and time. Section 3.2 shows the results from the statistical analyses to quantify and summarize spatial and temporal soil and terrain patterns. The animations published with the paper show 1) maps of soil and terrain properties and their changes through time, and 2) maps of elevation change by each geomorphic process and their changes through time.

\subsubsection{Simulated soil and landscape evolution}

The results of HydroLorica show clear differences in the development of soil profiles at different landscape positions, for the different rainfall and land-cover/land-use scenarios (Figure 5.2, Figure 5.3). In the natural phase, higher rainfall leads to deeper eluviation of clay at each landscape position, showing more pronounced Bt horizons. Also, the soil profiles get more disturbed by tree throw with higher rainfall, as can be seen by the fluctuations in elevation and SOM stocks. The depth to the Bt horizon remains at the same position below the surface at the eroding position. At all locations, SOM stocks reach an equilibrium after $\sim 3000$ years, but most of the SOM is generated in the first 500 years.

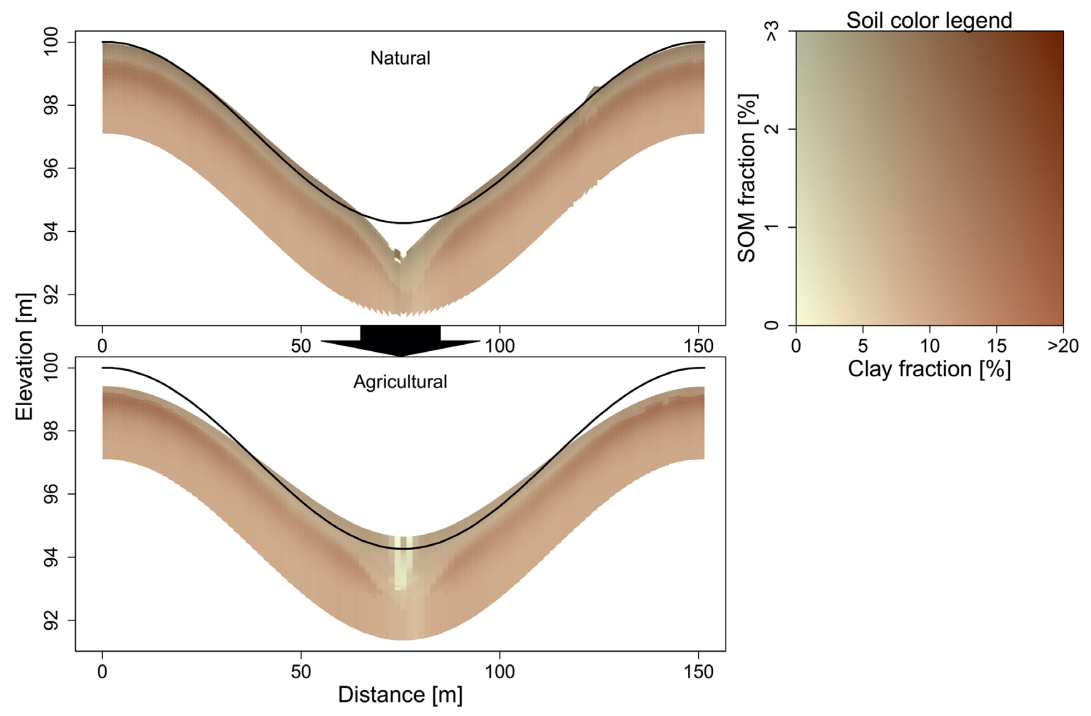

Figure 5.2: Transect through the catchment at the end of the natural phase and the end of the agricultural phase for the humid scenario $(P=600 \mathrm{~mm})$. The black line indicates initial topography. See Figure 5.1 for location of the transect. 

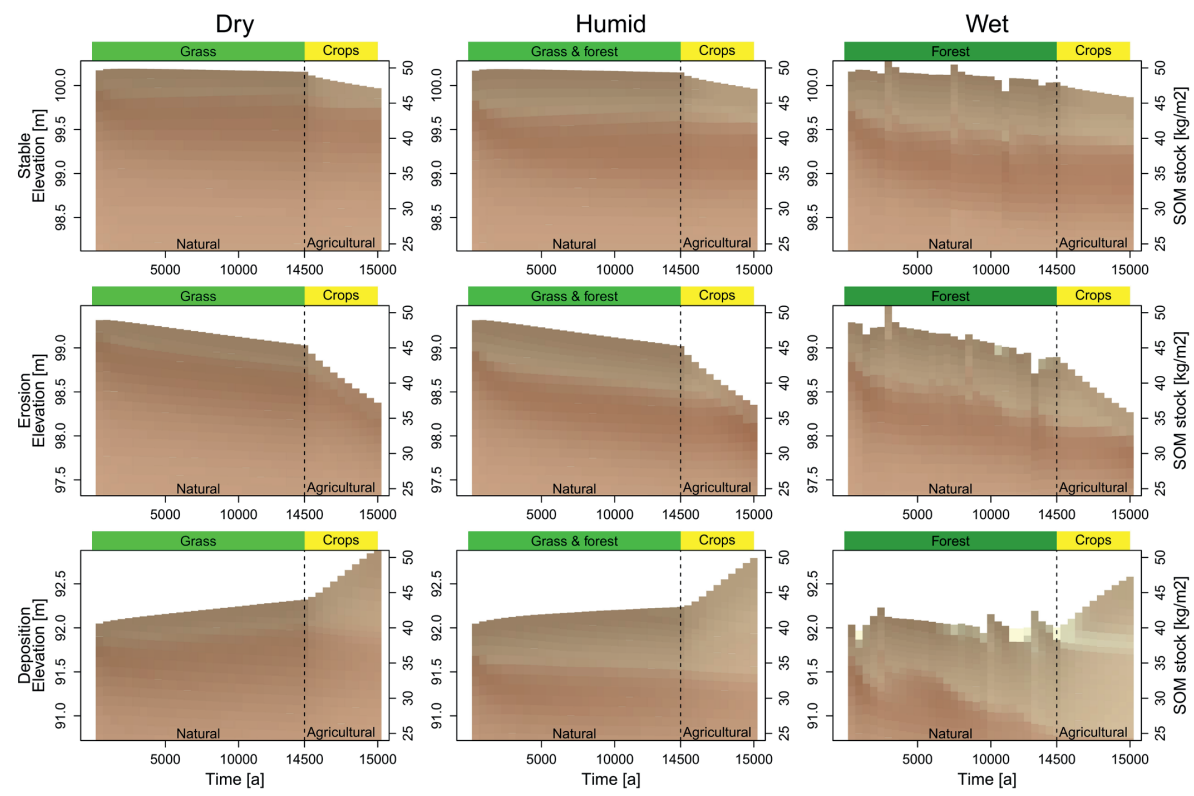

Figure 5.3: Evolution of soil profiles through time ( $x$-axis) on a stable, eroding and depositing position (rows), for the different rainfall scenarios (columns). The colored bars atop the plots indicate land cover (natural) and land use (agricultural). The points indicate the SOM stocks (right $\mathbf{y}$-axis). Note that the natural and agricultural system have different $\mathbf{x}$-axes scales to visualize both systems. In the agricultural system, an observation is shown each 500 years. In the agricultural phase each 50 years. See Figure 5.1 for locations of the soil profiles. See Figure 5.2 for the soil color legend.

In the agricultural phase, elevations change much faster, leading to truncation of the eroding soil profile (Figure 5.3). Also, SOM stocks decrease substantially in the soil profiles due to lower input. At the deposition site, there is a small increase in SOM stocks at the end of the agricultural phase, caused by the continuous input of soil material. The increased elevation change is well visible in Figure 5.2. After the natural phase, there is limited elevation change on the slopes, with some water erosion at the valley bottom forming a v-shaped gulley. After the agricultural phase, the hillslopes are heavily eroded, while the valley bottom is filled with colluvium. The high erodibility of clay that we simulated in the model affected the clay distributions in the model results. In the natural phase, topsoil clay gets laterally relocated from the hillslopes to tree throw pits and the valley bottom. This clay was partly replenished from the subsurface by bioturbation. This led to a net loss of clay from the entire depositional profile in the wet scenario, due to higher water flow and erosion potential (Figure 5.3). In the 
agricultural phase, clay does not get trapped in tree throw pits anymore, but leaves the catchment with the water. This reduced the clay contents even more at the valley bottom (Figure 5.2).

Figure 5.4 shows how clay and SOM fractions vary with depth throughout the entire catchment. The presented Probability Density Functions (PDFs) show multi-modal distributions of the soil properties, which cannot simply be captured using summary statistics. Both higher rainfall and agricultural land use increase the heterogeneity of clay profiles in the landscape, as can be seen by the wider ranges of the different PDFs throughout the entire depth profile. Also the occurrence of Bt horizons decreases with higher rainfall, due to losses of clay by lateral erosion rather than vertical transport as mentioned in the previous paragraph. With higher rainfall, the percentages of soils with a Bt horizon occurring in the natural settings are $98 \%, 93 \%$ and $62 \%$. For the SOM profiles, higher rainfall also leads to more heterogeneity. Especially in the topsoil a larger spread is simulated. Cultivation reduces the fraction and the topsoil variation, due to lower input and vertical and lateral topsoil homogenization (Figure $5.4 \&$ Table 5.2).

Table 5.2: Model and field organic carbon stocks $\left(\mathrm{kg} \mathrm{m}^{-2}\right)$ for different depth ranges, averaged over the catchment (average \pm standard deviation). The model results were converted from SOM to SOC by multiplying the SOM stocks with 0.58 (Wolff, 1864).

\begin{tabular}{|c|c|c|c|c|c|c|c|}
\hline & \multicolumn{3}{|c|}{ Natural phase (t 14500) } & \multicolumn{4}{|c|}{ Agricultural phase (t 15000) } \\
\hline Scenario & $\begin{array}{l}\text { Dry } \\
\text { (grassland) }\end{array}$ & $\begin{array}{l}\text { Humid } \\
\text { (mixed) }\end{array}$ & $\begin{array}{l}\text { Wet } \\
\text { (forest) }\end{array}$ & Dry & Humid & Wet & $\begin{array}{ll}\text { (Liu et } & \text { al., } \\
2011) & \end{array}$ \\
\hline $0-0.2$ & $4.7 \pm 0.3$ & $4.6 \pm 0.9$ & $4.1 \pm 2.1$ & $2.9 \pm 0.1$ & $2.9 \pm 0.3$ & $2.8 \pm 0.4$ & $3.0 \pm 1.9$ \\
\hline $0-0.4$ & $8.7 \pm 0.4$ & $8.5 \pm 1.1$ & $7.8 \pm 2.8$ & $5.5 \pm 0.2$ & $5.4 \pm 0.5$ & $5.3 \pm 0.6$ & $5.4 \pm 3.2$ \\
\hline $0-1$ & $17.1 \pm 0.4$ & $16.8 \pm 1.2$ & $15.7 \pm 3.5$ & $10.9 \pm 0.6$ & $10.8 \pm 0.8$ & $10.6 \pm 0.8$ & $8.8 \pm 4.4$ \\
\hline $0-2$ & $24.1 \pm 0.4$ & $23.7 \pm 1.3$ & $22.3 \pm 3.8$ & $15.7 \pm 1.2$ & $15.6 \pm 1.2$ & $15.4 \pm 1.1$ & $14.5 \pm 5.2$ \\
\hline $\begin{array}{l}\text { Complete } \\
\text { profile }\end{array}$ & $27.7 \pm 1.3$ & $27.1 \pm 1.7$ & $25.3 \pm 8.5$ & $18.6 \pm 16.1$ & $18.4 \pm 9.1$ & $17.8 \pm 10.1$ & - \\
\hline
\end{tabular}



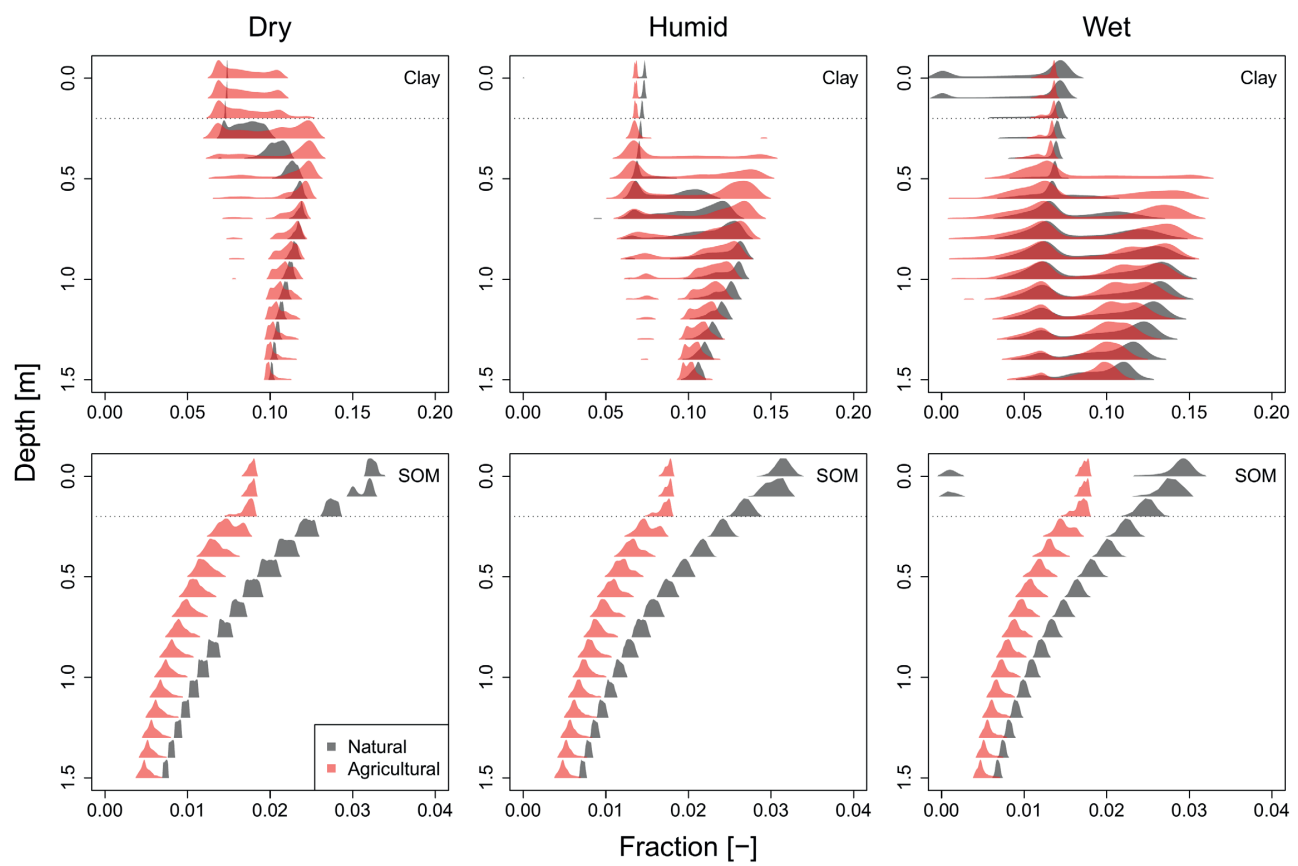

Figure 5.4: Probability Density Functions (PDFs) showing the multi-modal distributions of soil properties throughout the catchment per $10 \mathrm{~cm}$ depth increment. We only show probabilities larger than $5 \%$ for clarity. The presented soil properties are clay fraction (top) and SOM fraction (bottom), for the different rainfall scenarios (columns). Grey colors represent the natural soils, while red colors represent agricultural soils. The horizontal dotted line indicates the ploughing depth used for simulations $(20 \mathrm{~cm})$.

All scenarios show a net elevation loss in the natural phase (Figure 5.5a). Creep transported hillslope material to the valley bottom, which water erosion partly removed from the catchment. The terrain becomes rougher with higher rainfall, due to increased water erosion and a higher occurrence of tree throw. Indirectly, the rougher terrain leads to increased creep rates, because of the locally increased relief gradients. Tillage erosion has had by far the largest impact on the terrain (Figure 5.5), overprinting the effects of natural geomorphic processes. 


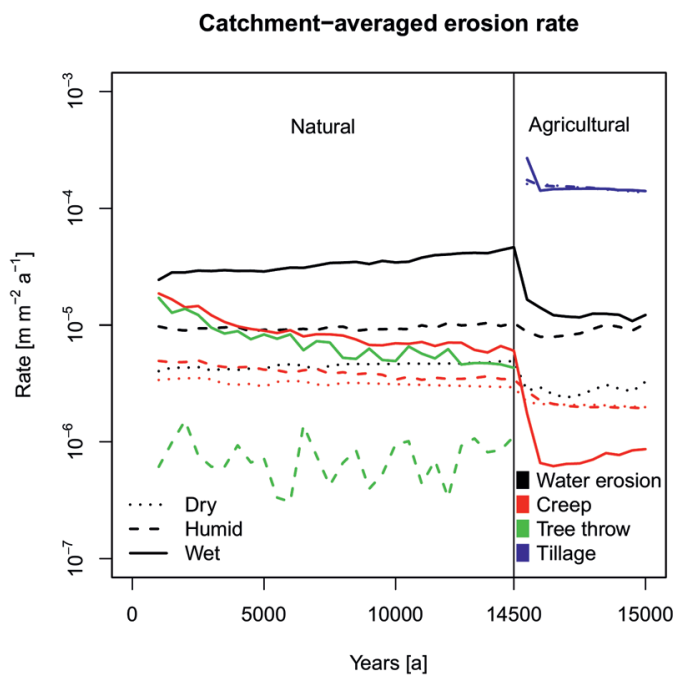

Cumulative elevation change [m]

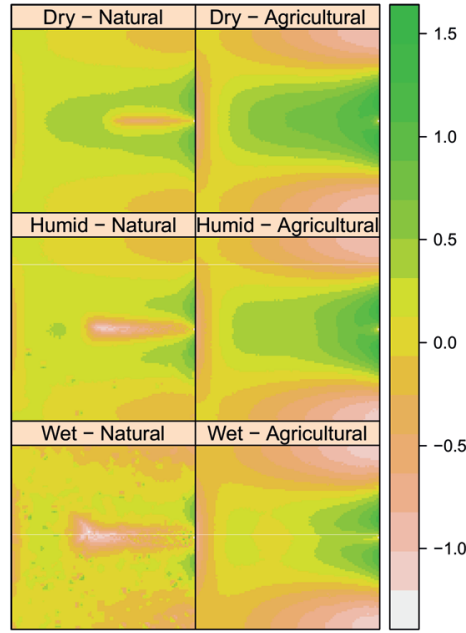

Figure 5.5: Left: average erosion rates throughout the catchment for the different geomorphic processes over time. The colors represent different geomorphic processes, and the line types represent different rainfall scenarios. Note that the $y$-axis is log scaled. Right: cumulative elevation change at the end of the natural and agricultural phase compared to the initial DEM for the different rainfall scenarios.

\subsubsection{Statistical analysis of soil and terrain properties}

Semivariograms summarize the spatial variation of soil and terrain properties as a function of distance between locations (Figure 5.6). Semivariance is a measure of the variation between properties of soils as a function of distance between soils. An increasing semivariance with distance indicates stronger spatial autocorrelation. In the natural phase, higher rainfall substantially increases the semivariance of soil and terrain properties regardless of distance; soils and terrain are thus more variable in space for higher rainfall. Especially the SOM stock shows high semivariance over all distances in the wet scenario, due to a larger spatial redistribution by water. 

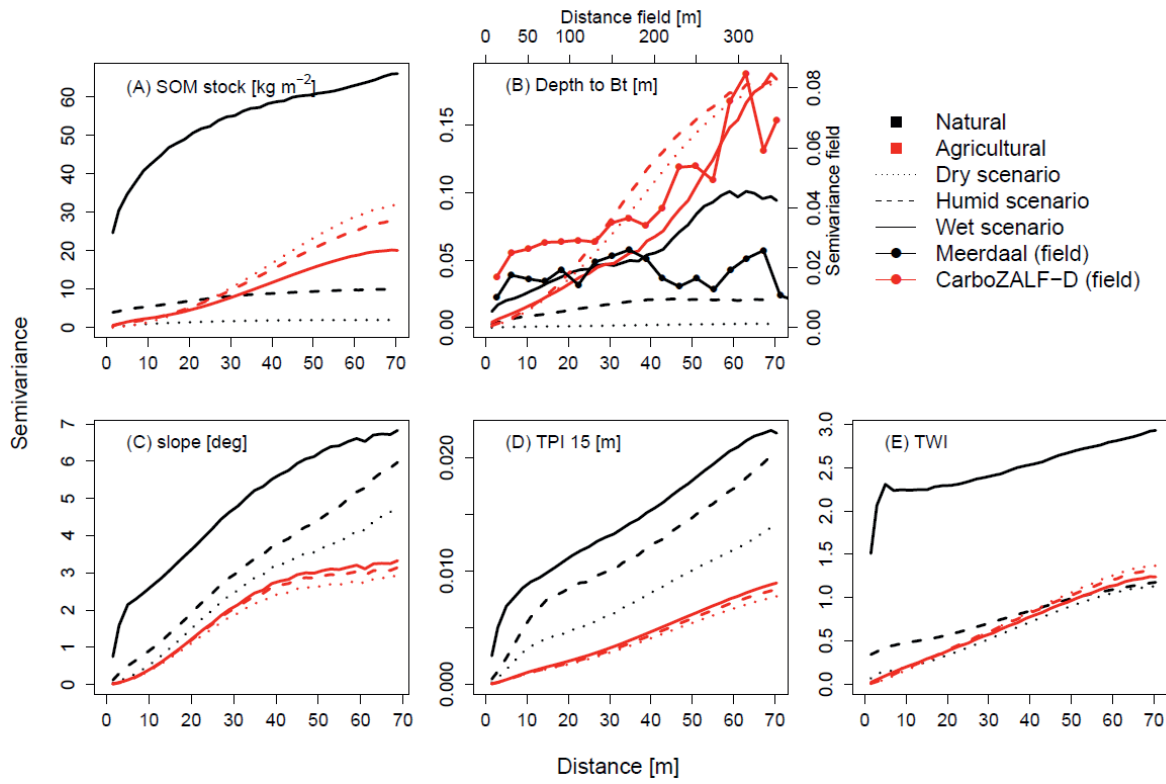

Figure 5.6: Experimental semivariograms showing semivariance (spatial autocorrelation) for different soil (A,B) and terrain properties (C-E) with different precipitation scenarios (line types) at the end of the natural (black) and agricultural (red) phases. The panel with depth to Bt includes experimental semivariograms for a natural area (Meerdaal forest, $P=800 \mathrm{~mm}$, Vanwalleghem et al., 2010) and an agricultural area (CarboZALF-D, $P=500 \mathrm{~mm}$, Van der Meij et al., 2017). Note that these field data are presented with separate axes to compare shapes of the semivariograms.

In the agricultural phase, the differences between the rainfall scenarios are much less pronounced; the variations in the properties are similar for each rainfall scenario. The local variation, expressed by the nugget (intercept of the semivariogram with the y-axis) decreases in the agricultural phase because of short-range homogenization by ploughing. For the soil properties (Figure 5.6A\&B), the variation over larger distances generally increases above the natural levels, while the topographic properties show semivariance similar to or lower than the natural settings. The differences in semivariance of the depth to Bt horizons in natural and agricultural settings appear also in semivariograms calculated from field data (Figure 5.6A). The data from Meerdaal (a natural forest in the loess belt in Belgium) shows a semivariance that fluctuates around a constant value, while the data from agricultural field CarboZALF-D (agricultural field located on glacial till in NE Germany) shows increasing semivariance with distance. The shapes of the field semivariograms match those of the model 
results, but the distances of the field data are five times larger than those of the model results, while semivariance is about half. Distance and semivariance are a function of soil and landscape heterogeneity. Natural landscapes are not as condensed as our DEM, leading to larger distances of spatial autocorrelation. The differences in semivariance are caused by lower values of depth to $\mathrm{Bt}$ and smaller differences therein. Values of semivariograms are thus very case study-specific, but the shape of the semivariogram can tell something about the distribution of the property in the landscape. In summary, the transition from a natural to an agricultural setting reduces terrain heterogeneity, but increases soil heterogeneity.

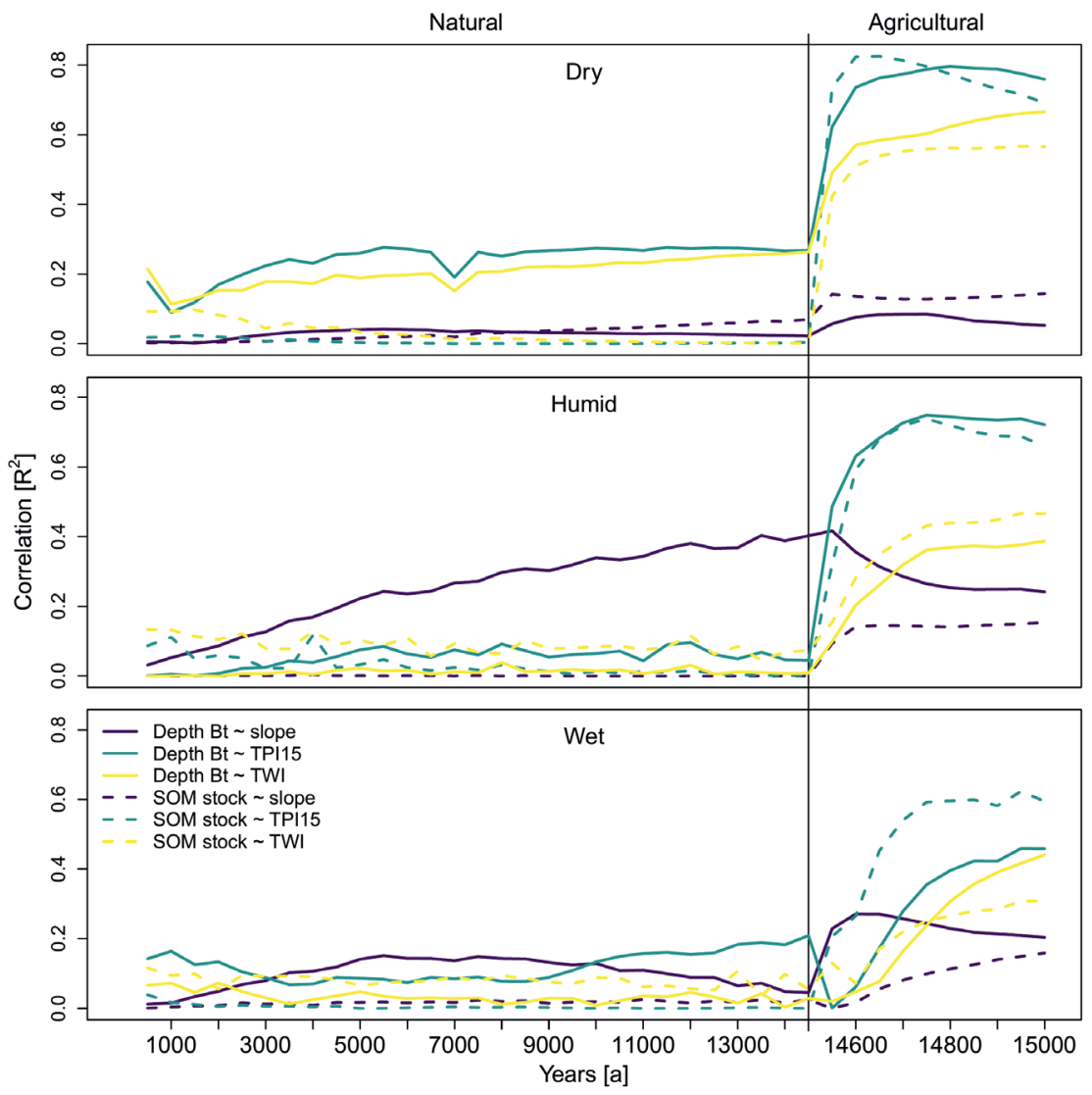

Figure 5.7: Correlations $\left(\mathrm{R}^{2}\right)$ between selected soil properties (line types) and topographic properties (colors) through time (left to right), for the different rainfall scenarios (top to bottom). In the natural system, the correlations are presented every 500 years, while in the agricultural system, the correlations are presented every 50 years. Note that for the latter phase the $x$-axis is stretched. 
The correlations between soil and terrain properties also differ between rainfall and land-use options (Figure 5.7). In the natural phase, soil-landscape correlations are generally limited to $25 \%$, with exception of the correlation between depth to Bt and slope in the humid scenario. In the agricultural phase, the correlations initially increase for each combination of soil and terrain property, up to $80 \%$. The correlations generally approach constant values in the agricultural phase. An exception to these patterns are the same correlations between slope and depth to the $\mathrm{Bt}$ horizon in the humid scenario. Those correlations increase to $40 \%$, and decline again in the agricultural phase. These large correlations in the natural phase appear from relatively little disturbance by tree throw and sufficient water to redistribute in the landscape. The small wiggles in the correlation lines are caused by minor uncertainties in our algorithm to derive soil properties from the model results.

Table 5.3: Results from the analysis of variance, indicating the proportion of variance in soil properties explained by the different soil forming factors. The data is both considered in total, and grouped per land use (natural or agricultural). The bold numbers indicate the largest part of the variance, either explained by one of the factors, or unexplained. All responses are significant $(\mathbf{p}<\mathbf{0 . 0 5})$.

\begin{tabular}{l|lll|lll}
\hline & \multicolumn{3}{|c|}{ Depth Bt } & \multicolumn{3}{c}{ SOM stock } \\
& Total & Natural & Agricultural & Total & Natural & Agricultural \\
\hline Rainfall & 0.18 & $\mathbf{0 . 4 9}$ & 0.08 & 0.02 & 0.14 & 0.02 \\
Landform & 0.23 & 0.04 & $\mathbf{0 . 5 1}$ & 0.04 & 0.01 & $\mathbf{0 . 5 6}$ \\
Land use & 0.01 & - & - & $\mathbf{0 . 7 2}$ & - & - \\
Unexplained & $\mathbf{0 . 5 8}$ & 0.47 & 0.41 & 0.22 & $\mathbf{0 . 8 5}$ & 0.42 \\
\hline
\end{tabular}

Table 5.3 shows the results from the analysis of variance, which shows how much of the variance in soil properties at the end of the natural and agricultural phases can be explained by different factors (Table 5.3). The variance in depth to the Bt horizon can be partly explained by rainfall (18\%) and landscape position (23\%), when considering all data together. However, the largest part of the variance remains unexplained. For the SOM stocks, most of the variance can be explained by the land use $(72 \%)$. When grouped per land cover/use, about half of the variance of depth to Bt can be explained by either rainfall (natural phase) or landform (agricultural phase). For the SOM stocks the dominant factors are the same, but the variance in the natural soil-landscape can only be partly explained by rainfall $(14 \%)$ and a large part remains unexplained. 


\subsection{Discussion}

\subsubsection{Soil patterns and properties}

\subsubsection{Soil patterns}

Soils have been affected by humans for over thousands of years, either directly by agricultural use, or indirectly by adjusting factors that form the soil, such as vegetation or climate (Dotterweich, 2008; Amundson et al., 2015; Bajard et al., 2017; Stephens et al., 2019). Therefore it is difficult, if not impossible, to find locations where truly natural soils can be observed and compared to agricultural soils in similar settings. Model simulations enable this comparison, as we show in this study. Unfortunately, there is limited field data to calibrate and verify the model. To our knowledge, the dataset from Vanwalleghem et al. (2010) is the only dataset that enables quantification of the spatial distribution of natural soils and link it to terrain properties at a local to regional scale, similar to the setting we simulated. In this Section, we rely mainly on this dataset to discuss and verify the patterns of natural soils we simulated with our model.

Our simulations show a large diversity of natural soil patterns, influenced by the amount of rainfall and associated vegetation type. The available water does not only lead to a regionally higher rate of soil development, for example in the form of deeper clay eluviation (Figure 5.3), but also to a greater lateral redistribution of soil material by water erosion and tree throw (Figure 5.5) and spatially varying infiltration rates. With more rainfall, the higher rates and interactions between these processes lead to a spatially more heterogeneous soil pattern, as expressed in higher semivariance (Figure 5.6). This local variation in pedogenesis due to different water input has been recognized and partly accounted for in other modeling studies (Saco et al., 2006; Finke et al., 2013; Shepard et al., 2017), but had not emerged from soillandscape evolution studies. Also the terrain, summarized by slope, TPI and TWI, becomes more heterogeneous with higher rainfall. Water flow thus affects soil and terrain patterns in a similar way. The data from Meerdaal forest largely match model results. The semivariogram of depth to $\mathrm{Bt}$ from Meerdaal $(\mathrm{P}=800 \mathrm{~mm})$ is most similar to the semivariograms from the humid and wet scenarios, while the terrain correlations from Meerdaal resemble most correlations simulated in the natural phase. The correlations in the model results are a bit larger than the ones from the Meerdaal dataset. This can be due to small variations and disturbances, for instance in parent material or human intervention, that 
we did not simulate. Nonetheless, the general soil patterns from model and field results agree, which indicates that our model HydroLorica simulated the essential processes that form natural soil patterns.

Agricultural soils display entirely different patterns, characterized by heterogeneity over larger distances. There is less small-distance, random variation due to the absence of tree throw and local homogenization by tillage, while variation in soil properties over larger distances has increased due to the slope-dependent intensity of tillage erosion (Phillips et al., 1999). This erosion leads to truncation of soils at convex positions, while concave positions have a net accumulation of material (De Alba et al., 2004). This truncation is well visible in many agricultural landscapes, because subsurface horizons with different colors get exposed at the surface on heavily eroded locations (e.g. Smetanová, 2009; Van der Meij et al., 2017). In contrast, terrain properties seem to get more homogeneous in agricultural landscapes. The smoothing effect of tillage on the terrain removed local pits and rills created in the natural phase. We hypothesized earlier that a smoother terrain would have higher hillslope connectivity, leading to increased water erosion (Van der Meij et al., 2017). However, we observed the contrary in our model results (Figure 5.5). The export of sediments from the catchment might be higher, but the uptake and local redistribution of sediments on the hillsope is lower, because local steep gradients are removed. Tillage is thus the dominant process forming agricultural soil patterns. The effect of anthropogenic soil erosion on soil heterogeneity far exceeds effects of changes in for example rainfall, which shows the huge impact we have as humans on soil-landscape development.

\subsubsection{Process calibration and verification}

The rates of the simulated processes were difficult to calibrate and verify. This is mainly due to a lack of field data that covers a range of climatic, topographic, chronologic and geographic settings (Van der Meij et al., 2018). Such data are essential for formulating pedogenic functions that are applicable in a wide range of settings instead of only in case studies, or for verifying model results. The chronosequence collection of Shepard et al. (2017) is a global dataset of soils in various settings covering different time steps. This dataset could be a good starting point for developing such functions owing to its large coverage. But as chronosequences are generally situated in relatively flat, stable landscapes, they often do not contain information about variations of soil properties at small distances, as function of local 
terrain (Harden, 1988; Sauer, 2015) - with the exception of some pro-glacial soil chronosequences whose use is limited because of their extreme climate and parent material (Egli et al., 2006; Temme and Lange, 2014). Such more complete information is essential for understanding the formation of soil patterns, as illustrated in the previous Section. Therefore, we suggest to include topographic variation in future chronosequence studies (Temme, 2019).

One soil property for which there is plenty of data on the spatiotemporal variation is soil organic matter or carbon, due to the current interest in its potential to store atmospheric carbon (Minasny et al., 2017). We used a regional dataset from the loess plateau to calibrate our SOM cycle in agricultural landscapes and we used carbon sequestration rates for adjusting the SOM balances for forest and grassland areas. The modeled SOM stocks for agricultural sites match the field data fairly well (Table 5.2), but stocks for natural areas are estimated higher than often observed. For example, in Bavaria, Germany, carbon stocks in the first meter are 9.8-11.8 $\mathrm{kg} \mathrm{m}^{-2}$ (Wiesmeier et al., 2012), where we simulated $15.7-17.1 \mathrm{~kg}$ $\mathrm{m}^{-2}$ in our natural settings. Also the depth distributions are different. De Vos et al. (2015) found that $50 \%$ of the carbon stock occurs in the top $20 \mathrm{~cm}$ in European forests on various parent materials. In our results this is around 20\%. This implies that agriculturally-derived SOM depth functions are not suitable to calibrate natural SOM depth functions, probably because input, vertical redistribution and decay of SOM behave differently in natural and agricultural sites. To calibrate these parameters, data from agricultural and natural sites in close vicinity are needed, to avoid effects of geographic and climatic differences.

\subsubsection{Drivers of soil formation}

\subsubsection{Soil forming factors}

Different soil forming factors dominate the variance in soil properties in natural and agricultural systems (Table 5.3). In natural systems, rainfall is dominant, while in agricultural systems, landform is dominant. This shift from external factors to internal factors marks the importance of geomophic processes on agricultural soil patterns. Although relief controls rates and directions of geomorphic processes, the type of process is human-controlled. Humans have a massive impact on soil development (Amundson and Jenny, 1991; Dudal, 2005). Direct effects include agricultural use, excavations, introduction of organisms and creation of new parent materials (Richter et al., 2015), while indirectly anthropogenic 
changes in climate can have severe effects on soil properties (Nearing et al., 2004; Schuur et al., 2015). We have focussed on only the main of these anthropogenic changes in loess landscapes: removal of forest and introduction of tillage. Humans as soil forming factor form new catenae (anthroposequences) and soil patterns, where the ultimate pattern only depends little on the initial variation (Figure 5.6). In our model results, we observe four of the six anthropogenic changes to soils, as described by Dudal (2005): human-made soil horizons, deep soil disturbance, topsoil changes and changes in landforms. These changes substantially affect soil functions, such as biodiversity and food security. Our simulations thus support that humans are the dominant factor for forming soils in agricultural landscapes.

\subsubsection{Soil-landscape (co-)evolution}

The development of soils and landscapes is not merely a collection of individual processes, but also of interactions between different processes. When processes interact, and when changes to soils and landscapes are in the same order of magnitude, soil-landscape coevolution can occur. This co-evolution can amplify or diminish certain processes, or can completely change the direction of soil and landscape evolution (Van der Meij et al., 2018). Often, co-evolution is used to describe soil and landscape processes with similar rates, but that do not necessarily interact (e.g. Willgoose, 2018). This would imply that these processes would co-occur rather than co-evolve. In this Section we evaluate some co-occurring processes in HydroLorica to see whether co-evolution occurred. There are different cooccurring processes in the natural phase of slow landscape change compared to the agricultural phase of intense landscape change.

\subsection{Lateral and vertical transport}

We will first consider vertical and lateral soil transport processes. Soils and hillslopes can be considered as a series of transport ways or conveyor belts (Román-Sánchez et al., 2019a). Vertical transport or mixing occurs by bioturbation including tree throw and clay translocation, whereas lateral transport occurs by creep, tree throw, water erosion and tillage erosion. Interactions between processes can occur where transport ways affect the same material. Two examples we will discuss here are the vertical and lateral transport of clay and the interaction between creep and water erosion in the valley bottom.

The vertical translocation of clay is simulated in our model by an advection-diffusion equation, where the advective part is the downward transport by water flow and the diffusive 
part a homogenization by bioturbation (Jagercikova et al., 2017). When the rates of advection and diffusion are equal, the upward transport of clay by bioturbation equals the amount of downward translocation by water; the clay-depth profile of the soil occurs in steady state and will not change substantially. Steady-state circumstances are however rare in natural soil systems (Phillips, 2010). Our simulations do not show steady-state circumstances, because in our simulations there is always lateral transport of soil material that continuously changes slope and terrain properties and affects the soil's clay balance, complicating the achievement of a steady state. Especially periodic water erosion can remove substantial amounts of clay that have been transported to the surface by bioturbation. This is well visible in the results of the wet scenario $(\mathrm{P}=900 \mathrm{~mm})$, where only $62 \%$ of the soils developed a Bt horizon. The other $38 \%$ had insufficient clay left to be classified as Bt according to our criteria. These results are quite extreme for such a small catchment as ours, probably due to too high simulated rates of water erosion, but they do show how pedogenic and geomorphic processes can interact in sloping terrain. In the natural phase the rates of clay translocation are similar to those of geomorphic processes. The recovery of the clay-depth profiles after disturbance of e.g. tree throw takes similar times $(\sim 1000$ s of years $)$ as the re-occurrence of a sequential tree throw event in the vicinity (Figure 5.3). Tree throw also temporarily changes rates of clay translocation by concentrating infiltration in the created pits. In the agricultural phase the rates of geomorphic processes far exceed the rates of clay translocation. This causes truncation of the soils, exposing the Bt horizons at the surface, and burying these horizons elsewhere in the landscape. The clay profiles at eroded sites do not have time to respond to the geomorphic disturbances. However, clay illuviation can start as a new pedogenic process in older depositional areas (supplementary information of Leopold and Völkel, 2007; Zádorová and Pení žek, 2018; Van der Meij et al., 2019).

Another interaction that emerged from the simulations occurred at the valley bottom. Soil creep transported hillslope material downslope, whence the concentrated water flow in the valley removed it from the catchment, creating a v-shaped valley bottom (Figure 5.2). This constant removal of material maintained the gradients that were used by soil creep to deliver new material. This interaction can be observed in various small hillslope catchments, which display typical v-shaped gulleys in the valley bottoms (e.g. Swanson and Swanston, 1977; West et al., 2013). Although this is not an interaction between pedogenic and geomorphic processes, it determines to a large extent how soil material gets redistributed along a hillslope 
and eventually gets exported from the catchment. In the agricultural phase, diffusive transport in the form of tillage erosion dominates over advective transport by water. As a consequence, the typical V-shapes fill up and are replaced by U-shaped valleys. These valley fillings consist of coarse material from which most clay was eroded (Figure 5.2). In agricultural areas, such infillings can temporarily remove erosion gulleys, but due to local water availability, they remain weak spots for future water erosion (Poesen, 2011).

\subsection{Soil organic matter dynamics}

Rates of SOM uptake and decomposition far exceed rates of clay translocation. SOM stocks recover quickly after a disturbance by tree throw and can keep up with intense landscape change by tillage (Figure 5.3). Freshly exposed, reactive soil material at eroding sites quickly accumulates new SOM, whereas SOM gets buried at depositional positions. Meanwhile, SOM decomposition increases during transport (Doetterl et al., 2012). In our simulations, the SOM stocks decrease substantially in the agricultural phase, mainly due to lower SOM input (Figure 5.3). Carbon stocks show relatively homogeneous distributions throughout the catchment (Figure 5.4), despite large spatial differences in erosion and deposition. This indicates that landscape change in both natural and agricultural systems did not induce substantial heterogeneity in SOM stocks. The small differences in SOM stocks in agricultural settings depend on landform (Table 5.3). These differences mainly emerge from differences in soil thickness at erosion and deposition positions. Deposition positions show a slight increase in SOM stocks after cultivation, while erosion positions show continually decreasing SOM stocks (Figure 5.3). The differences in SOM stocks in the model results are thus related to burial of colluvium in the valley bottom. SOM cycling is heavily influenced by erosion processes, but vice versa this is not the case. In tillage-dominated systems, erosion rates do not depend on SOM content or SOM dynamics in the soil. The co-occurrence of SOM cycling and tillage erosion in agricultural settings thus does not lead to co-evolution.

The interactions between erosion and the SOM cycle are currently under debate, especially whether agricultural redistribution provides a carbon source or sink (Harden et al., 1999; Van Oost et al., 2007; Chappell et al., 2015; Doetterl et al., 2016; Wang et al., 2017; Lugato et al., 2018; Lal, 2019), which shows the importance of considering landscape processes in pedogenic studies and vice versa. Moreover, intensive agriculture has been practiced for over 1000s of years in parts of the world (Stephens et al., 2019), emphasizing the need to consider centennial to millennial time periods in studies on anthropogenic forcing on soil systems. 


\subsection{Did co-evolution occur?}

The co-occurrence of processes does not necessarily implicate co-evolution. The analysis in this Section showed that soil and landscape processes co-occurred in both natural and agricultural settings, but that interactions between processes only occurred in natural settings. Rates of soil and landscape change are controlled by drivers such as water availability and vegetation type, and these drivers are influenced by soil, landscape and climate properties. Anthropogenic processes such as tillage erosion occur at such high rates that most natural processes cannot keep up, and rates of tillage erosion are not influenced by soil properties.

The soil and landscape interactions in natural settings emphasize the need of studying natural soil formation in a landscape context rather than a pedon context. Only when landscape are stable, flat and free of trees, changes in soil properties are not influenced by changes in terrain. In such settings, a 1D soil profile evolution model would suffice to simulate soil development in different landscape positions (Finke, 2012; Minasny et al., 2015). When rates of geomorphic processes far exceed those of pedogenic processes, for example in tillagedominated systems, a landscape evolution model would suffice (e.g. Temme et al., 2017), because changes in soil properties are limited to absent in the timespan of landscape change. In undulating landscapes where various hillslope processes occur, soils should be considered $3 \mathrm{D}$ bodies and soil-landscape evolution models are essential to simulate spatial drivers of soil and landscape evolution (Willgoose, 2018).

\subsubsection{Predictability of soil patterns}

In digital soil mapping, empirical relations between soil properties and their environment are used to predict soil properties through space (McBratney et al., 2003). In order to predict soil properties with environmental variables, the environmental variables should show variation over the same spatial scale as the variable to be predicted. On a hillslope scale, this variation often occurs in terrain properties (Gessler et al., 2000), while external factors such as climate often do not vary spatially at these scales. The shift from dominant external to dominant internal soil forming factors in explaining variance in observed soil properties (Table 5.3) thus has large implications for our ability to predict and map soil patterns. Human activity has created soil-landscapes that are well-suited for digital soil mapping. The correlations between soil and several terrain properties all give the same signal (Figure 5.7): the correlations in the natural phase are limited, but increase rapidly in the agricultural phase. 
The switch from a natural to agricultural phase thus increases soil heterogeneity, but also soil predictability. One should thus be careful extrapolating soil-terrain relationships from agricultural areas to natural areas, as these correlations depend on land management and can give wrong results.

Digital soil mapping performs well when predicting the spatial distribution of agricultural soils, but their applicability in time is limited because of limited temporal data (Grunwald, 2009; Gasch et al., 2015). The limited observations in space and time can be supplemented or extrapolated by incorporating biogeochemical process descriptions to improve DSM (Christakos, 2000, pp. 22; Heuvelink and Webster, 2001; Angelini et al., 2016). However, the response of soils and terrains to changes in soil forming factors takes longer (decades to millennia) than the timespan over which we have observations (days to decades). Processbased models thus become increasingly essential for understanding how soils might change under projected scenarios of land use and climate change (Opolot et al., 2015; Keyvanshokouhi et al., 2016), and HydroLorica shows a promising first example of such a model on a landscape scale that responds to changes in all five soil-forming factors, and by extension the human control on these factors. 


\subsection{Conclusions}

Soils undergo substantial changes in the transition from a natural land cover to agricultural land use. Although these changes can be described conceptually, quantitative data to describe the changes in soil pattern are scarce. We developed a soil-landscape evolution model, named HydroLorica, which is able to simulate the evolution of soils and landscapes in both natural and agricultural settings, by simulating spatially varying infiltration as driver of soil formation and by inclusion of essential natural and agricultural processes such as soil creep, tree throw and tillage. We used this model to simulate soil and landscape development in varying climatic settings, under changing land use, to quantify changes in variation and predictability of soil patterns. We reached the following conclusions:

- Natural and agricultural landscapes display different soil patterns. Natural soil patterns are more chaotic and random with higher precipitation. Their formation is dominated by local processes such as tree throw and spatially varying infiltration. Agricultural soil patterns are dominantly formed by tillage erosion processes. The patterns show low local variation that substantially increases with distance. Also, agricultural soil properties show larger correlations with terrain properties.

- In natural systems, rainfall is the main factor influencing soil variation. In agricultural systems, landform explains the largest part of variation. The most important factor affecting total soil variation is the human factor. Agricultural land use increases erosion rates, which changes soil patterns and creates and amplifies the topographic dependence of soil properties.

- In natural and agricultural settings there are different sets of processes that change soils and landscape with similar rates. In natural systems, these processes often interact and amplify or diminish each other, leading to soil-landscape co-evolution. In agricultural systems, these interactions are often missing and processes co-occur rather than co-evolve.

- Agricultural soil patterns are easier to predict than natural soil patterns, due to the shift from dominant external to internal factors that explain soil variation, which manifests itself in larger correlations between soil and terrain properties.

Soil-landscape evolution models are increasingly equipped to simulate soil-landscape development in a variety of settings. Our contribution shows the added value of using water 
availability as spatially varying driver of pedogenesis to simulate soil and landscape development in natural settings. These developments are essential to study the vulnerability and resilience of soil systems under the increasing pressure from land-use intensification and the changing climate.

\subsection{Acknowledgements}

We thank Tom Vanwalleghem (University of Cordoba, Spain) for sharing the Meerdaal dataset. 


\section{Supplement 5.1: Model equations and parameters of HydroLorica}

This supplementary information provides the equations and parameters used to run HydroLorica. We provide the equations for adjusted or newly introduced processes and we refer to earlier work for processes that haven't been modified from earlier versions. We conclude with Table S5.1 which provides all parameters we used in our simulations, including references.

Here we provide the model equations. The model parameters can vary in space and time, depending on parameter and process. We indicate this in the parameters by adding a subscript of $x y$ to indicate variation in space, subscript $l$ to indicate a specific soil layer, subscript $z$ to indicate a certain depth and subscript $t$ to indicate variation in time.

\section{S5.1.1 Hydrologic processes}

The hydrological module partitions rainfall $\left(P_{t}\right)$ into three components: evapotranspiration $\left(E T_{x y, t}\right)$, infiltration $\left(I_{x y, t}\right)$ and surface flow $\left(\operatorname{Ronn}_{x y, t} \& R O f f_{x y, t}\right)$. Evapotranspiration is calculated from longitude, temperature and slope position, and is corrected for vegetation type using a vegetation correction factor $c_{v e g}$ (Allen et al., 1998). The complete hydrological module is described in detail in Supplement 4.2 of Chapter 4 and Van der Meij et al. (2018).

\section{S5.1.2 Determination of vegetation type}

Distinction between grassland and forest vegetation in the natural phase of soil formation depends on local water availability. We adjusted the Budyko curve (Budyko and Miller, 1974) to determine local water stress, which is a determinant of vegetation type (Thompson et al., 2010). Instead of the traditional ratio between annual precipitation and potential evapotranspiration, we used the sum of annual infiltration $I_{x y, t}$ and actual evapotranspiration $E T a_{x y, t}$ to calculate water stress $W S_{x y, t}$ at location $x y$ in year $t$ (Eq. (5.1)). In landscapes without overland flow, infiltration plus actual evapotranspiration equals precipitation. However, in landscapes with overland flow, redistribution of water, captured by spatially varying infiltration rates, can change local water availability. Vegetation type at location $x y$ depends on the value of $W S_{x y, t}$, with wetter places having forest and drier places having grassland (Eq. $(\mathrm{S} 5.2))$. 


$$
\begin{aligned}
& W S_{x y, t}=\left(I_{x y, t}+E T a_{x y, t}\right) / E T 0_{x y, t} \\
& \text { vegetation }_{x y, t}=\left\{\begin{array}{c}
\text { grass }, W S_{x y, t}<1 \\
\text { forest }, W S_{x y, t} \geq 1
\end{array}\right.
\end{aligned}
$$

\section{S5.1.3 (Bio-)geomorphic processes}

Creep is simulated as diffusive process. The total amount of creep creep $_{x y, t}[\mathrm{~kg}]$ at location $x y$ and year $t$ is calculated by multiplying the potential creep creep $_{p o t, t}\left[\mathrm{~kg} \mathrm{~m}^{-2}\right]$ with the sine and cosine of the maximum slope $\Lambda_{\max }$ to all its neighboring cells and cell size $d x^{2}\left[\mathrm{~m}^{2}\right]$ (Gabet et al., 2003) (Eq. (S5.3)). creep pot, depends on vegetation type (Gabet et al., 2003; Wilkinson et al., 2009). The fraction of creep $_{x y, t}$ that is transported to neighboring cell $i\left(\right.$ creep $\left._{x y, t \rightarrow i}[\mathrm{~m}]\right)$ is calculated by dividing slope gradient $\Lambda_{i}$ towards neighbour $i$ to the power of factor $p$, by the sum of slope gradients to the power of factor $p$ to all lower neighbours $J$ (Eq. (S5.4)). creep $_{x y, t \rightarrow i}$ is distributed over all soil layers $L$, proportionally to the fraction of the integral of the depth decay function over the upper and lower depths ( $z_{u p p, x y, l, t}$ and $\left.z_{l o w, x y, l, t}[\mathrm{~m}]\right)$ of layer $l$ divided by the integral of that depth decay function over the entire soil depth $s d_{x y, t}[\mathrm{~m}]$ (Eq. (S5.5)). The shape of the depth decay function is controlled by depth decay parameter $d d_{C R}$ $\left[\mathrm{m}^{-1}\right]$ and average layer depth $z_{x y, l, t}$. The creep leaving layer $l$ is distributed over neighboring layers at location $i$ proportional to the size of the vertical boundary between the layers.

$$
\begin{aligned}
& \operatorname{creep}_{x y, t}=\operatorname{creep}_{p o t, t} * \sin \left(\Lambda_{\text {max }}\right) * \cos \left(\Lambda_{\text {max }}\right) * d x^{2} \\
& \operatorname{creep}_{x y, t \rightarrow i}=\frac{\Lambda_{i}^{p}}{\sum_{j}^{J} \Lambda_{j}^{p}} * \operatorname{creep}_{x y, t} \\
& \operatorname{creep}_{x y, t, l \rightarrow i}=\frac{\int_{z_{u p p p, x y y, l, t}}^{z_{l o w}}\left(1-\exp \left(-d d_{C R^{*} z_{x y}, t, t}\right)\right)}{\int_{0}^{s d_{x y, t}}\left(1-\exp \left(-d d_{\left.\left.C R^{*} z_{x y, l, t}\right)\right)}\right.\right.} * \operatorname{creep}_{x y, t \rightarrow i}
\end{aligned}
$$

Tree throw affects soil and landscape depending on the dimensions of the root clump and the transport distance. The depth $d$ and width $w$ dimensions of the root clump $\operatorname{dim}_{w d, a}[\mathrm{~m}]$ are scaled with tree age $a$ [years] and have maximum dimensions $\operatorname{dim}_{w d, \max }[\mathrm{m}]$ (Eq. (S5.6)). Soil material is collected from cells and layers that are covered by dimensions $\operatorname{dim}_{w d, a}$, proportionally to the overlap of the root clump with cell dimensions. The soil material is homogenized and deposited at cell $i$ that is located at distance $T D[\mathrm{~m}]$ in the direction of the 
fall. Transport distance $T D$ is calculated using root clump width $\operatorname{dim}_{w}$ and root clump depth $\operatorname{dim}_{d}$ and slope $\Lambda_{i}$ in the falling direction (Eq. (S5.7)).

$$
\begin{aligned}
& \operatorname{dim}_{w d, a}=\left\{\begin{array}{r}
\operatorname{dim}_{w d, \text { max }} *\left(\frac{3}{2} * \frac{\text { age }}{150}-0.5 *\left(\frac{\text { age }}{150}\right)^{3}, \text { age }<150\right. \\
\operatorname{dim}_{\mathrm{wd}, \mathrm{max}}, \text { age } \geq 150
\end{array}\right. \\
& T D=\frac{\operatorname{dim}_{w, a}}{2} *\left(\cos \left(\Lambda_{i}\right)-\sin \left(\Lambda_{i}\right)\right)-\frac{\operatorname{dim}_{d, a}}{2} *\left(\sin \left(\Lambda_{i}\right)-\cos \left(\Lambda_{i}\right)\right)
\end{aligned}
$$

Water erosion and deposition are calculated using the same approach as the original Lorica model, with the difference that we use the annual sum of daily overland flow as driver of erosion, in contrast to one annual calculation of water flow. We refer to Temme and Vanwalleghem (2016) for a detailed description of this process.

Tillage consists of two parts: homogenization and erosion. Homogenization occurs completely over all layers that fall in the predetermined plough depth $p d[\mathrm{~m}]$. Tillage erosion is simulated as diffusive process (Govers et al., 1994), using the equations of the landscape evolution model LAPSUS (Baartman et al., 2012). LAPSUS uses units in meters to calculate transport from one location to another. This is why we calculate local tillage transport in meters too. We use the ratio between local tillage $[\mathrm{m}]$ and the layer thicknesses at the eroding location $[\mathrm{m}]$ to determine the fraction of soil material that is transported from a certain layer. When this fraction is higher than one, the entire layer is transported and a new fraction is calculated for the underlying layer and remainder of the local tillage. Local tillage rate till $_{x y \rightarrow i}$ $[\mathrm{m}]$ is calculated based on potential tillage rate $\operatorname{till}_{p o t}[-]$, slope in transport direction $\Lambda i$, plough depth $p d[\mathrm{~m}]$ and a factor that distributes the tillage over all lower lying neighbors $\mathrm{J}$, proportional to their slope to the power of factor $p$ (Eq. (S5.8)).

$$
\operatorname{till}_{x y, t \rightarrow i}=\frac{\Lambda_{i}^{p}}{\sum_{j}^{J} \Lambda_{j}^{p}} * \Lambda_{i} * p d * \operatorname{till}_{p o t}
$$

\section{S5.1.4 (Bio-)pedogenic processes}

We simulated three (bio-)pedogenic processes that change texture and organic matter properties in loess landscapes. These are clay translocation, bioturbation and soil organic matter uptake and breakdown. 
We adapted a new way of simulating clay translocation, using the advection equation of Jagercikova et al. (2017). The diffusive part of clay translocation as described by Jagercikova et al. (2017) is separately modeled by bioturbation. The clay advection $a d v_{x y z, t}[\mathrm{~m}]$ at a given location $x y$ with depth $z[\mathrm{~m}]$ in year $t$ is a function of annual infiltration $I_{x y, t}[\mathrm{~m}]$ at that location and potential advection $a d v_{0}[\mathrm{~m}]$. We reduced the advection with infiltration asymptotically to limit translocation at high infiltration rates, when the amount of dispersible clay becomes a limiting factor. The parameters were chosen so that an infiltration of $500 \mathrm{~mm}$ resulted in an advection of $0.5^{*}$ potential advection $a d v 0$. The advection decreased exponentially with depth following depth decay rate $d d_{C T, x y, t}\left[\mathrm{~m}^{-1}\right]$ (Eq. (S5.9)), which is scaled with local infiltration from potential depth decay rate $d d_{C T}\left[\mathrm{~m}^{-1}\right]$ (Eq. (S5.10)). The local advection $a d v_{x y z, t}$ was multiplied with bulk density $\left[\mathrm{kg} \mathrm{m}^{-3}\right]$, clay fraction [-] and the dimensions of the cell $\left[\mathrm{m}^{-3}\right]$ to get the amount of clay to be eluviated [kg].

Not all clay in the soil can be translocated. Part of it is not available to the percolating water, because it is bonded to other minerals and organic matter. We used the equations of Brubaker et al. (1992) to estimate the part of the clay that is water-dispersible $f_{c l a y, x y z, w d}$ [-], i.e. that is available for translocation by water (Eq. (S5.12)). We estimated the required $C E C_{x y z}$ with a pedotransfer function from Ellis and Foth (1996), using the local fractions of clay $f_{\text {clay,xyz }}$ and organic matter $f_{O M, x y z}$ [-] (Eq. (S5.11)). This approach is similar to the one used in soil profile evolution model SoilGen2 (Finke, 2012).

$$
\begin{aligned}
& d d_{C T, x y, t}=d d_{C T}-\left(1-\exp \left(-\frac{I_{x y, t}}{\frac{2}{3}}\right)\right) \\
& a d v_{x y z, t}=100 * a d v_{0} *\left(1-\exp \left(-\frac{I_{x y, t}}{\frac{2}{3}}\right)\right) * \exp \left(-d d_{C T, x y, t} * z\right) \\
& C E C_{x y z}=0.1 *\left(32+3670 * \frac{f_{O M, x y z}}{1.72}+196 * f_{\text {clay }, x y z}\right)-300 * \frac{f_{O M, x y z}}{1.72} \\
& f_{\text {clay }, x y z, w d}=0.01 *\left(0.369 * f_{\text {clay }, x y z} * 100-8.96 * \frac{C E C}{f_{\text {clay }, x y z} * 100}+4.48\right)
\end{aligned}
$$

We used the same approach to calculate bioturbation and the soil organic matter uptake and decomposition as the original Lorica model. We refer to Temme and Vanwalleghem (2016) for a detailed description of these processes. 
Table S5.1: Overview of new and adjusted model parameters in this study. In the last column,

T\&V2016 refers to Temme and Vanwalleghem (2016), Cal. means the parameters are calibrated,

Est. means the parameters are estimated.

\begin{tabular}{|c|c|c|c|c|c|c|c|}
\hline Type & Process & Parameters & Symbol & Spec & Rate & Unit & Reference \\
\hline \multirow{3}{*}{ 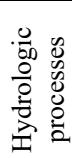 } & \multirow[t]{3}{*}{$\begin{array}{l}\text { Evapo- } \\
\text { transpiration }\end{array}$} & \multirow[t]{3}{*}{$\begin{array}{l}\text { Vegetation } \\
\text { correction }\end{array}$} & \multirow[t]{3}{*}{$C_{\text {veg }}$} & Grass & 0.75 & - & \multirow[t]{3}{*}{$\begin{array}{l}\text { (Allen et al., } \\
\text { 1998) }\end{array}$} \\
\hline & & & & Forest & 0.85 & - & \\
\hline & & & & Cereals & 0.45 & - & \\
\hline \multirow{16}{*}{ 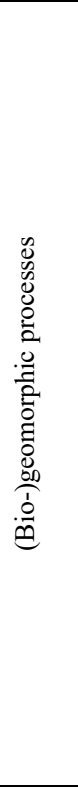 } & \multirow{5}{*}{$\begin{array}{l}\text { Water erosion } \\
\text { and } \\
\text { sedimentation }\end{array}$} & Multiple flow factor & $p$ & & 4 & - & \multirow[t]{5}{*}{ T\&V2016 } \\
\hline & & $\begin{array}{l}\text { Exponent of } \\
\text { overland flow }\end{array}$ & $m$ & & 1.67 & - & \\
\hline & & Exponent of slope & $n$ & & 1.3 & - & \\
\hline & & Erodibility & K & & 0.0003 & - & \\
\hline & & Erosion threshold & $T C_{\min }$ & & 0.1 & & \\
\hline & \multirow[t]{4}{*}{ Creep } & \multirow[t]{3}{*}{ Potential creep rate } & \multirow[t]{3}{*}{ creep $_{\text {pot }}$} & Grass & 4.3 & $\mathrm{~kg} \mathrm{~m}^{-2} \mathrm{a}^{-1}$ & $\begin{array}{l}\text { (Gabet et al., } \\
\text { 2003; }\end{array}$ \\
\hline & & & & Forest & 5.3 & $\mathrm{~kg} \mathrm{~m}^{-2} \mathrm{a}^{-1}$ & Wilkinson et \\
\hline & & & & Cereal & 4.3 & $\mathrm{~kg} \mathrm{~m}^{-2} \mathrm{a}^{-1}$ & al., 2009) \\
\hline & & Depth decay rate & $d d_{C R}$ & & 2 & $\mathrm{~m}^{-1}$ & T\&V2016 \\
\hline & \multirow[t]{5}{*}{ Tree throw } & $\begin{array}{l}\text { Max root clump } \\
\text { width }\end{array}$ & $\operatorname{dim}_{w, \max }$ & & 4 & $\mathrm{~m}$ & Est. \\
\hline & & $\begin{array}{l}\text { Max root clump } \\
\text { thickness }\end{array}$ & $\operatorname{dim}_{d, \max }$ & & 0.7 & $\mathrm{~m}$ & Est. \\
\hline & & Tree age & & Maximum & 300 & $\mathrm{a}$ & (Rozas, 2003) \\
\hline & & & & Fully grown & 150 & $\mathrm{a}$ & \\
\hline & & Fall frequency & & & 0.00002 & Trees $\mathrm{m}^{-2} \mathrm{a}^{-1}$ & \\
\hline & \multirow[t]{2}{*}{ Tillage } & Plough depth & $p d$ & & 0.2 & $\mathrm{~m}$ & $\begin{array}{l}\text { (Van der Meij } \\
\text { et al., 2019) }\end{array}$ \\
\hline & & Potential tillage & till $_{\text {pot }}$ & & 1 & - & Est. \\
\hline \multirow{13}{*}{ 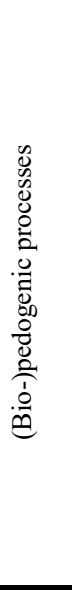 } & \multirow{2}{*}{$\begin{array}{l}\text { Clay } \\
\text { translocation }\end{array}$} & Potential advection & $A d v_{0}$ & & 0.0025 & $\mathrm{~m} \mathrm{a}^{-1}$ & Est. \\
\hline & & $\begin{array}{l}\text { Potential depth } \\
\text { decay rate }\end{array}$ & $d d_{C T}$ & & 3.5 & $\mathrm{~m}^{-1}$ & Est. \\
\hline & \multirow[t]{4}{*}{ Bioturbation } & \multirow[t]{3}{*}{$\begin{array}{l}\text { Potential } \\
\text { bioturbation rate }\end{array}$} & \multirow[t]{3}{*}{$B T_{p o t}$} & Grass & 4.3 & $\mathrm{~kg} \mathrm{~m}^{-2} \mathrm{a}^{-1}$ & $\begin{array}{l}\text { (Gabet et al., } \\
\text { 2003; }\end{array}$ \\
\hline & & & & Forest & 5.3 & $\mathrm{~kg} \mathrm{~m}^{-2} \mathrm{a}^{-1}$ & Wilkinson et \\
\hline & & & & Cereal & 4.3 & $\mathrm{~kg} \mathrm{~m}^{-2} \mathrm{a}^{-1}$ & al., 2009) \\
\hline & & Depth decay rate & $d d_{B T}$ & & 2 & $\mathrm{~m}^{-1}$ & T\&V2016 \\
\hline & \multirow[t]{7}{*}{ SOM cycle } & \multirow[t]{3}{*}{ Potential input } & \multirow[t]{2}{*}{$S O M_{p o t, i n}$} & Grass & 0.265 & $\mathrm{~kg} \mathrm{~m}^{-2} \mathrm{a}^{-1}$ & Cal. (Guo and \\
\hline & & & & Forest & 0.245 & $\mathrm{~kg} \mathrm{~m}^{-2} \mathrm{a}^{-1}$ & Gifford, \\
\hline & & & $d d_{C C, \text { in }}$ & Cereal & $\begin{array}{l}0.205 \\
2\end{array}$ & $\begin{array}{l}\mathrm{kg} \mathrm{m}^{-2} \mathrm{a}^{-1} \\
\mathrm{~m}^{-1}\end{array}$ & $\begin{array}{l}\text { 2002; Liu et } \\
\text { al., 2011) }\end{array}$ \\
\hline & & Fractionation factor & $f_{\text {hum }}$ & & 0.8 & - & T\&V2016 \\
\hline & & Decomposition rate & $S O M_{d e c, y}$ & Young OM & 5 & $\% \mathrm{a}^{-1}$ & Cal. (Guo and \\
\hline & & Depth decay rate & $S O M_{d e c, o}$ & Old OM & 1 & $\% \mathrm{a}^{-1}$ & Gifford, \\
\hline & & & $D d_{C C, d e c}$ & & 1 & $\mathrm{~m}^{-1}$ & $\begin{array}{l}\text { 2002; Liu et } \\
\text { al., 2011) }\end{array}$ \\
\hline
\end{tabular}




\section{Chapter 6. Synthesis}

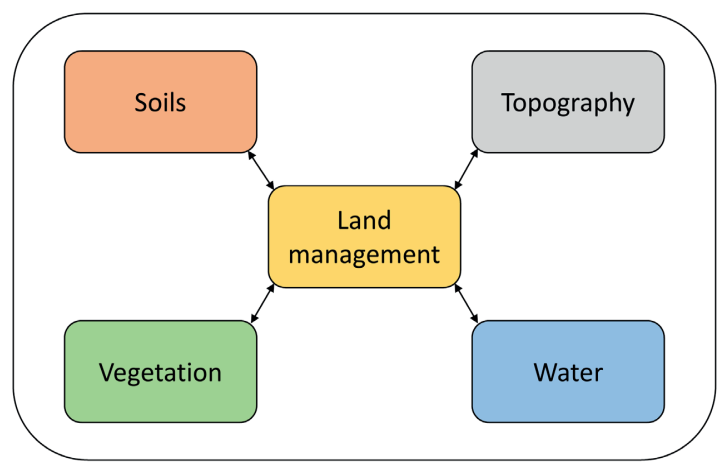


In this thesis I studied the response of soils and landscapes to increasingly intensive land management in the Anthropocene. This synthesis answers the research questions posed in Chapter 1 by integrating the findings from the research chapters and placing the research in a wider context. Section 6.1 discusses what methods can quantify evolution of soils and landscapes in the Anthropocene (objective 1). Section 6.2 describes and quantifies the evolution of soils and landscapes in undulating landscapes and links it to descriptive models in soil science (objective 2). Section 6.3 shows the implications of these findings for soillandscape co-evolution of natural and intensively managed landscapes (objective 3 ). Section 6.4 summarizes the lessons learned in this thesis, mentions implications for sustainable land management, provides an outlook for future research of soil-landscape evolution in the Anthropocene and gives a general conclusion.

\subsection{Methods for quantifying soil-landscape change}

Studying soil and landscape evolution in natural and agricultural settings required the development and improvement of methods that cover the spatial and temporal ranges over which this evolution occurred. The reconstruction and simulation methods for studying soillandscape evolution that were developed and applied in this thesis are extensively described in the corresponding research chapters. Table 6.1 provides a brief overview of the methods applied in this thesis, with objectives, improvements, and remaining limitations, which I discuss in the following Sections.

\subsubsection{Reconstruction of past landscapes and quantification of rates of landscape change}

To understand the effect of erosion processes on landforms and landscape functions, the impact and rates of landscape change have to be quantified. In this thesis we developed and applied methods to reconstruct the paleosurface (Chapter 2) and quantify rates of landscape change (Chapter 3) of study area CarboZALF-D.

Three main methods exist for the reconstruction of paleosurfaces in eroding agricultural landscapes (e.g. Dotterweich, 2008). These are reverse erosion modeling (Peeters et al., 2006; Temme et al., 2011b; Fox, 2019), interpolation of DEMs over distinct erosion features (e.g. gullies, Bergonse and Reis, 2015), and using variations in soil property-depth profiles to estimate erosion or deposition. These variations can for example be differences in 
radionuclide-depth profiles or radionuclide stocks at different landscape positions (Walling and Quine, 1995; Gosse and Stone, 2001; Calitri et al., 2019) or removals from or additions to standard soil horizon sequences (Rommens et al., 2005; Świtoniak, 2014). The applicability of these methods depends on the complexity of landform evolution, type of erosional features and availability of field data. In CarboZALF-D, there are no distinct erosional features which we could reconstruct by interpolation; the dominant process of tillage erosion affected the entire hillslope. Reverse erosion modeling faces more general complications with polygenesis and equifinality (Temme et al., 2011a). CarboZALF-D does have an extensive dataset of soil profile descriptions. Therefore, we decided to use these soil descriptions for estimating spatial erosion and deposition patterns at CarboZALF-D in Chapter 2 (Table 6.1). The extensive dataset enabled a unusually detailed reconstruction of the degree of erosion using soil-profile truncations and the degree of deposition using colluvium thickness.

The results showed strong relations between erosion intensity and slope and landscape position. The reconstructed surface displayed higher variation in slope and terrain positions due to a more heterogeneous surface and the occurrence of several now-removed surface depressions on the paleo-hillslope. The quality of the predictions depended on several factors: the assumptions of the initial soil-landscape system (e.g. spatially uniform soil depth), the assumption that most erosion occurred in recent times, the data availability and quality (e.g. occurrence of censored data) and interpolation quality. Due to these factors, the reconstructed paleosurface had a considerable uncertainty, but its patterns and properties were representative for pre-agricultural settings in undulating landscapes. I recommend to use soil profile descriptions for reconstructing paleotopographies when these profiles are welldeveloped and when the majority of them are not completely eroded. Soil profile descriptions are easy to obtain, are often part of larger environmental surveys, and facilitate a detailed spatial pattern of erosion and deposition. Truncation of soil profiles can also provide a qualitative estimate of erosion intensity (e.g. Figure 2.1) when quantitative data on initial profile thicknesses is absent or highly uncertain. 


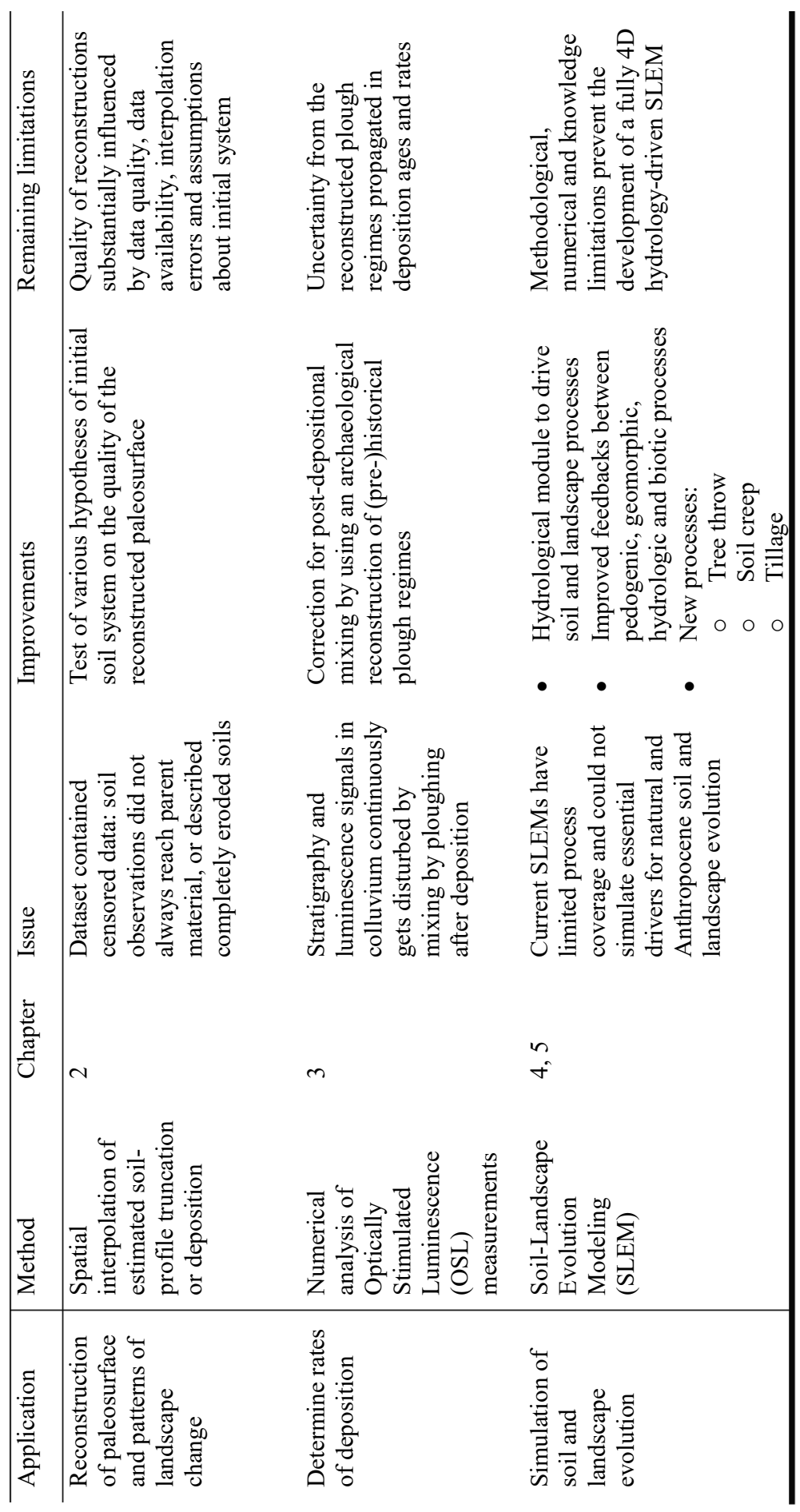

Table 6.1:

Overview of applied and improved methods in

this thesis. 
The results showed strong relations between erosion intensity and slope and landscape position. The reconstructed surface displayed higher variation in slope and terrain positions due to a more heterogeneous surface and the occurrence of several now-removed surface depressions on the paleo-hillslope. The quality of the predictions depended on several factors: the assumptions of the initial soil-landscape system (e.g. spatially uniform soil depth), the assumption that most erosion occurred in recent times, the data availability and quality (e.g. occurrence of censored data) and interpolation quality. Due to these factors, the reconstructed paleosurface had a considerable uncertainty, but its patterns and properties were representative for pre-agricultural settings in undulating landscapes. I recommend to use soil profile descriptions for reconstructing paleotopographies when these profiles are welldeveloped and when the majority of them are not completely eroded. Soil profile descriptions are easy to obtain, are often part of larger environmental surveys, and facilitate a detailed spatial pattern of erosion and deposition. Truncation of soil profiles can also provide a qualitative estimate of erosion intensity (e.g. Figure 2.1) when quantitative data on initial profile thicknesses is absent or highly uncertain.

We quantified rates of landscape change at CarboZALF-D using Optically Stimulated Luminescence (OSL) dating of colluvial deposits (Chapter 3). We developed a workflow to correct for poor bleaching and post-depositional mixing of agricultural chronologies by applying advanced statistical age modeling techniques and using archeologically reconstructed historical plough regimes (Table 6.1). These advanced techniques were essential to distill the desired ages from the heterogeneous measurements with acceptable remaining uncertainty and to prevent biases in deposition rates induced by post-depositional mixing. We dated 32 samples taken from five locations with high vertical (i.e. temporal) resolution. The results showed a complex spatiotemporal pattern of depositional infilling in the kettle hole of CarboZALF-D. The oldest deposits $(\sim 5 \mathrm{ka})$ occur at the fringes and the youngest deposits $(<0.3 \mathrm{ka})$ occur in the center and on top of the older sediments. Between the old and young deposits there appeared to be a depositional hiatus. The deposition rates show a 100-fold increase over time. This increase in deposition does not solely represent increased erosion in the catchment, but was also linked to agricultural drainage of the kettle hole that created larger gradients towards the depression and more space for deposits. Our provided methodology for applying OSL dating in colluvial sediments is applicable for ploughed systems worldwide; only the archaeological land-use reconstruction should be 
adjusted to the local settings. Our provided land-use reconstruction is applicable for northwestern Europe, but should be refined with local archaeological information to constrain uncertainty associated with the reconstructed ages and plough depths.

Rates of Anthropocene landscape change can be quantified using various other methods too, for example by radiocarbon dating (Dreibrodt et al., 2010), radionuclide dating (Schuller et al., 2004; Aldana Jague et al., 2016; Calitri et al., 2019), or a combination of different methods (Bajard et al., 2015; Huisman et al., 2018; Kappler et al., 2018). There are several disadvantages and advantages of OSL dating compared to these other methods. I will start with the disadvantages. First, OSL can only be used to measure deposition rates, and not erosion rates. We showed in Chapter 3 that these are not necessarily analogous. Erosion rates can only be measured spatially explicit using radionuclide dating. Second, the heterogeneous luminescence distributions of colluvial sediments require advanced statistical techniques for filtering and adjusting the depositional ages. In Chapter 3, we provide tools to do just that. Lastly, OSL dating can be quite costly and it is unrealistic to expect that studies will routinely measure chronologies with a lateral and vertical resolution similar to ours. However, we showed the added value of sampling more than one location in colluvial infillings to identify possible multiple phases of deposition. I urge others to carry out a soil-geomorphic survey (e.g. Chapter 2) and consider various landscape positions prior to selecting sampling sites, and rather sample one study site in high detail than multiple study sites in low detail when complex landscape change can be expected. This will avoid wrong interpretations of landscape evolution.

An advantage of OSL dating over radiocarbon dating in colluvial settings is that there is generally sufficient datable, sandy, material, which facilitates sampling with high vertical resolution. For radiocarbon dating, the vertical resolution and quality of dating is limited to the occurrence of non-polluted organic material, for instance charcoal or buried organic-rich horizons (Geyh et al., 1971). In other settings, such as lake sediments, radiocarbon dating is much more suitable than OSL dating due to the high occurrences of organic material and poor bleaching of sand grains. The potential high vertical resolution of OSL in colluvial settings can aid in establishing detailed chronologies and reconstructing deposition rates over time, which can help identify possible fluctuations and hiatuses in deposition. Such an exercise is currently impossible with dating methods that use radionuclide inventories of e.g. cesium, plutonium or beryllium. These methods generally provide one average short- or long- 
term erosion or deposition rate per location, based on radionuclide inventories or based on mathematical functions fitted through radionuclide distributions in a profile (e.g. Xinbao et al., 1990; Poreba, 2006; Arata et al., 2016). Distinguishing different phases and rates of erosion and deposition using radionuclides would require high resolution sampling and advanced simulation models, which are similar requirements as we had for our OSL study. Vandermaelen et al. (2019) are currently developing such a method, that fits numerous possible scenarios of alternating erosion, stability and deposition, constrained by independent age data, through a complex measured ${ }^{10} \mathrm{Be}$-depth profile to find the best fitting scenario. Their promising results show the potential of such methods for increasing usability of radionuclide dating for constraining chronologies and rates of landscape change.

The applicability and usefulness of various geochronological methods for determining rates of landscape change thus depends on availability of datable material, the time span and complexity of landscape change, geomorphic context and required methods for data analysis. Reviews of applicability and comparison of different geochronological methods in Holocene settings exist (e.g. sedimentary basins, Chamberlain et al., 2019), but such overviews are currently lacking for intensively managed landscapes. The findings from Chapter 3 can serve as base for such a review, highlighting the importance of considering the effect of all transport and mixing processes on the final chronologies, describing the required statistical methods to process and interpret measurements and urging to combine geochronological surveys (e.g. Chapter 3) with soil-geomorphic surveys (e.g. Chapter 2) to constrain both spatial and temporal patterns of agricultural landscape change.

\subsubsection{HydroLorica - a water-driven SLEM for studying Holocene and} Anthropocene soil-landscape evolution

At the start of my PhD project, Soil-Landscape Evolution Models (SLEMs) were not equipped to simulate soil development in natural systems, because some dominant drivers and processes were not included (Minasny et al., 2015). In Chapter 4, we reviewed the role that water plays as driver of natural soil and landscape evolution. The hydrological system shows complex co-evolution with the other constituents of the landscape in natural settings. The partitioning of water over lateral and vertical flow paths depends on surface topography, infiltration capacity and subsurface stagnating layers. These soil and topographic properties in turn are formed by processes driven by water flow. Unfortunately, these subsurface flow 
paths can currently not all be simulated in SLEMs due to three methodological obstructions: 1) the scale of measured soil hydraulic properties is often not representative for soil layers, catenae and entire soil landscapes, 2) the type and degree of soil structure and macro-porosity cannot be simulated or reliably estimated from soil physical properties that are currently simulated by SLEMs, and 3) methods to estimate soil hydraulic properties from soil physical properties do not necessarily agree with measured soil hydraulic properties. There are also three knowledge gaps preventing the simulation of the evolution of the hydrological system of landscapes: 1) there is little knowledge on the long-term evolution of soil hydraulic properties and soil hydrological systems, 2) the control of water flow on pedogenic processes needs to be better quantified, and 3) more data is required for the identification and quantification of flow paths.

For the development of HydroLorica in Chapter 5, we were able to overcome some of these obstructions (Table 6.1). We developed a module that simulates hydrologic processes with smaller time steps (days to seasons) than the pedogenic and geomorphic processes (years). This module improved the partitioning of rainfall at the soil surface between infiltration, evapotranspiration and overland flow, leading to spatially varying infiltration rates. These infiltration rates were used to drive the process of clay translocation and to determine vegetation type in a certain location based on water stress. Also, we programmed new processes that were essential for the evolution of soils and landscapes in natural and intensively managed landscapes. These were soil creep, tree throw and tillage. HydroLorica is true to my definition of the landscape (Section 1.3.1): a collection of coupled, spatially varying components, such as soils, topography, vegetation and the hydrological system. These components influence each other's development, leading to possible co-evolution (Figure 1.1).

The reduced complexity of models such as HydroLorica often faces criticism, because reduced-complexity models deliberately ignore processes that decrease their wider applicability or risk giving correct results via wrong processes (Hunter et al., 2007; Keylock, 2007; Opolot et al., 2015; Marschmann et al., 2019). On the other hand, such models challenge the user to critically think of the essential processes acting in a landscape and prevent extensive data requirements and over-parametrization of models (Murray, 2003; Formann et al., 2007; Hunter et al., 2007; Temme et al., 2011a; Snowden et al., 2017; Kirkby, 2018; Marschmann et al., 2019). HydroLorica builds further on reduced-complexity models 
LAPSUS (Schoorl et al., 2002), MILESD (Vanwalleghem et al., 2013), and Lorica (Temme and Vanwalleghem, 2016). These models have proven their usefulness in a number of studies, but minor modifications were often required to adapt the models to simulate essential processes that occurred in the landscapes where they were applied (e.g. Van Gorp et al., 2014; Van der Meij et al., 2016). I see this as a strength of reduced-complexity models. Every landscape evolves differently and a first grasp of the processes and drivers at play is essential to interpret model results and understand landscape functioning. Reduced-complexity models provide flexible frameworks which can be adjusted as required using simplified process formulations to study a certain problem. I encourage the development of additional models, both complex and reduced-complex, that can simulate soil and landscape evolution under various boundary conditions, to perform comparative studies on model quality (e.g. FACSIMILE, Maddy et al., 2018), or even to perform ensemble simulations (e.g. Tebaldi and Knutti, 2007) for more robust predictions of the future of soils in the Anthropocene.

Simulation methods and reconstruction methods should confront, complement and support each other in various ways (Phillips, 2008; Temme et al., 2017). Simulation methods can be used to test hypotheses developed through reconstruction studies and literature studies. The other way around, simulation methods can also be used to develop hypotheses that can be tested in the field. Both ways aid in increasing our understanding of soil and landscape evolution (Phillips, 2008; Ma et al., 2019a). Simulation and reconstruction methods both have limitations in accuracy and ease of use, and are applicable over different spatial and temporal scales. Together, they form a solid basis for studying soil and landscape evolution. The exchange of results from different methods can help improving predictions and simulations, formulating new hypotheses or define new scientific concepts (Phillips, 2008; Lin, 2010a; Ma et al., 2019b).

\subsection{Evolution of soils and landscapes in the Anthropocene}

\subsubsection{Drivers and scales of Anthropocene soil-landscape evolution}

Natural and agricultural soils develop under different dominant drivers that affect soils and landscapes at different spatial and temporal scales. The spatial organizations of soils range from soil particles to soil zones (Sommer, 2006; Lin, 2012a), while the temporal changes of soil properties occur in minutes to hundreds of millennia (Brantley, 2008). To study the 
response of soils to changes in their environmental conditions, the spatial and temporal scales of research have to be constrained to the scales where soils respond to these changes. In this Section I provide an overview of the drivers and scales associated with natural and agricultural soil development that were identified and quantified in the research chapters.

Table 6.2: Summary of drivers, scales and connectivity associated with natural and agricultural soils, as identified in the research chapters

\begin{tabular}{l|l|lll}
\hline & Property & Natural soils & Agricultural soils & Chapter \\
\hline Drivers & Dominant soil forming factor & Climate & Humans, relief & 4,5 \\
& Dominant driver & Water flow & Land use & $3-5$ \\
\multirow{3}{*}{ Scales } & Temporal change & $10^{2}-10^{4} \mathrm{a}$ & $10^{0}-10^{2} \mathrm{a}$ & $3-5$ \\
& Spatial heterogeneity & Random, local & Function of topography & $2-5$ \\
Connectivity & Connectivity & (Sub-)surface & (Sub-)surface water, & $2-5$ \\
& & water & sediments & \\
\hline
\end{tabular}

There are major differences between drivers and scales of natural and agricultural soil development (Table 6.2). In Chapter 5 we showed that the dominant soil forming factors shifted from external factors in natural systems (climate) controlling pedon-scale random processes such as tree throw to internal factors in agricultural systems (relief) dominantly controlling hillslope-scale erosion processes. This shift increased the predictability of soil properties based on topographic variables. Also the dominant driver of soil and landscape development shifted from water flow to land use. Natural soil and terrain patterns and properties in CarboZALF-D and in the model results from Chapter 5 changed substantially after cultivation (in accordance with findings by Phillips et al., 1999; Kalettka and Rudat, 2006), and the rates of change were a function of land-use intensity (Chapter 3, Sommer et al., 2008). Deforestation and tillage were not the only land management that triggered and aggravated deposition rates in CarboZALF-D, also agricultural drainage appeared to increase deposition rates by created larger gradients towards the depression and more space for deposits. The response of soils to increased erosion processes varied per soil property. Rapidly adjusting soil properties such as soil carbon stocks were able to keep up with the increased erosion, while slower adjusting properties such as the Bt horizon depth were not (Chapter 5).

The findings in this thesis support the assertion that humans are the dominant soil forming factor in agricultural landscapes (Amundson and Jenny, 1991; Dudal, 2005; Richter and 
Yaalon, 2012). The changes to soils in intensively managed landscapes fit in the global trend of land degradation in the late Holocene under increasing anthropogenic pressure (e.g. He et al., 2006; Anselmetti et al., 2007; Compton et al., 2010; Bajard et al., 2017; Rothacker et al., 2018). In the last few centuries, the landscapes changed from dominantly natural-influenced to dominantly human-influenced (Ellis et al., 2010), and landscapes now experience more rapid cycling of water, sediments and carbon (Kumar et al., 2018). Human interference uncoupled soil development from its natural environment and connected it with anthropogenic drivers, leading to altering, hindering or marginalizing natural processes and fluxes (Ellis et al., 2010). Also, humans change the way landscapes are connected in space and time (Brierley et al., 2006). These changes occur in most landscapes that are altered to improve human wellbeing, with both wanted and unwanted consequences. In agricultural landscapes, soil management to improve production increases erosion processes and lateral connectivity of soils by sediments (this thesis). In managed rivers, the river loses its lateral connectivity with the floodplains and the longitudinal connectivity of sediments and aquatic life (Kondolf et al., 2006). In dammed estuaries, measures to provide safety against flooding disrupt fluxes of sediments, nutrients and species and, together with eutrophication, can develop dead zones by oxygen depletion (Diaz and Rosenberg, 2008; Van Wesenbeeck et al., 2014; Ysebaert et al., 2016). These changes in drivers, scales and landscape connectivity should be recognized when developing nature-based management strategies. Nature-based management can align with and utilize natural processes and feedbacks to design naturebased landscapes, where unwanted consequences of earlier management can be prevented and restored, to improve living conditions for biota and humans.

The rates at which the drivers, scales and connectivity of soil-landscape evolution change depend on the strength of anthropogenic forcing. If there is an abrupt, substantial change in boundary conditions the system might shift suddenly (e.g. Sommer et al., 2008), while low to moderate anthropogenic forcing can slowly change the system, or even allow the system to resist a state-change (Nimmo et al., 2015; Ludwig et al., 2018). The response of soils to anthropogenic forcing depends largely on the capacity or resilience of the soil to recover from disturbances (Lal, 2001). This resilience differs per soil property, depending on the characteristic rates of processes affecting that property. This will be illustrated in the next section. 


\subsubsection{Pedogenic pathways}

The transition from natural land cover to agricultural land use had large consequences for the evolution of soils and landscapes. The impact of changing environmental conditions on soils is clearly illustrated in this thesis. Existing work suggested that in agricultural landscapes, erosion processes change pathways of soil development, introduce new soil types and concentrate soil types in certain landscape positions (Phillips et al., 1999). This has also been the case at CarboZALF-D. The topographic sequence of soils (i.e. catena) at CarboZALF-D underwent substantial changes through the Anthropocene. Starting from similar parent material, the natural sequence was mainly water-dominated, with Luvisols on the slopes, Gleysols on the fringes of the depression and Histosols in the center of the depression. The impacts of humans on the landscape of CarboZALF-D in the form of deforestation, tillage erosion and agricultural drainage created different local settings where soils could develop or degrade, depending on their landscape position (Sommer et al., 2008). The current agricultural sequence is mainly controlled by relief, with clustering of similar soil types at certain slope positions. Luvisols at different stages of degradation occur on various slope positions (Luvisols - Calcic Luvisols - Calcaric Regosols) and Colluvic Regosols with gleyic properties and post-depositional progressive pedogenesis in the depression (Chapter 2). This pattern also emerged from the numerical simulations in Chapter 5, where agricultural soil properties show smaller local variation, but larger large-scale variation than most natural soil patterns. This configuration of soil properties based on topographic position is characteristic for agricultural landscapes and is almost absent in natural landscapes (Phillips et al., 1999; Vanwalleghem et al., 2010; Román-Sánchez et al., 2018). The switch in pedogenic pathways between natural and agricultural systems thus did not only affect evolution of individual soils, but also the characteristic spread of soils in a landscape.

The consequences of cultivation on soil and landscape patterns have been illustrated and partly quantified in this thesis. However, the evolutionary trajectories of soils themselves, i.e. the pedogenic pathways, have not been quantified yet. Here, I will highlight and apply two methods to quantify pedogenic pathways in soil-landscape evolution: soil complexity and soil-landscape development state. Soil complexity describes the level of variation (heterogeneity) of soil properties in space (Phillips, 2017). Changes in soil complexity are driven by changes in soil forming factors, local disturbances, and nonlinearity in pedogenic processes. Increasing complexity with time indicates divergence of soil properties, while 
decreasing complexity indicates convergence of soil properties (Temme et al., 2015; Phillips, 2017). Soil-landscape development state (SLDS) is the name I give to the average level of soil-property development in a landscape. Development of soil properties follows progressive and regressive pathways (Johnson and Watson-Stegner, 1987; Phillips, 1993a; Sommer et al., 2008; Sauer, 2015), leading to changes in SLDS. Progressive pedogenesis indicates forward development of soil properties, characterized by e.g. soil horizonation, soil organic matter accumulation or soil deepening. Regressive pedogenesis on the other hand, indicates homogenization of the soil profile by e.g. biotic or anthropogenic soil mixing, SOM decomposition, or indicates soil truncation or burial by rapid erosion and deposition. The soil-development state is the net result of both progressive and regressive processes on a certain soil property. This property is spatially variable, because the drivers of progressive and regressive pedogenesis are spatially variable too (e.g. infiltration, erosion rate). Therefore, I define the soil-development state of the entire landscape (SLDS) as the average soil property development stage in space at a certain moment in time. An increase in SLDS indicates dominantly progressive pedogenesis and a decrease in SLDS indicates dominantly regressive pedogenesis on a landscape scale. This approach only works for quantitative soil properties; qualitative soil properties (e.g. soil structuring, type of redoximorphism) require different metrics.

Determining pedogenic pathways by quantifying changes in soil complexity and SLDS is problematic when using field data, because observations are often limited in space and time and it is impossible to sample the exact location multiple times without disturbing its development. However, numerical models provide plenty of spatiotemporal data for the quantification of pedogenic pathways. Here I show how this can be done for two soil properties using the model results from Chapter 5. Just like in Chapter 5, I selected the soil organic matter stock as a property that adjusts rapidly to disturbances and depth to Bt horizon as a property that adjusts slowly to disturbances. Soil complexity and SLDS can be quantified by calculating the standard deviation and mean of a certain soil property, respectively, in space at a certain time. Changes over time in complexity (Eq. (6.1)) indicate divergent $(+)$ or convergent (-) pedogenesis and changes in SLDS (Eq. (6.2)) indicate progressive (+) or regressive (-) pedogenesis. 


$$
\begin{aligned}
& \Delta \text { complexity }_{t}=\frac{\text { sd(soil property })_{\mathrm{t}}-s d(\text { soil property })_{t-\Delta t}}{\Delta t} \\
& \Delta S L D S_{t}=\frac{\text { mean(soil property } \left.)_{\mathrm{t}}-\text { mean (soil property }\right)_{t-\Delta t}}{\Delta t}
\end{aligned}
$$

I calculated changes in complexity and SLDS in the simulated depths to the Bt horizon and SOM stocks for every 500 years in the natural phase and for every 50 years in the agricultural phase $(\Delta t)$, for the dry $(\mathrm{P}=300 \mathrm{~mm})$ and wet $(\mathrm{P}=900 \mathrm{~mm})$ scenarios used in Chapter 5 .

Figure 6.1 shows changes in SLDS and complexity in soil properties from the model results from Chapter 5. The Figure is quite complex, due to the high information load. Here I will highlight certain aspects to support my discussion on changing pedogenic pathways in Anthropocene landscapes. The points in the quadrants show how the soil patterns evolve along various pathways. Each quadrant indicates a certain direction of soil-property development. When points converge to one specific location in the quadrants, the soil pattern either reaches a steady state in its development (origin of the graph), or the soil pattern has a steady rate of change (anywhere else in the graph).

The rate and direction of natural pedogenesis are a function of their environmental drivers. This is well visible in Figure 6.1, where higher precipitation shows more divergent pedogenic pathways that take longer to reach equilibrium. Pedogenic pathways of both soil properties in the dry scenario converge to the origin of the graph (Figure 6.1A\&B). Both pathways are dominantly progressive and there is little change in complexity of the soil patterns. The SOM stocks converge faster than depths to Bt horizon, because carbon uptake and decomposition are faster processes than clay translocation. In contrast, pedogenic pathways in the natural wet scenario are more divergent and do not converge to the origin of the graph (Figure $6.1 C \& D)$. Instead, the pedogenic pathways remain scattered in the regressive and progressive domains around the origin. The changes in complexity remain slightly divergent. The spatial variation of infiltration, water erosion and tree throw continuously changes the spatial variation of soil properties, preventing the reaching of a steady state. These patterns correspond to findings where local perturbations can induce divergent soil evolution (Phillips, 2001; Šamonil et al., 2018). The rates of local perturbations, or random processes, exceed the capacity of pedogenic processes to respond to these perturbations, causing dominant divergent pedogenesis (Phillips, 2017). For each plot in Figure 6.1, the first step in natural pedogenesis shows the largest changes. These findings conform to those from other 
studies, where initial soil development occurs with high rates, because the soil system is far from equilibrium and initial soils contain more reactive surfaces than soils in older settings (Mavris et al., 2010; Dümig et al., 2011; Kabala and Zapart, 2012; Elmer et al., 2013).
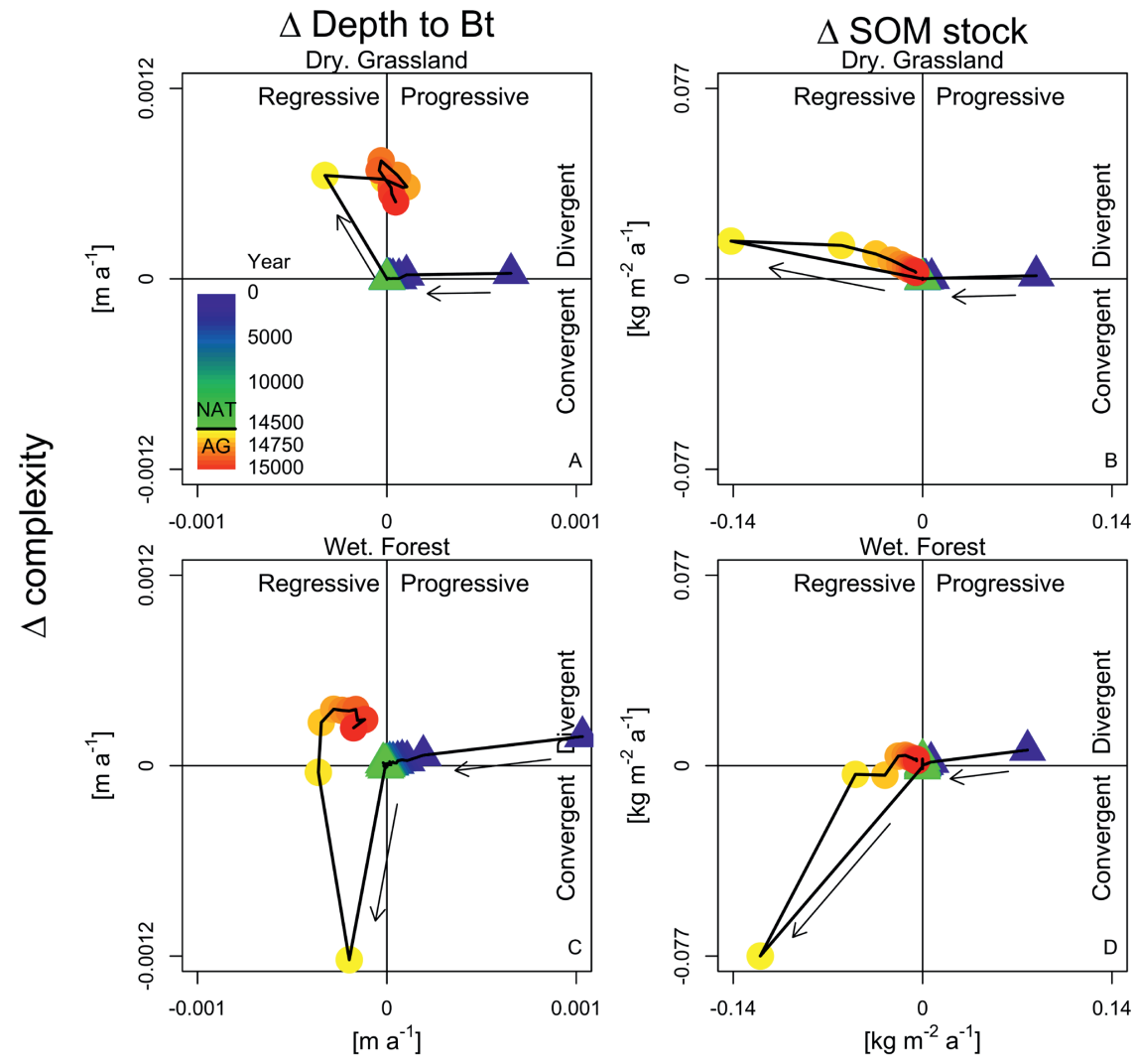

$\triangle$ SLDS

Figure 6.1: Pedogenic pathways in the simulations from Chapter 5, for two soil properties (columns) and two rainfall scenarios (rows). The small texts above the graphs indicate climatic setting and dominant vegetation type during natural development. The colors indicate the year. For the natural phase (year 0 to 14500, triangles) the pathways were calculated for every 500 years. For the agricultural phase (year 14500 to 15000, circles) the pathways were calculated for every 50 years.

The magnitude of long-term natural soil change is minor compared to soil change after cultivation of the land. In each plot in Figure 6.1, the first step of anthropogenic soil change equals or exceeds the first step of initial natural pedogenesis, implying that human impact on 
soils far exceeds any natural rate of soil formation. All changes in the agricultural system initially show minor to major regressive pedogenesis, which indicates that overall, soils have less SOM and shallower Bt horizons. These changes are driven by lower SOM input in agricultural systems, redistribution and export of soil material and potential clay translocation in colluvial positions. Depending on climatic setting, the initial change in complexity after cultivation is either divergent (dry) or convergent (wet). The response of pedogenic pathways due to anthropogenic forcing thus depends on the properties of the natural soil pattern. If the natural soil pattern was already highly complex, initial erosion and land management reduced this complexity. After this initial change, all pedogenic pathways turn divergent and approach a new steady state (SOM stocks, Figure $6.1 \mathrm{~B} \& \mathrm{D}$ ) or approach a steady rate of change (depth to Bt, Figure 6.1A\&C). The model simulations show that a steady state in soil formation can indeed be reached, but only for fast changing properties under stable circumstances, and it is thus a rare occurrence (Phillips, 2010; Sauer, 2015).

These findings suggest that soils do not necessarily evolve to mature climax soils, but rather that soil patterns diverge to stable complexity. The spatial configuration of soil properties might change, but the pattern characteristics stay the same. This complexity is a function of disturbance cycles in the landscape, such as tree throw occurrence (Phillips, 2017). When disturbance rates are high, as is the case in intensively managed landscapes, the complexity of patterns of slowly responding soil properties keeps changing, while patterns of fast responding soil properties reach a new stable complexity. A simple distinction between natural progressive and agricultural regressive pedogenesis (Sommer et al., 2008) does not do justice to these complex responses of different soil properties to natural and anthropogenic forcing. The response of soils to sudden shifts in boundary conditions depends on the rates of change of the terrain and the ability of soil properties to recover from these disturbances. Assessment of evolution of soils and landscapes should be done per individual process or soil property rather than for the entire soil (e.g. Phillips, 1993b), and should be performed on a landscape scale rather than a pedon scale. A comparison of soil-pattern complexity and SLDS of slow and fast changing soil properties can assist in forming hypotheses of soil-landscape history and land-use intensity, as the complexity is a function of land-use history and rates of landscape change. 


\subsection{Implications for soil-landscape co-evolution}

\subsubsection{Does soil-landscape co-evolution occur in intensively managed landscapes?}

Soil-landscape co-evolution indicates tightly coupled interactions in the development of soils and other domains of the landscape (topography, vegetation and/or the hydrological system, Figure 1.1). Co-evolution can occur along a range of spatial and temporal scales, but key is that interactions occur between properties and processes from the different landscape domains. It is thus more than a simple action-response system of different soil and landscape processes and properties. Co-evolution in itself is not necessarily desired, but the interactions between soils and different aspects of the landscape can help, or counteract, measures to prevent soil degradation and should therefore be considered in designing management strategies.

A fine example of soil-landscape co-evolution is explored in Chapter 4. Water flow as main driver of natural pedogenesis forms soils and landscape by transforming and transporting matter and facilitating plant growth. Changes in vegetation, topography and soil properties in turn can affect the routing of water through the landscape (Gao et al., 2018). Topography affects infiltration rate and overland flow, vegetation controls evapotranspiration, and soil properties determine the subsurface routing of water through pores and over less permeable layers. This example formed the basis of the model HydroLorica, although unfortunately, not all of these interactions can be modeled currently. There are plenty of other examples of landscape co-evolution, especially between soils, topography and vegetation. Vegetation interacts with its growing environment from pedon to catchment scale, by optimizing soil properties to improve their own growing conditions, by organizing into patterns through feedbacks with hydrologic and geomorphic processes and by promoting the weathering of bedrock into soil (Targulian and Krasilnikov, 2007; Hahm et al., 2014; Baartman et al., 2018). Porder (2014) placed such findings in a wider context of co-evolution of landscapes and life.

These examples all describe co-evolution in natural systems by self-regulating processes. In agricultural systems, soil and landscape evolution acts on different scales and under different drivers compared to natural systems (Ellis and Haff, 2009). Sivapalan and Blöschl (2015) explicitly distinguish between evolution of hydrological systems with and without humans, because humans actively steer the development of hydrological systems to suit their own 
needs and do not necessarily follow natural constraints and optimality laws in doing so. In Chapter 5 we showed that co-evolution only occurred in the simulations of the natural setting and not in the agricultural setting, because in agricultural settings vegetation type is controlled by humans and rates of anthropogenic erosion are not affected by the conditions of the soil. Even for processes with similar rates, such as anthropogenic erosion and carbon cycling, co-evolution does not occur. Soil erosion can promote uptake or decomposition of organic matter (Lal, 2003; Doetterl et al., 2012; Lal, 2019) and carbon dynamics show interactions with water erosion (Yan et al., 2019). However, processes in the carbon cycle do not influence rates of tillage erosion, which is often the dominant erosion process in agricultural landscapes (Van Oost et al., 2005b; Van Oost et al., 2009; Kumar et al., 2018), and therefore the essential interactions between these processes are limited or absent.

Although the term co-evolution is widely, and sometimes loosely, applied to describe soil and landscape evolution in various settings (Phillips, 2009; Willgoose, 2018; Yan et al., 2019), I argue that soil-landscape co-evolution in intensively managed landscapes does not occur in the sense that it does in natural settings, because the essential interactions between landscape components are missing. The dominance of tillage erosion and human control on vegetation prevent natural feedbacks that can regulate the response of soils to anthropogenic disturbance. Rather, the response of soils to erosion under intense management simply comes down to the balance between impact of geomorphic and pedogenic processes, i.e. between soil degradation and soil formation (Johnson and Watson-Stegner, 1987; Lal, 1997), which varies per soil property and topographic position (e.g. Sommer et al., 2008).

\subsubsection{Co-evolution of landscapes and their management}

There is one aspect that interacts and co-evolves with the physical landscape: the management of that landscape. The decision to plough, fertilize, irrigate or drain an agricultural field is controlled by the physical state and functions of the landscape, and has the purpose to actively change that physical state or utilize its functions (Vogel et al., 2018). In other words, humans control the development of soils and landscapes, but their decision to do so depends on the conditions of the soils or landscape. In return, (unintended) effects of certain management strategies elsewhere in the landscape can lead to adjustments in management. Such feedbacks drive soil conservation measures and nature-based land 
management: adjustments in management are made to improve certain soil or landscape properties using the knowledge of the functioning of soils and landscapes.

Co-evolution of management and the physical landscape occurs in a large variety of settings (e.g. German, 2003; Brown, 2005; Van Apeldoorn et al., 2013; Tempels and Hartmann, 2014; Wang et al., 2015). To come back to the examples I gave in Section 6.2.1, channelized and managed rivers are currently restored to improve their water storing capacity and ecological values (Palmer and Bernhardt, 2006), and dammed estuaries are partly reconnected with oceanic tides and currents to improve living conditions for biota (Van Wesenbeeck et al., 2014). Agricultural fields are especially subject to changes in management to improve negative effects of earlier management. A few examples: fields are tilled less intense or not at all to prevent compaction and soil erosion (Blevins et al., 2018), crop production is optimized in a sustainable way with precision agriculture (Gebbers and Adamchuk, 2010), organic amendments are supplied to increase soil carbon stocks (Minasny et al., 2017), and some fields can be reforested to improve soil carbon stocks, biodiversity or water storage and water quality (Cunningham et al., 2015). Nature-based land management in agricultural fields aims to counteract degradation of landscape functions on local (e.g. productivity), regional (e.g. natural habitats) or global scale (e.g. carbon sequestration). Land management is thus an integral part of the development and evolution of anthropogenic landscapes and should be considered as an internal landscape component rather than an external driver when developing management strategies (Figure 6.2).
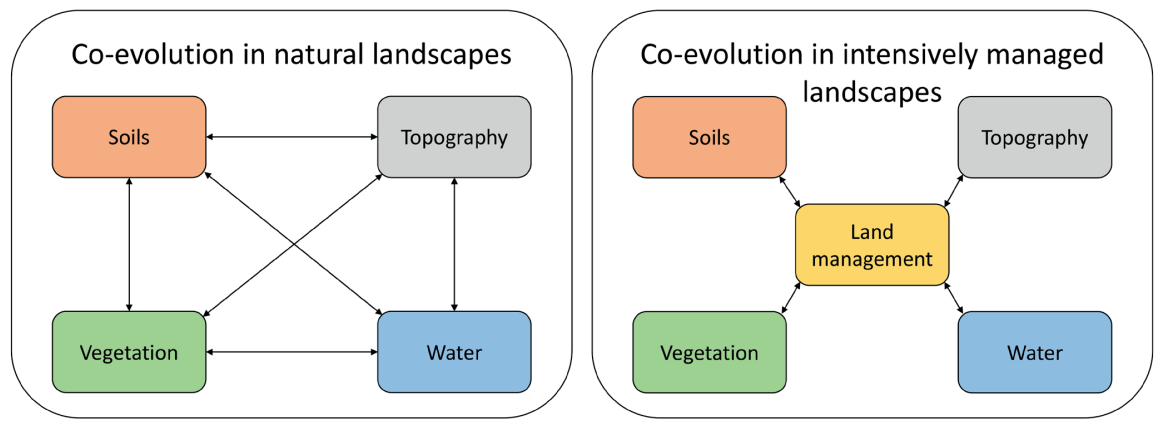

Figure 6.2: Co-evolution in natural and intensively managed landscapes.

Nature-based land management should consider the effects of previous and planned management on the integral landscape to acknowledge (past) anthropogenic control on soil- 
landscape change, utilize natural and anthropogenic landscape processes and prevent unwanted longer-term consequences of management elsewhere in the landscape (Kumar et al., 2018). Such a holistic approach balancing dynamics of water, sediments, solutes, carbon, organisms and yield can aid the development of sustainable land management that supports the environment and future generations. 


\subsection{Learned lessons and future directions}

In this thesis I provided reconstructions, rates and implications of anthropogenic forcing on soils and topography in intensively managed landscapes, using various methods. In this section I summarize the lessons learned in this thesis and suggest recommendations and directions for future research for different aspects of soil and landscape evolution studies. I end with a general conclusion.

Soil-landscape evolution in the Anthropocene. The findings from the research chapters and this synthesis provide the following lessons on long-term soil-landscape evolution in undulating landscapes under increasingly intensive management:

- Humans have influenced evolution of soils and landscapes through agricultural practices since pre-historic times.

- Soil and landscape evolution in intensively managed landscapes follows different pedogenic pathways compared to natural landscapes.

- The response of soils to erosion and deposition in intensively managed landscapes is a balance of soil formation and degradation with limited to absent interactions between pedogenic and geomorphic processes.

- Anthropogenic forcing on soils should be assessed per individual soil property, because each soil property responds at different rates to disturbances.

- Components of intensively managed landscapes co-evolve with their management rather than that they mutually co-evolve as happens in natural landscapes.

Data. In Chapters 2 and 3 I used data with high spatial density to identify patterns and rates of change in study site CarboZALF-D. This high density enabled a reconstruction of the preagricultural landscape pattern and provided surprising insights in the evolution of the landscape. Essential variations in soil properties and chronology might not have been identified when only few samples and observations would have been available for the study area. Such densely sampled study sites are essential for accurate determination of patterns and rates of landscape change. Also, such study sites can help identify key interactions between different domains of the landscape when they are designed for multi-disciplinary research. I therefore encourage the preservation and foundation of new interdisciplinary landscape laboratories such as CarboZALF-D (Sommer et al., 2016), Critical Zone Observatories (CZOs, Anderson et al., 2008), International Long Term Ecological Research 
networks (ILTERs, Mirtl et al., 2018) and other long-term field experiments. These landscape laboratories must be representative for their geographical setting, so that the findings can be extrapolated over a wider region. For example, the effects of anthropogenic erosion on soil and landscape patterns in CarboZALF-D are recognized in hummocky landscapes worldwide (e.g. Bedard-Haughn and Pennock, 2002). However, the chronology and land-use history represent a more regional signal and are therefore more representative for hummocky landscapes in the directly surrounding Uckermark catchment. A wide range of geographic regions should be covered by landscape laboratories to identify key environmental factors and drivers of soil-landscape evolution. I want to place extra emphasis on synthesizing existing temporal soil data from the rich body of literature, or gathering new temporal soil data, using chronosequences or palaeosols (e.g. Shepard, 2018; Targulian and Bronnikova, 2019). This information is essential for identifying and constraining pedogenic pathways (Stevens and Walker, 1970; Sauer, 2015; Shepard, 2018). Topographic information should be included too in future chronosequence studies to quantify spatial variation as well as temporal variation (Temme, 2019).

Geochronology. The stratigraphy and chronology of soils and sediments in intensively managed landscapes is subject to disturbance by various mixing processes. Especially postdepositional mixing by tillage can disturb chronologies. We illustrated this mechanism and provided a solution for OSL dating in Chapter 3. Correcting for post-depositional mixing by tillage increases uncertainty of deposition rates, but ignoring this dominant process will introduce a bias and can give false sense of certainty. The provided workflow is applicable for OSL dating in ploughed systems worldwide, as long as there are sufficient available archaeological sources for making a reconstruction of (pre-)historical land use. Our provided land-use reconstruction is applicable for northwestern Europe, but should be refined with local archaeological information to reduce uncertainty. Mixing by tillage also distorts other chronological proxies, such as radionuclide inventories and the depth of datable organic material such as pieces of charcoal. Dominant processes that are responsible for development and possible disturbances of chronologies should be identified prior to geochronological sampling through extensive soil-geomorphic research. Recognition of these dominant processes aids in selecting sampling sites and determine sampling density. OSL dating is an ideal tool for quantifying agricultural landscape change, because sampling density is not constrained by limited dating material and non-linear deposition. Also, depositional hiatuses 
can easily be identified when using high-density sampled chronologies. However, the relatively high uncertainty of derived ages and rates should be recognized and considered in the data analysis. A review of current geochronological applications in agricultural settings would facilitate the selection of proper methods for dating and analyzing colluvial sediments to distill ages and rates from these disturbed chronologies.

Soil-landscape evolution modeling. In Chapters 4 and 5 I coupled hydrological and ecological processes to a SLEM. These adjustments enable the simulation of soil evolution in both natural and agricultural landscapes and provide a promising platform for future improvements to SLEMs. The development and evaluation of modeling studies should be tightly coupled with other methods and tools to identify key processes and drivers and assess quality of model predictions. The current HydroLorica model is only applicable in loamy landscapes due to its limited process coverage. This is a challenge for all soil evolution models, but 3D soil-landscape evolution models lag behind in process coverage compared to e.g. 1D soil profile models (Minasny et al., 2015). A tighter coupling between dominant drivers such as water flow and soil and landscape processes can assist in including new processes and promote applicability in a wider range of geographic settings. However, first the methodological and knowledge gaps identified in Chapter 4 should be resolved. This requires joint efforts from modelers, soil physicists, pedologists, pedometricians and hydrologists. Model comparisons should be carried out to identify strengths and weaknesses of different models to guide future model developments and to perform more robust predictions of future soil development.

Evaluation of soil management strategies. A holistic approach is required when designing and evaluating soil management strategies; the soil is after all just one of the components of the landscape. A certain management can have unintended effects elsewhere in the landscape, and can do more harm than good in the long-term. Such effects should be taken into account when developing sustainable land management for restoring and improving soil and landscape functions. Close interaction between scientists and policy makers is required to develop effective and sustainable management adapted to the entire landscape.

Conclusion. Soils in intensively managed undulating landscapes underwent substantial changes throughout the Anthropocene. Increased anthropogenic forcing changed the dominant processes and drivers of soil and landscape evolution, increased rates of landscape 
change and created new characteristic soil patterns. Anthropogenic forcing affects each soil property differently, because each property responds to disturbances with different rates. Agricultural systems show co-evolution between the landscape and its management rather than co-evolution between individual landscape components as occurs in natural systems. A combination of reconstruction and simulation methods is essential for developing, constraining and testing hypotheses of soil and landscape evolution. Sustainable land management should use a holistic approach with a long-term view to prevent unwanted effects of a certain management strategy elsewhere in the landscape. 


\section{References}

Abiven, S., Menasseri, S., Chenu, C. 2009. The effects of organic inputs over time on soil aggregate stability - A literature analysis. Soil Biology and biochemistry 41 (1): 112. https://doi.org/10.1016/j.soilbio.2008.09.015

Ad-hoc-AG Boden. 2005. Bodenkundliche Kartieranleitung 5. In: Sponagel, H.; Grottenthaler, W.; Hartmann, K.-J.; Hartwich, R.; Janetzko, P.; Joisten, H.; Kühn, D.; Sabel, K.-J.; Traidl, R. (Editors), p 438, Hannover.

Ahrens, B., Braakhekke, M.C., Guggenberger, G., Schrumpf, M., Reichstein, M. 2015. Contribution of sorption, DOC transport and microbial interactions to the $14 \mathrm{C}$ age of a soil organic carbon profile: Insights from a calibrated process model. Soil Biology and biochemistry 390-402. https://doi.org/10.1016/j.soilbio.2015.06.008

Aitken, M.J. 1985. Thermoluminescence dating. Academic press, Orlando, Florida.

Al Majou, H., Bruand, A., Duval, O., Cousin, I. 2007. Variation of the water-retention properties of soils: Validity of class-pedotransfer functions. Comptes Rendus Geoscience 339 (9): 632-639. https://doi.org/10.1016/j.crte.2007.07.005

Alaoui, A., Lipiec, J., Gerke, H.H. 2011. A review of the changes in the soil pore system due to soil deformation: A hydrodynamic perspective. Soil and Tillage Research 115116: 1-15. https://doi.org/10.1016/j.still.2011.06.002

Aldana Jague, E., Sommer, M., Saby, N.P.A., Cornelis, J.-T., Van Wesemael, B., Van Oost, K. 2016. High resolution characterization of the soil organic carbon depth profile in a soil landscape affected by erosion. Soil and Tillage Research 156: 185-193. https://doi.org/10.1016/j.still.2015.05.014

Alewell, C., Egli, M., Meusburger, K. 2015. An attempt to estimate tolerable soil erosion rates by matching soil formation with denudation in Alpine grasslands. Journal of Soils and Sediments 15 (6): 1383-1399. https://doi.org/10.1007/s11368-014-0920-6

Alewell, C., Meusburger, K., Juretzko, G., Mabit, L., Ketterer, M.E. 2014. Suitability of 239+ $240 \mathrm{Pu}$ and $137 \mathrm{Cs}$ as tracers for soil erosion assessment in mountain grasslands. Chemosphere 103: 274-280. https://doi.org/10.1016/j.chemosphere.2013.12.016

Ali, G., Oswald, C., Spence, C., Wellen, C. 2018. The T-TEL Method for Assessing Water, Sediment, and Chemical Connectivity. Water Resources Research 54 (2): 634-662. https://doi.org/10.1002/2017WR020707

Allen, R.G., Pereira, L.S., Raes, D., Smith, M. 1998. Crop evapotranspiration-Guidelines for computing crop water requirements. Irrigation and drainage paper 56. FAO, Rome.

Ameli, A.A., Beven, K., Erlandsson, M., Creed, I.F., McDonnell, J.J., Bishop, K. 2017. Primary weathering rates, water transit times, and concentration-discharge relations: A theoretical analysis for the critical zone. Water Resources Research 53 (1): 942 960. https://doi.org/10.1002/2016WR019448

Amundson, R., Berhe, A.A., Hopmans, J.W., Olson, C., Sztein, A.E., Sparks, D.L. 2015. Soil and human security in the 21st century. Science 348 (6235): 1261071. https://doi.org/10.1126/science.1261071 
Amundson, R., Jenny, H. 1991. The place of humans in the state factor theory of ecosystems and their soils. Soil Science 151 (1): 99-109.

Andersen, T.B., Jensen, P.S., Skovsgaard, C.V. 2016. The heavy plow and the agricultural revolution in Medieval Europe. Journal of Development Economics 118: 133-149. https://doi.org/10.1016/j.jdeveco.2015.08.006

Anderson, H.A., Berrow, M.L., Farmer, V.C., Hepburn, A., Russell, J.D., Walker, A.D. 1982. A reassessment of podzol formation processes. Journal of Soil Science 33 (1): 125 136. https://doi.org/10.1111/j.1365-2389.1982.tb01753.x

Anderson, J.L., Bouma, J. 1973. Relationships between saturated hydraulic conductivity and morphometric data of an argillic horizon. Soil Science Society of America Journal 37 (3): 408-413. https://doi.org/10.2136/sssaj1973.03615995003700030029x

Anderson, S.P., Bales, R.C., Duffy, C.J. 2008. Critical Zone Observatories: Building a network to advance interdisciplinary study of Earth surface processes. Mineralogical Magazine $\quad 72 \quad$ (1): 10. https://doi.org/10.1180/minmag.2008.072.1.7

Andersson, G. 1998. Genesis of hummocky moraine in the Bolmen area, southwestern Sweden. Boreas 27 (1): 55-67. https://doi.org/10.1111/j.1502-3885.1998.tb00867.x

Angelini, M.E. 2018. Structural equation modelling for digital soil mapping. Wageningen University, Wageningen. $\mathrm{PhD}$ thesis

Angelini, M.E., Heuvelink, G.B.M., Kempen, B., Morrás, H.J.M. 2016. Mapping the soils of an Argentine Pampas region using structural equation modelling. Geoderma 281: 102-118. https://doi.org/10.1016/j.geoderma.2016.06.031

Angermann, L., Jackisch, C., Allroggen, N., Sprenger, M., Zehe, E., Tronicke, J., Weiler, M., Blume, T. 2017. Form and function in hillslope hydrology: characterization of subsurface flow based on response observations. Hydrology and Earth System Sciences 21 (7): 3727. https://doi.org/10.5194/hess-21-3727-2017

Anselmetti, F.S., Hodell, D.A., Ariztegui, D., Brenner, M., Rosenmeier, M.F. 2007. Quantification of soil erosion rates related to ancient Maya deforestation. Geology 35 (10): 915-918. https://doi.org/10.1130/g23834a.1

Arata, L., Alewell, C., Frenkel, E., A’Campo-Neuen, A., Iurian, A.-R., Ketterer, M.E., Mabit, L., Meusburger, K. 2016. Modelling Deposition and Erosion rates with RadioNuclides (MODERN) - Part 2: A comparison of different models to convert $239+240 \mathrm{Pu}$ inventories into soil redistribution rates at unploughed sites. Journal of Environmental Radioactivity 162-163: 97-106. https://doi.org/10.1016/j.jenvrad.2016.05.009

Armson, K.A., Fessenden, R.J. 1973. Forest windthrows and their influence on soil morphology. Soil Science Society of America Journal 37 (5): 781-783. https://doi.org/10.2136/sssaj1973.03615995003700050041x

Armstrong, A.C., Matthews, A.M., Portwood, A.M., Leeds-Harrison, P.B., Jarvis, N.J. 2000. CRACK-NP: a pesticide leaching model for cracking clay soils. Agricultural Water Management 44 (1): 183-199. https://doi.org/10.1016/S0378-3774(99)00091-8 
Arnold, L.J., Roberts, R.G. 2009. Stochastic modelling of multi-grain equivalent dose (De) distributions: Implications for OSL dating of sediment mixtures. Quaternary Geochronology 4 (3): 204-230. https://doi.org/10.1016/j.quageo.2008.12.001

Arnold, L.J., Roberts, R.G., Galbraith, R.F., DeLong, S.B. 2009. A revised burial dose estimation procedure for optical dating of youngand modern-age sediments. Quaternary Geochronology $\quad 4 \quad$ (4): https://doi.org/10.1016/j.quageo.2009.02.017

Baartman, J.E.M., Temme, A.J.A.M., Saco, P.M. 2018. The effect of landform variation on vegetation patterning and related sediment dynamics. Earth Surface Processes and Landforms 43 (10): 2121-2135. https://doi.org/10.1002/esp.4377

Baartman, J.E.M., Temme, A.J.A.M., Schoorl, J.M., Braakhekke, M.H.A., Veldkamp, T. 2012. Did tillage erosion play a role in millennial scale landscape development? Earth Surface Processes and Landforms 37 (15): 1615-1626. https://doi.org/10.1002/esp.3262

Baartman, J.E.M., Temme, A.J.A.M., Veldkamp, T., Jetten, V.G., Schoorl, J.M. 2013. Exploring the role of rainfall variability and extreme events in long-term landscape

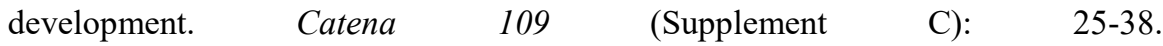
https://doi.org/10.1016/j.catena.2013.05.003

Bai, Z.G., Dent, D.L., Olsson, L., Schaepman, M.E. 2008. Proxy global assessment of land degradation. Soil Use and Management 24 (3): 223-234. https://doi.org/10.1111/j.1475-2743.2008.00169.x

Bajard, M., Poulenard, J., Sabatier, P., Develle, A.-L., Giguet-Covex, C., Jacob, J., Crouzet, C., David, F., Pignol, C., Arnaud, F. 2017. Progressive and regressive soil evolution phases in the Anthropocene. Catena 150: 39-52. https://doi.org/10.1016/j.catena.2016.11.001

Bajard, M., Sabatier, P., David, F., Develle, A.-L., Reyss, J.-L., Fanget, B., Malet, E., Arnaud, D., Augustin, L., Crouzet, C., Poulenard, J., Arnaud, F. 2015. Erosion record in Lake La Thuile sediments (Prealps, France): Evidence of montane landscape dynamics throughout the Holocene. The Holocene $26 \quad$ (3): 350-364. https://doi.org/10.1177/0959683615609750

Bakker, M.M., Govers, G., Kosmas, C., Vanacker, V., Van Oost, K., Rounsevell, M. 2005. Soil erosion as a driver of land-use change. Agriculture, Ecosystems \& Environment 105 (3): 467-481. https://doi.org/10.1016/j.agee.2004.07.009

Barto, E.K., Alt, F., Oelmann, Y., Wilcke, W., Rillig, M.C. 2010. Contributions of biotic and abiotic factors to soil aggregation across a land use gradient. Soil Biology and biochemistry 42 (12): 2316-2324. https://doi.org/10.1016/j.soilbio.2010.09.008

Becze-Deàk, J., Langohr, R., Verrecchia, E.P. 1997. Small scale secondary CaCO3 accumulations in selected sections of the European loess belt. Morphological forms and potential for paleoenvironmental reconstruction. Geoderma 76 (3): 221-252. https://doi.org/10.1016/S0016-7061(96)00106-1 
Bedard-Haughn, A.K., Pennock, D.J. 2002. Terrain controls on depressional soil distribution in a hummocky morainal landscape. Geoderma 110 (3-4): 169-190. https://doi.org/10.1016/S0016-7061(02)00229-X

Beerten, K., Deforce, K., Mallants, D. 2012. Landscape evolution and changes in soil hydraulic properties at the decadal, centennial and millennial scale: A case study from the Campine area, northern Belgium. Catena 95 (Supplement C): 73-84. https://doi.org/10.1016/j.catena.2012.03.005

Behre, K.-E. 2008. Landschaftsgeschichte Norddeutschlands: Umwelt und Siedlung von der Steinzeit bis zur Gegenwart. Wachholtz, Hamburg.

Berger, G.W., Mahaney, W.C. 1990. Test of thermoluminescence dating of buried soils from Mt. Kenya, Kenya. Sedimentary Geology $66 \quad$ (1): 45-56. https://doi.org/10.1016/0037-0738(90)90005-E

Bergonse, R., Reis, E. 2015. Reconstructing pre-erosion topography using spatial interpolation techniques: A validation-based approach. Journal of Geographical Sciences 25 (2): 196-210. https://doi.org/10.1007/s11442-015-1162-2

Bertolino, A.V.F.A., Fernandes, N.F., Miranda, J.P.L., Souza, A.P., Lopes, M.R.S., Palmieri, F. 2010. Effects of plough pan development on surface hydrology and on soil physical properties in Southeastern Brazilian plateau. Journal of Hydrology 393 (1): 94-104. https://doi.org/10.1016/j.jhydrol.2010.07.038

Beven, K., Germann, P. 2013. Macropores and water flow in soils revisited. Water Resources Research 49 (6): 3071-3092. https://doi.org/10.1002/wrcr.20156

Beven, K.J., Kirkby, M.J., Schofield, N., Tagg, A.F. 1984. Testing a physically-based flood forecasting model (TOPMODEL) for three UK catchments. Journal of Hydrology 69 (1-4): 119-143. https://doi.org/10.1016/0022-1694(84)90159-8

BGR. 2008. Bodengroßlandschaften von Deutschland 1: 5000000 (BGL5000) v2.0.

Bibby, J.S., Mackney, D. 1969. Land use capability classification. Rothamsted Experimental Station, Harpenden, England.

Birkeland, P.W. 1992. Quaternary soil chronosequences in various environments - extremely arid to humid tropical. In: Martini, I.P.; Chesworth, W. (Editors), Weathering, soils \& paleosols, 261-281. Elsevier, Amsterdam.

Blanco-Canqui, H., Lal, R. 2008. Wind Erosion. Principles of Soil Conservation and Management, 55-80. Springer Netherlands, Dordrecht.

Blevins, R.L., Lal, R., Doran, J.W., Langdale, G.W., Frye, W.W. 2018. Conservation tillage for erosion control and soil quality. In: Pierce, F.J.; Frye, W.W. (Editors), Advances in soil and water conservation, 51-68. Routledge, London.

Blöschl, G., Sivapalan, M. 1995. Scale issues in hydrological modelling: a review. Hydrological Processes 9 (3-4): 251-290. https://doi.org/10.1002/hyp.3360090305

Blum, W.E.H. 2005. Functions of soil for society and the environment. Reviews in Environmental Science and Bio/Technology $4 \quad$ (3): 75-79. https://doi.org/10.1007/s11157-005-2236-X

Blume, H.-P., Brümmer, G.W., Fleige, H., Horn, R., Kandeler, E., Kögel-Knabner, I., Kretzschmar, R., Stahr, K., Wilke, B.-M. 2016. Soil Geography. 
Scheffer/SchachtschabelSoil Science, 391-408. Springer Berlin Heidelberg, Berlin, Heidelberg.

Blume, H.-P., Leinweber, P. 2004. Plaggen Soils: landscape history, properties, and classification. Journal of Plant Nutrition and Soil Science 167 (3): 319-327. https://doi.org/10.1002/jpln.200420905

Bodner, G., Scholl, P., Loiskandl, W., Kaul, H.P. 2013. Environmental and management influences on temporal variability of near saturated soil hydraulic properties. Geoderma 204-205: 120-129. https://doi.org/10.1016/j.geoderma.2013.04.015

Bogaard, A. 2004. Neolithic farming in central Europe: an archaeobotanical study of crop husbandry practices. Routledge, London.

Boivin, P., Garnier, P., Tessier, D. 2004. Relationship between clay content, clay type, and shrinkage properties of soil samples. Soil Science Society of America Journal 68 (4): 1145-1153. https://doi.org/10.2136/sssaj2004.1145

Boll, J., Brooks, E.S., Crabtree, B., Dun, S., Steenhuis, T.S. 2015. Variable source area hydrology modeling with the water erosion prediction project model. Journal of the American Water Resources Association $51 \quad$ (2): 330-342. https://doi.org/10.1111/1752-1688.12294

Boorman, D.B., Hollis, J.M., Lilly, A. 1995. Hydrology of soil types: a hydrologically-based classification of the soils of United Kingdom. Institute of Hydrology, Wallingford, UK.

Borrelli, P., Robinson, D.A., Fleischer, L.R., Lugato, E., Ballabio, C., Alewell, C., Meusburger, K., Modugno, S., Schütt, B., Ferro, V., Bagarello, V., Van Oost, K., Montanarella, L., Panagos, P. 2017. An assessment of the global impact of $21 \mathrm{st}$ century land use change on soil erosion. Nature Communications 8 (1): 2013. https://doi.org/10.1038/s41467-017-02142-7

Bouchoms, S., Wang, Z., Vanacker, V., Doetterl, S., Van Oost, K. 2017. Modelling longterm soil organic carbon dynamics under the impact of land cover change and soil redistribution. Catena 151: 63-73. https://doi.org/10.1016/j.catena.2016.12.008

Bouma, J. 2006. Hydropedology as a powerful tool for environmental policy research. Geoderma 131 (3): 275-286. https://doi.org/10.1016/j.geoderma.2005.03.009

Bouma, J. 2014. Soil science contributions towards sustainable development goals and their implementation: linking soil functions with ecosystem services. Journal of Plant $\begin{array}{lllll}\text { Nutrition } \quad \text { and Soil } & \text { Science } & 177 & \text { (2): }\end{array}$ https://doi.org/10.1002/jpln.201300646

Bouma, J., Jongmans, A.G., Stein, A., Peek, G. 1989. Characterizing spatially variable hydraulic properties of a boulder clay deposit in the Netherlands. Geoderma 45 (1): 19-29. https://doi.org/10.1016/0016-7061(89)90054-2

Bourennane, H., King, D., Couturier, A. 2000. Comparison of kriging with external drift and simple linear regression for predicting soil horizon thickness with different sample densities. Geoderma 97 (3-4): 255-271. http://dx.doi.org/10.1016/S00167061(00)00042-2 
Bourgault, R.R., Ross, D.S., Bailey, S.W. 2015. Chemical and morphological distinctions between vertical and lateral podzolization at Hubbard Brook. Soil Science Society of America Journal 79 (2): 428-439. https://doi.org/10.2136/sssaj2014.05.0190

Brantley, S.L. 2008. Understanding Soil Time. Science 321 (5895): 1454-1455. https://doi.org/10.1126/science.1161132

Brasington, J., Richards, K. 2007. Reduced-complexity, physically-based geomorphological modelling for catchment and river management. Geomorphology 90 (3): 171-177. https://doi.org/10.1016/j.geomorph.2006.10.028

Brierley, G., Fryirs, K., Jain, V. 2006. Landscape connectivity: the geographic basis of geomorphic applications. Area 38 (2): 165-174. https://doi.org/10.1111/j.1475$\underline{\text { 4762.2006.00671.x }}$

Bronick, C.J., Lal, R. 2005. Soil structure and management: a review. Geoderma 124 (1): 322. https://doi.org/10.1016/j.geoderma.2004.03.005

Bronk Ramsey, C. 2008. Deposition models for chronological records. Quaternary Science Reviews 27 (1-2): 42-60. https://doi.org/10.1016/j.quascirev.2007.01.019

Bronk Ramsey, C. 2009. Bayesian analysis of radiocarbon dates. Radiocarbon 51 (1): 337360. https://doi.org/10.1017/S0033822200033865

Brooks, E.S., Boll, J., McDaniel, P.A. 2004. A hillslope-scale experiment to measure lateral saturated hydraulic conductivity. Water Resources Research 40 W04208. https://doi.org/10.1029/2003WR002858

Brooks, E.S., Boll, J., McDaniel, P.A. 2012. Chapter 10 - Hydropedology in Seasonally Dry Landscapes: The Palouse Region of the Pacific Northwest USA In: Lin, H.S. (Editor), Hydropedology, 329-350. Academic Press, Boston.

Brooks, S.M., Richards, K.S. 1993. Establishing the role of pedogenesis in changing soil hydraulic properties. Earth Surface Processes and Landforms 18 (6): 573-578. https://doi.org/10.1002/esp.3290180609

Brown, J.D., Heuvelink, G.B.M. 2006. Assessing uncertainty propagation through physically based models of soil water flow and solute transport. Encyclopedia of hydrological sciences: 1181-1195. John Wiley \& Sons, Ltd.

Brown, M.T. 2005. Landscape restoration following phosphate mining: 30 years of coevolution of science, industry and regulation. Ecological Engineering 24 (4): 309329. https://doi.org/10.1016/j.ecoleng.2005.01.014

Brubaker, S.C., Holzhey, C.S., Brasher, B.R. 1992. Estimating the water-dispersible clay content of soils. Soil Science Society of America Journal 56 (4): 1226-1232. https://doi.org/10.2136/sssaj1992.03615995005600040036x

Brus, D.J., Heuvelink, G.B.M. 2007. Optimization of sample patterns for universal kriging $\begin{array}{lllll}\text { of environmental variables. Geoderma } 138 & \text { (1-2): }\end{array}$ https://doi.org/10.1016/j.geoderma.2006.10.016

Budyko, M.I., Miller, D.H. 1974. Climate and life. Academic press, New York.

Butzer, K.W. 1974. Accelerated soil erosion: a problem of man-land relationships. In: Manners, I. R., Allikesell, M.W. (Editors), Perspectives on the Environment, 57-78. Association of American Geographers, Washington, D.C.. 
Calitri, F., Sommer, M., Norton, K., Temme, A.J.A.M., Brandová, D., Portes, R., Christl, M., Ketterer, M.E., Egli, M. 2019. Tracing the temporal evolution of soil redistribution rates in an agricultural landscape using $239+240 \mathrm{Pu}$ and $10 \mathrm{Be}$. Earth Surface Processes and Landforms 44 (9): 1783-1798. https://doi.org/10.1002/esp.4612

Campforts, B., Vanacker, V., Vanderborght, J., Baken, S., Smolders, E., Govers, G. 2016. Simulating the mobility of meteoric $10 \mathrm{Be}$ in the landscape through a coupled soilhillslope model (Be2D). Earth and Planetary Science Letters 439: 143-157. https://doi.org/10.1016/j.eps1.2016.01.017

Carré, F., Caudeville, J., Bonnard, R., Bert, V., Boucard, P., Ramel, M. 2017. Soil Contamination and Human Health: A Major Challenge for Global Soil Security. In: Field, D.J.; Morgan, C.L.S.; McBratney, A.B. (Editors), Global Soil Security, 275295. Springer International Publishing, Cham.

Catt, J.A. 2001. The agricultural importance of loess. Earth-Science Reviews 54 (1): 213229. https://doi.org/10.1016/S0012-8252(01)00049-6

Cerdan, O., Govers, G., Le Bissonnais, Y., Van Oost, K., Poesen, J., Saby, N., Gobin, A., Vacca, A., Quinton, J., Auerswald, K., Klik, A., Kwaad, F.J.P.M., Raclot, D., Ionita, I., Rejman, J., Rousseva, S., Muxart, T., Roxo, M.J., Dostal, T. 2010. Rates and spatial variations of soil erosion in Europe: A study based on erosion plot data. Geomorphology 122 (1): 167-177. https://doi.org/10.1016/j.geomorph.2010.06.011

Cerdan, O., Souchère, V., Lecomte, V., Couturier, A., Le Bissonnais, Y. 2002. Incorporating soil surface crusting processes in an expert-based runoff model: Sealing and Transfer by Runoff and Erosion related to Agricultural Management. Catena 46 (2): 189-205. https://doi.org/10.1016/S0341-8162(01)00166-7

Chadwick, O.A., Chorover, J. 2001. The chemistry of pedogenic thresholds. Geoderma 100 (3): 321-353. https://doi.org/10.1016/S0016-7061(01)00027-1

Chamberlain, E.L., Goodbred, S.L., Hale, R., Steckler, M.S., Wallinga, J., Wilson, C. 2019. Integrating geochronologic and instrumental approaches across the Bengal Basin. Earth Surface Processes and Landforms 45: 56-74. https://doi.org/10.1002/esp.4687

Chamberlain, E.L., Wallinga, J., Shen, Z. 2018. Luminescence age modeling of variablybleached sediment: Model selection and input. Radiation Measurements 120: 221227. https://doi.org/10.1016/j.radmeas.2018.06.007

Chanasyk, D.S., Mapfumo, E., Willms, W. 2003. Quantification and simulation of surface runoff from fescue grassland watersheds. Agricultural Water Management 59 (2): 137-153. https://doi.org/10.1016/S0378-3774(02)00124-5

Chappell, A., Baldock, J., Sanderman, J. 2015. The global significance of omitting soil erosion from soil organic carbon cycling schemes. Nature Climate Change 6: 187. https://doi.org/10.1038/nclimate2829

Chorover, J., Troch, P.A., Rasmussen, C., Brooks, P.D., Pelletier, J.D., Breshears, D.D., Huxman, T.E., Kurc, S.A., Lohse, K.A., McIntosh, J.C. 2011. How water, carbon, and energy drive critical zone evolution: The Jemez-Santa Catalina Critical Zone 
Observatory. Vadose Zone Journal $10 \quad$ (3): 884-899.

https://doi.org/10.2136/vzj2010.0132

Christakos, G. 2000. Modern spatiotemporal geostatistics. Oxford University Press, Oxford.

Christiaens, K., Feyen, J. 2001. Analysis of uncertainties associated with different methods to determine soil hydraulic properties and their propagation in the distributed hydrological MIKE SHE model. Journal of Hydrology 246 (1): 63-81. https://doi.org/10.1016/S0022-1694(01)00345-6

Clark, M.P., Fan, Y., Lawrence, D.M., Adam, J.C., Bolster, D., Gochis, D.J., Hooper, R.P., Kumar, M., Leung, L.R., Mackay, D.S., Maxwell, R.M., Shen, C., Swenson, S.C., Zeng, X. 2015. Improving the representation of hydrologic processes in Earth System Models. Water Resources Research 51 (8): 5929-5956. https://doi.org/10.1002/2015WR017096

Clemens, G., Stahr, K. 1994. Present and past soil erosion rates in catchments of the $\begin{array}{llllll}\text { Kraichgau area (SW-Germany). Catena } 22 & \text { (2): 153-168. }\end{array}$ https://doi.org/10.1016/0341-8162(94)90023-X

Cohen, S., Willgoose, G., Svoray, T., Hancock, G., Sela, S. 2015. The effects of sediment transport, weathering, and aeolian mechanisms on soil evolution. Journal of Geophysical Research: Earth Surface 120 (2): 260-274. https://doi.org/10.1002/2014JF003186

Compton, J.S., Herbert, C.T., Hoffman, M.T., Schneider, R.R., Stuut, J.-B. 2010. A tenfold increase in the Orange River mean Holocene mud flux: implications for soil erosion in South Africa. The Holocene 20 (1): 115-122. https://doi.org/10.1177/0959683609348860

Conrad, O., Bechtel, B., Bock, M., Dietrich, H., Fischer, E., Gerlitz, L., Wehberg, J., Wichmann, V., Böhner, J. 2015. System for Automated Geoscientific Analyses (SAGA) v. 2.1.4. Geoscientific Model Development 8 (7): 1991-2007. https://doi.org/10.5194/gmd-8-1991-2015

Cornu, S., Quénard, L., Cousin, I., Samouëlian, A. 2014. Experimental approach of lessivage: Quantification and mechanisms. Geoderma 213 (0): 357-370. http://dx.doi.org/10.1016/j.geoderma.2013.08.012

Cowie, A.L., Orr, B.J., Castillo Sanchez, V.M., Chasek, P., Crossman, N.D., Erlewein, A., Louwagie, G., Maron, M., Metternicht, G.I., Minelli, S., Tengberg, A.E., Walter, S., Welton, S. 2018. Land in balance: The scientific conceptual framework for Land Degradation Neutrality. Environmental Science \& Policy 79: 25-35. https://doi.org/10.1016/j.envsci.2017.10.011

Crutzen, P.J. 2002. Geology of mankind. Nature 415 (6867): 23-23. https://doi.org/10.1038/415023a

Cunningham, A.C., Wallinga, J. 2012. Realizing the potential of fluvial archives using robust OSL chronologies. Quaternary Geochronology 12: 98-106. https://doi.org/10.1016/j.quageo.2012.05.007

Cunningham, S.C., Mac Nally, R., Baker, P.J., Cavagnaro, T.R., Beringer, J., Thomson, J.R., Thompson, R.M. 2015. Balancing the environmental benefits of reforestation in 
agricultural regions. Perspectives in Plant Ecology, Evolution and Systematics 17 (4): 301-317. https://doi.org/10.1016/j.ppees.2015.06.001

Daniels, R.B., Gamble, E.E. 1967. The edge effect in some Ultisols in the North Carolina Coastal Plain. Geoderma 1 (2): 117-124. https://doi.org/10.1016/00167061(67)90003-1

Davidson, E.A., Janssens, I.A. 2006. Temperature sensitivity of soil carbon decomposition and feedbacks to climate change. Nature 440 (7081): 165. https://doi.org/10.1038/nature04514

Davies, B.R., Biggs, J., Williams, P.J., Lee, J.T., Thompson, S. 2008. A comparison of the catchment sizes of rivers, streams, ponds, ditches and lakes: implications for protecting aquatic biodiversity in an agricultural landscape. Hydrobiologia 597 (1): 7-17. https://doi.org/10.1007/s10750-007-9227-6

Davis, B.M. 1987. Uses and abuses of cross-validation in geostatistics. Mathematical Geology 19 (3): 241-248. https://doi.org/10.1007/bf00897749

De Alba, S., Lindstrom, M., Schumacher, T.E., Malo, D.D. 2004. Soil landscape evolution due to soil redistribution by tillage: a new conceptual model of soil catena evolution in agricultural landscapes. Catena 58 (1): 77-100. https://doi.org/10.1016/j.catena.2003.12.004

De Jonge, L.W., Moldrup, P., Vendelboe, A.L., Tuller, M., Wildenschild, D. 2012. Soil Architecture and Physicochemical Functions: An Introduction. Vadose Zone Journal 11 (1). https://doi.org/10.2136/vzj2011.0185

De Oliveira, V. 2012. Bayesian inference and prediction of Gaussian random fields based on censored data. Journal of Computational and Graphical Statistics. https://doi.org/10.1198/106186005X27518

De Vos, B., Cools, N., Ilvesniemi, H., Vesterdal, L., Vanguelova, E., Carnicelli, S. 2015. Benchmark values for forest soil carbon stocks in Europe: Results from a large scale forest soil survey. Geoderma 251-252: 33-46. https://doi.org/10.1016/j.geoderma.2015.03.008

Deumlich, D., Schmidt, R., Sommer, M. 2010. A multiscale soil-landform relationship in the glacial-drift area based on digital terrain analysis and soil attributes. Journal of Plant Nutrition and Soil Science $173 \quad$ (6): $843-851$. https://doi.org/10.1002/jpln.200900094

Dexter, A.R., Czyż, E.A., Richard, G., Reszkowska, A. 2008. A user-friendly water retention function that takes account of the textural and structural pore spaces in soil. Geoderma 143 (3): 243-253. https://doi.org/10.1016/j.geoderma.2007.11.010

Diaz, R.J., Rosenberg, R. 2008. Spreading Dead Zones and Consequences for Marine Ecosystems. Science 321 (5891): 926-929. https://doi.org/10.1126/science.1156401

Ding, D., Zhao, Y., Feng, H., Peng, X., Si, B. 2016. Using the double-exponential water retention equation to determine how soil pore-size distribution is linked to soil texture. Soil and Tillage Research 156 (Supplement C): 119-130. https://doi.org/10.1016/j.still.2015.10.007 
Doetterl, S., Berhe, A.A., Nadeu, E., Wang, Z., Sommer, M., Fiener, P. 2016. Erosion, deposition and soil carbon: A review of process-level controls, experimental tools and models to address $\mathrm{C}$ cycling in dynamic landscapes. Earth-Science Reviews 154: 102-122. http://dx.doi.org/10.1016/j.earscirev.2015.12.005

Doetterl, S., Six, J., Van Wesemael, B., Van Oost, K. 2012. Carbon cycling in eroding landscapes: geomorphic controls on soil organic $\mathrm{C}$ pool composition and $\mathrm{C}$ stabilization. Global Change Biology $18 \quad$ (7): 2218-2232. https://doi.org/10.1111/j.1365-2486.2012.02680.x

Dominati, E., Patterson, M., Mackay, A. 2010. A framework for classifying and quantifying the natural capital and ecosystem services of soils. Ecological Economics 69 (9): 1858-1868. https://doi.org/10.1016/j.ecolecon.2010.05.002

Dotterweich, M. 2008. The history of soil erosion and fluvial deposits in small catchments of central Europe: Deciphering the long-term interaction between humans and the environment - A review. Geomorphology 101 (1-2): 192-208. https://doi.org/10.1016/j.geomorph.2008.05.023

Dotterweich, M., Ivester, A.H., Hanson, P.R., Larsen, D., Dye, D.H. 2014. Natural and human-induced prehistoric and historical soil erosion and landscape development in Southwestern Tennessee, USA. Anthropocene 8: 6-24. https://doi.org/10.1016/j.ancene.2015.05.003

Doupoux, C., Merdy, P., Montes, C.R., Nunan, N., Melfi, A.J., Pereira, O.J.R., Lucas, Y. 2017. Modelling the genesis of equatorial podzols: age and implications for carbon fluxes. Biogeosciences 14 (9): 2429. https://doi.org/10.5194/bg-14-2429-2017

Downer, C.W., Ogden, F.L. 2004. Appropriate vertical discretization of Richards' equation for two-dimensional watershed-scale modelling. Hydrological Processes 18 (1): 122. https://doi.org/10.1002/hyp.1306

Dreibrodt, S., Lubos, C., Terhorst, B., Damm, B., Bork, H.R. 2010. Historical soil erosion by water in Germany: Scales and archives, chronology, research perspectives. Quaternary International $222 \quad$ (1-2): https://doi.org/10.1016/j.quaint.2009.06.014

Dreibrodt, S., Nelle, O., Lütjens, I., Mitusov, A., Clausen, I., Bork, H.-R. 2009. Investigations on buried soils and colluvial layers around Bronze Age burial mounds at Bornhöved (northern Germany): an approach to test the hypothesis of landscape openness' by the incidence of colluviation. The Holocene 19 (3): 487-497. https://doi.org/10.1177/0959683608101397

Du, E., Rhett Jackson, C., Klaus, J., McDonnell, J.J., Griffiths, N.A., Williamson, M.F., Greco, J.L., Bitew, M. 2016. Interflow dynamics on a low relief forested hillslope: Lots of fill, little spill. Journal of Hydrology 534: 648-658. https://doi.org/10.1016/j.jhydrol.2016.01.039

Dudal, R. 2005. The sixth factor of soil formation. Eurasian Soil Science 38 (1): S60-S65.

Duller, G.A.T. 2008. Single-grain optical dating of Quaternary sediments: why aliquot size matters in luminescence dating. Boreas 37 (4): 589-612. https://doi.org/10.1111/j.1502-3885.2008.00051.x 
Dümig, A., Smittenberg, R., Kögel-Knabner, I. 2011. Concurrent evolution of organic and mineral components during initial soil development after retreat of the Damma $\begin{array}{lllll}\text { glacier, } & \text { Switzerland. } & \text { Geoderma } & 163 & \text { (1): }\end{array}$ https://doi.org/10.1016/j.geoderma.2011.04.006

Dunne, T., Black, R.D. 1970. Partial area contributions to storm runoff in a small New England watershed. Water Resources Research 6 (5): 1296-1311. https://doi.org/10.1029/WR006i005p01296

Dürr, H.H., Meybeck, M., Dürr, S.H. 2005. Lithologic composition of the Earth's continental surfaces derived from a new digital map emphasizing riverine material transfer. Global Biogeochemical Cycles $19 \quad$ GB4S10. https://doi.org/10.1029/2005GB002515

DWD Climate Data Center (CDC). 2017a. Historical daily station observations (temperature, pressure, precipitation, sunshine duration, etc.) for Germany, version v005.

DWD Climate Data Center (CDC). 2017b. Historical hourly station observations of precipitation for Germany, version v005.

DWD Climate Data Center (CDC). 2018a. Historical daily station observations (temperature, pressure, precipitation, sunshine duration, etc.) for Germany, version v006.

DWD Climate Data Center (CDC). 2018b. Historical hourly station observations of precipitation for Germany, version v006.

Egli, M., Brandová, D., Böhlert, R., Favilli, F., Kubik, P.W. 2010. 10Be inventories in Alpine soils and their potential for dating land surfaces. Geomorphology 119 (1-2): 62-73. https://doi.org/10.1016/j.geomorph.2010.02.019

Egli, M., Fitze, P. 2001. Quantitative aspects of carbonate leaching of soils with differing ages and climates. Catena 46 (1): 35-62. https://doi.org/10.1016/S0341$\underline{8162(01) 00154-0}$

Egli, M., Wernli, M., Kneisel, C., Haeberli, W. 2006. Melting glaciers and soil development in the proglacial area Morteratsch (Swiss Alps): I. Soil type chronosequence. Arctic, Antarctic, and Alpine Research 38 (4): 499-509. https://doi.org/10.1657/15230430(2006)38[510:MGASDI]2.0.CO;2

Ehrlich, P.R., Raven, P.H. 1964. Butterflies and plants: a study in coevolution. Evolution 18 (4): 586-608. https://doi.org/10.1111/j.1558-5646.1964.tb01674.x

Ellis, B., Foth, H. 1996. Soil fertility. CRC Press, Boca Raton, Florida.

Ellis, E.C., Haff, P.K. 2009. Earth Science in the Anthropocene: New Epoch, New Paradigm, New Responsibilities. Eos, Transactions American Geophysical Union 90 (49): 473-473. https://doi.org/10.1029/2009eo490006

Ellis, E.C., Klein Goldewijk, K., Siebert, S., Lightman, D., Ramankutty, N. 2010. Anthropogenic transformation of the biomes, 1700 to 2000. Global Ecology and Biogeography 19 (5): 589-606. https://doi.org/10.1111/j.1466-8238.2010.00540.x

Elmer, M., Gerwin, W., Schaaf, W., Zaplata, M.K., Hohberg, K., Nenov, R., Bens, O., Hüttl, R.F. 2013. Dynamics of initial ecosystem development at the artificial catchment Chicken Creek, Lusatia, Germany. Environmental Earth Sciences 69 (2): 491-505. https://doi.org/10.1007/s12665-013-2330-2 
Enters, D., Dörfler, W., Zolitschka, B. 2008. Historical soil erosion and land-use change during the last two millennia recorded in lake sediments of Frickenhauser See, northern Bavaria, central Germany. The Holocene 18 (2): 243-254. https://doi.org/10.1177/0959683607086762

Eriksson, M.G., Olley, J.M., Payton, R.W. 2000. Soil erosion history in central Tanzania based on OSL dating of colluvial and alluvial hillslope deposits. Geomorphology 36 (1): 107-128. https://doi.org/10.1016/S0169-555X(00)00054-4

European Commission. 2015. Nature-Based Solutions | Environment, Research \& Innovation - European Commission. Retrieved: 12-11-2015. from https://ec.europa.eu/research/environment/index.cfm?pg=nbs

FAO. 2006. Guidelines for soil description, Rome.

Favis-Mortlock, D., Boardman, J., Bell, M. 1997. Modelling long-term anthropogenic erosion of a loess cover: South Downs, UK. The Holocene 7 (1): 79-89. https://doi.org/10.1177/095968369700700107

Fick, S.E., Hijmans, R.J. 2017. WorldClim 2: new 1-km spatial resolution climate surfaces for global land areas. International Journal of Climatology 37 (12): 4302-4315. https://doi.org/10.1002/joc.5086

Fiedler, S., Sommer, M. 2004. Water and Redox Conditions in Wetland Soils - Their Influence on Pedogenic Oxides and Morphology. Soil Science Society of America Journal 68 (1): 326-335. https://doi.org/doi:10.2136/sssaj2004.3260

Filipović, V., Gerke, H.H., Filipović, L., Sommer, M. 2018. Quantifying subsurface lateral flow along sloping horizon boundaries in soil profiles of a hummocky ground moraine. Vadose Zone Journal 17:170106. https://doi.org/10.2136/vzj2017.05.0106

Finke, P.A. 2012. Modeling the genesis of luvisols as a function of topographic position in loess parent material. Quaternary International 265: 3-17. https://doi.org/10.1016/j.quaint.2011.10.016

Finke, P.A., Hutson, J.L. 2008. Modelling soil genesis in calcareous loess. Geoderma 145 (3): 462-479. https://doi.org/10.1016/j.geoderma.2008.01.017

Finke, P.A., Samouëlian, A., Suarez-Bonnet, M., Laroche, B., Cornu, S.S. 2015. Assessing the usage potential of SoilGen2 to predict clay translocation under forest and agricultural land uses. European Journal of Soil Science 66 (1): 194-205. https://doi.org/10.1111/ejss.12190

Finke, P.A., Vanwalleghem, T., Opolot, E., Poesen, J., Deckers, J. 2013. Estimating the effect of tree uprooting on variation of soil horizon depth by confronting pedogenetic simulations to measurements in a Belgian loess area. Journal of Geophysical Research: Earth Surface 118 (4): 2124-2139. https://doi.org/10.1002/jgrf.20153

Fischer-Zujkov, U. 2001. Die Schwarzerden Nordostdeutschlands. Humboldt-Universität zu Berlin, Mathematisch-Naturwissenschaftliche Fakultät II. PhD thesis

Formann, E., Habersack, H.M., Schober, S. 2007. Morphodynamic river processes and techniques for assessment of channel evolution in Alpine gravel bed rivers. Geomorphology 90 (3): 340-355. https://doi.org/10.1016/j.geomorph.2006.10.029 
Fox, M. 2019. A linear inverse method to reconstruct paleo-topography. Geomorphology 337: 151-164. https://doi.org/10.1016/j.geomorph.2019.03.034

Fridley, B.L., Dixon, P. 2007. Data augmentation for a Bayesian spatial model involving $\begin{array}{lllll}\text { censored observations. } & \text { Environmetrics } 18 & \text { (2): }\end{array}$ https://doi.org/10.1002/env.806

Frielinghaus, M., Vahrson, W.-G. 1998. Soil translocation by water erosion from agricultural cropland into wet depressions (morainic kettle holes). Soil and Tillage Research 46 (1): 23-30. https://doi.org/10.1016/S0167-1987(98)80104-9

Fuchs, M., Lang, A. 2009. Luminescence dating of hillslope deposits-a review. Geomorphology 109 (1-2): 17-26. https://doi.org/10.1016/j.geomorph.2008.08.025

Fussell, G.E. 1966. Ploughs and Ploughing before 1800. Agricultural History 40 (3): 177186.

Gabet, E.J., Reichman, O.J., Seabloom, E.W. 2003. The effects of bioturbation on soil processes and sediment transport. Annual Review of Earth and Planetary Sciences 31 (1): 249-273. https://doi.org/10.1146/annurev.earth.31.100901.141314

Galbraith, R.F., Roberts, R.G. 2012. Statistical aspects of equivalent dose and error calculation and display in OSL dating: An overview and some recommendations. Quaternary Geochronology 11: 1-27. https://doi.org/10.1016/j.quageo.2012.04.020

Galbraith, R.F., Roberts, R.G., Laslett, G.M., Yoshida, H., Olley, J.M. 1999. Optical dating of single and multiple grains of quartz from Jinmium rock shelter, northern Australia: part I, experimental design and statistical models. Archaeometry 41 (2): 339-364. https://doi.org/10.1111/j.1475-4754.1999.tb00987.x

Gallaway, J.M., Martin, Y.E., Johnson, E.A. 2009. Sediment transport due to tree root throw: integrating tree population dynamics, wildfire and geomorphic response. Earth Surface Processes and Landforms $34 \quad$ (9): 1255-1269. https://doi.org/10.1002/esp.1813

Gannon, J.P., Bailey, S.W., McGuire, K.J. 2014. Organizing groundwater regimes and response thresholds by soils: A framework for understanding runoff generation in a headwater catchment. Water Resources Research 50 (11): 8403-8419. https://doi.org/10.1002/2014WR015498

Gao, H., Sabo, J.L., Chen, X., Liu, Z., Yang, Z., Ren, Z., Liu, M. 2018. Landscape heterogeneity and hydrological processes: a review of landscape-based hydrological models. Landscape Ecology 33 (9): 1461-1480. https://doi.org/10.1007/s10980018-0690-4

Garen, D.C., Moore, D.S. 2005. Curve number hydrology in water quality modeling: Uses, abuses, and future directions. Journal of the American Water Resources Association 41 (2): 377-388. https://doi.org/10.1111/j.1752-1688.2005.tb03742.x

Gasch, C.K., Hengl, T., Gräler, B., Meyer, H., Magney, T.S., Brown, D.J. 2015. Spatiotemporal interpolation of soil water, temperature, and electrical conductivity in 3D + T: The Cook Agronomy Farm data set. Spatial Statistics 14: 70-90. https://doi.org/10.1016/j.spasta.2015.04.001 
Gebbers, R., Adamchuk, V.I. 2010. Precision Agriculture and Food Security. Science 327 (5967): 828-831. https://doi.org/10.1126/science.1183899

Gerke, H.H., Hierold, W. 2012. Vertical bulk density distribution in C-horizons from marley till as indicator for erosion history in a hummocky post-glacial soil landscape. Soil and Tillage Research 125 (0): 116-122. https://doi.org/10.1016/j.still.2012.06.005

Gerke, H.H., Koszinski, S., Kalettka, T., Sommer, M. 2010. Structures and hydrologic function of soil landscapes with kettle holes using an integrated hydropedological approach. Journal of Hydrology $393 \quad$ (1-2): 123-132. https://doi.org/10.1016/j.jhydrol.2009.12.047

Gerke, H.H., Maurer, T., Schneider, A. 2013. A three-dimensional structure and process model for integrated hydro-geo-pedologic analysis of a constructed hydrological catchment. Vadose Zone Journal 12: 1-17. https://doi.org/10.2136/vzj2013.02.0040

Gerke, H.H., Rieckh, H., Sommer, M. 2016. Interactions between crop, water, and dissolved organic and inorganic carbon in a hummocky landscape with erosion-affected pedogenesis. Soil and Tillage Research 156: 230-244. https://doi.org/10.1016/j.still.2015.09.003

Gerke, H.H., Van Genuchten, M.T. 1993. A dual-porosity model for simulating the preferential movement of water and solutes in structured porous media. Water Resources Research 29 (2): 305-319. https://doi.org/10.1029/92WR02339

Gerke, K.M., Sidle, R.C., Mallants, D. 2015. Preferential flow mechanisms identified from staining experiments in forested hillslopes. Hydrological Processes 29 (21): 4562 4578. https://doi.org/10.1002/hyp. 10468

German, L.A. 2003. Historical contingencies in the coevolution of environment and livelihood: contributions to the debate on Amazonian Black Earth. Geoderma 111 (3): 307-331. https://doi.org/10.1016/S0016-7061(02)00270-7

Gerwin, W., Schaaf, W., Biemelt, D., Fischer, A., Winter, S., Hüttl, R.F. 2009. The artificial catchment "Chicken Creek" (Lusatia, Germany) - A landscape laboratory for interdisciplinary studies of initial ecosystem development. Ecological Engineering 35 (12): 1786-1796. https://doi.org/10.1016/j.ecoleng.2009.09.003

Gessler, P.E., Chadwick, O.A., Chamran, F., Althouse, L., Holmes, K. 2000. Modeling SoilLandscape and Ecosystem Properties Using Terrain Attributes. Soil Science Society of America Journal 64 (6): 2046-2056. https://doi.org/10.2136/sssaj2000.6462046x

Geyh, M.A., Benzler, J.H., Roeschmann, G. 1971. Problems of dating Pleistocene and Holocene soils by radiometric methods. In: Yaalon, D.H. (Editor), Nature, origin and dating of paleosols, 63-75. Israel Universities Press, Jerusalem.

Gillijns, K., Poesen, J., Deckers, J. 2005. On the characteristics and origin of closed depressions in loess-derived soils in Europe - a case study from central Belgium. Catena 60 (1): 43-58. https://doi.org/10.1016/j.catena.2004.10.001

Gocke, M., Pustovoytov, K., Kühn, P., Wiesenberg, G.L.B., Löscher, M., Kuzyakov, Y. 2011. Carbonate rhizoliths in loess and their implications for paleoenvironmental reconstruction revealed by isotopic composition: $\delta 13 \mathrm{C}, 14 \mathrm{C}$. Chemical Geology 283 (3-4): 251-260. https://doi.org/10.1016/j.chemgeo.2011.01.022 
Gonet, S., Markiewicz, M., Marszelewski, W., Dziamski, A. 2010. Soil transformations in catchment of disappearing Sumówko Lake (Brodnickie Lake District, Poland). Limnological Review 10 (3-4): 133-137. https://doi.org/10.2478/v10194-011-0015$\underline{3}$

González-Hidalgo, J.C., De Luis, M., Batalla, R.J. 2009. Effects of the largest daily events on total soil erosion by rainwater. An analysis of the USLE database. Earth Surface Processes and Landforms 34 (15): 2070-2077. https://doi.org/10.1002/esp.1892

Gosse, J.C., Phillips, F.M. 2001. Terrestrial in situ cosmogenic nuclides: theory and application. Quaternary Science Reviews 20 (14): 1475-1560. https://doi.org/10.1016/S0277-3791(00)00171-2

Gosse, J.C., Stone, J.O. 2001. Terrestrial cosmogenic nuclide methods passing milestones toward paleo-altimetry. Eos, Transactions American Geophysical Union 82 (7): 8289. https://doi.org/10.1029/01eo00045

Goudie, A.S. 2013. The human impact on the natural environment: past, present, and future, 7th edition. Wiley-Blackwell, Oxford.

Govers, G., Quine, T.A., Desmet, P.J.J., Walling, D.E. 1996. The relative contribution of soil tillage and overland flow erosion to soil redistribution on agricultural land. Earth Surface Processes and Landforms $21 \quad$ (10): 929-946. https://doi.org/10.1002/(SICI)1096-9837(199610)21:10\%3C929::AID-

ESP631\%3E3.0.CO;2-C

Govers, G., Vandaele, K., Desmet, P., Poesen, J., Bunte, K. 1994. The role of tillage in soil redistribution on hillslopes. European Journal of Soil Science 45 (4): 469-478. https://doi.org/10.1111/j.1365-2389.1994.tb00532.x

Graham, C.B., Lin, H.S. 2012. Chapter 18 - Subsurface Flow Networks at the Hillslope Scale: Detection and Modeling. In: Lin, H.S. (Editor), Hydropedology, 559-593. Academic Press, Boston.

Gralow, K.D. 1981. Zur bandkeramischen Besiedlung des Uecker-Randow-Raumes. Mitteilungen des Bezirksfachausschusses für Ur-und Frühgeschichte Neubrandenburg 28: 8-27.

Gray, D.M., Toth, B., Zhao, L., Pomeroy, J.W., Granger, R.J. 2001. Estimating areal snowmelt infiltration into frozen soils. Hydrological Processes 15 (16): 3095-3111. https://doi.org/10.1002/hyp.320

Greco, R. 2002. Preferential flow in macroporous swelling soil with internal catchment: model development and applications. Journal of Hydrology 269 (3): 150-168. https://doi.org/10.1016/S0022-1694(02)00215-9

Green, W.H., Ampt, G.A. 1911. Studies on Soil Phyics. The Journal of Agricultural Science 4 (01): 1-24. https://doi.org/10.1017/S0021859600001441

Greiner, L., Keller, A., Grêt-Regamey, A., Papritz, A. 2017. Soil function assessment: review of methods for quantifying the contributions of soils to ecosystem services. Land Use Policy 69: 224-237. https://doi.org/10.1016/j.landusepol.2017.06.025 
Grunwald, S. 2009. Multi-criteria characterization of recent digital soil mapping and modeling approaches. Geoderma $152 \quad$ (3-4): 195-207. https://doi.org/10.1016/j.geoderma.2009.06.003

Guérin, G., Mercier, N., Adamiec, G. 2011. Dose-rate conversion factors: update. Ancient TL 29 (1): 5-8.

Guerra, A.J.T., Fullen, M.A., Jorge, M.d.C.O., Bezerra, J.F.R., Shokr, M.S. 2017. Slope Processes, Mass Movement and Soil Erosion: A Review. Pedosphere 27 (1): 27-41. https://doi.org/10.1016/S1002-0160(17)60294-7

Guo, L., Chen, J., Lin, H.S. 2014. Subsurface lateral preferential flow network revealed by time-lapse ground-penetrating radar in a hillslope. Water Resources Research 50 (12): 9127-9147. https://doi.org/10.1002/2013WR014603

Guo, L., Lin, H.S. 2018. Chapter Two - Addressing Two Bottlenecks to Advance the Understanding of Preferential Flow in Soils. In: Sparks, D.L. (Editor), Advances in Agronomy, 61-117. Academic Press, Boston.

Guo, L., Lin, H.S., Fan, B., Nyquist, J., Toran, L., Mount, G.J. 2019. Preferential flow through shallow fractured bedrock and a 3D fill-and-spill model of hillslope subsurface hydrology. Journal of Hydrology 576: 430-442. https://doi.org/10.1016/j.jhydrol.2019.06.070

Guo, L.B., Gifford, R.M. 2002. Soil carbon stocks and land use change: a meta analysis. Global Change Biology 8 (4): 345-360. https://doi.org/10.1046/j.13541013.2002.00486.x

Guzha, A.C. 2004. Effects of tillage on soil microrelief, surface depression storage and soil water storage. Soil and Tillage Research $76 \quad$ (2): 105-114. https://doi.org/10.1016/j.still.2003.09.002

Hahm, W.J., Riebe, C.S., Lukens, C.E., Araki, S. 2014. Bedrock composition regulates mountain ecosystems and landscape evolution. Proceedings of the national academy of sciences 111 (9): 3338. https://doi.org/10.1073/pnas.1315667111

Hancock, G.R., J.B.C, L., Coulthard, T.J. 2015. Catchment reconstruction — erosional stability at millennial time scales using landscape evolution models. Geomorphology 231: 15-27. https://doi.org/10.1016/j.geomorph.2014.10.034

Hancock, G.R., Lowry, J.B.C., Coulthard, T.J., Evans, K.G., Moliere, D.R. 2010. A catchment scale evaluation of the SIBERIA and CAESAR landscape evolution models. Earth Surface Processes and Landforms 35 (8): 863-875. https://doi.org/10.1002/esp.1863

Hancock, G.R., Willgoose, G.R., Lowry, J. 2014. Transient landscapes: gully development and evolution using a landscape evolution model. Stochastic environmental research and risk assessment 28 (1): 83-98. https://doi.org/10.1007/s00477-013$\underline{0741-y}$

Hansen, H.-O., Steensberg, A., Lerche, G., Fenton, A. 1969. Experimental ploughing with a Døstrup ard replica. Tools and Tillage 1 (2): 67-92. 
Harden, J.W. 1988. Genetic interpretations of elemental and chemical differences in a soil $\begin{array}{llll}\text { chronosequence, } & \text { California. } & \text { Geoderma } 43 & \text { (2): }\end{array}$ https://doi.org/10.1016/0016-7061(88)90042-0

Harden, J.W., Sharpe, J.M., Parton, W.J., Ojima, D.S., Fries, T.L., Huntington, T.G., Dabney, S.M. 1999. Dynamic replacement and loss of soil carbon on eroding cropland. Global Biogeochemical Cycles $13 \quad$ (4): https://doi.org/10.1029/1999gb900061

Hargreaves, G.H., Samani, Z.A. 1985. Reference crop evapotranspiration from temperature. $\begin{array}{llllll}\text { Applied engineering in agriculture } & 1 & (2): & 96-99 .\end{array}$ https://doi.org/10.13031/2013.26773

Harte, J. 2007. Human population as a dynamic factor in environmental degradation. Population and Environment 28 (4): 223-236. https://doi.org/10.1007/s11111-007$\underline{0048-3}$

Hartz, S., Lübke, H., Terberger, T. 2007. From fish and seal to sheep and cattle: new research into the process of neolithisation in northern Germany. In: Whittle, A.; Cumnings, V. (Editors), GOING OVER, The Mesolithic-Neolithic Transition in Northwest Europe, 567-594. Oxford University Press, Oxford.

Hayashi, M., Van der Kamp, G., Schmidt, R. 2003. Focused infiltration of snowmelt water in partially frozen soil under small depressions. Journal of Hydrology 270 (3): 214 229. https://doi.org/10.1016/S0022-1694(02)00287-1

He, X., Vepraskas, M., Lindbo, D., Skaggs, R. 2003. A method to predict soil saturation frequency and duration from soil color. Soil Science Society of America Journal 67 (3): 961-969. https://doi.org/10.2136/sssaj2003.9610

He, X., Zhou, J., Zhang, X., Tang, K. 2006. Soil erosion response to climatic change and human activity during the Quaternary on the Loess Plateau, China. Regional Environmental Change 6 (1): 62-70. https://doi.org/10.1007/s10113-005-0004-7

Hedwall, P.-O., Brunet, J., Rydin, H. 2017. Peatland plant communities under global change: negative feedback loops counteract shifts in species composition. Ecology 98 (1): 150-161. https://doi.org/10.1002/ecy.1627

Hendrickx, J.M.H., Flury, M. 2001. Uniform and preferential flow mechanisms in the vadose zone. Conceptual models of flow and transport in the fractured vadose zone, 149187. The National Academies Press, Washington D.C.

Herbrich, M., Gerke, H.H. 2017. Scales of water retention dynamics observed in eroded Luvisols from an arable postglacial soil landscape. Vadose Zone Journal 16 (10). https://doi.org/10.2136/vzj2017.01.0003

Herrmann, K. 1985. Pflügen, Säen, Ernten: Landarbeit und Landtechnik in der Geschichte. Rowohlt, Reinbek.

Hesse, R. 2014. Geomorphological traces of conflict in high-resolution elevation models. Applied Geography 46: 11-20. https://doi.org/10.1016/j.apgeog.2013.10.004

Heuvelink, G.B.M., Webster, R. 2001. Modelling soil variation: past, present, and future. Geoderma 100 (3): 269-301. https://doi.org/10.1016/S0016-7061(01)00025-8 
Hewlett, J.D., Hibbert, A.R. 1967. Factors affecting the response of small watersheds to precipitation in humid areas. In: Sopper, W.E.; Lull, H.W. (Editors), Forest hydrology, 275-290. Pergamon Press, Oxford.

Hijmans, R.J. 2016. raster: Geographic Data Analysis and Modeling. R package version 2.58. https://CRAN.R-project.org/package=raster.

Hinze, K. 1981. Die Bevölkerung Preußens im 17. und 18. Jahrhundert nach Quantität und Qualität. In: Büsch, O.; Neugebauer, W. (Editors), Moderne Preußische Geschichte 1648-1947, 282-315. De gruyter, Berlin.

Hlaváčiková, H., Novák, V., Šimůnek, J. 2016. The effects of rock fragment shapes and positions on modeled hydraulic conductivities of stony soils. Geoderma 281: 39-48. https://doi.org/10.1016/j.geoderma.2016.06.034

Hock, R. 2003. Temperature index melt modelling in mountain areas. Journal of Hydrology 282 (1): 104-115. https://doi.org/10.1016/S0022-1694(03)00257-9

Hoffmann, M., Jurisch, N., Borraz, E.A., Hagemann, U., Drösler, M., Sommer, M., Augustin, J. 2015. Automated modeling of ecosystem CO2 fluxes based on periodic closed chamber measurements: A standardized conceptual and practical approach. Agricultural and Forest Meteorology 200: 30-45. https://doi.org/10.1016/j.agrformet.2014.09.005

Hoffmann, M., Jurisch, N., Garcia Alba, J., Albiac Borraz, E., Schmidt, M., Huth, V., Rogasik, H., Rieckh, H., Verch, G., Sommer, M., Augustin, J. 2017. Detecting small-scale spatial heterogeneity and temporal dynamics of soil organic carbon (SOC) stocks: a comparison between automatic chamber-derived $\mathrm{C}$ budgets and repeated soil inventories. Biogeosciences 14 (4): 1003-1019. https://doi.org/10.5194/bg-14-1003-2017

Hoffmann, M., Pohl, M., Jurisch, N., Prescher, A.K., Mendez Campa, E., Hagemann, U., Remus, R., Verch, G., Sommer, M., Augustin, J. 2018. Maize carbon dynamics are driven by soil erosion state and plant phenology rather than nitrogen fertilization form. Soil and Tillage Research 175: 255-266. https://doi.org/10.1016/j.still.2017.09.004

Holmgren, P. 1994. Multiple flow direction algorithms for runoff modelling in grid based elevation models: An empirical evaluation. Hydrological Processes 8 (4): 327-334. https://doi.org/10.1002/hyp.3360080405

Hoosbeek, M.R., Bryant, R.B. 1992. Towards the quantitative modeling of pedogenesis - a review. Geoderma 55 (3): 183-210. https://doi.org/10.1016/0016-7061(92)90083-J

Horton, R.E. 1941. An approach toward a physical interpretation of infiltration-capacity. Soil Science Society of America Journal $5 \quad$ (C): 399-417. https://doi.org/10.2136/sssaj1941.036159950005000C0075x

Hu, W., Shao, M., Wang, Q., Fan, J., Horton, R. 2009. Temporal changes of soil hydraulic properties under different land uses. Geoderma 149 (3): 355-366. https://doi.org/10.1016/j.geoderma.2008.12.016

Huggett, R.J. 1975. Soil landscape systems: A model of soil Genesis. Geoderma 13 (1): 122. https://doi.org/10.1016/0016-7061(75)90035-X 
Hughes, J.D., Thirgood, J.V. 1982. Deforestation, erosion, and forest management in ancient Greece and Rome. Journal of Forest History 26 (2): 60-75. https://doi.org/10.2307/4004530

Huisman, H., De Kort, J.W., Ketterer, M.E., Reimann, T., Schoorl, J.M., Van der Heiden, M., Van Soest, M., Van Egmond, F. 2018. Erosion of archaeological sites: Quantifying the threat using optically stimulated luminescence and fallout isotopes. Geoarchaeology 34: 478-494. https://doi.org/10.1002/gea.21716

Hunter, N.M., Bates, P.D., Horritt, M.S., Wilson, M.D. 2007. Simple spatially-distributed models for predicting flood inundation: A review. Geomorphology 90 (3): 208-225. https://doi.org/10.1016/j.geomorph.2006.10.021

IPBES. 2019. Summary for policymakers of the global assessment report on biodiversity and ecosystem services of the Intergovernmental Science-Policy Platform on Biodiversity and Ecosystem Services. In: Díaz, S.; Settele, J.; Brondizio, E.S.; Ngo, H.T.; Guèze, M.; Agard, J.; Arneth, A.; Balvanera, P.; Brauman, K.A.; Butchart, S.H.M.; Chan, K.M.A.; Garibaldi, L.A.; Ichii, K.; Liu, J.; Subramanian, S.M.; Midgley, G.F.; Miloslavich, P.; Molnár, Z.; Obura, D.; Pfaff, A.; Polasky, S.; Purvis, A.; Razzaque, J.; Reyers, B.; Roy Chowdhury, R.; Shin, Y.J.; Visseren-Hamakers, I.J.; Willis, K.J.; Zayas, C.N. (Editors). IPBES secretariat, Bonn, Germany.

IPCC. 2019. Climate Change and Land: an IPCC special report on climate change, desertification, land degradation, sustainable land management, food security, and greenhouse gas fluxes in terrestrial ecosystems. P.R. Shukla, J. Skea, E. Calvo Buendia, V. Masson-Delmotte, H.-O. Pörtner, D. C. Roberts, P. Zhai, R. Slade, S. Connors, R. van Diemen, M. Ferrat, E. Haughey, S. Luz, S. Neogi, M. Pathak, J. Petzold, J. Portugal Pereira, P. Vyas, E. Huntley, K. Kissick, M. Belkacemi, J. Malley, (eds.). In press.

IUSS Working Group WRB. 2015. World Reference Base for Soil Resources 2014, update 2015 International soil classification system for naming soils and creating legends for soil maps. World Soil Resources Reports No. 106, p 192. FAO, Rome.

Jackisch, C., Angermann, L., Allroggen, N., Sprenger, M., Blume, T., Tronicke, J., Zehe, E. 2017. Form and function in hillslope hydrology: in situ imaging and characterization of flow-relevant structures. Hydrology and Earth System Sciences. https://doi.org/10.5194/hess-21-3749-2017

Jackson, C.R., Du, E., Klaus, J., Griffiths, N.A., Bitew, M., McDonnell, J.J. 2016. Interactions among hydraulic conductivity distributions, subsurface topography, and transport thresholds revealed by a multitracer hillslope irrigation experiment. Water Resources Research 52 (8): 6186-6206. https://doi.org/10.1002/2015WR018364

Jacques, D., Šimůnek, J., Mallants, D., Van Genuchten, M.T. 2008. Modelling coupled water flow, solute transport and geochemical reactions affecting heavy metal migration in a podzol soil. Geoderma $145 \quad$ (3-4): 449-461. https://doi.org/10.1016/j.geoderma.2008.01.009 
Jagercikova, M., Cornu, S., Bourlès, D., Evrard, O., Hatté, C., Balesdent, J. 2017. Quantification of vertical solid matter transfers in soils during pedogenesis by a multi-tracer approach. Journal of Soils and Sediments 17 (2): 408-422. https://doi.org/10.1007/s11368-016-1560-9

Jahn, A. 1989. The soil creep on slopes in different altitudinal and ecological zones of Sudetes Mountains. Geografiska Annaler. Series A. Physical Geography 71 (3:4): 161-170. https://doi.org/10.1080/04353676.1989.11880284

Jahns, S. 2000. Late-glacial and Holocene woodland dynamics and land-use history of the Lower Oder valley, north-eastern Germany, based on two, AMS14C-dated, pollen profiles. Vegetation History and Archaeobotany 9 (2): 111-123. https://doi.org/10.1007/bf01300061

Jahns, S. 2001. On the Late Pleistocene and Holocene history of vegetation and human impact in the Ücker valley, north-eastern Germany. Vegetation History and Archaeobotany 10 (2): 97-104. https://doi.org/10.1007/PL00006924

Jana, R.B., Mohanty, B.P. 2012. On topographic controls of soil hydraulic parameter scaling at hillslope scales. Water Resources Research 48 (2). https://doi.org/10.1029/2011WR011204

Jarvis, N.J. 2007. A review of non-equilibrium water flow and solute transport in soil macropores: principles, controlling factors and consequences for water quality. European Journal of Soil Science 58 (3): 523-546. https://doi.org/10.1111/j.13652389.2007.00915.x

Jarvis, N.J., Villholth, K.G., Ulen, B. 1999. Modelling particle mobilization and leaching in macroporous soil. European Journal of Soil Science 50 (4): 621-632. https://doi.org/10.1046/j.1365-2389.1999.00269.x

Jenny, H. 1941. Factors of soil formation: a system of quantitative pedology. McGraw-Hill, New York.

Jin, L., Andrews, D.M., Holmes, G.H., Lin, H.S., Brantley, S.L. 2011. Opening the "Black Box": Water Chemistry Reveals Hydrological Controls on Weathering in the Susquehanna Shale Hills Critical Zone Observatory. Vadose Zone Journal 10 (3): 928-942. https://doi.org/10.2136/vzj2010.0133

Jirků, V., Kodešová, R., Nikodem, A., Mühlhanselová, M., Žigová, A. 2013. Temporal variability of structure and hydraulic properties of topsoil of three soil types. Geoderma 204-205: 43-58. https://doi.org/10.1016/j.geoderma.2013.03.024

Johnson, D.L. 2002. Darwin would be proud: Bioturbation, dynamic denudation, and the power of theory in science. Geoarchaeology $17 \quad$ (1): 7-40. https://doi.org/10.1002/gea.10001

Johnson, D.L., Watson-Stegner, D. 1987. Evolution model of pedogenesis. Soil Science 143 (5): 349-366. https://doi.org/10.1097\%2F00010694-198705000-00005

Johnson, M.O., Mudd, S.M., Pillans, B., Spooner, N.A., Keith Fifield, L., Kirkby, M.J., Gloor, M. 2014. Quantifying the rate and depth dependence of bioturbation based on optically-stimulated luminescence (OSL) dates and meteoric 10Be. Earth 
Surface Processes and Landforms $39 \quad$ (9): $1188-1196$. https://doi.org/10.1002/esp.3520

Kabala, C., Zapart, J. 2012. Initial soil development and carbon accumulation on moraines of the rapidly retreating Werenskiold Glacier, SW Spitsbergen, Svalbard archipelago. Geoderma 175: 9-20. https://doi.org/10.1016/j.geoderma.2012.01.025

Kadereit, A., Kühn, P., Wagner, G.A. 2010. Holocene relief and soil changes in loess-covered areas of south-western Germany: The pedosedimentary archives of BrettenBauerbach (Kraichgau). Quaternary International 222 (1-2): 96-119. https://doi.org/10.1016/j.quaint.2009.06.025

Kaiser, K., Küster, M., Fülling, A., Theuerkauf, M., Dietze, E., Graventein, H., Koch, P.J., Bens, O., Brauer, A. 2014. Littoral landforms and pedosedimentary sequences indicating late Holocene lake-level changes in northern central Europe - A case study from northeastern Germany. Geomorphology 216 (0): 58-78. https://doi.org/10.1016/j.geomorph.2014.03.025

Kaiser, K., Lorenz, S., Germer, S., Juschus, O., Küster, M., Libra, J., Bens, O., Hüttl, R.F. 2012. Late Quaternary evolution of rivers, lakes and peatlands in northeast Germany reflecting past climatic and human impact-an overview. E\&G Quaternary Science Journal 61 (2): 103-132. https:/doi.org/10.3285/eg.61.2.01

Kalettka, T., Rudat, C. 2006. Hydrogeomorphic types of glacially created kettle holes in North-East Germany. Limnologica - Ecology and Management of Inland Waters 36 (1): 54-64. https://doi.org/10.1016/j.limno.2005.11.001

Kappler, C., Kaiser, K., Küster, M., Nicolay, A., Fülling, A., Bens, O., Raab, T. 2019. Late Pleistocene and Holocene terrestrial geomorphodynamics and soil formation in northeastern Germany: A review of geochronological data. Physical Geography 40 (5): 1-28. https://doi.org/10.1080/02723646.2019.1573621

Kappler, C., Kaiser, K., Tanski, P., Klos, F., Fülling, A., Mrotzek, A., Sommer, M., Bens, O. 2018. Stratigraphy and age of colluvial deposits indicating Late Holocene soil erosion in northeastern Germany. Catena 170: 224-245. https://doi.org/10.1016/j.catena.2018.06.010

Karasiewicz, M.T., Hulisz, P., Noryśkiewicz, A.M., Krześlak, I., Świtoniak, M. 2014. The record of hydroclimatic changes in the sediments of a kettle-hole in a young glacial landscape (north-central Poland). Quaternary International 328: 264-276. https://doi.org/10.1016/j.quaint.2013.09.045

Kasper, M., Buchan, G.D., Mentler, A., Blum, W.E.H. 2009. Influence of soil tillage systems on aggregate stability and the distribution of $\mathrm{C}$ and $\mathrm{N}$ in different aggregate fractions. Soil and Tillage Research $105 \quad$ (2): 192-199. https://doi.org/10.1016/j.still.2009.08.002

Kavetski, D., Binning, P., Sloan, S.W. 2001. Adaptive time stepping and error control in a mass conservative numerical solution of the mixed form of Richards equation. Advances in Water Resources 24 (6): 595-605. https://doi.org/10.1016/S03091708(00)00076-2 
Keesstra, S., Mol, G., De Leeuw, J., Okx, J., De Cleen, M., Visser, S. 2018a. Soil-related sustainable development goals: Four concepts to make land degradation neutrality and restoration work. Land 7 (4): 133. https://doi.org/10.3390/land7040133

Keesstra, S., Nunes, J., Novara, A., Finger, D., Avelar, D., Kalantari, Z., Cerdà, A. 2018b. The superior effect of nature based solutions in land management for enhancing ecosystem services. Science of The Total Environment 610-611: 997-1009. https://doi.org/10.1016/j.scitotenv.2017.08.077

Keesstra, S., Pereira, P., Novara, A., Brevik, E.C., Azorin-Molina, C., Parras-Alcántara, L., Jordán, A., Cerdà, A. 2016. Effects of soil management techniques on soil water erosion in apricot orchards. Science of The Total Environment 551-552: 357-366. https://doi.org/10.1016/j.scitotenv.2016.01.182

Kern, J., Giani, L., Teixeira, W., Lanza, G., Glaser, B. 2019. What can we learn from ancient fertile anthropic soil (Amazonian Dark Earths, shell mounds, Plaggen soil) for soil carbon Sequestration? $\quad$ Catena 172: 104-112. https://doi.org/10.1016/j.catena.2018.08.008

Keylock, C.J. 2007. Identifying linear and non-linear behaviour in reduced complexity modelling output using surrogate data methods. Geomorphology 90 (3): 356-366. https://doi.org/10.1016/j.geomorph.2006.10.027

Keyvanshokouhi, S. 2018. Projecting the evolution of soil due to global change. Earth science of the environment, $\mathrm{p}$ 195. Aix-Marseille University, Marseille.

Keyvanshokouhi, S., Cornu, S., Samouelian, A., Finke, P. 2016. Evaluating SoilGen2 as a tool for projecting soil evolution induced by global change. Science of The Total Environment 571: 110-123. https://doi.org/10.1016/j.scitotenv.2016.07.119

Kietzer, B. 2007. Aufklärung der Bodenverlagerung durch Bearbeitungserosion in Jungmoränenlandschaften. Planen Bauen Umwelt, p 136. Technische Universität Berlin, Berlin.

King, K.W., Arnold, J.G., Bingner, R.L. 1999. Comparison of Green-Ampt and curve number methods on Goodwin Creek watershed using SWAT. Transactions of the ASAE 42 (4): 919-925. https://doi.org/10.13031/2013.13272

Kirkby, M.J. 1977. Soil development models as a component of slope models. Earth surface processes 2 (2-3): 203-230. https://doi.org/10.1002/esp.3290020212

Kirkby, M.J. 1985. A basis for soil profile modelling in a geomorphic context. Journal of Soil Science 36 (1): 97-121. https://doi.org/10.1111/j.1365-2389.1985.tb00316.x

Kirkby, M.J. 2018. A conceptual model for physical and chemical soil profile evolution. Geoderma 331: 121-130. https://doi.org/10.1016/j.geoderma.2018.06.009

Kirleis, W., Klooß, S., Kroll, H., Müller, J. 2012. Crop growing and gathering in the northern German Neolithic: a review supplemented by new results. Vegetation History and Archaeobotany 21 (3): 221-242. https://doi.org/10.1007/s00334-011-0328-9

Kirsch, E. 1994. Beiträge zur älteren Trichterbecherkultur in Brandenburg. Brandenburgisches Landesamt für Denkmalpflege und Archäologische Landesmuseum, Potsdam. 
Knotters, M., Brus, D.J., Oude Voshaar, J.H. 1995. A comparison of kriging, co-kriging and kriging combined with regression for spatial interpolation of horizon depth with censored observations. Geoderma 67 (3): 227-246.

Knuteson, J.A., Richardson, J.L., Patterson, D.D., Prunty, L. 1989. Pedogenic Carbonates in a Calciaquoll Associated with a Recharge Wetland. Soil Science Society of America Journal 53

495-499. https://doi.org/10.2136/sssaj1989.03615995005300020032x

Kochanowska, R., Pienkowski, P., Wolejko, L. 1998. Characteristics of intrafield water holes in Western Pomerania in relation to differentiation of the young-glacial landscape and human impact. Journal of Water and Land Development 2: 85-100.

Kodešová, R., Vignozzi, N., Rohošková, M., Hájková, T., Kočárek, M., Pagliai, M., Kozák, J., Šimůnek, J. 2009. Impact of varying soil structure on transport processes in different diagnostic horizons of three soil types. Journal of Contaminant Hydrology 104 (1-4): 107-125. https://doi.org/10.1016/j.jconhyd.2008.10.008

Kołodyńska-Gawrysiak, R., Poesen, J., Gawrysiak, L. 2018. Assessment of long-term Holocene soil erosion rates in Polish loess areas using sedimentary archives from closed depressions. Earth Surface Processes and Landforms 43 (5): 978-1000. https://doi.org/10.1002/esp.4296

Kondolf, G.M., Boulton, A.J., O'Daniel, S., Poole, G.C., Rahel, F.J., Stanley, E.H., Wohl, E., Bång, Å., Carlstrom, J., Cristoni, C. 2006. Process-based ecological river restoration: visualizing three-dimensional connectivity and dynamic vectors to recover lost linkages. Ecology \& society 11 (2): 1-16.

Koster, E.A. 2009. The "European Aeolian Sand Belt": Geoconservation of Drift Sand Landscapes. Geoheritage 1 (2): 93-110. https://doi.org/10.1007/s12371-009-0007$\underline{8}$

Kumar, P., Le, P.V.V., Papanicolaou, A.N.T., Rhoads, B.L., Anders, A.M., Stumpf, A., Wilson, C.G., Bettis, E.A., Blair, N., Ward, A.S., Filley, T., Lin, H., Keefer, L., Keefer, D.A., Lin, Y.-F., Muste, M., Royer, T.V., Foufoula-Georgiou, E., Belmont, P. 2018. Critical transition in critical zone of intensively managed landscapes. Anthropocene 22: 10-19. https://doi.org/10.1016/j.ancene.2018.04.002

Kust, G., Andreeva, O., Cowie, A. 2017. Land Degradation Neutrality: Concept development, practical applications and assessment. Journal of Environmental Management 195: 16-24. https://doi.org/10.1016/j.jenvman.2016.10.043

Kværnø, S.H., Øygarden, L. 2006. The influence of freeze-thaw cycles and soil moisture on aggregate stability of three soils in Norway. Catena 67 (3): 175-182. https://doi.org/10.1016/j.catena.2006.03.011

Lafortezza, R., Chen, J., Van den Bosch, C.K., Randrup, T.B. 2018. Nature-based solutions for resilient landscapes and cities. Environmental Research 165: 431-441. https://doi.org/10.1016/j.envres.2017.11.038

Lal, R. 1997. Degradation and resilience of soils. Philosophical Transactions of the Royal Society of London. Series B: Biological Sciences 352 (1356): 997-1010. https://doi.org/10.1098\%2Frstb.1997.0078 
Lal, R. 2001. Soil degradation by erosion. Land Degradation \& Development 12 (6): 519539. https://doi.org/10.1002/ldr.472

Lal, R. 2003. Soil erosion and the global carbon budget. Environment International 29 (4): 437-450. https://doi.org/10.1016/S0160-4120(02)00192-7

Lal, R. 2019. Accelerated Soil erosion as a source of atmospheric CO2. Soil and Tillage Research 188: 35-40. https://doi.org/10.1016/j.still.2018.02.001

Lamentowicz, M., Obremska, M., Mitchell, E.A.D. 2008. Autogenic succession, land-use change, and climatic influences on the Holocene development of a kettle-hole mire in Northern Poland. Review of Palaeobotany and Palynology 151 (1): 21-40. https://doi.org/10.1016/j.revpalbo.2008.01.009

Landi, A., Mermut, A.R., Anderson, D.W. 2004. Carbon distribution in a hummocky landscape from Saskatchewan, Canada. Soil Science Society of America Journal 68 (1): 175-184. https://doi.org/10.2136/sssaj2004.1750

Larsen, L.A. 2016. The mouldboard plough in the Danish area 200-1500 AD. Agrarian Technology in the Medieval Landscape: Agrartechnik in mittelalterlichen Landschaften. Technologie agraire dans le paysage médiéval. 9th - 15th September 2013 225-236, Smolenice, Slovakia.

Lauren, J.G., Wagnet, R.J., Bouma, J., Wosten, J.H.M. 1988. Variability of saturated hydraulic conductivity in a Glossaquic Hapludalf with macropores. Soil Science 145 (1): 20-28. https://doi.org/10.1097\%2F00010694-198801000-00003

Lechterbeck, J., Edinborough, K., Kerig, T., Fyfe, R., Roberts, N., Shennan, S. 2014. Is Neolithic land use correlated with demography? An evaluation of pollen-derived land cover and radiocarbon-inferred demographic change from Central Europe. The Holocene 24 (10): 1297-1307. https://doi.org/10.1177\%2F0959683614540952

Leciejewicz, L., Gringmuth-Dallmer, E. 1996. Mensch und Umwelt im mittleren und unteren Odergebiet. Beiträge zur ur- und frühgeschichtlichen Besiedlung. Instytut Archeologii i Etnologii, Wraclaw.

Leguédois, S., Séré, G., Auclerc, A., Cortet, J., Huot, H., Ouvrard, S., Watteau, F., Schwartz, C., Morel, J.L. 2016. Modelling pedogenesis of Technosols. Geoderma 262: 199212. https://doi.org/10.1016/j.geoderma.2015.08.008

Leopold, M., Völkel, J. 2007. Colluvium: Definition, differentiation, and possible suitability for reconstructing Holocene climate data. Quaternary International 162-163: 133140. https://doi.org/10.1016/j.quaint.2006.10.030

Lerche, G. 1994. Publication 8: Ploughing implements and tillage practices in Denmark from the Viking period to about 1800 experimentally substantiated [ard, replica, pepples, ridges, plough marks, fossil fields]. Royal Danish Academy of Sciences and Letters, Copenhagen.

Lewis, H. 2012. Investigating ancient tillage : an experimental and soil micromorphological study. Archaeopress, Oxford

Lewis, S.L., Maslin, M.A. 2015. Defining the Anthropocene. Nature 519: 171. https://doi.org/10.1038/nature14258 
Li, Y., Frielinghaus, M., Bork, H.R., Friedland, E.M., Schkade, U.K., Naumann, M., Schäfer, H. 2002. Slope Basis Deposits Linked to Long-Term Land Use in NE-Germany. Archives of Agronomy and Soil Science 48 (4): 335-342. https://doi.org/10.1080/03650340214199

Lin, H., Brooks, E., McDaniel, P., Boll, J. 2008. Hydropedology and surface/subsurface runoff processes. In: Anderson, M.G.; McDonnell, J.J. (Editors), Encyclopedia of hydrological sciences.

Lin, H.S. 2003. Hydropedology: bridging disciplines, scales and data. Vadose Zone Journal 2 (1): 1-11. https://doi.org/10.2136/vzj2003.1000

Lin, H.S. 2006. Temporal stability of soil moisture spatial pattern and subsurface preferential flow pathways in the Shale Hills Catchment. Vadose Zone Journal 5 (1): 317-340. https://doi.org/10.2136/vzj2005.0058

Lin, H.S. 2010a. Earth's Critical Zone and hydropedology: concepts, characteristics, and advances. Hydrology and Earth System Sciences 14 (1): 25. https://doi.org/10.5194/hess-14-25-2010

Lin, H.S. 2010b. Linking principles of soil formation and flow regimes. Journal of Hydrology 393 (1-2): 3-19. https://doi.org/10.1016/j.jhydrol.2010.02.013

Lin, H.S. 2011. Three principles of soil change and pedogenesis in time and space. Soil Science Society of America Journal $75 \quad$ (6): 2049-2070. https://doi.org/10.2136/sssaj2011.0130

Lin, H.S. 2012a. Chapter 2 - Understanding Soil Architecture and Its Functional Manifestation across Scales. In: Lin, H.S. (Editor), Hydropedology, 41-74. Academic Press, Boston.

Lin, H.S. 2012b. Hydropedology: Synergistic integration of soil science and hydrology. Academic Press, Boston.

Lin, H.S., Kogelmann, W., Walker, C., Bruns, M.A. 2006. Soil moisture patterns in a forested catchment: A hydropedological perspective. Geoderma 131 (3): 345-368. https://doi.org/10.1016/j.geoderma.2005.03.013

Lin, H.S., McInnes, K.J., Wilding, L.P., Hallmark, C.T. 1999. Effects of soil morphology on hydraulic properties II. Hydraulic pedotransfer functions. Soil Science Society of America Journal 63 (4): 955-961. https://doi.org/10.2136/sssaj1999.634955x

Lin, H.S., Zhang, W., Yu, H. 2014. Hydropedology: Linking Dynamic Soil Properties with Soil Survey Data. In: Teixeira, W.G.; Ceddia, M.B.; Ottoni, M.V.; Donnagema, G.K. (Editors), Application of Soil Physics in Environmental Analyses: Measuring, Modelling and Data Integration, 23-50. Springer International Publishing, Cham.

Liu, Q.-Q., Chen, L., Li, J.-C. 2001. Influences of Slope Gradient on Soil Erosion. Applied $\begin{array}{llll}\text { Mathematics } \quad \text { and } & \text { Mechanics } & \end{array}$ https://doi.org/10.1023/A:1016303213326

Liu, Z., Shao, M.a., Wang, Y. 2011. Effect of environmental factors on regional soil organic carbon stocks across the Loess Plateau region, China. Agriculture, Ecosystems \& Environment 142 (3): 184-194. https://doi.org/10.1016/j.agee.2011.05.002 
Logsdon, S.D., Allmaras, R.R., Wu, L., Swan, J.B., Randall, G.W. 1990. Macroporosity and its relation to saturated hydraulic conductivity under different tillage practices. Soil Science Society of America Journal $54 \quad$ (4): 1096-1101. https://doi.org/10.2136/sssaj1990.03615995005400040029x

Lohse, K.A., Dietrich, W.E.C.W. 2005. Contrasting effects of soil development on hydrological properties and flow paths. Water Resources Research 41 (12): n/a-n/a. https://doi.org/10.1029/2004wr003403

Loosvelt, L., Pauwels, V.R.N., Cornelis, W.M., De Lannoy, G.J.M., Verhoest, N.E.C. 2011. Impact of soil hydraulic parameter uncertainty on soil moisture modeling. Water Resources Research 47 W03505. https://doi.org/10.1029/2010WR009204

Lucas, Y., Montes, C.R., Mounier, S., Cazalet, M.L., Ishida, D., Achard, R., Garnier, C., Coulomb, B., Melfi, A. 2012. Biogeochemistry of an Amazonian podzol-ferralsol soil system with white kaolin. Biogeosciences 9 (9): 3705-3720. https://doi.org/10.5194/bg-9-3705-2012

Ludwig, M., Wilmes, P., Schrader, S. 2018. Measuring soil sustainability via soil resilience. Science of The Total Environment 626: 1484-1493. https://doi.org/10.1016/i.scitotenv.2017.10.043

Lugato, E., Smith, P., Borrelli, P., Panagos, P., Ballabio, C., Orgiazzi, A., Fernandez-Ugalde, O., Montanarella, L., Jones, A. 2018. Soil erosion is unlikely to drive a future carbon sink in Europe. Science advances 4 (11): eaau3523. https://doi.org/10.1126/sciadv.aau3523

Lundström, U.S., Van Breemen, N., Bain, D. 2000. The podzolization process. A review. Geoderma 94 (2): 91-107. https://doi.org/10.1016/S0016-7061(99)00036-1

Lüthgens, C., Böse, M., Preusser, F. 2011. Age of the Pomeranian ice-marginal position in northeastern Germany determined by Optically Stimulated Luminescence (OSL) dating of glaciofluvial sediments. Boreas 40 (4): 598-615. https://doi.org/10.1111/j.1502-3885.2011.00211.x

Lv, M., Hao, Z., Liu, Z., Yu, Z. 2013. Conditions for lateral downslope unsaturated flow and effects of slope angle on soil moisture movement. Journal of Hydrology 486: 321 333. https://doi.org/10.1016/j.jhydrol.2013.02.013

Ma, L., Jin, L., Brantley, S.L. 2011. Geochemical behaviors of different element groups during shale weathering at the Susquehanna/Shale Hills Critical Zone Observatory. $\begin{array}{llll}\text { Applied } & \text { Geochemistry } & 26 & \text { (Supplement): }\end{array}$ https://doi.org/10.1016/j.apgeochem.2011.03.038

Ma, Y.-J., Li, X.-Y., Guo, L., Lin, H.S. 2017. Hydropedology: Interactions between pedologic and hydrologic processes across spatiotemporal scales. Earth-Science Reviews 171: 181-195. https://doi.org/10.1016/j.earscirev.2017.05.014

Ma, Y., Minasny, B., Malone, B.P., Mcbratney, A.B. 2019a. Pedology and digital soil mapping (DSM). European Journal of Soil Science 70 (2): 216-235. https://doi.org/10.1111/ejss.12790

Ma, Y., Minasny, B., Welivitiya, W.D.D.P., Malone, B.P., Willgoose, G.R., McBratney, A.B. 2019b. The feasibility of predicting the spatial pattern of soil particle-size 
distribution using a pedogenesis model. Geoderma 341: 195-205. https://doi.org/10.1016/j.geoderma.2019.01.049

Mackney, D. 1961. A podzol development sequence in oakwoods and heath in Central England. Journal of Soil Science 12 (1): 23-40. https://doi.org/10.1111/j.13652389.1961.tb00893.x

Maddy, D., Veldkamp, A., Wainwright, J. 2018. FACSIMILE - field and computer simulation in landscape evolution. Retrieved: 24 September 2019. from http://facsimile.maddyonline.co.uk/

Madsen, A.T., Murray, A.S. 2009. Optically stimulated luminescence dating of young sediments: a review. Geomorphology $109 \quad$ (1-2): 3-16. https://doi.org/10.1016/j.geomorph.2008.08.020

Madsen, A.T., Murray, A.S., Andersen, T.J., Pejrup, M., Breuning-Madsen, H. 2005. Optically stimulated luminescence dating of young estuarine sediments: a comparison with $210 \mathrm{~Pb}$ and $137 \mathrm{Cs}$ dating. Marine Geology 214 (1): 251-268. https://doi.org/10.1016/j.margeo.2004.10.034

Mao, D., Cherkauer, K.A. 2009. Impacts of land-use change on hydrologic responses in the Great Lakes region. Journal of Hydrology 374 (1): 71-82. https://doi.org/10.1016/j.jhydrol.2009.06.016

Marschmann, G.L., Pagel, H., Kügler, P., Streck, T. 2019. Equifinality, sloppiness, and emergent structures of mechanistic soil biogeochemical models. Environmental Modelling \& Software: 104518. https://doi.org/10.1016/j.envsoft.2019.104518

Mason, J.A., Jacobs, P.M., Gruley, K.E., Reyerson, P., Hanson, P.R. 2016. Parent material influence on soil response to vegetation change, Southeastern Minnesota, USA. Geoderma 275: 1-17. https://doi.org/10.1016/j.geoderma.2016.04.004

Masselink, R.J.H., Heckmann, T., Temme, A.J.A.M., Anders, N.S., Gooren, H.P.A., Keesstra, S.D. 2017. A network theory approach for a better understanding of overland flow connectivity. Hydrological Processes 31 (1): 207-220. https://doi.org/10.1002/hyp.10993

Mauruszat, A. 2016. Prenzlauer Kreisbahn. Retrieved: 16 June 2016. from http://bahnstrecken.de/indexf.htm?http://bahnstrecken.de/pkb.htm

Mavris, C., Egli, M., Plötze, M., Blum, J.D., Mirabella, A., Giaccai, D., Haeberli, W. 2010. Initial stages of weathering and soil formation in the Morteratsch proglacial area (Upper Engadine, Switzerland). Geoderma $155 \quad$ (3-4): 359-371. https://doi.org/10.1016/j.geoderma.2009.12.019

McBratney, A.B., Minasny, B., Cattle, S.R., Vervoort, R.W. 2002. From pedotransfer functions to soil inference systems. Geoderma 109 (1): 41-73. https://doi.org/10.1016/S0016-7061(02)00139-8

McBratney, A.B., Santos, M.M., Minasny, B. 2003. On digital soil mapping. Geoderma 117 (1): 3-52. https://doi.org/10.1016/S0016-7061(03)00223-4

McBratney, A.B., Webster, R. 1983. How many observations are needed for regional estimation of soil properties? Soil Science 135 (3): 177-183. 
McFadgen, B.G. 1980. Maori plaggen soils in New Zealand, their origin and properties. Journal of the Royal Society of New Zealand 10 (1): 3-18. https://doi.org/10.1080/03036758.1980.10426547

McGlynn, B.L., McDonnell, J.J. 2003. Quantifying the relative contributions of riparian and hillslope zones to catchment runoff. Water Resources Research 39 (11). https://doi.org/10.1029/2003WR002091

Mehta, V.K., Walter, M.T., Brooks, E.S., Steenhuis, T.S., Walter, M.F., Johnson, M., Boll, J., Thongs, D. 2004. Application of SMR to modeling watersheds in the Catskill Mountains. Environmental Modeling \& Assessment 9 (2): 77-89. https://doi.org/10.1023/B:ENMO.0000032096.13649.92

Mejdahl, V. 1979. Thermoluminescence dating: Beta-dose attenuation in quartz grains. Archaeometry 21 (1): 61-72. https://doi.org/10.1111/j.1475-4754.1979.tb00241.x

Mendyk, Ł., Markiewicz, M., Bednarek, R., Świtoniak, M., Gamrat, W.W., Krześlak, I., Sykuła, M., Gersztyn, L., Kupniewska, A. 2016. Environmental changes of a shallow kettle lake catchment in a young glacial landscape (Sumowskie Lake catchment), North-Central Poland. Quaternary International 418: 116-131. https://doi.org/10.1016/j.quaint.2015.10.008

Merriam-Webster. 2019. Landscape. Retrieved: 12 September 2019. from https://www.merriam-webster.com/dictionary/landscape

Miller, B.A., Koszinski, S., Hierold, W., Rogasik, H., Schröder, B., Van Oost, K., Wehrhan, M., Sommer, M. 2016. Towards mapping soil carbon landscapes: Issues of sampling scale and transferability. Soil and Tillage Research 156: 194-208. https://doi.org/10.1016/j.still.2015.07.004

Minasny, B., Finke, P.A., Stockmann, U., Vanwalleghem, T., McBratney, A.B. 2015. Resolving the integral connection between pedogenesis and landscape evolution. Earth-Science $\quad$ Reviews 150: 102-120. https://doi.org/10.1016/j.earscirev.2015.07.004

Minasny, B., Malone, B.P., McBratney, A.B., Angers, D.A., Arrouays, D., Chambers, A., Chaplot, V., Chen, Z.-S., Cheng, K., Das, B.S., Field, D.J., Gimona, A., Hedley, C.B., Hong, S.Y., Mandal, B., Marchant, B.P., Martin, M., McConkey, B.G., Mulder, V.L., O'Rourke, S., Richer-de-Forges, A.C., Odeh, I., Padarian, J., Paustian, K., Pan, G., Poggio, L., Savin, I., Stolbovoy, V., Stockmann, U., Sulaeman, Y., Tsui, C.-C., Vågen, T.-G., Van Wesemael, B., Winowiecki, L. 2017. Soil carbon 4 per mille. Geoderma 292: 59-86. https://doi.org/10.1016/j.geoderma.2017.01.002

Minasny, B., McBratney, A.B., Salvador-Blanes, S. 2008. Quantitative models for pedogenesis - A review. Geoderma $144 \quad$ (1-2): 140-157. https://doi.org/10.1016/j.geoderma.2007.12.013

Mirtl, M., Borer, E.T., Djukic, I., Forsius, M., Haubold, H., Hugo, W., Jourdan, J., Lindenmayer, D., McDowell, W.H., Muraoka, H. 2018. Genesis, goals and achievements of long-term ecological research at the global scale: a critical review of ILTER and future directions. Science of The Total Environment 626: 1439-1462. https://doi.org/10.1016/j.scitotenv.2017.12.001 
Mirus, B.B. 2015. Evaluating the importance of characterizing soil structure and horizons in parameterizing a hydrologic process model. Hydrological Processes 29 (21): 4611 4623. https://doi.org/10.1002/hyp.10592

Mischka, D. 2011. The Neolithic burial sequence at Flintbek LA 3, north Germany, and its cart tracks: a precise chronology. Antiquity 85 (329): 742-758. https://doi.org/10.1017/S0003598X00068289

Montagne, D., Cornu, S., Le Forestier, L., Cousin, I. 2009. Soil Drainage as an Active Agent of Recent Soil Evolution: A Review. Pedosphere 19 (1): 1-13. https://doi.org/10.1016/S1002-0160(08)60078-8

Montagne, D., Cornu, S., Le Forestier, L., Hardy, M., Josière, O., Caner, L., Cousin, I. 2008. Impact of drainage on soil-forming mechanisms in a French Albeluvisol: Input of mineralogical data in mass-balance modelling. Geoderma 145 (3-4): 426-438. https://doi.org/10.1016/j.geoderma.2008.02.005

Montanarella, L., Pennock, D.J., McKenzie, N., Badraoui, M., Chude, V., Baptista, I., Mamo, T., Yemefack, M., Singh Aulakh, M., Yagi, K., Young Hong, S., Vijarnsorn, P., Zhang, G.L., Arrouays, D., Black, H., Krasilnikov, P., Sobocká, J., Alegre, J., Henriquez, C.R., De Lourdes Mendonça-Santos, M., Taboada, M., EspinosaVictoria, D., AlShankiti, A., AlaviPanah, S.K., Elsheikh, E.A.E.M., Hempel, J., Camps Arbestain, M., Nachtergaele, F., Vargas, R. 2016. World's soils are under threat. SOIL 2 (1): 79-82. https://doi.org/10.5194/soil-2-79-2016

Montgomery, D.R. 2007. Soil erosion and agricultural sustainability. Proceedings of the national academy of sciences $104 \quad$ (33): $13268-13272$. https://doi.org/10.1073/pnas.0611508104

Morbidelli, R., Saltalippi, C., Flammini, A., Govindaraju, R.S. 2018. Role of slope on infiltration: a review. Journal of Hydrology 557: 878-886. https://doi.org/10.1016/j.jhydrol.2018.01.019

Muhs, D.R. 2007. Loess deposits, origins and properties. Encyclopedia of Quaternary Science 1405-1418. https://doi.org/10.1016/B0-44-452747-8/00158-7

Murray, A.B. 2003. Contrasting the goals, strategies, and predictions associated with simplified numerical models and detailed simulations. In: Wilcock, P.R.; Iverson, R.M. (Editors), Prediction in geomorphology, Volume 135, 151-168. American Geophysical Union, Washington, DC, USA.

Murray, A.S., Wintle, A.G. 2003. The single aliquot regenerative dose protocol: potential for improvements in reliability. Radiation Measurements 37 (4): 377-381. https://doi.org/10.1016/S1350-4487(03)00053-2

Naveed, M., Moldrup, P., Arthur, E., Wildenschild, D., Eden, M., Lamandé, M., Vogel, H.J., De Jonge, L.W. 2013. Revealing soil structure and functional macroporosity along a clay gradient using x-ray computed tomography. Soil Science Society of America Journal 77 (2): 403-411. https://doi.org/10.2136/sssaj2012.0134

Nearing, M.A., Pruski, F.F., O'Neal, M.R. 2004. Expected climate change impacts on soil erosion rates: A review. Journal of Soil and Water Conservation 59 (1): 43-50. 
Nemes, A., Schaap, M.G., Wösten, J.H.M. 2003. Functional Evaluation of Pedotransfer Functions Derived from Different Scales of Data Collection. Soil Science Society of America Journal 67 (4): 1093-1102. https://doi.org/10.2136/sssaj2003.1093

Nikorych, V.A., Szymański, W., Polchyna, S.M., Skiba, M. 2014. Genesis and evolution of the fragipan in Albeluvisols in the Precarpathians in Ukraine. Catena 119 (Supplement C): 154-165. https://doi.org/10.1016/j.catena.2014.02.011

Nimmo, D.G., Mac Nally, R., Cunningham, S.C., Haslem, A., Bennett, A.F. 2015. Vive la résistance: reviving resistance for 21 st century conservation. Trends in Ecology \& Evolution 30 (9): 516-523. https://doi.org/10.1016/j.tree.2015.07.008

Novak, V., Šimåunek, J., Van Genuchten, M.T. 2000. Infiltration of water into soil with cracks. Journal of Irrigation and Drainage Engineering 126 (1): 41-47. https://doi.org/10.1061/(ASCE)0733-9437(2000)126:1(41)

Nyssen, J., Govaerts, B., Araya, T., Cornelis, W.M., Bauer, H., Haile, M., Sayre, K., Deckers, J. 2011. The use of the marasha ard plough for conservation agriculture in Northern Ethiopia. Agronomy for Sustainable Development 31 (2): 287-297. https://doi.org/10.1051/agro/2010014

Opitz, K. 1938. Über die Bedeutung der Bodenbearbeitung und Kalkdüngung für die Ertragsfähigkeit leichter Böden. Bodenkunde und Pflanzenernährung 9 (1): 150158. https://doi.org/10.1002/jpln.19380090116

Opolot, E., Yu, Y.Y., Finke, P.A. 2015. Modeling soil genesis at pedon and landscape scales: Achievements and problems. Quaternary International 376: 34-46. https://doi.org/10.1016/j.quaint.2014.02.017

Pachepsky, Y., Hill, R.L. 2017. Scale and scaling in soils. Geoderma 287 (Supplement C): 4-30. https://doi.org/10.1016/j.geoderma.2016.08.017

Pachepsky, Y.A., Rawls, W.J. 2003. Soil structure and pedotransfer functions. European Journal of Soil Science 54 (3): 443-452. https://doi.org/10.1046/j.13652389.2003.00485.x

Pachepsky, Y.A., Rawls, W.J., Lin, H.S. 2006. Hydropedology and pedotransfer functions. Geoderma 131 (3): 308-316. https://doi.org/10.1016/j.geoderma.2005.03.012

Padarian, J., Minasny, B., McBratney, A.B. 2019. Using deep learning for digital soil mapping. SOIL 5 (1): 79-89. https://doi.org/10.5194/soil-5-79-2019

Palmer, M.A., Bernhardt, E.S. 2006. Hydroecology and river restoration: Ripe for research and synthesis. Water Resources Research 42 W03S07. https://doi.org/10.1029/2005wr004354

Panday, S., Huyakorn, P.S. 2004. A fully coupled physically-based spatially-distributed model for evaluating surface/subsurface flow. Advances in Water Resources 27 (4): 361-382. https://doi.org/10.1016/j.advwatres.2004.02.016

Pape, J.C. 1970. Plaggen soils in the Netherlands. Geoderma 4 (3): 229-255. https://doi.org/10.1016/0016-7061(70)90005-4

Parazoo, N.C., Koven, C.D., Lawrence, D.M., Romanovsky, V., Miller, C.E. 2018. Detecting the permafrost carbon feedback: talik formation and increased cold-season 
respiration as precursors to sink-to-source transitions. The Cryosphere 12 (1): 123 144. https://doi.org/10.5194/tc-12-123-2018

Pavelka, J., Smetanová, A., Rejman, J., Kováčik, P. 2017. An interdisciplinary tillage erosion experiment: establishing a field in grassland with reconstructed ard plough of the Bronze Age-Iron Age. Cuadernos de Investigación Geográfica 43 (1): 101-118. http://doi.org/10.18172/cig.3131

Pawlik, Ł., Šamonil, P. 2018. Soil creep: The driving factors, evidence and significance for biogeomorphic and pedogenic domains and systems - A critical literature review. Earth-Science Reviews 178: 257-278. https://doi.org/10.1016/j.earscirev.2018.01.008

Pebesma, E.J. 2004. Multivariable geostatistics in S: the gstat package. Computers \& Geosciences 30 (7): 683-691. https://doi.org/10.1016/j.cageo.2004.03.012

Pécsi, M. 1990. Loess is not just the accumulation of dust. Quaternary International 7-8: 121. https://doi.org/10.1016/1040-6182(90)90034-2

Peeters, I., Rommens, T., Verstraeten, G., Govers, G., Van Rompaey, A., Poesen, J., Van Oost, K. 2006. Reconstructing ancient topography through erosion modelling. Geomorphology 78 (3): 250-264. https://doi.org/10.1016/j.geomorph.2006.01.033

Pennock, D.J. 2003. Multi-site assessment of cultivation-induced soil change using revised landform segmentation procedures. Canadian Journal of Soil Science 83 (5): 565 580. https://doi.org/10.4141/S03-010

Pennock, D.J., Bedard-Haughn, A., Viaud, V. 2011. Chernozemic soils of Canada: Genesis, distribution, and classification. Canadian Journal of Soil Science 91 (5): 719-747. https://doi.org/10.4141/cjss10022

Pennock, D.J., Zebarth, B.J., De Jong, E. 1987. Landform classification and soil distribution in hummocky terrain, Saskatchewan, Canada. Geoderma 40 (3): 297-315. https://doi.org/10.1016/0016-7061(87)90040-1

Perrin, C., Michel, C., Andréassian, V. 2001. Does a large number of parameters enhance model performance? Comparative assessment of common catchment model structures on 429 catchments. Journal of Hydrology 242 (3): 275-301. https://doi.org/10.1016/S0022-1694(00)00393-0

Perron, J.T., Fagherazzi, S. 2012. The legacy of initial conditions in landscape evolution. Earth Surface Processes and Landforms $37 \quad$ (1): 52-63. https://doi.org/10.1002/esp.2205

Petersen, C.T., Trautner, A., Hansen, S. 2008. Spatio-temporal variation of anisotropy of saturated hydraulic conductivity in a tilled sandy loam soil. Soil and Tillage Research 100 (1): 108-113. https://doi.org/10.1016/j.still.2008.05.004

Philip, J.R. 1957. The theory of infiltration: 1 . The infiltration equation and its solution. Soil Science 83 (5): 345-358.

Phillips, J.D. 1993a. Progressive and Regressive Pedogenesis and Complex Soil Evolution. Quaternary Research 40 (2): 169-176. https://doi.org/10.1006/qres.1993.1069 
Phillips, J.D. 1993b. Stability implications of the state factor model of soils as a nonlinear dynamical system. Geoderma 58 (1): 1-15. https://doi.org/10.1016/00167061(93)90082-V

Phillips, J.D. 2001. Divergent evolution and the spatial structure of soil landscape variability. Catena 43 (2): 101-113. https://doi.org/10.1016/S0341-8162(00)00122-3

Phillips, J.D. 2003. Sources of nonlinearity and complexity in geomorphic systems. Progress $\begin{array}{lllll}\text { in } & \text { Physical } & \text { Geography } & 27 & \text { (1): }\end{array}$ https://doi.org/10.1191\%2F0309133303pp340ra

Phillips, J.D. 2008. Soil system modelling and generation of field hypotheses. Geoderma 145 (3): 419-425. https://doi.org/10.1016/j.geoderma.2007.07.001

Phillips, J.D. 2009. Soils as extended composite phenotypes. Geoderma 149 (1): 143-151. https://doi.org/10.1016/j.geoderma.2008.11.028

Phillips, J.D. 2010. The convenient fiction of steady-state soil thickness. Geoderma 156 (3): 389-398. https://doi.org/10.1016/j.geoderma.2010.03.008

Phillips, J.D. 2017. Soil Complexity and Pedogenesis. Soil Science 182 (4): 117-127. https://doi.org/10.1097/SS.0000000000000204

Phillips, J.D. 2019. Evolutionary Pathways in Soil-Geomorphic Systems. Soil Science 184 (1): 1-12. https://doi.org/10.1097/ss.0000000000000246

Phillips, J.D., Gares, P.A., Slattery, M.C. 1999. Agricultural soil redistribution and landscape complexity. Landscape Ecology $14 \quad$ (2): $197-211$. https://doi.org/10.1023/a:1008024213440

Phillips, J.D., Lorz, C. 2008. Origins and implications of soil layering. Earth-Science Reviews 89 (3-4): 144-155. https://doi.org/10.1016/j.earscirev.2008.04.003

Phillips, J.D., Šamonil, P., Pawlik, Ł., Trochta, J., Daněk, P. 2017. Domination of hillslope denudation by tree uprooting in an old-growth forest. Geomorphology 276: 27-36. https://doi.org/10.1016/j.geomorph.2016.10.006

Phong, V.V.L., Kumar, P. 2014. Power law scaling of topographic depressions and their hydrologic connectivity. Geophysical Research Letters 41 (5): 1553-1559. https://doi.org/10.1002/2013GL059114

Pierik, H.J., Van Lanen, R.J., Gouw-Bouman, M.T.1.J., Groenewoudt, B.J., Wallinga, J., Hoek, W.Z. 2018. Controls on late-Holocene drift-sand dynamics: The dominant role of human pressure in the Netherlands. The Holocene 28 (9): 1361-1381. https://doi.org/10.1177/0959683618777052

Pimentel, D. 2006. Soil Erosion: A Food and Environmental Threat. Environment, Development and Sustainability 8 (1): 119-137. https://doi.org/10.1007/s10668$\underline{005-1262-8}$

Pimentel, D., Burgess, M. 2013. Soil erosion threatens food production. Agriculture 3 (3): 443-463. https://doi.org/10.3390/agriculture3030443

Pimentel, D., Harvey, C., Resosudarmo, P., Sinclair, K., Kurz, D., McNair, M., Crist, S., Shpritz, L., Fitton, L., Saffouri, R., Blair, R. 1995. Environmental and economic costs of soil erosion and conservation benefits. Science 267 (5201): 1117-1122. https://doi.org/10.1126/science.267.5201.1117 
Pimentel, D., Kounang, N. 1998. Ecology of Soil Erosion in Ecosystems. Ecosystems 1 (5): 416-426. https://doi.org/10.1007/s100219900035

Pistocchi, A., Bouraoui, F., Bittelli, M. 2008. A simplified parameterization of the monthly topsoil water budget. Water Resources Research 44 (12). https://doi.org/10.1029/2007WR006603

Poesen, J. 2011. Challenges in gully erosion research. Landform Analysis 17: 5-9.

Poesen, J. 2018. Soil erosion in the Anthropocene: Research needs. Earth Surface Processes and Landforms 43 (1): 64-84. https://doi.org/10.1002/esp.4250

Pongratz, J., Reick, C., Raddatz, T., Claussen, M. 2008. A reconstruction of global agricultural areas and land cover for the last millennium. Global Biogeochemical Cycles 22 GB3018. https://doi.org/10.1029/2007gb003153

Porder, S. 2014. Coevolution of life and landscapes. Proceedings of the national academy of sciences 111 (9): 3207-3208. https://doi.org/10.1073/pnas.1400954111

Poreba, G.J. 2006. Caesium-137 as a soil erosion tracer: a review. Geochronometria 25 (3746).

Prescott, J.R., Hutton, J.T. 1994. Cosmic ray contributions to dose rates for luminescence and ESR dating: large depths and long-term time variations. Radiation Measurements 23 (2): 497-500. https://doi.org/10.1016/1350-4487(94)90086-8

Preußische Urmesstischblätter. 1826. Aufnahme Dedelow.

Pringle, M.J., Romano, N., Minasny, B., Chirico, G.B., Lark, R.M. 2007. Spatial evaluation of pedotransfer functions using wavelet analysis. Journal of Hydrology 333 (2): 182-198. https://doi.org/10.1016/j.jhydrol.2006.08.007

Purton, K., Pennock, D., Leinweber, P., Walley, F. 2015. Will changes in climate and land use affect soil organic matter composition? Evidence from an ecotonal climosequence. Geoderma 253: 48-60. https://doi.org/10.1016/j.geoderma.2015.04.007

Quénard, L., Samouëlian, A., Laroche, B., Cornu, S. 2011. Lessivage as a major process of soil formation: A revisitation of existing data. Geoderma 167-168 (0): 135-147. https://doi.org/10.1016/j.geoderma.2011.07.031

Rainer, H., Xinhua, P., Heiner, F., Jose, D. 2014. Pore rigidity in structured soils - only a theoretical boundary condition for hydraulic properties? Soil science and plant nutrition 60 (1): 3-14. https://doi.org/10.1080/00380768.2014.886159

Rasmussen, C., Tabor, N.J. 2007. Applying a Quantitative Pedogenic Energy Model across a Range of Environmental Gradients. Soil Science Society of America Journal 71 (6): 1719-1729. https://doi.org/10.2136/sssaj2007.0051

Regmi, N.R., McDonald, E.V., Rasmussen, C. 2019. Hillslope response under variable microclimate. Earth Surface Processes and Landforms 44: 2615-2627. https://doi.org/10.1002/esp.4686

Reimann, T., Román-Sánchez, A., Vanwalleghem, T., Wallinga, J. 2017. Getting a grip on soil reworking - Single-grain feldspar luminescence as a novel tool to quantify soil reworking rates. Quaternary Geochronology 42: 1-14. https://doi.org/10.1016/j.quageo.2017.07.002 
Rhodes, E.J., Bronk Ramsey, C., Outram, Z., Batt, C., Willis, L., Dockrill, S., Bond, J. 2003. Bayesian methods applied to the interpretation of multiple OSL dates: high precision sediment ages from Old Scatness Broch excavations, Shetland Isles. Quaternary Science Reviews $22 \quad$ (10-13): 1231-1244. https://doi.org/10.1016/S0277-3791(03)00046-5

Richter, D.d., Bacon, A.R., Brecheisen, Z., Mobley, M.L. 2015. Soil in the Anthropocene. IOP Conference Series: Earth and Environmental Science, p 012010. IOP Publishing.

Richter, D.d., Yaalon, D.H. 2012. "The Changing Model of Soil” Revisited. Soil Science Society of America Journal 76 (3): 766-778. https://doi.org/10.2136/sssaj2011.0407

Rieckh, H., Gerke, H.H., Glæsner, N., Kjaergaard, C. 2015. Tracer, dissolved organic carbon, and colloid leaching from erosion-affected arable hillslope soils. Vadose Zone Journal 14 (12). https://doi.org/10.2136/vzj2015.08.0110

Rieckh, H., Gerke, H.H., Siemens, J., Sommer, M. 2014. Water and dissolved carbon fluxes in an eroding soil landscape depending on terrain position. Vadose Zone Journal 13 (7). https://doi.org/10.2136/vzj2013.10.0173

Rieckh, H., Gerke, H.H., Sommer, M. 2012. Hydraulic properties of characteristic horizons depending on relief position and structure in a hummocky glacial soil landscape. Soil and Tillage Research $125 \quad$ (0): 123-131. https://doi.org/10.1016/j.still.2012.07.004

Ritchie, J.C., McHenry, J.R. 1990. Application of radioactive fallout cesium-137 for measuring soil erosion and sediment accumulation rates and patterns: a review. Journal of Environmental Quality $19 \quad$ (2): 215-233. https://doi.org/10.2134/jeq1990.00472425001900020006x

Rodzik, J., Mroczek, P., Wiśniewski, T. 2014. Pedological analysis as a key for reconstructing primary loess relief - a case study from the magdalenian site in klementowice (eastern poland). Catena 117: 50-59. https://doi.org/10.1016/j.catena.2013.09.001

Roering, J.J., Almond, P., Tonkin, P., McKean, J. 2002. Soil transport driven by biological processes over millennial time scales. Geology 30 (12): 1115-1118. https://doi.org/10.1130/0091-7613(2002)030<1115:STDBBP $>2.0 . C O ; 2$

Roering, J.J., Kirchner, J.W., Dietrich, W.E. 2001a. Hillslope evolution by nonlinear, slopedependent transport: Steady state morphology and equilibrium adjustment timescales. Journal of Geophysical Research: Solid Earth 106 (B8): 16499-16513. https://doi.org/10.1029/2001JB000323

Roering, J.J., Kirchner, J.W., Sklar, L.S., Dietrich, W.E. 2001b. Hillslope evolution by nonlinear creep and landsliding: An experimental study. Geology 29 (2): 143-146. https://doi.org/10.1130/0091-7613(2001)029\%3C0143:HEBNCA\%3E2.0.CO;2

Román-Sánchez, A., Laguna, A., Reimann, T., Giraldez, J., Peña, A., Vanwalleghem, T. 2019a. Bioturbation and erosion rates along the soil-hillslope conveyor belt, part 2: quantification using an analytical solution of the diffusion-advection equation. 
Earth Surface Processes and Landforms 44: 2066-2080. https://doi.org/10.1002/esp.4626

Román-Sánchez, A., Reimann, T., Wallinga, J., Vanwalleghem, T. 2019b. Bioturbation and erosion rates along the soil-hillslope conveyor belt, part 1: insights from single-grain feldspar luminescence. Earth Surface Processes and Landforms 44: 2051-2065. https://doi.org/10.1002/esp.4628

Román-Sánchez, A., Vanwalleghem, T., Peña, A., Laguna, A., Giráldez, J.V. 2018. Controls on soil carbon storage from topography and vegetation in a rocky, semi-arid landscapes.

Geoderma

311:

159-166.

https://doi.org/10.1016/j.geoderma.2016.10.013

Romano, N., Palladino, M. 2002. Prediction of soil water retention using soil physical data and terrain attributes. Journal of Hydrology 265 (1): 56-75. https://doi.org/10.1016/S0022-1694(02)00094-X

Rommens, T., Verstraeten, G., Lang, A., Poesen, J., Govers, G., Van Rompaey, A., Peeters, I. 2005. Soil erosion and sediment deposition in the Belgian loess belt during the Holocene: establishing a sediment budget for a small agricultural catchment. The Holocene 15 (7): 1032-1043. https://doi.org/10.1191/0959683605hl876ra

Roosevelt, A.C. 2013. The Amazon and the Anthropocene: 13,000 years of human influence in a tropical rainforest. Anthropocene 4: 69-87. https://doi.org/10.1016/j.ancene.2014.05.001

Rosenbloom, N.A., Doney, S.C., Schimel, D.S. 2001. Geomorphic evolution of soil texture and organic matter in eroding landscapes. Global Biogeochemical Cycles 15 (2): 365-381. https://doi.org/10.1029/1999GB001251

Rothacker, L., Dosseto, A., Francke, A., Chivas, A.R., Vigier, N., Kotarba-Morley, A.M., Menozzi, D. 2018. Impact of climate change and human activity on soil landscapes over the past 12,300 years. Scientific Reports 8 (1): 247. https://doi.org/10.1038/s41598-017-18603-4

Roulier, S., Jarvis, N.J. 2003. Modeling Macropore Flow Effects on Pesticide Leaching. Journal of Environmental Quality $32 \quad$ (6): 2341-2353. https://doi.org/10.2134/jeq2003.2341

Rozas, V. 2003. Tree age estimates in Fagus sylvatica and Quercus robur: testing previous and improved methods. Plant Ecology $167 \quad$ (2): 193-212. https://doi.org/10.1023/a:1023969822044

Rumpel, C., Amiraslani, F., Chenu, C., Garcia Cardenas, M., Kaonga, M., Koutika, L.-S., Ladha, J., Madari, B., Shirato, Y., Smith, P., Soudi, B., Soussana, J.-F., Whitehead, D., Wollenberg, E. 2019. The 4p1000 initiative: Opportunities, limitations and challenges for implementing soil organic carbon sequestration as a sustainable development strategy. Ambio 49: 350-360. https://doi.org/10.1007/s13280-019$\underline{01165-2}$

Rumpel, C., Kögel-Knabner, I. 2011. Deep soil organic matter - a key but poorly understood component of terrestrial C cycle. Plant and Soil 338 (1-2): 143-158. https://doi.org/10.1007/s11104-010-0391-5 
Saco, P.M., Willgoose, G.R., Hancock, G.R. 2006. Spatial organization of soil depths using a landform evolution model. Journal of Geophysical Research: Earth Surface 111 F02016. https://doi.org/10.1029/2005JF000351

Saey, T., Simpson, D., Vitharana, U.W., Vermeersch, H., Vermang, J., Van Meirvenne, M. 2008. Reconstructing the paleotopography beneath the loess cover with the aid of an electromagnetic induction sensor. Catena 74 (1): 58-64. https://doi.org/10.1016/j.catena.2008.03.007

Samia, J., Temme, A.J.A.M., Bregt, A., Wallinga, J., Guzzetti, F., Ardizzone, F., Rossi, M. 2017. Do landslides follow landslides? Insights in path dependency from a multitemporal landslide inventory. Landslides $14 \quad$ (2): 547-558. https://doi.org/10.1007/s10346-016-0739-x

Šamonil, P., Daněk, P., Schaetzl, R., Vašíčková, I., Valtera, M. 2015. Soil mixing and genesis as affected by tree uprooting in three temperate forests. European Journal of Soil Science 66 (3): 589-603. https://doi.org/10.1111/ejss.12245

Šamonil, P., Daněk, P., Schaetzl, R.J., Tejnecký, V., Drábek, O. 2018. Converse pathways of soil evolution caused by tree uprooting: A synthesis from three regions with varying soil formation processes. Catena 161: 122-136. https://doi.org/10.1016/j.catena.2017.09.032

Šamonil, P., Valtera, M., Schaetzl, R.J., Adam, D., Vašíčková, I., Daněk, P., Janík, D., Tejnecký, V. 2016. Impacts of old, comparatively stable, treethrow microtopography on soils and forest dynamics in the northern hardwoods of Michigan, USA. Catena 140 (Supplement C): 55-65. https://doi.org/10.1016/j.catena.2016.01.006

Samouëlian, A., Finke, P., Goddéris, Y., Cornu, S. 2012. Chapter 19 - Hydrologic Information in Pedologic Models. In: Lin, H.S. (Editor), Hydropedology, 595-636. Academic Press, Boston.

Šarauskis, E., Vaiciukevičius, E., Sakalauskas, A., Romaneckas, K., Jasinskas, A., Lillak, R. 2008. Impact of sowing speed on the introduction of winter wheat seeds in differently-tilled soils. Agronomy Research 6: 315-327. https://doi.org/20.500.12259/80953

Sauer, D. 2015. Pedological concepts to be considered in soil chronosequence studies. Soil Research 53 (6): 577-591. https://doi.org/10.1071/SR14282

Sauer, D., Finke, P., Sørensen, R., Sperstad, R., Schülli-Maurer, I., Høeg, H., Stahr, K. 2012. Testing a soil development model against southern Norway soil chronosequences. Quaternary International 265: 18-31. https://doi.org/10.1016/j.quaint.2011.12.018

Sauer, D., Schülli-Maurer, I., Wagner, S., Scarciglia, F., Sperstad, R., Svendgård-Stokke, S., Sørensen, R., Schellmann, G. 2015. Soil development over millennial timescales-a comparison of soil chronosequences of different climates and lithologies. IOP Conference Series: Earth and Environmental Science, 012009. IOP Publishing.

Sawicka, K., Heuvelink, G.B.M. 2016. 'spup' - An R package for uncertainty propagation in spatial environmental modelling. In: Bailly, J.-S.; Griffith, D.; Josselin, D. (Editors), 
Proceedings of Spatial Accuracy 2016, 275-282. International Spatial Accuracy Research Association (ISARA).

Schaap, M.G., Leij, F.J., Van Genuchten, M.T. 2001. ROSETTA: a computer program for estimating soil hydraulic parameters with hierarchical pedotransfer functions. Journal of Hydrology 251 (3): 163-176. https://doi.org/10.1016/S00221694(01)00466-8

Schädel, C., Koven, C.D., Lawrence, D.M., Celis, G., Garnello, A.J., Hutchings, J., Mauritz, M., Natali, S.M., Pegoraro, E., Rodenhizer, H., Salmon, V.G., Taylor, M.A., Webb, E.E., Wieder, W.R., Schuur, E.A.G. 2018. Divergent patterns of experimental and model-derived permafrost ecosystem carbon dynamics in response to Arctic warming. Environmental Research Letters $13 \quad$ (10): 105002. https://doi.org/10.1088/1748-9326/aae0ff

Schaetzl, R.J., Thompson, M.L. 2015. Soils. University press, Cambridge

Schatz, T. 2000. Untersuchungen zur holozänen Landschaftsentwicklung Nordostdeutschlands. ZALF, Müncheberg, Germany.

Schier, W. 2009. Extensiver Brandfeldbau und die Ausbreitung der neolithischen Wirtschaftsweise in Mitteleuropa und Südskandinavien am Ende des 5. Jahrtausends v. Chr. Prähistorische Zeitschrift $84 \quad$ (1): 15-43. https://doi.org/10.1515/pz.2009.002

Schimmack, W., Bunzl, K., Flessa, H. 1994. Short-term and long-term effects of ploughing on the vertical distribution of radiocaesium in two Bavarian soils. Soil Use and Management 10 (4): 164-168. https://doi.org/10.1111/j.1475-2743.1994.tb00480.x

Schlesinger, W.H., Amundson, R. 2019. Managing for soil carbon sequestration: Let's get realistic. Global Change Biology $25 \quad$ (2): 386-389. https://doi.org/10.1111/gcb.14478

Schlüter, S., Vogel, H.-J. 2016. Analysis of soil structure turnover with Garnet particles and X-Ray microtomography. PloS one $11 \quad$ (7): 0159948. https://doi.org/10.1371/journal.pone.0159948

Schmidt, K., Behrens, T., Daumann, J., Ramirez-Lopez, L., Werban, U., Dietrich, P., Scholten, T. 2014. A comparison of calibration sampling schemes at the field scale. Geoderma 232-234: 243-256. https://doi.org/10.1016/j.geoderma.2014.05.013

Schoorl, J.M., Veldkamp, A. 2001. Linking land use and landscape process modelling: A case study for the Álora region (South Spain). Agriculture, Ecosystems and Environment 85 (1-3): 281-292. https://doi.org/10.1016/S0167-8809(01)00194-3

Schoorl, J.M., Veldkamp, A., Bouma, J. 2002. Modeling Water and Soil Redistribution in a Dynamic Landscape Context. Soil Science Society of American Journal 66 (5): 1610-1619. https://doi.org/10.2136/sssaj2002.1610

Schuller, P., Walling, D.E., Sepulveda, A., Trumper, R.E., Rouanet, J.L., Pino, I., Castillo, A. 2004. Use of $137 \mathrm{Cs}$ measurements to estimate changes in soil erosion rates associated with changes in soil management practices on cultivated land. Applied $\begin{array}{llll}\text { Radiation } \quad \text { and } & \text { Isotopes } & \text { 759-766. }\end{array}$ https://doi.org/10.1016/j.apradiso.2003.11.087 
Schülli-Maurer, I., Sauer, D., Stahr, K., Sperstad, R., Sørensen, R. 2007. Soil formation in marine sediments and beach deposits of southern Norway: Investigations of soil chronosequences in the Oslofjord region. Revista Mexicana de Ciencias Geologicas 24 (2): 237-246.

Schuur, E.A.G., McGuire, A.D., Schädel, C., Grosse, G., Harden, J.W., Hayes, D.J., Hugelius, G., Koven, C.D., Kuhry, P., Lawrence, D.M. 2015. Climate change and the permafrost carbon feedback. Nature 520 (7546): 171-179. https://doi.org/10.1038/nature14338

Sevink, J., Koster, E.A., Van Geel, B., Wallinga, J. 2013. Drift sands, lakes, and soils: the multiphase Holocene history of the Laarder Wasmeren area near Hilversum, the Netherlands. Netherlands Journal of Geosciences 92 (04): 243-266. https://doi.org/10.1017/S0016774600000196

Shan, Y., Wang, Q. 2012. Simulation of salinity distribution in the overlap zone with doublepoint-source drip irrigation using HYDRUS-3D. Australian Journal of crop science $6(2): 238$.

Shepard, C. 2018. Understanding quaternary soil formation using a synthesis of soil chronosequences. Department of soil, water and environmental science. University of Arizona, Arizona.

Shepard, C., Schaap, M.G., Pelletier, J.D., Rasmussen, C. 2017. A probabilistic approach to quantifying soil physical properties via time-integrated energy and mass input. SOIL 3 (1): 67. https://doi.org/10.5194/soil-3-67-2017

Sherratt, A. 1981. Plough and pastoralism: aspects of the secondary products revolution. In: Isaac, G.L.; Hammond, N. (Editors), Pattern of the past: studies in honour of David Clarke, 155-199. Camvridge University Press, Cambridge.

Shi, J.S., Wu, L.Z., Wu, S.R., Li, B., Wang, T., Xin, P. 2016. Analysis of the causes of largescale loess landslides in Baoji, China. Geomorphology 264 (Supplement C): 109117. https://doi.org/10.1016/j.geomorph.2016.04.013

Shouse, M., Phillips, J.D. 2016. Soil deepening by trees and the effects of parent material. Geomorphology 269: 1-7. https://doi.org/10.1016/j.geomorph.2016.06.031

Sietz, D., Fleskens, L., Stringer, L.C. 2017. Learning from Non-Linear Ecosystem Dynamics Is Vital for Achieving Land Degradation Neutrality. Land Degradation \& Development 28 (7): 2308-2314. https://doi.org/10.1002/ldr.2732

Šimůnek, J., Jarvis, N.J., Van Genuchten, M.T., Gärdenäs, A. 2003. Review and comparison of models for describing non-equilibrium and preferential flow and transport in the vadose zone. Journal of Hydrology 272 (1): 14-35. https://doi.org/10.1016/S00221694(02)00252-4

Šimůnek, J., Van Genuchten, M.T., Šejna, M. 2006. The HYDRUS software package for simulating two-and three-dimensional movement of water, heat, and multiple solutes in variably-saturated media, Version 1.0. Technical manual, version, $\mathrm{p} 241$. PC Progress, Prague, Czech Republic.

Sivapalan, M., Blöschl, G. 2015. Time scale interactions and the coevolution of humans and water. Water Resources Research. https://doi.org/10.1002/2015WR017896 
Smetanová, A. 2009. Bright patches on Chernozems and their relationship to relief. Geografický časopis 61 (3): 215-227.

Smith, B.D., Zeder, M.A. 2013. The onset of the Anthropocene. Anthropocene 4: 8-13. https://doi.org/10.1016/j.ancene.2013.05.001

Snowden, T.J., Van der Graaf, P.H., Tindall, M.J. 2017. Methods of Model Reduction for Large-Scale Biological Systems: A Survey of Current Methods and Trends. Bulletin of Mathematical Biology 79 (7): 1449-1486. https://doi.org/10.1007/s11538-0170277-2

Sommer, M. 2006. Influence of soil pattern on matter transport in and from terrestrial biogeosystems - A new concept for landscape pedology. Geoderma 133 (1-2): 107123. https://doi.org/10.1016/j.geoderma.2006.03.040

Sommer, M., Augustin, J., Kleber, M. 2016. Feedbacks of soil erosion on SOC patterns and carbon dynamics in agricultural landscapes - The CarboZALF experiment. Soil \& Tillage Research 156: 182-184. https://doi.org/10.1016/j.still.2015.09.015

Sommer, M., Gerke, H.H., Deumlich, D. 2008. Modelling soil landscape genesis - A "time split” approach for hummocky agricultural landscapes. Geoderma 145 (3-4): 480493. https://doi.org/10.1016/j.geoderma.2008.01.012

Sommer, M., Halm, D., Weller, U., Zarei, M., Stahr, K. 2000. Lateral podzolization in a granite landscape. 64 (4): 1434-1442. https://doi.org/10.2136/sssaj2000.6441434x

Sommer, M., Schlichting, E. 1997. Archetypes of catenas in respect to matter - a concept for structuring and grouping catenas. Geoderma 76 (1-2): 1-33. https://doi.org/10.1016/S0016-7061(96)00095-X

Sommer, M., Thies, H., Kolb, E., Bächle, H., Stahr, K. 1997. Biogeochemistry of a cirquelake landscape: An interdisciplinary study in a catchment of the northern Black Forest, Germany. Water Resources Research 33 (9): 2129-2142. https://doi.org/10.1029/97WR01501

Song, Y., Liu, L., Yan, P., Cao, T. 2005. A review of soil erodibility in water and wind erosion research. Journal of Geographical Sciences 15 (2): 167-176. https://doi.org/10.1007/BF02872682

Sørensen, L., Karg, S. 2014. The expansion of agrarian societies towards the north-new evidence for agriculture during the Mesolithic/Neolithic transition in Southern Scandinavia. Journal of Archaeological Science 51: 98-114. https://doi.org/10.1016/j.jas.2012.08.042

Stephens, L., Fuller, D., Boivin, N., Rick, T., Gauthier, N., Kay, A., Marwick, B., Armstrong, C.G., Barton, C.M., Denham, T., Douglass, K., Driver, J., Janz, L., Roberts, P., Rogers, J.D., Thakar, H., Altaweel, M., Johnson, A.L., Sampietro Vattuone, M.M., Aldenderfer, M., Archila, S., Artioli, G., Bale, M.T., Beach, T., Borrell, F., Braje, T., Buckland, P.I., Jiménez Cano, N.G., Capriles, J.M., Diez Castillo, A., Çilingiroğlu, Ç., Negus Cleary, M., Conolly, J., Coutros, P.R., Covey, R.A., Cremaschi, M., Crowther, A., Der, L., di Lernia, S., Doershuk, J.F., Doolittle, W.E., Edwards, K.J., Erlandson, J.M., Evans, D., Fairbairn, A., Faulkner, P., Feinman, G., Fernandes, R., Fitzpatrick, S.M., Fyfe, R., Garcea, E., Goldstein, S., Goodman, 
R.C., Dalpoim Guedes, J., Herrmann, J., Hiscock, P., Hommel, P., Horsburgh, K.A., Hritz, C., Ives, J.W., Junno, A., Kahn, J.G., Kaufman, B., Kearns, C., Kidder, T.R., Lanoë, F., Lawrence, D., Lee, G.-A., Levin, M.J., Lindskoug, H.B., López-Sáez, J.A., Macrae, S., Marchant, R., Marston, J.M., McClure, S., McCoy, M.D., Miller, A.V., Morrison, M., Motuzaite Matuzeviciute, G., Müller, J., Nayak, A., Noerwidi, S., Peres, T.M., Peterson, C.E., Proctor, L., Randall, A.R., Renette, S., Robbins Schug, G., Ryzewski, K., Saini, R., Scheinsohn, V., Schmidt, P., Sebillaud, P., Seitsonen, O., Simpson, I.A., Sołtysiak, A., Speakman, R.J., Spengler, R.N., Steffen, M.L., Storozum, M.J., Strickland, K.M., Thompson, J., Thurston, T.L., Ulm, S., Ustunkaya, M.C., Welker, M.H., West, C., Williams, P.R., Wright, D.K., Wright, N., Zahir, M., Zerboni, A., Beaudoin, E., Munevar Garcia, S., Powell, J., Thornton, A., Kaplan, J.O., Gaillard, M.-J., Klein Goldewijk, K., Ellis, E. 2019. Archaeological assessment reveals Earth's early transformation through land use. Science 365 (6456): 897. https://doi.org/10.1126/science.aax1192

Stevens, P.R., Walker, T.W. 1970. The Chronosequence Concept and Soil Formation. The Quarterly Review of Biology 45 (4): 333-350. https://doi.org/10.1086/406646

Stockmann, U., Salvador-Blanes, S., Vanwalleghem, T., Minasny, B., McBratney, A.B. 2018. One-, Two- and Three-Dimensional Pedogenetic Models. In: McBratney, A.B.; Minasny, B.; Stockmann, U. (Editors), Pedometrics, 555-593. Springer International Publishing, Cham.

Stumpp, C., Hendry, M.J. 2012. Spatial and temporal dynamics of water flow and solute transport in a heterogeneous glacial till: The application of high-resolution profiles of $\delta 18 \mathrm{O}$ and $\delta 2 \mathrm{H}$ in pore waters. Journal of Hydrology 438-439: 203-214. https://doi.org/10.1016/j.jhydrol.2012.03.024

Swanson, F.J., Swanston, D.N. 1977. Complex mass-movement terrains in the western Cascade Range, Oregon. In: Coates, D.R. (Editor), Reviews in Engineering Geology, 113-124. The geological society of America.

Swift Jr, L.W. 1976. Algorithm for solar radiation on mountain slopes. Water Resources Research 12 (1): 108-112. https://doi.org/10.1029/WR012i001p00108

Świtoniak, M. 2014. Use of soil profile truncation to estimate influence of accelerated erosion on soil cover transformation in young morainic landscapes, North-Eastern Poland. Catena 116: 173-184. https://doi.org/10.1016/j.catena.2013.12.015

Świtoniak, M., Mroczek, P., Bednarek, R. 2016. Luvisols or Cambisols? Micromorphological study of soil truncation in young morainic landscapes - Case study: Brodnica and Chełmno Lake Districts (North Poland). Catena 137: 583-595. https://doi.org/10.1016/j.catena.2014.09.005

Szymański, W., Skiba, M., Skiba, S. 2011. Fragipan horizon degradation and bleached tongues formation in Albeluvisols of the Carpathian Foothills, Poland. Geoderma 167-168 (Supplement C): 340-350. https://doi.org/10.1016/j.geoderma.2011.07.007

Szymański, W., Skiba, S. 2011. Micromorphological properties of the fragipan horizon in Albeluvisols of the Carpathian Foothills. Polish Journal of Soil Science 44 (2): 193 200. 
Tan, Z.X., Lal, R., Wiebe, K.D. 2005. Global Soil Nutrient Depletion and Yield Reduction. Journal of Sustainable Agriculture $26 \quad$ (1): 123-146. https://doi.org/10.1300/J064v26n01_10

Targulian, V.O., Bronnikova, M.A. 2019. Soil Memory: Theoretical Basics of the Concept, Its Current State, and Prospects for Development. Eurasian Soil Science 52 (3): 229243. https://doi.org/10.1134/s1064229319030116

Targulian, V.O., Krasilnikov, P.V. 2007. Soil system and pedogenic processes: Selforganization, time scales, and environmental significance. Catena 71 (3): 373-381. https://doi.org/10.1016/j.catena.2007.03.007

Tebaldi, C., Knutti, R. 2007. The use of the multi-model ensemble in probabilistic climate projections. Philosophical Transactions of the Royal Society A: Mathematical, Physical and Engineering Sciences 365 (1857): 2053-2075. https://doi.org/10.1098/rsta.2007.2076

Temme, A.J.A.M. 2019. The Uncalm Development of Proglacial Soils in the European Alps Since 1850. Geomorphology of Proglacial Systems: Landform and Sediment Dynamics in Recently Deglaciated Alpine Landscapes, 315-326. Springer International Publishing, Cham.

Temme, A.J.A.M., Armitage, J., Attal, M., Van Gorp, W., Coulthard, T.J., Schoorl, J.M. 2017. Developing, choosing and using landscape evolution models to inform fieldbased landscape reconstruction studies. Earth Surface Processes and Landforms 42 (13): 2167-2183. https://doi.org/10.1002/esp.4162

Temme, A.J.A.M., Claessens, L., Veldkamp, A., Schoorl, J.M. 2011 a. Evaluating choices in multi-process landscape evolution models. Geomorphology 125 (2): 271-281. https://doi.org/10.1016/j.geomorph.2010.10.007

Temme, A.J.A.M., Heckmann, T., Harlaar, P. 2016. Silent play in a loud theatre Dominantly time-dependent soil development in the geomorphically active proglacial area of the Gepatsch glacier, Austria. Catena 147: 40-50. https://doi.org/10.1016/j.catena.2016.06.042

Temme, A.J.A.M., Lange, K. 2014. Pro-glacial soil variability and geomorphic activity - the case of three Swiss valleys. Earth Surface Processes and Landforms 39 (11): 14921499. https://doi.org/10.1002/esp.3553

Temme, A.J.A.M., Lange, K., Schwering, M.F.A. 2015. Time development of soils in mountain landscapes - divergence and convergence of properties with age. Journal of Soils and Sediments 15 (6): 1373-1382. https://doi.org/10.1007/s11368-014$\underline{0947-8}$

Temme, A.J.A.M., Peeters, I., Buis, E., Veldkamp, A., Govers, G. 2011b. Comparing landscape evolution models with quantitative field data at the millennial time scale in the Belgian loess belt. Earth Surface Processes and Landforms 36 (10): 13001312. https://doi.org/10.1002/esp.2152

Temme, A.J.A.M., Schaap, J.D., Sonneveld, M.P.W., Botha, G.A. 2012. Hydrological effects of buried palaeosols in eroding landscapes: A case study in South Africa. 
Quaternary International $265 \quad$ (Supplement $\quad$ C): $\quad 32-42$. https://doi.org/10.1016/j.quaint.2011.11.010

Temme, A.J.A.M., Vanwalleghem, T. 2016. LORICA - A new model for linking landscape and soil profile evolution: development and sensitivity analysis. Computers \& Geosciences 90 (part B): 131-143. https://doi.org/10.1016/j.cageo.2015.08.004

Temme, A.J.A.M., Veldkamp, A. 2009. Multi-process Late Quaternary landscape evolution modelling reveals lags in climate response over small spatial scales. Earth Surface Processes and Landforms 34 (4): 573-589. https://doi.org/10.1002/esp.1758

Tempels, B., Hartmann, T. 2014. A co-evolving frontier between land and water: dilemmas of flexibility versus robustness in flood risk management. Water International 39 (6): 872-883. https://doi.org/10.1080/02508060.2014.958797

Thaer, A.D. 1803. Dr. A. Thaer's Beschreibung der nutzbarsten neuen Ackergeräthe. bey den Gebrüdern Hahn, Hannover.

Thompson, S.E., Harman, C.J., Heine, P., Katul, G.G. 2010. Vegetation-infiltration relationships across climatic and soil type gradients. Journal of Geophysical Research: Biogeosciences 115 (G2). https://doi.org/10.1029/2009JG001134

Ticehurst, J.L., Cresswell, H.P., McKenzie, N.J., Glover, M.R. 2007. Interpreting soil and topographic properties to conceptualise hillslope hydrology. Geoderma 137 (3): 279-292. https://doi.org/10.1016/j.geoderma.2006.06.016

Tóth, B., Weynants, M., Nemes, A., Makó, A., Bilas, G., Tóth, G. 2015. New generation of hydraulic pedotransfer functions for Europe. European Journal of Soil Science 66 (1): 226-238. https://doi.org/10.1111/ejss.12192

Tranter, G., Minasny, B., McBratney, A.B., Murphy, B., McKenzie, N.J., Grundy, M., Brough, D. 2007. Building and testing conceptual and empirical models for predicting soil bulk density. Soil Use and Management 23 (4): 437-443. https://doi.org/10.1111/j.1475-2743.2007.00092.x

Troch, P.A., Lahmers, T., Meira, A., Mukherjee, R., Pedersen, J.W., Roy, T., Valdés-Pineda, R. 2015. Catchment coevolution: A useful framework for improving predictions of hydrological change? Water Resources Research 51: 4903-4922. https://doi.org/10.1002/2015WR017032

Tromp-van Meerveld, H.J., McDonnell, J.J. 2006. Threshold relations in subsurface stormflow: 2. The fill and spill hypothesis. Water Resources Research 42 W02411. https://doi.org/10.1029/2004WR003800

Tscharntke, T., Clough, Y., Wanger, T.C., Jackson, L., Motzke, I., Perfecto, I., Vandermeer, J., Whitbread, A. 2012. Global food security, biodiversity conservation and the future of agricultural intensification. Biological conservation 151 (1): 53-59. https://doi.org/10.1016/j.biocon.2012.01.068

Tscharntke, T., Klein, A.M., Kruess, A., Steffan-Dewenter, I., Thies, C. 2005. Landscape perspectives on agricultural intensification and biodiversity-ecosystem service management. Ecology letters 8 (8): 857-874. https://doi.org/10.1111/j.1461$\underline{0248.2005 .00782 . x}$ 
Tucker, G.E., Hancock, G.R. 2010. Modelling landscape evolution. Earth Surface Processes and Landforms 35 (1): 28-50. https://doi.org/10.1002/esp.1952

Twine, T.E., Kucharik, C.J., Foley, J.A. 2004. Effects of land cover change on the energy and water balance of the Mississippi River basin. Journal of Hydrometeorology 5 (4): 640-655. https://doi.org/10.1175/1525-7541(2004)005<0640:eolcco >2.0.co;2

USDA-SCS. 1972. SCS National Engineering Handbook, Section 4, Hydrology. Chapter 10, Estimation of Direct Runoff From Storm Rainfall. 10.11-10.24. U.S. Department of Agriculture, Soil Conservation Service, Washington D.C.

Van Andel, T.H., Zangger, E., Demitrack, A. 1990. Land Use and Soil Erosion in Prehistoric and Historical Greece. Journal of Field Archaeology 17 (4): 379-396. https://doi.org/10.1179/009346990791548628

Van Apeldoorn, D.F., Kempen, B., Sonneveld, M.P.W., Kok, K. 2013. Co-evolution of landscape patterns and agricultural intensification: An example of dairy farming in a traditional Dutch landscape. Agriculture, Ecosystems \& Environment 172: 16-23. https://doi.org/10.1016/j.agee.2013.04.002

Van den Broeke, P.W. 2005. Blacksmiths and potters, material culture and technology. In: Kooijmans, L.P.; van der Broeke, W.; Fokkens, H.; van Gijn, A.L. (Editors), The prehistory of the Netherlands, 603-625. Amsterdam: University Press, Amsterdam.

Van der Meij, W.M., Reimann, T., Vornehm, V.K., Temme, A.J.A.M., Wallinga, J., Van Beek, R., Sommer, M. 2019. Reconstructing rates and patterns of colluvial soil redistribution in agrarian (hummocky) landscapes. Earth Surface Processes and Landforms 44: 2408-2422. https://doi.org/10.1002/esp.4671

Van der Meij, W.M., Temme, A.J.A.M., De Kleijn, C.M.F.J.J., Reimann, T., Heuvelink, G.B.M., Zwoliński, Z., Rachlewicz, G., Rymer, K., Sommer, M. 2016. Arctic soil development on a series of marine terraces on central Spitsbergen, Svalbard: a combined geochronology, fieldwork and modelling approach. SOIL 2 (2): 221-240. https://doi.org/10.5194/soil-2-221-2016

Van der Meij, W.M., Temme, A.J.A.M., Lin, H.S., Gerke, H.H., Sommer, M. 2018. On the role of hydrologic processes in soil and landscape evolution modeling: concepts, complications and partial solutions. Earth-Science Reviews 185: 1088-1106. https://doi.org/10.1016/j.earscirev.2018.09.001

Van der Meij, W.M., Temme, A.J.A.M., Wallinga, J., Hierold, W., Sommer, M. 2017. Topography reconstruction of eroding landscapes - A case study from a hummocky ground moraine (CarboZALF-D). Geomorphology 295: 758-772. https://doi.org/10.1016/j.geomorph.2017.08.015

Van der Plicht, J. 1993. The Groningen radiocarbon calibration program. Radiocarbon 35 (1): 231-237. https://doi.org/10.1017/S0033822200013916

Van der Wal, R., Truscott, A.-M., Pearce, I.S.K., Cole, L., Harris, M.P., Wanless, S. 2008. Multiple anthropogenic changes cause biodiversity loss through plant invasion. Global Change Biology 14 (6): 1428-1436. https://doi.org/10.1111/j.13652486.2008.01576.x 
Van Genuchten, M.T. 1980. A closed-form equation for predicting the hydraulic conductivity of unsaturated soils. Soil Science Society of America Journal 44 (5): 892-898. https://doi.org/10.2136/sssaj1980.03615995004400050002x

Van Gorp, W., Temme, A.J.A.M., Baartman, J.E.M., Schoorl, J.M. 2014. Landscape Evolution Modelling of naturally dammed rivers. Earth Surface Processes and Landforms 39 (12): 1587-1600. https://doi.org/10.1002/esp.3547

Van Looy, K., Bouma, J., Herbst, M., Koestel, J., Minasny, B., Mishra, U., Montzka, C., Nemes, A., Pachepsky, Y., Padarian, J., Schaap, M.G., Tóth, B., Verhoef, A., Vanderborght, J., Van der Ploeg, M.J., Weihermüller, L., Zacharias, S., Zhang, Y., Vereecken, H. 2017. Pedotransfer functions in Earth system science: challenges and perspectives. Reviews of Geophysics 55: 1199-1256. https://doi.org/10.1002/2017RG000581

Van Oost, K., Beuselinck, L., Hairsine, P.B., Govers, G. 2004. Spatial evaluation of a multiclass sediment transport and deposition model. Earth Surface Processes and Landforms 29 (8): 1027-1044. https://doi.org/10.1002/esp.1089

Van Oost, K., Cerdan, O., Quine, T.A. 2009. Accelerated sediment fluxes by water and tillage erosion on European agricultural land. Earth Surface Processes and Landforms 34 (12): 1625-1634. https://doi.org/10.1002/esp.1852

Van Oost, K., Govers, G., Desmet, P. 2000. Evaluating the effects of changes in landscape structure on soil erosion by water and tillage. Landscape Ecology 15 (6): 577-589. https://doi.org/10.1023/a:1008198215674

Van Oost, K., Govers, G., Quine, T.A., Heckrath, G., Olesen, J.E., De Gryze, S., Merckx, R. 2005a. Landscape-scale modeling of carbon cycling under the impact of soil redistribution: The role of tillage erosion. Global Biogeochemical Cycles 19 (4). https://doi.org/10.1029/2005GB002471

Van Oost, K., Quine, T.A., Govers, G., De Gryze, S., Six, J., Harden, J.W., Ritchie, J.C., McCarty, G.W., Heckrath, G., Kosmas, C. 2007. The impact of agricultural soil erosion on the global carbon cycle. Science 318 (5850): 626-629. https://doi.org/10.1126/science.1145724

Van Oost, K., Van Muysen, W., Govers, G., Deckers, J., Quine, T.A. 2005b. From water to tillage erosion dominated landform evolution. Geomorphology 72 (1-4): 193-203. https://doi.org/10.1016/j.geomorph.2005.05.010

Van Tol, J.J., Le Roux, P.A.L., Lorentz, S.A., Hensley, M. 2013. Hydropedological classification of South African hillslopes. Vadose Zone Journal 12 1:10. https://doi.org/10.2136/vzj2013.01.0007

Van Wesenbeeck, B.K., Mulder, J.P.M., Marchand, M., Reed, D.J., De Vries, M.B., De Vriend, H.J., Herman, P.M.J. 2014. Damming deltas: A practice of the past? Towards nature-based flood defenses. Estuarine, Coastal and Shelf Science 140: 16. https://doi.org/10.1016/j.ecss.2013.12.031

Vandenberghe, D., De Corte, F., Buylaert, J.P., Kučera, J., Van den haute, P. 2008. On the internal radioactivity in quartz. Radiation Measurements 43 (2): 771-775. https://doi.org/10.1016/j.radmeas.2008.01.016 
Vandermaelen, N., Vanacker, V., Beerten, K., Christl, M. 2019. Constraining complex history of fluvial deposits using a 10Be copmplex depth profile, OSL dating and modelling. 20th Congress of the International Union for Quaternary Research (INQUA), Dublin, Ireland.

Vanwalleghem, T., Gómez, J.A., Infante Amate, J., González de Molina, M., Vanderlinden, K., Guzmán, G., Laguna, A., Giráldez, J.V. 2017. Impact of historical land use and soil management change on soil erosion and agricultural sustainability during the Anthropocene. Anthropocene

17:

13-29. https://doi.org/10.1016/j.ancene.2017.01.002

Vanwalleghem, T., Poesen, J., McBratney, A., Deckers, J. 2010. Spatial variability of soil horizon depth in natural loess-derived soils. Geoderma 157 (1-2): 37-45. https://doi.org/10.1016/j.geoderma.2010.03.013

Vanwalleghem, T., Stockmann, U., Minasny, B., McBratney, A.B. 2013. A quantitative model for integrating landscape evolution and soil formation. Journal of Geophysical Research: Earth Surface 118 (2): 331-347. https://doi.org/10.1029/2011jf002296

Vepraskas, M.J., Craft, C.B. 2016. Wetland soils: genesis, hydrology, landscapes, and classification. CRC press, Boca Raton, Florida.

Verch, G. 2018. Head of ZALF research station in Dedelow (Uckermark). Personal communication.

Vereecken, H., Huisman, J.A., Hendricks Franssen, H.J., Brüggemann, N., Bogena, H.R., Kollet, S., Javaux, M., Van der Kruk, J., Vanderborght, J. 2015. Soil hydrology: Recent methodological advances, challenges, and perspectives. Water Resources Research 51 (4): 2616-2633. https://doi.org/10.1002/2014WR016852

Vereecken, H., Schnepf, A., Hopmans, J., Javaux, M., Or, D., Roose, T., Vanderborght, J., Young, M., Amelung, W., Aitkenhead, M. 2016. Modeling soil processes: Review, key challenges, and new perspectives. Vadose Zone Journal 15 (5). https://doi.org/10.2136/vzj2015.09.0131

Vereecken, H., Weynants, M., Javaux, M., Pachepsky, Y., Schaap, M.G., Van Genuchten, M.T. 2010. Using pedotransfer functions to estimate the van Genuchten-Mualem soil hydraulic properties: A review. Vadose Zone Journal 9 (4): 795-820. https://doi.org/10.2136/vzj2010.0045

Vermeer, J.A.M., Finke, P.A., Zwertvaegher, A., Gelorini, V., Bats, M., Antrop, M., Verniers, J., Crombé, P. 2014. Reconstructing a prehistoric topography using legacy point data in a depositional environment. Earth Surface Processes and Landforms 39 (5): 632-645. https://doi.org/10.1002/esp.3472

Vitharana, U.W.A., Van Meirvenne, M., Simpson, D., Cockx, L., De Baerdemaeker, J. 2008. Key soil and topographic properties to delineate potential management classes for precision agriculture in the European loess area. Geoderma 143 (1): 206-215. https://doi.org/10.1016/j.geoderma.2007.11.003 
Vogel, H.-J., Ippisch, O. 2008. Estimation of a Critical Spatial Discretization Limit for Solving Richards' Equation at Large Scales. Vadose Zone Journal 7 (1): 112-114. https://doi.org/10.2136/vzj2006.0182

Vogel, H.J., Bartke, S., Daedlow, K., Helming, K., Kögel-Knabner, I., Lang, B., Rabot, E., Russell, D., Stößel, B., Weller, U., Wiesmeier, M., Wollschläger, U. 2018. A systemic approach for modeling soil functions. SOIL 4 (1): 83-92. https://doi.org/10.5194/soil-4-83-2018

Vogel, H.J., Roth, K. 2001. Quantitative morphology and network representation of soil pore structure. Advances in Water Resources 24 (3): 233-242. https://doi.org/10.1016/S0309-1708(00)00055-5

von Schmettau, F.W.K.G. 1787. Schmettausche Kartenwerk.

Vreeken, W.J. 1975. Principal kinds of chronosequences and their significance in soil history. Journal of Soil Science 26 (4): 378-394. https://doi.org/10.1111/j.13652389.1975.tb01962.x

Wadoux, A.M.J.C. 2019. Using deep learning for multivariate mapping of soil with quantified uncertainty. Geoderma 591: https://doi.org/10.1016/j.geoderma.2019.05.012

Walling, D.E., Quine, T.A. 1995. Use of fallout radionuclide measurements in soil erosion investigations. IAEA, International Atomic Energy Agency (IAEA).

Wallinga, J., Cunningham, A.C. 2013. Luminescence Dating, Uncertainties, and Age Range. Encyclopedia of Scientific Dating Methods, 1-9. Springer Netherlands, Dordrecht.

Wang, F., Mu, X., Li, R., Fleskens, L., Stringer, L.C., Ritsema, C.J. 2015. Co-evolution of soil and water conservation policy and human-environment linkages in the Yellow River Basin since 1949. Science of The Total Environment 508: 166-177. https://doi.org/10.1016/j.scitotenv.2014.11.055

Wang, Z., Hoffmann, T., Six, J., Kaplan, J.O., Govers, G., Doetterl, S., Van Oost, K. 2017. Human-induced erosion has offset one-third of carbon emissions from land cover change. Nature Climate Change 7: 345. https://doi.org/10.1038/NCLIMATE3263

Wang, Z., Van Oost, K. 2018. Modeling global anthropogenic erosion in the Holocene. The Holocene 29 (3): 367-379. https://doi.org/10.1177/0959683618816499

Webster, R., Oliver, M.A. 2001. Local estimation or prediction: kriging. Geostatistics for environmental scientists. Wiley \& Sons, Ltd, Chichester.

Weiler, M., McDonnell, J.J. 2007. Conceptualizing lateral preferential flow and flow networks and simulating the effects on gauged and ungauged hillslopes. Water Resources Research 43 (3). https://doi.org/10.1029/2006WR004867

Weiss, A. 2001. Topographic position and landforms analysis. ESRI user conference, San Diego, CA.

Welivitiya, W.D.D.P., Willgoose, G.R., Hancock, G.R. 2019. A coupled soilscape-landform evolution model: model formulation and initial results. Earth Surface Dynamics 7: 591-607. https://doi.org/10.5194/esurf-7-591-2019

Welivitiya, W.D.D.P., Willgoose, G.R., Hancock, G.R., Cohen, S. 2016. Exploring the sensitivity on a soil area-slope-grading relationship to changes in process parameters 
using a pedogenesis model. Earth Surface Dynamics 4 (3): 607. https://doi.org/10.5194/esurf-4-607-2016

West, N., Kirby, E., Bierman, P., Slingerland, R., Ma, L., Rood, D., Brantley, S. 2013. Regolith production and transport at the Susquehanna Shale Hills Critical Zone Observatory, part 2: insights from meteoric 10Be. Journal of Geophysical Research: Earth Surface 118 (3): 1877-1896. https://doi.org/10.1002/jgrf.20121

Wiesmeier, M., Spörlein, P., Geuß, U., Hangen, E., Haug, S., Reischl, A., Schilling, B., von Lützow, M., Kögel-Knabner, I. 2012. Soil organic carbon stocks in southeast Germany (Bavaria) as affected by land use, soil type and sampling depth. Global Change Biology 18 (7): 2233-2245. https://doi.org/10.1111/j.13652486.2012.02699.x

Wilkinson, B.H. 2005. Humans as geologic agents: A deep-time perspective. Geology 33 (3): 161-164. https://doi.org/10.1130/g21108.1

Wilkinson, M.T., Richards, P.J., Humphreys, G.S. 2009. Breaking ground: Pedological, geological, and ecological implications of soil bioturbation. Earth-Science Reviews 97 (1): 257-272. https://doi.org/10.1016/j.earscirev.2009.09.005

Willemen, L., Verburg, P.H., Hein, L., Van Mensvoort, M.E.F. 2008. Spatial characterization of landscape functions. Landscape and urban planning 88 (1): 34-43. https://doi.org/10.1016/j.landurbplan.2008.08.004

Willgoose, G. 2018. Principles of Soilscape and Landscape Evolution. University Press, Cambridge.

Wilson, C.G., Abban, B., Keefer, L.L., Wacha, K., Dermisis, D., Giannopoulos, C., Zhou, S., Goodwell, A.E., Woo, D.K., Yan, Q. 2018. The Intensively Managed Landscape Critical Zone Observatory: A scientific testbed for understanding critical zone processes in agroecosystems. Vadose Zone Journal 17 (1). https://doi.org/10.2136/vzj2018.04.0088

Wilson, G.V., Nieber, J.L., Fox, G.A., Dabney, S.M., Ursic, M., Rigby, J.R. 2017. Hydrologic connectivity and threshold behavior of hillslopes with fragipans and soil pipe networks. Hydrological Processes $31 \quad$ (13): 2477-2496. https://doi.org/10.1002/hyp.11212

Wolff, E. 1864. Entwurf zur Bodenanalyse. Zeitschrift für analytische Chemie 3 (1): 85-115. https://doi.org/10.1007/bf01345998

Wösten, J.H.M., Pachepsky, Y.A., Rawls, W.J. 2001. Pedotransfer functions: bridging the gap between available basic soil data and missing soil hydraulic characteristics. Journal of Hydrology 251 (3): 123-150. https://doi.org/10.1016/S0022$\underline{1694(01) 00464-4}$

Wulf, M., Sommer, M., Schmidt, R. 2010. Forest cover changes in the Prignitz region (NE Germany) between 1790 and 1960 in relation to soils and other driving forces. Landscape Ecology 25 (2): 299-313. https://doi.org/10.1007/s10980-009-9411-3

Wysocka-Czubaszek, A., Czubaszek, R. 2014. Tillage erosion: the principles, controlling factors and main implications for future research. Journal of Ecological Engineering 15 (4): 150-159. https://doi.org/10.12911/22998993.1125470 
Xinbao, Z., Higgitt, D.L., Walling, D.E. 1990. A preliminary assessment of the potential for using caesium-137 to estimate rates of soil erosion in the Loess Plateau of China. Hydrological $\quad$ Sciences $\quad$ Journal $35 \quad$ (3): https://doi.org/10.1080/02626669009492427

Yan, Q., Le, P.V.V., Woo, D.K., Hou, T., Filley, T., Kumar, P. 2019. Three-Dimensional modeling of the coevolution of landscape and soil organic carbon. Water Resources Research 55 (2): 1218-1241. https://doi.org/10.1029/2018wr023634

Yli-Halla, M., Mokma, D.L., Alakukku, L., Drees, R., Wilding, L.P. 2009. Evidence for the formation of Luvisols/Alfisols as a response to coupled pedogenic and anthropogenic influences in a clay soil in Finland. Agricultural and Food Science 18 (3-4): 388-401. https://doi.org/10.23986/afsci.5965

Yoo, K., Amundson, R., Heimsath, A.M., Dietrich, W.E. 2006. Spatial patterns of soil organic carbon on hillslopes: Integrating geomorphic processes and the biological C cycle. Geoderma 130 (1): 47-65. https://doi.org/10.1016/j.geoderma.2005.01.008

Yoo, K., Ji, J., Aufdenkampe, A., Klaminder, J. 2011. Rates of soil mixing and associated carbon fluxes in a forest versus tilled agricultural field: Implications for modeling the soil carbon cycle. Journal of Geophysical Research: Biogeosciences $116(\mathrm{G1})$. https://doi.org/10.1029/2010JG001304

Yoo, K., Mudd, S.M. 2008. Toward process-based modeling of geochemical soil formation across diverse landforms: A new mathematical framework. Geoderma 146 (1): 248260. https://doi.org/10.1016/j.geoderma.2008.05.029

Young, M.H., McDonald, E.V., Caldwell, T.G., Benner, S.G., Meadows, D.G. 2004. Hydraulic Properties of a Desert Soil Chronosequence in the Mojave Desert, USA. Vadose Zone Journal 3 (3): 956-963. https://doi.org/10.2136/vzj2004.0956

Ysebaert, T., Van der Hoek, D.-J., Wortelboer, R., Wijsman, J.W.M., Tangelder, M., Nolte, A. 2016. Management options for restoring estuarine dynamics and implications for ecosystems: A quantitative approach for the Southwest Delta in the Netherlands. Ocean \& Coastal Management 121: 33-48. https://doi.org/10.1016/j.ocecoaman.2015.11.005

Yu, X., Duffy, C., Baldwin, D.C., Lin, H. 2014. The role of macropores and multi-resolution soil survey datasets for distributed surface-subsurface flow modeling. Journal of Hydrology 516: 97-106. https://doi.org/10.1016/j.jhydrol.2014.02.055

Zacharias, S., Altdorff, D., Samaniego-Eguiguren, L., Dietrich, P. 2009. Hydropedology and pedotransfer functions. Precision agriculture 9: 545-550.

Zádorová, T., Pení žek, V. 2018. Formation, morphology and classification of colluvial soils: a review. European Journal of Soil Science 69 (4): 577-591. https://doi.org/10.1111/ejss.12673

Zaidel'man, F.R. 2007. Lessivage and its relation to the hydrological regime of soils. $\begin{array}{llll}\text { Eurasian Soil } & \text { Science } & 40 & \text { (2): }\end{array}$ https://doi.org/10.1134/S1064229307020019

Zender, C.S., Newman, D., Torres, O. 2003. Spatial heterogeneity in aeolian erodibility: Uniform, topographic, geomorphic, and hydrologic hypotheses. Journal of 
Geophysical Research: $\quad$ Atmospheres $108 \quad$ (D17). https://doi.org/10.1029/2002JD003039

Zeraatpisheh, M., Ayoubi, S., Jafari, A., Tajik, S., Finke, P. 2019. Digital mapping of soil properties using multiple machine learning in a semi-arid region, central Iran. Geoderma 338: 445-452. https://doi.org/10.1016/j.geoderma.2018.09.006

Zhang, K., Li, S., Peng, W., Yu, B. 2004. Erodibility of agricultural soils on the Loess Plateau of China. Soil and Tillage Research $76 \quad$ (2): 157-165. https://doi.org/10.1016/j.still.2003.09.007

Zhang, Y., Slingerland, R., Duffy, C. 2016. Fully-coupled hydrologic processes for modeling landscape evolution. Environmental Modelling \& Software 82: 89-107. https://doi.org/10.1016/j.envsoft.2016.04.014

Zhao, G., Mu, X., Wen, Z., Wang, F., Gao, P. 2013. Soil erosion, conservation, and ecoenvironment changes in the loess plateau of China. Land Degradation \& Development 24 (5): 499-510. https://doi.org/10.1002/ldr.2246

Zheng, F.-L. 2006. Effect of Vegetation Changes on Soil Erosion on the Loess Plateau1 1Project supported by the Chinese Academy of Sciences (No. KZCX3-SW-422) and the National Natural Science Foundation of China (Nos. 9032001 and 40335050). Pedosphere 16 (4): 420-427. https://doi.org/10.1016/S1002-0160(06)60071-4

Zhu, Q., Lin, H. 2010. Comparing Ordinary Kriging and Regression Kriging for Soil Properties in Contrasting Landscapes. Pedosphere 20 (5): 594-606. https://doi.org/10.1016/S1002-0160(10)60049-5

Zimmer, M.A., McGlynn, B.L. 2018. Lateral, vertical, and longitudinal source area connectivity drive runoff and carbon export across watershed scales. Water Resources Research 54 (3): 1576-1598. https://doi.org/10.1002/2017WR021718

Zwertvaegher, A., Finke, P., De Smedt, P., Gelorini, V., Van Meirvenne, M., Bats, M., De Reu, J., Antrop, M., Bourgeois, J., De Maeyer, P. 2013. Spatio-temporal modeling of soil characteristics for soilscape reconstruction. Geoderma 207: 166-179. https://doi.org/10.1016/j.geoderma.2013.05.013 


\section{Summary}

Soils provide numerous functions to support natural and human life. Soils and their functions develop over long timescales (decennia to millennia) under influence of environmental properties and drivers such as water flow, vegetation type and topography of the landscape. At the same time, these environmental properties develop too, often under influence of soil properties and processes. This interactive co-evolution of soils and the landscape forms a complex system that can aggravate, or diminish, rates and direction of soil-landscape evolution. In the Anthropocene, a proposed geological Epoch where humans are the main forcing actors, soil-landscape evolution changed substantially under influence of anthropogenic processes. Deforestation, tillage and agricultural drainage all left their mark on the landscape, often by triggering and accelerating erosion processes. In current intensively managed agricultural landscapes in undulating settings, rates of anthropogenic erosion far exceed rates of natural soil development, leading to severe soil and land degradation. Sustainable nature-based land management is crucial to counteract this degradation, and to preserve and restore soil functions for the environment and future generations. The large spatial and temporal dimensions and complex interactions of soillandscape co-evolution requires the development and improvement of methods to disentangle and quantify complex evolution of soils in intensively managed landscapes.

The aim of my thesis is to identify and quantify how soils and landscape have evolved and possibly co-evolved during the transition from natural land cover to intensive land management in the Anthropocene. This knowledge is essential in nature-based management, which utilizes natural processes for improving soil functions in anthropogenic settings. I have the following research objectives:

1. Develop methods for studying soil and landscape change that cover spatial and temporal dimensions of soil-landscape evolution in the Anthropocene.

2. Gather insights in directions and rates of soil-landscape evolution in intensively managed landscapes.

3. Evaluate implications of possible soil-landscape co-evolution on sustainable land management.

The first part of this thesis (Chapter 2-3) aims at reconstructing the impact and rates of anthropogenic landscape change on complex agricultural fields. As study site I use the 
landscape laboratory CarboZALF-D, which was designed for researching the interactions between anthropogenic erosion, carbon dynamics and soil functions. CarboZALF-D is a kettle-hole catchment of 4 ha with elevation differences up to 8 meters, located in northeastern Germany. The catchment is characterized by complex small-scale topography, heterogeneities in the hydrological system and a long history of agricultural use. The colluvium in the closed kettle hole catchment provides a complete geo-archive of landscape change.

In Chapter 2 we reconstruct the paleosurface of study site Carbo-ZALF-D prior to the anthropogenic erosion. We used an extensive dataset of soil descriptions, which enabled a detailed spatial estimate of erosion and deposition by estimating erosion based on soil profile truncations and deposition based on colluvium thickness. The paleosurface shows a high variation in topographic properties and suggests that natural soils and landscapes contain considerable spatial heterogeneity.

We reconstruct the rates of deposition in Carbo-ZALF-D in Chapter 3 using Optically Stimulated Luminescence (OSL) dating. OSL dating measures the luminescence signal of soil grains, which is a proxy for sediment deposition age. This signal is reset when a grain is exposed to daylight, and builds up in response to natural background radiation exposure after burial. OSL dating in colluvial settings is complicated, because not all grains are sufficiently exposed to daylight during transport and deposition to reset the OSL signal, and some grains get exposed to daylight due to tillage reworking after deposition. We present a novel methodology to extract OSL ages from heterogeneous colluvial sediments and to correct for the post-depositional mixing. Our results show a 100-fold increase in deposition rates, starting around 5000 years ago. This increase does not solely represent increased erosion in the catchment, but is also caused by indirect effects of agricultural drainage. The kettle hole shows a complex spatiotemporal pattern of colluvial infilling and landscape evolution, which we were only able to reconstruct using a high OSL sampling density and extensive soil geomorphic research.

The second part of this thesis aims at simulating the evolution of soils and landscapes under varying climatic and anthropogenic forcing. In Chapter 4 we review the role of water as dominant driver in natural soil and landscape evolution and its potential as driver in simulations with soil-landscape evolution models (SLEMs). Water plays a pivotal role in soil 
and landscape evolution, by transporting and transforming soil material and facilitating vegetation growth. In turn, surface and subsurface flow paths of water are controlled by soil and landscape properties. The co-evolution of soils, topography and the hydrological system is essential for understanding the response of soils and landscapes to changes in climate. However, this co-evolution can currently not be simulated over long timescales with SLEMs due to challenges such as high calculation demands, limited methods for estimating soil hydraulic properties and limited data on the long-term evolution of hydrological systems. We provide partial solutions for the high calculation demands and the link between water flow and soil development.

In Chapter 5 we utilize these partial solutions to develop our SLEM HydroLorica. HydroLorica simulates soil and landscape evolution with various dynamic drivers such as water flow, vegetation type and land use. We included additional essential processes such as tree throw, soil creep and tillage. We use HydroLorica to simulate the evolution of soils and landscape under various rainfall and land-use scenarios for an artificial undulating landscape. The results show that in natural systems, rainfall amount is the dominant factor controlling soil and landscape heterogeneity, while for agricultural systems landform explains most of the variation. This switch in dominant factors is due to the introduction of anthropogenic erosion processes. Cultivation of natural landscapes increases soil heterogeneity, but also increases correlations between soil and terrain properties. This indicates a higher predictability of the soil pattern based on environmental properties for agricultural systems relative to natural systems. Our results confirm that humans have become the dominant soil forming factor in intensively managed landscapes.

In the third part of this thesis (Chapter 6), I synthesize the findings from the research chapters to meet the objectives of this thesis. I critically evaluate the developed reconstruction methods in Chapters 2 and 3 and compare them with other potential methods. The applied paleosurface reconstruction in Chapter 2 was most suitable for landscapes that have undergone similar landscape evolution as CarboZALF-D. The processes disturbing chronologies for OSL dating affect other geochronological methods similarly. I call for a review of geochronological methods for intensively managed landscapes, which should provide an overview of available methods, required statistical data analysis and combination with soil-geomorphic surveys. The development of HydroLorica in Chapters 4 and 5, with water flow as explicit driver and with increased process coverage, is a big step forward in 
soil-landscape evolution modelling. The reduced complexity of HydroLorica limits direct wider applicability, but also provides a flexible framework which can easily be adapted to local processes and drivers. A combination of reconstruction and simulation methods is essential for developing and testing hypotheses of soil-landscape co-evolution.

Soil-landscape evolution in natural and intensively managed landscapes have different characteristics due to different driving forces and dominant processes. In natural landscapes, soils develop to patterns where individual soils might be disturbed occasionally, but where the average properties are stable. In intensively managed landscapes, disturbance rates are much higher than in natural settings. As a consequence, slowly developing soil properties degrade, while fast-developing soil properties can form a new equilibrium. Assessment of soil degradation in response to anthropogenic erosion should thus be performed per process or soil property rather than for the entire soil.

The co-evolution of soils and landscapes that occurs in natural settings is often controlled by biotic processes. In agricultural settings, humans control vegetation type and aggravate erosion processes through tillage. As a consequence, co-evolution does not occur in the sense that it does in natural settings, because interactions between landscape components are missing. However, the management of soils and landscapes is often adapted to counteract unintended changes to soils and landscapes under earlier management. In intensively managed landscapes, land management may thus co-evolve with the rest of the landscape. The integral effects of past, present and planned management on the entire landscape should be considered in nature-based management. I conclude the thesis with an overview of the lessons learned and I suggest directions for future research on soil-landscape evolution in the Anthropocene. 


\section{Samenvatting}

Bodems bieden talloze functies die het menselijke en natuurlijke leven ondersteunen. Bodems en hun functies ontwikkelen zich over lange tijdschalen (decennia tot millennia) onder invloed van hun omgeving en factoren en processen zoals stroming van water, groei van vegetatie en de topografie van het landschap. Tegelijkertijd ontwikkelen deze omgevingsfactoren zich ook, onder invloed van bodemeigenschappen en -processen. Deze interactieve co-evolutie van bodems en het landschap vormt een complex systeem dat de snelheid en richting van de evolutie van bodems en landschappen kan versterken of verzwakken. In het Antropoceen, een voorgestelde geologische periode waarin de mens de dominante kracht achter de ontwikkeling van de aarde is, is de evolutie van bodems en landschappen substantieel veranderd. Ontbossing, ploegen en drainage hebben allemaal een effect gehad op het landschap, vaak door het veroorzaken of versterken van erosieprocessen. In de huidige intensief gebruikte landbouwlandschappen in glooiende gebieden zijn de snelheden van erosie veel hoger dan die van natuurlijke bodemvorming, wat leidt tot ernstige bodem- en landdegradatie. Duurzaam, op de natuur gebaseerd landgebruik is cruciaal om deze degradatie tegen te gaan en om de bodemfuncties te behouden en te herstellen, zodat de natuur en toekomstige generaties er ook nog gebruik van kunnen maken. De grote ruimtelijke en temporele dimensies en de complexe interacties van de co-evolutie van bodems en landschappen vereisen de ontwikkeling en verbetering van methoden om deze complexe evolutie in intensief gebruikte landschappen te kunnen ontrafelen en te kunnen kwantificeren.

Het doel van mijn proefschrift is om te identificeren en kwantificeren hoe bodems en het landschap zijn geëvolueerd, en mogelijk geco-evolueerd, tijdens de overgang van een natuurlijke situatie naar intensief landbeheer in het Antropoceen. Deze kennis is essentieel voor natuur-gebaseerd beheer van bodems en landschappen, waarin natuurlijke processen worden gebruikt om bodemfuncties in antropogene landschappen te verbeteren. Ik heb de volgende onderzoeksdoelstellingen:

1. Het ontwikkelen van methoden voor het bestuderen van bodem- en landschapsverandering die toepasbaar zijn over de ruimtelijke en temporele dimensies van bodem-landschapsevolutie in het Antropoceen.

2. Het verkrijgen van inzichten in de richting en snelheid van bodemlandschapsevolutie in intensief gebruikte landschappen. 
3. Het evalueren van de implicatie van mogelijke bodem-landschaps-co-evolutie voor duurzaam landgebruik

Het eerste deel van mijn proefschrift (hoofdstuk 2 en 3) heeft als doel de impact en snelheid van antropogene landschapsverandering in complexe landbouwlandschappen te reconstrueren. Als studiegebied gebruik ik het landschapslaboratorium CarboZALF-D, welke is ontwikkeld om de interacties tussen antropogene erosie, koolstofdynamiek en bodemfuncties te bestuderen. CarboZALF-D is een stroomgebied van 4 hectare groot dat is ontstaan rond een doodijsgat, en is gelegen in Noordoost-Duitsland. De omgeving van CarboZALF-D is gekenmerkt door een lokaal zeer variabele topografie, een heterogeen hydrologisch systeem en een lange geschiedenis van agrarisch gebruik. Het colluvium in het gesloten doodijsgat bevat een compleet geo-archief van de veranderingen in het landschap.

In hoofdstuk 2 reconstrueren we het landoppervlak van CarboZALF-D voordat deze werd beïnvloedt door antropogene erosie. We gebruikten een grote dataset van bodembeschrijvingen waarmee we een gedetailleerde ruimtelijke schatting konden maken van de mate van erosie en sedimentatie door te kijken naar hoeveel bodemmateriaal er op een locatie is verdwenen of bijgekomen. Het gereconstrueerde voormalige landoppervlak vertoont een hoge variatie in topografische eigenschappen en suggereert dat natuurlijke bodems en landschappen een hoge mate aan ruimtelijke variatie in eigenschappen bevatten.

We reconstrueerden de snelheden van depositie in CarboZALF-D in hoofdstuk 3 met behulp van Optically Stimulated luminescence (OSL)-datering. OSL-datering maakt gebruik van het luminescentiesignaal van bodemkorrels, wat een indicator is voor het moment dat het sediment afgezet is. Het luminescentiesignaal wordt gereset door blootstelling aan daglicht, en bouwt zich weer op door natuurlijke achtergrondstraling in de bodem na begraving. OSLdatering in colluviale systemen is lastig, omdat niet alle bodemdeeltjes aan daglicht worden blootgesteld tijdens hun transport en afzetting. Andere deeltjes worden na afzetting opnieuw blootgesteld aan daglicht door het mixen van de grond door ploegen. We presenteren een nieuwe methode om de OSL-leeftijden uit de heterogene colluviale sedimenten af te leiden en om te corrigeren voor het mixen na afzetting van de bodem. Onze resultaten laten zien dat de depositie van bodemdeeltjes ongeveer 5000 jaar geleden was begonnen en dat er een honderdvoudige toename van depositiesnelheden is sindsdien. Deze toename komt niet alleen door toegenomen erosie in het stroomgebied, maar wordt ook veroorzaakt door 
indirecte effecten van agrarische drainage. Het stroomgebied bevat een complex ruimtelijk en temporeel patroon van colluviale opvulling en landschapsevolutie, welke we alleen konden achterhalen door onze hoge bemonsteringsdichtheid en uitgebreid bodemkundig en geomorfologisch onderzoek.

Het tweede deel van het proefschrift heeft als doel de evolutie van bodems en landschappen onder variërende klimatologische en antropogene factoren te simuleren met een computermodel. In hoofdstuk 4 schrijven we een review over de rol van water als dominante factor in natuurlijke bodem- en landschapsvorming en over de mogelijkheid om deze rol te simuleren in bodem-landschapsevolutiemodellen. Water speelt de hoofdrol in bodem- en landschapsevolutie, door het transporteren en transformeren van bodemmateriaal en door het faciliteren van plantgroei. De stroomroutes van water over en door de grond worden bepaald door bodem- en landschapseigenschappen. Begrip van de co-evolutie van bodems, topografie en het hydrologische systeem is essentieel om te begrijpen hoe bodems en landschappen reageren op een veranderende klimatologische situatie. Deze co-evolutie kan momenteel echter niet worden gesimuleerd over lange tijdschalen met bodem-landschapsevolutiemodellen vanwege uitdagingen als lange rekentijden, beperkte methoden voor het schatten van bodem-hydrologische eigenschappen en beperkte data van de langetermijnsontwikkeling van hydrologische systemen in bodems en landschappen. We geven oplossingen voor de lange rekentijden en de koppeling tussen waterstroming en bodemvorming.

In hoofdstuk 5 gebruiken we deze oplossingen om ons bodem-landschapsevolutiemodel HydroLorica te ontwikkelen. HydroLorica simuleert bodem-landschapsevolutie met verschillende dynamische aansturingen zoals waterstroming, vegetatietype en landgebruik. We hebben ook ander essentiële processen toegevoegd, zoals het effect van vallen van bomen, bodem-creep en ploegen op bodem- en landschapseigenschappen. We gebruiken HydroLorica om de evolutie van bodem en landschappen in verschillende regenval- en landgebruiksscenario's te simuleren in een artificieel glooiend landschap. De resultaten laten zien dat in natuurlijke systemen de hoeveelheid regen een belangrijke factor is voor de mate van bodem- en landschapsheterogeniteit, terwijl in agrarische systemen de landvorm de meeste variatie verklaart. De omslag in dominante factoren komt door de introductie van antropogene erosieprocessen. Ontginning van natuurlijke landschappen vergroot de heterogeniteit in bodemeigenschappen, maar vergroot ook de correlaties tussen bodem- en 
landschapseigenschappen. Dit duidt op een hogere voorspelbaarheid van het bodempatroon op basis van de topografie. Onze resultaten bevestigen dat de mens de dominante bodemvormende factor in intensief gebruikte landschappen is.

In het derde deel van dit proefschrift (hoofdstuk 6) synthetiseer ik de bevindingen van hoofdstukken 2-5 om de doelstellingen van het proefschrift te bereiken. Ik evalueer de ontwikkelde reconstructiemethoden kritisch en ik vergelijk ze met andere potentiële methoden. De toegepaste methode voor het reconstrueren van het voormalige landoppervlak in hoofdstuk 2 is het meest geschikt voor de landschappen die een vergelijkbare evolutie hebben ondergaan als CarboZALF-D. De processen die chronologieën voor OSL-datering verstoren, beïnvloeden ander geochronologische methode op een vergelijkbare wijze. Ik pleit voor een review van geochronologische methoden voor intensief gebruikte landschappen, welke een overzicht zou moeten bieden van beschikbare methoden, vereiste statistische dataanalyse en noodzakelijke combinaties met bodem-geomorfologische studies. De ontwikkeling van HydroLorica in hoofdstukken 4 en 5 is een grote stap voorwaarts in het simuleren van bodem-landschapsevolutie. De versimpelde formulering van de processen in HydroLorica zorgt ervoor dat het model niet wijd inzetbaar is, maar geeft ook een flexibel kader welke makkelijk aangepast kan worden aan lokale processen en bodemvormende factoren. Een combinatie van reconstructie- en simulatiemethoden is essentieel voor het ontwikkelen en testen van hypotheses over bodem-landschapsco-evolutie.

Bodem- en landschapsevolutie in natuurlijke en intensief gebruikte landschappen hebben verschillende kenmerken doordat er verschillende vormende factoren en processen een rol spelen. In natuurlijke landschappen ontwikkelen bodempatronen waarin bodems lokaal verstoord kunnen worden, maar waar de gemiddelde eigenschappen gelijk blijven. In intensief gebruikte landschappen worden bodems veel vaker verstoord dan in natuurlijke landschappen. Als gevolg degraderen langzaam vormende bodemeigenschappen, terwijl snel vormende bodemeigenschappen een nieuw evenwicht kunnen vinden met het snel veranderende landschap. Beoordeling van bodemdegradatie als reactie op antropogene erosie moet dus uitgevoerd worden per proces of bodemeigenschap in plaats van voor de gehele bodem.

De co-evolutie van bodems en landschappen in natuurlijke systemen wordt vaak gedreven door biotische processen. In agrarische systemen wordt de vegetatie door de mens bepaald 
en worden erosieprocessen versterkt door ploegen. Als gevolg treedt er geen co-evolutie meer op zoals in natuurlijke systemen, omdat de interacties tussen de verschillende domeinen van het landschap missen. Het beheer van bodems en landschappen wordt echter wel aangepast om onbedoelde veranderingen in de bodem onder eerder beheer tegen te gaan. In intensief gebruikte landschappen kan het landgebruik dus co-evolueren met de rest van het landschap. In natuur-gebaseerd landgebruik moet rekening gehouden worden met de effecten van vroeger, huidig en toekomstig landgebruik op het integrale landschap. Ik sluit het proefschrift af met een overzicht van de verkregen inzichten en ik geef suggesties voor toekomstig onderzoek naar bodem- en landschapsevolutie in het Antropoceen. 


\section{About the author}

Willem Marijn van der Meij was born on 25

November 1991 in the Netherlands. He grew up in the municipality called De Ronde Venen, a former peat area in the western Netherlands (currently $-6 \mathrm{~m}$ below sea level). After high school he moved to Wageningen

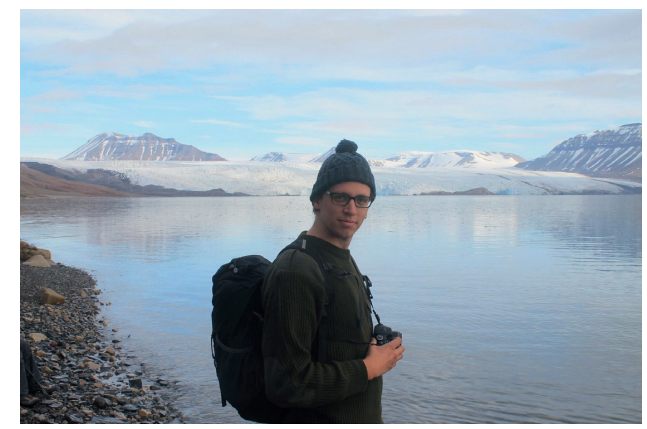
to study the bachelor Soil, Water and Atmosphere at Wageningen University and Research, with a minor in philosophy at the Radboud University in Nijmegen. During his studies, he was treasurer of Popcultuur Wageningen, a foundation promoting live music in Wageningen. He continued his bachelor with the master Earth and Environment with a specialization in soil geography, also in Wageningen. For his master thesis he visited the Svalbard archipelago to study the evolution of Arctic soils along a sequence of raised marine beaches. After obtaining his MSc degree, he worked as a garbage man for a few months before starting his $\mathrm{PhD}$ research in May 2015. The PhD was co-supervised by the working group Landscape Pedology at Leibniz-Zentrum für Agrarlandschaftsforschung (ZALF) in Müncheberg, Germany, and the Soil Geography and Landscape group at Wageningen University and Research. During his $\mathrm{PhD}$, Marijn spent a few months at the Hydropedology group at Pennsylvania State University and the department of Geography at Kansas State University. In October 2018, he started working part-time as an applied geomorphologist at Wageningen Environmental Research next to his $\mathrm{PhD}$, a function he continued full-time since January 2020 after submitting his thesis. In his free time he loves listening to dark music, drinking (homebrewed) craft beer, hiking around the Netherlands and playing board games. 


\section{List of scientific publications}

Van der Meij, W.M., Temme, A.J.A.M., de Kleijn, C.M.F.J.J., Reimann, T., Heuvelink, G.B.M., Zwoliński, Z., Rachlewicz, G., Rymer, K., and Sommer, M., 2016. Arctic soil development on a series of marine terraces on central Spitsbergen, Svalbard: a combined geochronology, fieldwork and modelling approach. Soil 2 (2): 221-240. https://doi.org/10.5194/soil-2-221-2016

Van der Meij, W.M., Temme, A.J.A.M., Wallinga, J., Hierold, W., and Sommer, M., 2017. Topography reconstruction of eroding landscapes - A case study from a hummocky ground moraine (CarboZALF-D). Geomorphology 295: 758-772. https://doi.org/10.1016/j.geomorph.2017.08.015

Van der Meij, W.M., Temme, A.J.A.M., Lin, H.S., Gerke, H.H., and Sommer, M., 2018. On the role of hydrologic processes in soil and landscape evolution modeling: concepts, complications and partial solutions. Earth-Science Reviews 185: 10881106. https://doi.org/10.1016/j.earscirev.2018.09.001

Van der Meij, W.M., Reimann, T., Vornehm, V., Temme, A.J.A.M., Wallinga, J., van Beek, R., and Sommer, M., 2019. Reconstructing rates and patterns of colluvial soil redistribution in agrarian (hummocky) landscapes. Earth Surface processes and Landforms 44: 2408-2422. https://doi.org/10.1002/esp.4671

Van der Kroef, I., Koszinski, S., Grinat, M., van der Meij, W.M., Hierold, W., Südekum, W., and Sommer, M., 2020. Digital mapping of buried soil horizons using 2D and pseudo-3D geoelectrical measurements in a ground moraine landscape. European Journal of Soil Science 71: 10-26, https://doi.org/10.1111/ejss.12842

Van der Meij, W.M., Temme, A.J.A.M., Wallinga, J., Sommer, M., 2019. Modelling soil and landscape evolution - the effect of rainfall and land use change on soil and landscape patterns. SOIL Discussions. https://doi.org/10.5194/soil-2019-82, in review.

\section{List of conference presentations}

Van der Meij, W.M., De Kleijn, C.M.F.J.J., Temme, A.J.A.M., Zwoliński, Z., and Rymer, K., 2015. Observing and simulating soil development using a chronosequence of cold raised marine terraces on Spitsbergen. European Geosciences Union (EGU), Vienna, Austria. Oral

Van der Meij, W.M., Temme, A.J.A.M., Sommer, M., 2016. Reconstructing paleo- and initial landscapes using a multi-method approach in hummocky NE Germany. European Geosciences Union (EGU), Vienna, Austria. PICO 
Van der Meij, W.M., Temme, A.J.A.M., Vanwalleghem, T., Sommer, M., 2016. Unraveling intertwined soil and landscape development: sources of heterogeneity in the Lorica model. International Soil Modeling Conference (ISMC), Austin, Texas, USA. Poster

Van der Meij, W.M., Temme, A.J.A.M., Wallinga, J., Hierold, W., and Sommer, M., 2017. Topography reconstruction in eroding landscapes - a case study from a hummocky ground moraine in NE Germany (CarboZALF-D). Pedometrics, Wageningen, The Netherlands. Oral

Van der Meij, W.M., Temme, A.J.A.M., Wallinga, J., Hierold, W., and Sommer, M., 2017. Rekonstruktion der Topografie in erodierende Landschaften - eine Fallstudie in das norddeutsche Jungmoränengebiet (CarboZALF-D). Deutsche Bodenkundliche Gesellschaft (DBG) Jahrestagung, Göttingen, Germany. Poster.

Van der Meij, W.M., Temme, A.J.A.M., Reimann, T., Wallinga, J., Vornehm, V., and Sommer M., 2018. Spatiotemporal landscape changes under human influence recorded in an agrarian kettle hole. 21st World Congress of Soil Science, Rio de Janeiro, Brazil. Oral

Van der Meij, W.M., Temme, A.J.A.M., Sommer, M., 2018. Spatiotemporal patterns of human-induced landscape change in a German agricultural landscape. Annual meeting of the Great Plains-Rocky Mountains division of the association of American Geographers (GPRM). Manhattan, Kansas, USA. Oral

Van der Meij W.M., Temme, A.J.A.M., Lin, H.S., Gerke H.H., and Sommer M., 2018. Challenges for implementing hydrologic processes in soil and landscape evolution models. International Soil Modeling Conference (ISMC), Wageningen, The Netherlands. Oral

Van der Meij, W.M., Maas, G., Okx, J., van der Maas, D., and van der Maas, R., 2019. Geomorfologisch karteren met Convolutional Neural Networks. BIS symposium, Wageningen, the Netherlands. Oral.

Van der Meij, W.M., Reimann, T., Temme, A.J.A.M., Wallinga, J., van Beek, R., and Sommer, M., 2019. OSL dating in agrarian settings: how to deal with postdepositional mixing of sediments. $20^{\text {th }}$ Congress of the International Union for Quaternary Research (INQUA), Dublin, Ireland. Poster

Van der Meij, W.M., van der Maas, D., Maas, G., and Okx, J., 2019. Mapping distinct geomorphic units using a convolutional neural network. 20 th Congress of the International Union for Quaternary Research (INQUA),, Dublin, Ireland. Poster. 


\section{PE\&RC Training and Education Statement}

With the training and education activities listed below the $\mathrm{PhD}$ candidate has complied with the requirements set by the C.T. de Wit Graduate School for Production Ecology and Resource Conservation (PE\&RC) which comprises of a minimum total of 32 ECTS (= 22 weeks of activities)

\section{Review of literature (4.5 ECTS)}

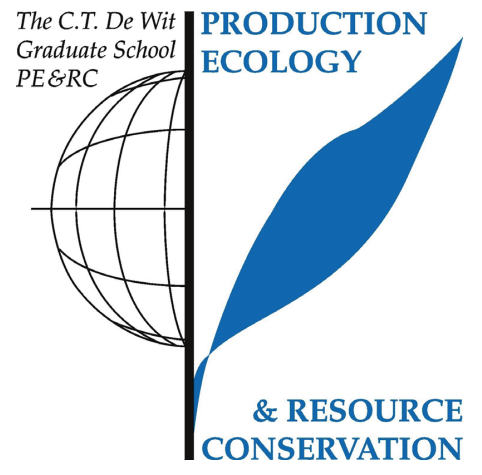

- Co-evolution of soils and landscapes in Holocene hummocky landscapes

\section{Writing of project proposal (4.5 ECTS)}

- Co-evolution of soils, landscapes and the hydrological system in Holocene hummocky postglacial landscapes

\section{Postgraduate courses (4.5 ECTS)}

- Summer school for flow and transport in terrestrial systems; TU Clausthal, Germany (2016)

- $\quad$ Machine learning for spatial data; WUR, the Netherlands (2019)

\section{Laboratory training and working visits (3.9 ECTS)}

- Relations between soil development and soil hydrology (hydropedology);

Department of Ecosystem Science and management, Pennsylvania State University, State College, Pennsylvania, United States of America (April to June 2017)

- Evolution of soils in layered-lithology landscapes; Department of Geography, Kansas State University, Manhattan, Kansas, United States of America (October 2018)

\section{Invited review of (unpublished) journal manuscript (2 ECTS)}

- $\quad$ Earth Surface Dynamics: erosion modelling

- Geografiska Annaler: ferrogenic rhizoconcretions

\section{Deficiency, refresh, brush-up courses (2 ECTS)}

- $\quad$ The $4^{\text {th }}$ dimension in earth sciences; WUR, the Netherlands (2016) 


\section{Competence strengthening / skills courses (4.6 ECTS)}

- $\quad$ Online course Modeling in C\#; edX (2015)

- Course in German, towards B1; Wageningen in' to languages (2016)

- $\quad$ Scientific writing; WGS (2017)

- $\quad$ Ethics in environmental sciences; PE\&RC (2018)

\section{PE\&RC Annual meetings, seminars and the PE\&RC weekend (1.5 ECTS)}

- $\quad$ PhD Workshop carousel (2016)

- $\quad$ PE\&RC $1^{\text {st }}$ Years weekend (2016)

- $\quad$ PE\&RC Day (2017)

Discussion groups / local seminars / other scientific meetings (4.5 ECTS)

- $\quad$ Landscape dynamics discussion group $(2017,2018)$

\section{International symposia, workshops and conferences (16.7 ECTS)}

- International Soil Modeling Conference (ISMC); Austin, Texas, USA (2016)

- $\quad$ European Geosciences Union (EGU); Vienna, Austria (2016)

- $\quad$ Pedometrics; Wageningen, Netherlands (2017)

- $\quad$ Deutsche Bodenkundliche Gesellschaft (DBG) Jahrestagung; Göttingen, Germany (2017)

- $\quad$ World congress of soil science (WCSS); Rio de Janeiro, Brazil (2018)

- $\quad$ Annual meeting of the Great Plains/Rocky Mountain (GPRM) division; Manhattan, Kansas, USA (2018)

- International Soil Modeling Conference (ISMC); Wageningen, Netherlands (2018)

- $\quad$ International Union for Quaternary Research (INQUA); Dublin, Ireland (2019)

\section{Lecturing / supervision of practicals / tutorials (7.5 ECTS)}

- Integration course soil water and atmosphere, field excursions (2016)

- Soils and landscapes of the Rhine-Meuse delta, field excursions (2016-2018)

- $\quad$ Erosion processes and modelling, practical guidance and lecturing (2016-2019)

\section{Supervision of MSc students (4.5 ECTS)}

- Distribution and hydrology of kettle holes

- $\quad$ OSL dating in agricultural settings

- Soil evolution in layered-lithology landscapes 
The research described in this thesis was financially supported by the ZALF program for early career researchers. Financial support from Wageningen University for printing this thesis is gratefully acknowledged.

Cover design by W.M. van der Meij

Printed by proefschriftmaken.nl || Proefschriftmaken on FSC-certified paper 
